\title{
ENCYCLOPEDIE SCIENTIFIQUE
}

PUBLIEE SOUS LA DIRECTION DU OR TOULOUSE

\section{BIBLIOTHĖQUE}

DE BIOLOGIE GENERALE
DIRECTEUR Maurice CAULLERY

\section{Le Parasitisme et \\ la Symbiose}

\section{PAR \\ Lie Professeur M.CAULler}

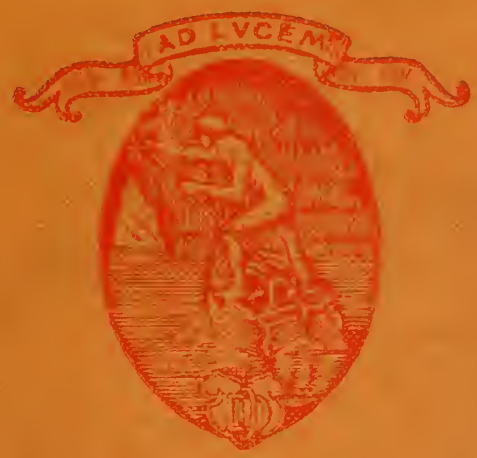

LIRRAIRIE OCTAVE DOIN

\section{GASTON DOIN.EDIRUR:PARIS}





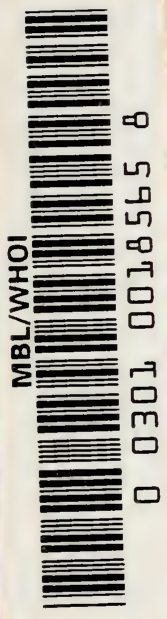



Gaston DoIN, Éditeur, 8, place de l'0déon, Paris $-6^{\circ}$

\section{ENCYCLOPÉDIE SCIENTIFIQUE}

Publiée sous la direction du $\mathrm{D}^{\mathrm{r}}$ TOULOUSE

\section{BIBLIOTHÈQUE \\ DE BIOLOGIE GÉNÉRALE \\ Directeur : Maurice GAULLERY \\ Professeur à la Faculté des Sciences de Paris}

Le développement et le progrès des Sciences ont, tout à la fois, pour condition et pour résultat, leur fractionnement de plus en plus grand en spécialités qui, dans la pratique, deviennent, non seulement indépendantes, mais même étrangères les unes aux autres. C'est là une fâcheuse nécessité. Elle dérive de ce que la méthode scientifique est analytique par essence. Mais l'analyse faite, il faut en rapprocher les résultats: plus la spécialisation est poussée loin, plus ce besoin est impérieux et en même temps plus il est difficile de le satisfaire.

Les sciences biologiques, par la complexité même de leur objet, ont subi au plus haut degré cet émiettement inéluctable et, plus que toutes les autres, elles exigent cette synthèse: car l'organisme est un et les divers points de vue auxquels on le considère, dans les divers compartiments de la Biologie, n'ont de valeur véritable que confrontés les uns aux autres et agencés, en quelque sorte, pour reconstituer la Vie, dans la mesure où cela est possible. La liste des Bibliothèques 
composant l'Encyclopédie, illustre suffisamment la multiplicité des sciences partielles auxquelles donnent lieu les Êtres vivants; la bibliothèque de Biologie générale doit être le lien entre toutes; elle a la lourde charge d'en représenter la synthèse.

Par là même, elle est plus malaisée à concevoir et surtout à exécuter. Il est assez facile d'inventorier et de découper le domaine d'une science spéciale; on trouve, sans trop de peine, des spécialistes qualifiés pour fournir une mise au point de chacun des fragments ainsi délimités. Il n'en va pas de même pour la Biologie générale. Pour en traiter les problèmes d'une façon satisfaisante, il faut unir une connaissance précise et critique des faits et des techniques diverses à la vue d'ensemble qui permet de dominer ces faits et d'en extraire la signification générale.

On s'efforcera d'atteindre ce but dans les livres de la présente série. La liste et les titres, qui figurent ci-dessous, n'en sont pas donnés ne varietur. Ils expriment simplement le plan conçu.

La Biologie générale étant comprise comme la synthèse des disciplines particulières : zoologie, botanique, paléontologie, physiologie, chimie et physique biologique, etc., elle doit envisager les manifestations et le fonctionnement des organismes d'une façon globale.

Il faut donc extraire tout d'abord de ces sciences particulières les caractères généraux des phénomènes vitaux et préciser leurs rapports avec ceux qu'offre la matière inanimée. Ce sera l'objet d'un volume d'introduction.

Ayant ainsi dégagé ce qu'on peut, à l'heure actuelle, considérer comme le propre de la Vie et ajusté à nos connaissances modernes le vieux problème du mécanisme et du vitalisme, nous envisagerons le fonction- 
nemént vital dans son substratum, l'Organisme. Ma is cet examen peut et doit se faire à une série d'échell es différentes, si l'on peut dire.

Il y a une vie élémentaire, dont la Biologie $\mathrm{d} u$ $\mathbf{x} \mathbf{x}^{\mathbf{e}}$ siècle a mis en évidence l'absolue généralité, c'est la vie cellulaire; pour beaucoup d'organismes inf érieurs, c'est même toute la vie; la cellule est l'un i té fondamentale en matière d'organismes. Sa connai ssance est la base sur laquelle doit être construite la Biologie générale.

Une seconde étape est l'étude de l'individu considéré comme édifice pluricellulaire. Une série de volumes, formant la seconde partie de la Bibliothèque, seront consacrés aux lois générales de la réalisation, de la reproduction et du fonctionnement synergique de ces édifices. Il s'en dégagera la notion si complexe et parfois si fugitive de l'individualité, qui sera étudiée et discutée spécialement.

La vie de l'organisme ne se conçoit que dans le milieu, et mème les frontières de l'organisme et du milieu sont beaucoup plus malaisées à tracer qu'on ne l'imagine communément. La troisième partie de la Bibliothèque sera faite de volumes où ces rapports généraux seront étudiés. Certains se rattachent plus intimement à la Physiologie; mais en ce cas, ou bien ils envisagent des fonctions extrêmement générales, telles que l'irritabilité on l'assimilation et alors ils rentrent dans l'étude générale des rapports de l'organisme et du milieu; ou bien ils traitent de fonctions (comme la luminosité, par exemple) qui, - tout en ayant une grande valeur biologique, pleinement reconnue pa $r$ les physiologistes et se rattachant intimement aux conditions fondamentales du fonctionnement vital échappent cependant à peu près complètement, en fait, au cadre de la physiologie classique. Celle-ci est, en 
effet, délimitée surtout, en réalité, par l'expérimentation sur les Vertébrés, où ces fonctions sont rudimentaires et font pratiquement défaut; si elles sont bien représentées, c'est en tous cas, sur des types qui ne font pas partie de ce qu'on pourrait appeler assez irrévérencieusement la faune des laboratoires physiologiques.

Dans cette partie de la Bibliothèque, on voudrait aussi faire à l'Éthologie la part qui lui est due et qui n'est pas suffisamment reconnue.

La dernière partie de la série envisage les organismes à une échelle supérieure à l'individu, celle de la lignée ou de l'espèce. Est-il besoin de souligner que, depuis Darwin, ce point de vue, qui n'est autre que le problème de l'Évolution, domine toute la Biologie générale. Pour le traiter autrement que d'une manière philosophique et spéculative, il faut considérer les rapporls de l'organisme et du milieu dans la succession des générations: c'est-à-dire étudier, par les méthodes positives: l'Hérédité ; la Variation sous ses diverses formes; la combinaison des lignées hétérugènes, c'està-dire l'Hybridation; le problème de l'établissement de la conformité de l'organisme aux conditions du milieu, c'est-à-dire l'Adaptation ; les transformations successives des lignées, c'est-à-dire la Phylogénie; enfin envisager les mécanismes par lesquels nous pouvons nous représenter ces transformations, c'est-àdire les théories évolutionnistes. Là, plus qu'ailleurs, il serait fructueux de réaliser des livres courts, clairs, suffisamment documentés et d'une critique judicieuse.

11 est dans la nature des choses que la section de Biologie générale chevauche parfois sur les bibliothèques spéciales. Dans son intégralité, elle est une mise en œuvre des matériaux de celles-ci, mais à un point de vue différent et qui évitera tout double emploi 
véritable. Elle est, d'autre part, nécessairement dégagée du caractère strictement technique et souvent pratique, qui convient à beaucoup de volumes de ces bibliothèques particulières.

Elle ne vise cependant pas moins à l'utilité. Nous espérons qu'elle rencontrera un accueil favorable auprès de catégories très variées de lecteurs: biolo. gistes, médecins, philosophes, esprits simplement cultivés, et aussi spécialistes divers.

La spécialisation enlève le plus communément le loisir de coordonner les notions partielles et cependant il y a là une nécessité essentielle pour la culture de l'esprit et même pour la conduite judicieuse des travaux particuliers.

La Bibliothèque de Biologie générale s'efforcera de répondre à ce besoin, et, sans demander aux auteurs d'abdiquer leur personnalité, elle tâchera de conserver, dans son ensemble, une unité correspondant à celle de son objet: La Vie.

Les volumes sont publiés dans le format in-18 jésus cartonné ; ils forment chacun 400 pages environ, avec ou sans figures dans le texte. Chaque ouvrage se vend séparément.

Voir, à la fin du volume, la notice sur l'ENGYGLOPÉDIE SCIENTIFIQUE, pour les conditions générales de publication. 



\section{TABLE DES YOLUMES \\ ET LISTE DES COLLABORATEURS}

Les volumes publiés sont indiqués par un*

\section{Introduction}

1. Les Phénomènes vitaux.

\section{I. - La Vie élémentaire.}

2-3. La Cellule (Morphologie et Physiologie), 2 vol., par M. Henneguy, Membre de l'Institut, Professeur au Collège de France.

\section{II. - L'Individu.}

-4. L'Eruf et les facteurs de l'Ontogenèse, par M. A. BraChвt, Professeur à l'Université de Bruxelles.

* 5. La Tératogenèse, par M. Et. Rabaud, Maître de conférences à la Faculté des Sciences de Paris.

6. Les Formes larvaires et les Métamorphoses, par M. Ch. Pérez, Professeur-adjoint à la Faculté des Sciences de Paris.

7. La Reproduction asexuée.

8. La Régénération et la Greffe, par M. Ed. BordaGe, Chef des travaux pratiques à l'Ecole des Hautes-Etudes.

9. La Sexualité et la Parthénogenèse . 
10. Les Corrélations organiques et l'Individualité, par M. l.. Gưénot, Préparateur à la Faculté des Sciences de Paris.

\section{III. - L'Organisme et le Milieu.}

11. L'Irritabilité et les Tropismes.

12. Les mutations matérielles dans les êtres vivants (aliment et milieux nutritifs).

13. Les mutations énergiques dans les êtres vivants (luminosité, chaleur, électricité, etc.).

14. La Biologie des Pigments.

15. Éthologie et organisation.

*16. Parasitisme et Symbiose, par M. M. Caullery. Professeur à la Faculté des Sciences de Paris .

17. Les Milieux biologiques marins, par M. P. Marais DE Beauchamp, Préparateur à la Faculté des Sciences de Paris.

18. La Biologie des eaux douces.

19. Les principaux faciès biologiques terrestres .

20. La Concurrence vitale.

\section{IV. - L'Espèce et l'Évolution}

21. L'Hérédité.

22. La Variation.

23. L'Hybridation.

24. L'Espèce.

23. L'Adaptation.

26. La Phylogénie.

27. Les Théories évolutionnistes. 


\section{ENCYCLOPÉDIE. SCIENTIFIQUE}

PUBLIÉE SOUS LA DIRECTION

du Dr TOULOUSE, Directeur de Laboratoire à l'École des Hautes-Études.

Secrétaire général : H. PIÉRON

\section{BibLIOTHĖQUE DE RIOLOGIE GÉNÉRALE}

Directeur : M. CAULLERY

Professeur à la Faculté des Sciences de Paris

\section{PARASITISIIE ET SYIIBIOSE}




\section{DU MÈME AUTEUR :}

Les universités et la vie scientifique aux ÉtatsUnis, I vol. in-12. Paris (Arm. Colin), r917.

Les problèmes de la sexualité, I vol. Bibliothèque de philosophie scientifique. Paris (Flammarion), $8^{\ominus}$ mille. 


\section{LE PARASITISME}

ET

\section{LA SYMBIOSE}

PAR

\section{Maurice GAULLERY}

Propessetr a la Sorbonne

Avec 53 figures dans le texte

\section{PARIS}

LIBRAIRIE OCTAVE DOIN GASTON DOIN, EDITEUR

8, PlaGe de L'odéon, 8

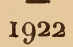

T us droit réservés 



\section{TABLE DES MATIÈRES}

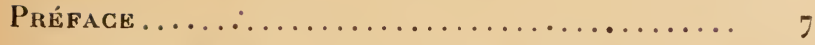

Chapitre premier. - Le commensalisme...... 13

Sommarre. - Délinitions. - Commensalisme, synocie, mutualisme. - Nécessité d'une étude in vivo, autant que possible expérimentale. - Ubiquité de ces associations. - Exemples divers tirés de la faune marine.-Les Pagures et leurs commensaux. - Les Crabes porteurs d'Actinies. - Rapprochemènt avec l'instinct de déguisement de certains Crabes.

Chapitre II. - Le commensalisme (suite)......

Sommire. - Exemples tirés de la faune terrestre. Les commensaux des foumis et des Termites (synoeques, synechthres, symphiles). - Les sympliiles : Lomechusa, Paussides, Diptères, Chenilles de Lycænides, etc... les Pucerons et la trophobiose. Caractères adaptatifs des symphiles. - L'esclavage chez les Fourmis; son origine (théories de WAsManN, Escherich, Wheeler, etc.). - Les plantes myrmécophiles.

Chapitre III. - Du commensalisme à l'inquili nisme et au parasitisme..................

Sommarr. - L'inquilinisme; transition au parasitisme proprement dit; exemples divers. - Les animaux épizoaires. - Les parasites intermittents; les animaux hématophages. - Sens général des moditications produites par le parasitisme.

II. Ciullery. - Le Parasitisme 
Ghapitre IV. - Exemples particuliers d'adaptation au parasitisme: Annélides, Mollusques..

Sommarre. - Les Annélides Polychètes parasites. Etude spéciale d'Ichthyotomus sanguinarius d'après les recherches d'H. Eisig. - L'adaptation au parasitisme chez les Gastropodes : Capulidae (Thyca ); Eulimida (Eulima, Mucronalia, Stylifer, ctc.); Gasterosiphon deimatis; Entoconchidce.

Chapitre V. - L'adaptation au parasitisme chez

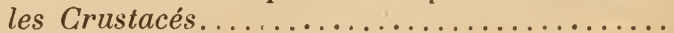

Sommalre. - Les Gnathiide (Anceus et Praniza); les Cymothoidoe.

Les Isopodes Epicarides. - Phases de leur développement. - Les principales familles : Bopyrida, Entoniscidce, Dajida, Cryptoniscidae. - Dualité de constitution de la cavité incubatrice dans le groupe. - Hermaphrodisme successif des Cryptoniscido.

Les Rhizocéphales. - Evolution de la Sacculine. Larves Nauplius et Cypris. - Phase de Sacculine interne (travaux de Y. Delage et G. Smith). - Différenciation de la Sacculine externe. - Le genre Thompsonia. - Multiplication asexuée par bourgeonnement (Thompsonia, Peltogaster socialis).

Les Copépodes parasites. - Le genre Xenocoloma; rapports anatomiques et physiologiques avec l'hôte ; évolution.

Chapitre VI. - Le parasitisme provisoire ou pro-

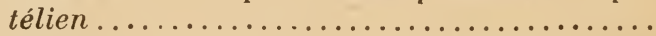

Sommaire. - Définition. - Le parasitisme larvaire des Monstrillider; signification des appendices absorbants. - Le parasitisme placentaire (GrARD); adaptations parasitaires ne portant que sur des organes provisoires ou des annexes et n'atteignant pas les organes définitifs. - Le cycle évolutif des Orthonectides. - Les Euniciens parasites. - La phase parasitaire des larves d'Unionidae (Glochidium) sur les Poissons. - Les Gordiens.

L.es Insectes entomophages : leur importance dans la nature et leur ròle dans l'équilibre des espèces. Leur utilisation aux Etats-Unis dans la lutte contre 
les Insectes nuisibles. - Principales conditions de développement. - Formes larvaires spéciales (larve cyclopoïde des Platygaster, Planidium, larve primaire d'Eucoila, etc...). - Action de l'hôté.

\section{Chapitre VII. - Les parasites hétéroxènes et leurs}

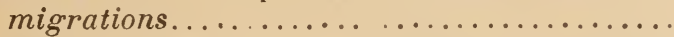

Sommarre. - Définition. - Cestodes : Oncosphères et Cysticerques. Cycle et hôtes successifs des Bothriocéphales. - Trématodes: Miracidium et Sporocyste, Cercaire et Métacercaire. - Cycle des Schistosomum (Bilharzia), etc... - Némathelmin. thes : Spiropteres, Trichine, Filaires, Gordiens, Acanthocéphales. - Protozoaires : Grégarines (Aggregata, Nematopsis). - Hėmosporidies (Plasmodium, Hémcgrégarines, etc.). - Hémoflagellés (Trypanosomes, Piroplasmes, Leishmania). - Le problème de l'hòte définitif chez les Protozoaires hétéroxènes.

Chapitre VIII. - Les modifications adaptatives de la reproduction chez les parasites..........

Sommarre, - Fréquence de l'hermaphrodisme, ou rapprochement permanent des sexes avec exagération du dimorplisme sexuel. - Elévation considérable du nombre des œufs.

Intercalation de processus de multiplication au cours du déreloppement: schizogonie des Sporozoaires. - Agamogonie des Dicyémides. - Plasmodes des Orthonectides. - Bourgeonnement larvaire chez les Cœlentérés parasites. - Cestodes : strobilisation; pluralité des scolex sur certains cysticerques. Trématodes : formation des rédies et des cercaires. - Rhizocéphales : bourgeonnement chez les Thompsonia et chez les Peltogaster socialis. - Polyembryonie des Insectes entomophages.

Rapport entre ces processus et l'affaiblissement de l'individualité physiologique. - Analogie avec les animaux fixés.

Chaprtre IX. - La spécificité parasitaire et les modes divers de l'infestation de l'hôte....... 213

SommațRe, - Exemples de spécificité rigoureuse : 
Grégarines, Crustacés .-Théorie de Grandet J. Bonvier : idées différentes de G. O. SARs ețin. J. HaNsrs. - Cas de spécificité moins précise : Trématodes el Cestodes. - L'hôte normal et les hơtes accidentels. - Réservoirs de virus. - La théorie de la prophylaxie trophique ou des écrans protecteurs (Roubaud) - Changements d'équilibre entre les hotes et les parasites : exemples des Insectes entomophages aux Etats-Unis. - La spécificité est une propriété relative et le résultat d'une évolution.

La spécificité et les conditions d'accès à l'bôte. Exemples divers. - Pénćtration dermique: Hémosporidies, Filaires, Ankylostomes, Sacculine, elc. Migrations d'Ascaris lumbricoides. - Les divers modes d'infestation par les larves de Tachinaires et dans les myiases. - Propagation des parasites par l'œuf et transmission liéréditaire.

Chapitre X. - Actions réciproques du parasite et

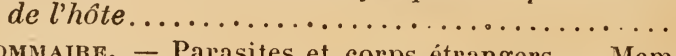

Sommaire. - Parasites et corps étrangers. - Membranes anhystes ou cellulaires tendant à isoler les parasites. - Réactions d'ordre phagocytaire. - Parasites normaux et anormaux. - Produits solubles : Antiferments élaborés par les parasites intestinaux. - Toxines parasitaires. - Eosinophilie et anti-corps spécifiques chez l'hôtc. - Action des parasites sur le métabolisme général de l'hôte (cas de la Sacculine. - Castration parasitaire. - Exemples divers chez les animaux et les végétaux. - Cas spéciaux de réaction de l'hôte à un parasite (Ver du Cayor, Glochidium, Sporozoaires divers etc.).

Les galles animales (thylacies) et végétales (cécidies). - Essais de reproduction expérimentale des cécidies.

Cha pitre XI. - La symbiose che : les animanx...

Sommairf. - Définition. - Zoochlorelles et zooxanthelles; leur extension, leur nature, leurs rapports physiologiques avec les animaux quiles renferment. - Pénétration et transmission. - Les levires intracellulaires des Insectes et la symbiose héréditaire. - Historique; étude du cas d'Icerra purchasi. 'Pansmission par l'keuf ; cultures in vitro: msesto- 
cytes. - Le mycétome el ses diverses catégories: son rôle physiologique.

Les Bactéroïdes chez divers animaux: Blatte, Cyclostome, etc. La symbiose chez les Diptères hématophages stricts (Glossines, Pupipares).

Recherches de Pieliantoxisur les organes lumineux. - La luminosité intimale est-elle due à des bactéries symbiotiques?

Chapitre XII. - La syribiose chez les végétall.x...

Sommare. - Les lichens. Historique. - Nature des rapports de l'algue et du champignon. - Théories diverses. - Etude expérimentale de l'algue. - Recherches de Crodat.

Les bactéroürles des Légumineuses.

Les mycorhizes endotrophes et ectotrophes.- Les mycorhizes des Orchidées: historique. - Recherches de Noël Berrard. - La germination naturelle de Neottia nidus acis. - Germination des graines d'Orchidées en tubes stériles par ensemencement de Rhisoctonia. - Spécificité de ces Rhizoctonia; leurs rapports avec l'Orchidée.-Conditions d'infestation. - Variation de virulence. - Exaltation par passages. - Phagocytose et immunité. - La symbiose et l'évolution des végétaux.

La symbiose frontière de la maladie. - Symbiose, mutualisme et parasitisme.

Cha PITRE XIII. - La symbiose est-elle une caractéristique primordiale de la vie cellulaire ?....

Sommire. - Les théories particulaires de l'hérédité. - Les granules d'Altuaxx et les nitochondries.Généralisations de Pieraxtoxi à partir des faits de symbiose héréditaire,chezles Insectes et les Céphalopodes: passage des bactéries intracellulaices à la forme granulaire; réalisation des diverses fonctions de la cellule par des bactéries symbiotiques. La théorie des symbiotes de Portine : dualisme de la cellule; les mitochondries seraient d"s bactéries symbiotiques. - Critique de la conception symbiotique des Isaria chez les Insectes. - Possibilité de la vie aseptique; sa réalisstion rigrourense et à grande échelle chez les Drosophiles (Gurixot). Les bactéries cultirées par Portier, à partir de di- 
vers organes, ne peuvent être des mitochondries, de par leurs propriétés.

Aucun fait ne vient présentement à l'encontre de l'unité fondamentale de la cellule.- La symbiose intracellulaire est un fait exceptionnel, quoique assez répandu.

Bibliographie.................... 35 g

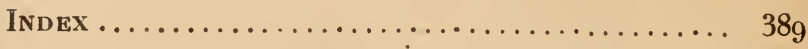




\section{PRÉFACE}

Les matières du présent volume ont été l'objet de mon cours à la Sorbonne pendant le semestre d'hiver r9r9-r920. Je n'ai pas besoin, je pense, de justifier la publication d'un volume sur Le Parasitismeet la Symbiose dans la Bibliothèque de Biologie générale de l'Encyclopédie scientifique. Sa place y était évidemment marquée. De toute façon, je crois qu'il comble à l'heure présente une lacune dans l'ensemble des ouvrages de Biologie dont disposent les lecteurs français. Ce n'est point que'nous manquons de tous livres récents sur les parasites. Il a paru, en particulier, en France, plusieurs excellents Précis de Parasitologie à l'usage des étudiants en médecine. Le Traité de Zoologie médicale de A. Railliet est un livre excellent, dont il faut regretter seulement qu'il n'existe pas une réédition récente. l'ans ces livres, étudiants, zoologistes et médecins trouveront énormément de 
renseignements d'ordre particulier.De mème les traités de Zoologie, dont nous sommes malheureusement insulfisamment pourvus en France, présentent, à propos des divers groupes, beaucoup de données sur les parasites. Mais je n’ai cherché ici, ni à faire un inventaire méthodique des parasites - particulièrement de ceux qui intéressent l'homme d'une façon directe, - ni à discuter les affinités zoologiques des diverses formes.

J'ai envisagé le parasitisme du point de vue de la Biologie générale, comme manifestation globale et en le raltachant aux phénomènes qui en sont connexes. Le parasitisme est un rapport de dépendance directe et étroite entre deux organismes généralement bien déterminés d'une façon réciproque, l'hòte et le parasite, dont le second vit aux dépens du premier. Ce n'est qu'un cas spécial des rapports de tout organisme avec le milieu ambiant et en particulier avec les autres organismes, une association particulièrement précise. Or, il existe des associations entreorganismes, moins étroites, - mais qui très souvent sont aussi spécifiques, - et que l'on a désignées sous le nom de commensalisme et de mutualisme. Il en est d'autres au contraire plus étroites, encore plus constantes et moins unilatérales, auxquelles on a donné le nom de srmbiose. Commensalisme, parasitisme, symbiose 
sont des catégories de notre esprit, qui ne sont séparées dans la nature par aucune discontinuité et qui offrent des aspects divers des mêmes lois générales. C'est ce que ce livre cherche à dégager en les examinant successivement. J'étudie ces associations dans le cadre de l'idée d'Evolution. Si ignorants que nous soyons encore des mécanismes par lesquels l'Evolution s'estaccomplie, sa réalité comme fait est difficilement contestable et s'impose de plus en plus, à mesure que progressent nos connaissances. Les parasites sont peut-être les organismes pour qui cela est le plus évident. Ils sont en effet étroitement adaptés aux conditions très particulières dans lesquelles ils vivent et leur organisation, si spéciale soit-elle, apparaît toujours, non comme celle de types autonomes constituant une classe d'èlres indépendante, mais bien comme la transformation de divers types d'animaux vivant dans des conditions normales. Le monde des parasites s'est formé peu à peu, après la différenciation générale des divers groupes. Il estle résultat d'une évolution secondaire moins lointaine. Autrement. il faudrait supposer qu'une Providence capricieuse ait attaché spécialement à chaque forme animale un cortège de parasites bizarrement déformés suivant un plan fixé d'avance. Et pourquoi, dans ce cas, ces parasites n'eussent-ils pas constitué des groupes 
spéciaux ? L'étude du parasitisme est une illustration particulièrement nette de l'Evolution.

Ce livre n'envisage pas d'une façon tout à fait équivalente le domaine du parasitisme chez les animaux et les plantes, comme le suggérerait une logique rigoureuse. Zoologiste, l'auteur n'a pas pu ne pas donner aux faits tirés du règne animal une place prépondérante,ne seraitce que parce qu'il se sentait plus compétent pour en traiter. Il a essayé cependant de marquer les faits essentiels relatifs au parasitisme des végétaux. De même, il est tout un vaste domaine qui se rattache intimement au parasitisme el qui reste cependant à peu près complètement hors du cadre de ce livre : c'est la Bactériologie. La plupart des bactéries, pathogènes ou non, sont des parasites. Leurs rapports avec leurs hôtes contiennent avant tout le problème capital de l'immunité naturelle ou acquise et l'on s'étonnera peut-être qu'il n'occupe pas ici la place à laquelle il semble qu'il ait droit. En fait la Bactériologie et les questions qu'elle soulève ont, par leur importance théorique et pratique, leur place dans d'autres parties de l'Encyclopédie; on les à donc laissées de cóté ici.

Il va de soi que, tout en ayant en vue les questions d'ordre général, on ne peut les traiter que sur des faits précis et concrets. Le général, dans le domaine biologique, ne vil réellement 
que par le particulier. On s'est donc efforcé de ramener toutes les idées exprimées à des faits précis. Ainsi, pour donner une idée des déformations dues au parasitisme, au lieu de s'en tenir à des affirmations de principe ou à des vues générales, a-t-on choisi un certain nombre d'exemples spéciaux caractéristiques. On les a empruntés de préférence à des recherches récentes, en s'abstenant de reprendre en détail des cas devenus classiques. Ce livre pourra done aider à la diffusion des résultats particuliers les plus importants, qui ont été acquis dans ces dernières années.

L'auteur ne se pique nullement d'une connaissance complète de la bibliographie récente. Le trouble jeté par la guerre dans les recueils bibliographiques et dans les bibliothèques est très loin d'être dissipé : les difficultés des relations internationales et les complications économiques empèchent de consulter bien des recueils. Il est donc très possible et mème probable que des travaux récents qu'il aurait été naturel de résumer ici soient oubliés.

Je n'oublie pas que cet ouvrage a eu, en langue française, des devanciers, en particulier le livre de P. J. Van Beneden Commensaux et Parasites, (dans la Bibliothèque scientifique internationale). En le lisant, aujourd'hui encore, on est frappé de l'étendue et de la solidité de sa 
documentation zoologique. L'importance qu'allaient prendre diverses questions, à peine ébauchées lors de son apparition, y est comme pressentie et elles sont notées, malgré l'insignifiance qu'elles avaient alors. Le temps et les idées ont bien marché depuis. Le livre de P.J. Van BeneDEN est çonçu dans un langage et un esprit très anthropomorphique, finaliste et providentiel, et en opposition formelle avec les doctrines évolutionnistes. Aussi aujourd'hui ce livre appartientil au passé et l'on voudra bien considérer, j'espère, qu'on pouvait, sans craintede superfétation, se proposer de traiter le même sujet dans le cadre renouvelé de nos idées et de nos connais. sances.

Novembre 1920.

N.-B. - Les nombres en italiques entre parenthèses renvoient à l'index bibliographique à la fin du volume. 


\section{LE PARASITISME}

ET

\section{LA SYMBIOSE}

\section{CHAPITRE PREMIER}

\section{LE COMMHNSALIS.ME}

Sommare. - Définitions : commensalisme, synœcie, mutualisme.-Nécessité d'une étude invivo, autant que possible expérimentale. - Ubiquité de ces associations. - Exemples divers lirés de la faune marine. - Les pagures e leurs commensaux. - Les crabes porteurs d'actinies. Rapprochement avec l'instinct de déguisement de certains crabes.

Le parasitisme peut être défini la condition de vie normale et nécessaire d'un organisme qui se nourrit aux dépens d'un autre -- appelé l'hôte - sans le détruire, comme le fait le prédateur à l'égard de sa proie. A la vérité, il y a toutes les transitions entre les deux régimes. Pour vivre régulièrement de l'hote, le parasite - saul cas exceptionnels - vit en contact permanent avec lui, soit sur sa surface extérieure, soit à son intérieur. Le parasitisme se manifeste donc comme une association générale- 
ment continue entre deux organismes différents, dont l'un vit aux dépens de l'autre. L'association a un caractère essentiellement unilatéral : elle est nécessaire au parasite, qui meurt s'il est séparé de son hôte, faute de pouvoir se nourrir; elle ne l'est nullement à l'hôte. L'organisation du parasite est spécialisée corrélativement aux conditions où il vit sur l'hôte : l'adaptation est la marque du parasitisme.

Mais on peut concevoir et il existe en fait, des associations n'ayant pas le même caractère unilatéral: deux espèces vivant régulièrement associées, sans que l'une vive de l'autre. L'une pourra réaliser ainsi des avantages particuliers pour sa protection ou sa nutrition, sans que l'autre en trouve d'équivalents. Ces associations ont été groupées sous le nom de commensalisme. Dans certaines d'entre elles, auxquelles on donne le nom de mutualisme, il y a nettement réciprocité d'avantages pour les associés. On conçoit qu'il y ait toutes les transitions entre des groupements de cet ordre et le parasitisme qui n'en est logiquement qu'une déviation fortement unilatérale. L'étude du commensalisme et du mutualisme est donc comme la préface normale de celle du parasitisme et elle nous permettra de saisir la diversité des rapports qui peuvent s'établir ainsi entre deux espèces.

On peut considérer comme sensiblement équivalent à celui de commensalisme le terme de synocie (ouv avec, oĩxos maison) qui a été proposẻ pour certains cas particuliers. Toutefois la synœcie implique plus qu'un simple rapprochement dans l'espace, qui est un phénomène beaucoup plus vaste. Il y a, en effet, 
dans le groupement des organismes, un déterminisme général, qui est bien lié aux lois de leur interdépendance, mais qui est hors de notre cadre présent, et qui crée les faciès généraux de la faune et de la flore, les peuplements organiques. Ainsi se réalise ce que les botanistes ont appelé les formations de végétation. Le zoologiste citera aisément des peuplements analogues. Un récif corallien est un grand groupement de ce genre, qui comporte une certaine solidarité régulière entre tous les êtres qui y vivent et qui 's'y rencontrent d'une façon constante. On pourrait citer sur nos plages beaucoup de groupements plus restreints du même ordre (I), comportant chacun une population déterminée. La faune terrestre en oftre d'également nets; nous aurons à revenir sur ceux qui se constituent autour des Insectes sociaux, principalement des fourmis et des termites. Sur une plante isolée, un arbre surtout, se groupent régulièrement toute une série d'espèces et on trouvera une analyse intéressante d'un groupement de ce genre, faite récemment par F. Picard sous le titre : Le Peuplernent du figuier (2). Mais ces groupements généraux n'impliquent qu'une solidarité très lâche, infiniment moins précise que celle que comporte le terme de commensalisme.

Le commensalisme comporte l'association régulière entre deux espèces déterminées, se retrouvant d'une façon constante, dans des localités très éloi-

I. Voir à ce sujet le livre très substantiel de P. de BEAUchamp, Les grèves de Roscoff. Paris (L. Lhomme), 1914.

2. Thèse Fac. des Sci. Paris, rgr9 et Annales des Epiphyties, t. 5 . 
gnées les uns des autres. Quand on l'analyse, on constate que ce simple rapprochement entraine des différenciations très accentuées, en particulier au point de vue psychophysiologique. Le double écueil de l'étude de cet ordre de faits est d'une part d'y apporter des préoccupations trop subjectives aboutissant à un anthropomorphisme illusoire, d'autre part de vouloir trop ramener des faits complexes à de simples réactions physiques élémentaires et purement actuelles.

Considérons ainsi le commensalisme classique entre les Squales et le Pilote (Naucrates ductor) ou le Remora (Echeneis remora). Ces Scombrida accompagnent les Squales, le Remora se fixantà eux temporairement par la nageoire dorsale transformée en ventouse. Ce mode de vie suppose, en réalité, une adaptation des réflexes nerveux très précise, qu'on devine, quand on voit, comme j'en ai eu l'occasion à l'aquarium des îles Bermudes, un Remora et un Carcharias : le premier suit le second comme une pièce de fer accompagnerait un aimant, obéissant instantanément aux changements de route incessants et irréguliers du Squale dans l'aquarium. La nage de conserve avec le squale doit correspondre à une adaptation étroite des organes sensoriels et des centres nerveux, adaptation aussi différenciée que l'est, dans l'ordre morphologique, la ventouse ellemême. Déjà, sur ce cas, apparaît la nécessité, pour juger des faits de commensalisme, de les étudier sur le vivant et, quand c'est possible, par l'expérimentation.

Sous une apparence très simple, mais probable- 
ment tıès complexe en réalité, se présente de mème l'association entre poissons et actinies que l'on a observée en des points très variés des mers chaudes et que Suurter $(52)$ a étudiée avec précision à Batavia.

Un poisson du genre Trachichthrs (ou Amphiprion) se tient toujours an milieu des tentacules d'une grande actinie (Plıte a observé également cette association dans la mer Rouge, où l'actinie serait d'après lui Crambactis arabica, large de plus de $30 \mathrm{~cm}$.). Si l'actinie se referme, le poisson se laisse recouvrir par eux et pénètre momentanément dans la cavité digestive. Or, il suffit d'assister à la capture'd'une proie venant à rencontrer les tentacules de l'actinie et sur laquelle celle-ci se referme, pour savoir combien le contact des nématocystes est redoutable. Les poissons cités ici doivent donc avoir, vis-à-vis des poisons urticants des actinies qu'ils fréquentent, une immunité qui a sans doute été graduellement acquise et qui, à elle seule, témoigne du caractère très défini de cette association en apparence purement contingente. Cette association satisfait à un double objet: nutrition et pro. tection. En ce qui regarde la nutrition, les auteurs ne donnent pas de renseignements très formels, mais on peut conjecturer que, quand l'actinie englóutit une proie et se referme en même temps sur le poisson, celui-ci en dévore une partie. Quant à la protection, Sluiter l'a mise directement en évidence. II a pu, en effet, garder plusieurs mois vivants des Trachichthys, dans un aquarium où il avait placé des poissons carnivores et où il y avait en mème temps 
l'actinie. Les Trachichthys ne s'écartent jamais de celle-ci. Au contraire, mis seuls avec les espèces carnivores dans un aquarium, ils étaient régulièrement dévorés au bout de quelques heures. Nous avons donc ici un exemple d'association très efficace, comportant une immunité physiologique précise et très probablement un ensemble coordonné des réflexes chez les deux associés.

C'est évidemment de la même façon qu'il faut interpréter l'association très commune et facile à observer dans nos mers, au voisinage de nos côtes, entre des Méduses acalèphes, en particulier Rhizostoma cuvieri, et des Amphipodes Hrperina medusarum, ou des jeunes poissons, surtout des Caranx trachurus.

Les Hypérines nagent en troupe sous l'ombrelle des Méduses et vont se réfugier dans des cavités sous-génitales. De même les Caranx nagent en groupes assez nombreux, sans jamais s'écarter de la Méduse, et se réfugient aussi parfois en elle comme les Hypérines. La même association se rencontre dans des régions extrêmement éloignèes. Elle a été signalée aux îles Gambier dans le Pacifique austral, par Secrat entre un Caranx et une Crambesside et au voisinage de l'île Maurice, par Luner (40) entre Caranx melampygus et Crambessa palmipes.

Les Physalies, dont les nématocystes sont particulièrement urticants, sont aussi fréquemment accompagnées de petits poissons voisins des Caranx (Nomeus gronovii) qui paraissent avoir l'immunité vis-à-vis de la Physalie; ils sont évidemment protégés par son voisinage et peut-être profitent d'une 
partie des proies capturées par le Siphonophore.

Des associations du genre des précédentes sont extrèmement fréquentes dans les récifs coralliens. Courière $(26)$ en a observé divers cas à Djibouti. Un Pontoniide Periclymenes) transparent se tient d'une façon constante, comme les poissons cités plus haut, dans la zone de protection des tentacules d'une grande actinie ; des anchois (Engraulis) se réfugient entre les longs piquants d'un oursin (Diadema setosum); une grande astérie du genre Culcita abrite en permanence sous son disque un Hippolytidie. De nombreux Alpheidæe vivent à l'abri de Madrépores (Pocillopora, l'orites, etc.). Aux ìles Gambier, Seurat (in Coutière 2 8 ) a observé un Arete dorsalis qui vit à còté d'un oursin (Heterocentrotus mamillatus), dans des trous que celui-ci occupe dans un madrépore et l'alphéide est homochrome de l'oursin, comme cela avait lieu d'ailleurs dans plusieurs des cas précédents. Роттs (48), au détroit de Torrès, signale que Synalpheus brucei se tient par couples (mâle et femelle) entreles bras d'une Comatule (Comanthus annulatus) et il a observé divers autres Crustacés (Alpheidae, Pontoniidce, Galathées, Cirolana, etc. Annélides et Gastropodes qui sont commensaux des Grinoïdes, dans les mêmes conditions, sur les récifs. A Madagascar, Geay ( $I$ J) a observé un crabe, Lissocarcinus orbicularis, qui reste en permanence à l'entrée de la bouche d'une holothurie, et qui, quand les tentacules se rétractent, est englobé par eux et.momentanément entrainé dans le vestibule buccal, à la façon dont les poissons cités plus haut le sont dans les actinies. Le crabe, ici 
encore, est homochrome de l'holothurie. BorraDAILE signale un fait du même genre aux îles Maldives.

Parfois même, le commensal déforme pour s'abriter, l'animal auprès duquel il se réfugie, déterminant sur lui une sorte de galle. Tel est un crabe Eumedon convictor, observé par Seurat ( I g) aux îles Gambier et qui vit dans une cavité presque close et assez vaste, déterminée par le refoulement de la région apicale d'un oursin (Echinothrix turca) avec lequel il est homochrome. Des déformations de même ordre sont produites sur des Pocillopores par d'autres crabes(Hapalocarcinus marsupialis) observés d'abord par Semper aux Philippines etréétudiés depuis par Ports $(350)$ au détroit de Torrès.

Une bien curieuse association (fig. I) est celle d'un Géphyrien du genre Aspidosiphon avec un polypier solitaire du genre Heteropsammia (ou Heterocyathus). Elle a été étudiée notamment par Bouvier (I 7 ) et par Sluiter (5 I). L'Aspidosiphon commence par s'établir dans une petite coquille vide de Gastropode, à la façon d'un pagure, et, sur cette coquille, vient se fixer la larve du polypier, qui la recouvre et la déborde largement, formant une masse considérable, dans laquelle le ver serait emmuré, s'il n'y maintenait une galerie qui vient s'ouvrir au dehor's et qui, en outre, communique avec l'extérieur par une série d'orifices latéraux. L'Aspidosiphon est ainsi protégé efficacement par le polypier; il assure à celui-ci la mobilité ; il peut, en effet, faire saillir au dehor's son extrémité antérieure et, en s'arcboutant sur elle, il se déplace en 
entraînaut le coralliaire. Par la façon dont cette association se réalise, il semble qu'elle ne puisse être que l'effet du hasard. Or, elle est très constante, entre les mêmes espèces, en des points aussi éloignés les uns des autres que la Réunion, la mer Rouge et l'archipel Malais.

Beaucoup de faits de commensalisme ont été signalés sans avoir été étudiés suffisamment sur le

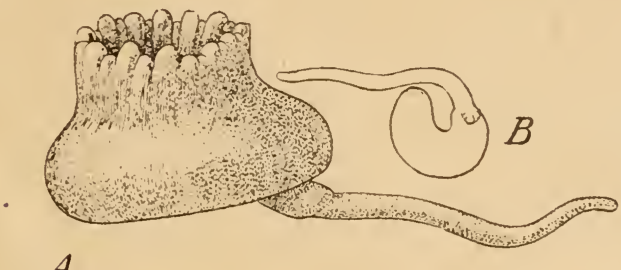

A

Fig. I. - Aspidosiphon et Heteropsammir cochlea (d'après

Bouvigr): A, le géphyrien sortant et trainant le polypier;

- B le géphyrien isolé.

vivant. Dans le sable de nos plages, l'Echinocardium cordatum, oursin spatangide, est accompagné très souvent d'un mollusque lamellibranche, Montacuta ferruginosa que l'on trouve au voisinage de l'anus du spatangue, et qui vit aussi dans les mèmes relations de voisinage avec des synaptes, ainsi d'ailleurs qu'un amphipode Urothoe marinus. Ces animaux utilisent probablement le courant d'eau produit par l'oursin. Dans les replis latéraux que présente la région antérieure des Balanoglossus (Ptychodera), se rencontrent régulièrement diverses annélides, qui doivent être attirées aussi par le cou- 
rant d'eau des branchies de l'Entéropneuste. Giard (36) a observé ainsi un Hésionien Ophiodromus herrmanni, sur un Balanoglossus desîles Glénans ; Gravier (37)a décrit, vivant dans les mêmes conditions, un grand Polynoïdien (Lepidasthenia digueti) sur un Balanoglossus du golfe de Californie. L'ornementation du commensal le rend peu visible sur l'Entéropneuste. D'autres Polynoïdiens, tels que Nrchia cirrosa, Lanilla setosissima, vivent dans les tubes du Chétoptère. Sur le Balanoglossus du golfe de Californie où vit Lepidasthenia digueti, on rencontre fréquemment avec elle un crustacé du genre Lrsiosquilla. Un genre de Copépodes, Hersiliodes, est représenté par des espèces qui vivent dans lesgaleries creusées dans le sable par un Clyménien ou par des Ciallianasses. Dans le tube, d'une grande Térébelle des mers chaudes, Loimia medusa, on trouve très fréquemment des Porcellanes du genre Polyonyx. De Saint-Joseph (5o) les a observées en abondance sur des échantillons de cette espèce provenant du Sénégal et j'ai eu l'occasion de constater la même association avec des Loimia medusa, récoltées dans l'archipel Malais par l'expédition du Siboga. Les Polyonrx s'associent dans les mèmes conditions à d'autres Annélides. En effet, sur 99 Chétoptères récoltés à Beaufort (N. Car), sur la côte A tlantique américaine, ENders $(3 I)$ n'en a trouvé que onze sans Polyonyx, tandis que 75 tubes de Chétoptère renfermaient 156 de ces Porcellanes. Cet auteur note qu'il est extrêmement rare de trouver le Grustacé libre et qu'ıl ne tarde pas à périr dans le tube quand le Chétoptère meurt; il est probable que 
le courant d'eau produit par le Chétoptère est indispensable à sa respiration.

Ces quelques exemples, auxquels on en pourrait ajouter beaucoup d'autres, donnent une idée de la fréquence et de la régularitéde ces associations. Nous nous arrêterons à celles auxquelles donnent lieu les pagures et sur lesquelles il a été fait des observations approfondies et instructives.

$$
{ }^{*} *
$$

Les Pagures ou Bernards l'Ermite s'abritent comme on sait dans des coquilles vides de Gastropodes et sont profondément adaptés à cet habitat, comme l'indique la mollesse et la dissymétrie de leur abdomen, la conformation de leurs dernières pattes (uropodes) et une série d'autres particularités (I). Or, aux pagures sont associés des commensaux nombreux. Nous en examinerons quelques-uns.

Ces associations sont très variées, même pour les seules espèces de nos côtes. Chevreux (22) a examiné méthodiquement les coquilles de Buccins habitées par l'Éupagurus bernhardus sur la côte normande, où cette espèce est pêchée et utilisée à la tois pour l'alimentation et comme amorce. Les coquilles portent souvent une actinie Sagartia para-

I. Sur les transformations adaptatives et le retour ultérieur, soit à la symétrie par habitat dans des cavités rectilignes, soit à la vie sans abri, voir le très intéressant mémoire de Bouvier (Rercherches sur les affinités des Lithodes et des Lomis avec les Paguridés (Ann. Sci. Nat., Zoologie, sér. $7, \mathrm{t}$. XVIII, x895. 
sitica (Calliactis effota). Presque toujour's elles sont tapissées par un Hydraire (Hydractinia echinata); ro o/o d'entre elles renferment un Polynoïdien ( Har. mothoe cueliata S. J.) ; 3o o/o la Tiereilepas fucata sur laquelle nous reviendrons (MALAQuin la trouve dans 5o o/o des cas au Portel). Dans beaucoup de ces coquilles, vivait encore un Copépode Sunaristes paguriet Chevreux y a récolté enfin 8 espèces d'Amphipodes, dont quatre en abondance; or l'une de ces dernières était jusqu'alors considérée comme une rareté et l'on peut en conclure que son habitat normal est dans les coquilles habitées par des pagures. Il est extrêmement probable que des statistiques étendues, comme celles établies par Chevreux, faites sur d'autres espèces et en d'autres localités donneraient des résultats analogues. Bonnier et Pérez (16), dans la mer Rouge, ont trouvé, dans les coquilles habitées par Pagurus brevipes, un Schizopode qui est le type d'une famille nouvelle (Gnathomrsis gerlachei).

Le commensalisme de Nereilepas fucata a été l'objet d'observations intéressantes de Chevineux et de Coupin (25). Il faut noter d'abord que c'est toujours cette espèce que l'on rencontre dans ces conditions, et jamais les autres Nereis ; il y a spécificité rigoureuse de l'association. Le ver se blottit dans les derniers tours de la coquille où il trouve un abri sûr. Il est un véritable commensal, au sens strict du mot. Chevreux, en effet, lorsqu'il nourrissait, en aquarium, des Eupagurus bernhardus avec des moules, a constaté que, dès que le Pagure en recevait une, la Nereis, attirée probablement par une sensation 
olfactive, sortait du fond de la coquille et venait saisir, jusqu'entre les mandibules du Crustacé, des fragments de la proie. Coupin a fait des constatations analogues, en nourrissant le pagure avec des Cardium et il remarque que le pagure n'essaye jamais de dévorer l'Annélide, ce qui cependant lui serait facile. Il y a de sa part une tolérance évidente, qui suppose des réflexes et des instincts précis. Dans cette association, nous voyons aussi que, les rôles des deux partenaires ne sont pas équivalents. Le ver détourne une partie des proies capturées par le crustacé. Il vit donc à ses dépens.

Les coquilles habitées par des pagures sont très fréquemment recouvertes, dans les régions voisines de l'orifice, par des Hydraires, Podocoryne ou Hydractinia. Les polypes se dressent sur une surtace générale de consistance cornée, qui, dans le cas de l'Hydractinia, dépasse même le bord de la coquille et le prolonge. Il semble bien que, dans cette association, il y ait des avantages réciproques: les nématocystes de l'Hydraire doivent constituer pour le pagure une certaine protection et l'Hydraire doit bénéficier des déplacements et des chasses du pagure pour sa nourriture.

Examinons maintenant les actinies fixées sur ces mêmes coquilles. Dans nos mers, Sagartia parasitica se trouve áinsi associée à diverses espèces de pagures: Eupagurus bernhardus, Pagurus striatus, $P$. angulatus ; Adamsia palliata, au contraire, est toujours commensale d'Eupagurus priedeauxi. Dans les grandes profondeurs, Pagurus pilosimanus habite régulièrement des coquilles tapissées par 
une actinie bourgeonnante Epizoanthus parasiticus. Dans ces deux dernier's cas, l'actinie prolonge la coquille par son propre corps, agrandissant ainsi la demeure du pagure, surtout dans le cas de l'Epizoanthus. Il est à remarquer que Sagartia parasitica et Adamsia palliata sont des formes présentant un très grand développement des aconties, longs filaments chargés de nématocystes qu'elles expulsent par des orifices latéraux (cinclides) et il n'est pas douteux qu'il y a là une particularité qui joue un rôle de défense, à la fois pour elles et pour le pagure.

L'association Sagartia-pagure est beaucoup moins intime que celle de l'Adamsia avec $E$. priedeauxi. On trouve jusqu'à - 8 Sagartia sur une même coquille et occupant nécessairement des positions très variées. Cette actinie est encore capable de vivre isolément, mais son mode de vie normal est l'association avec le pagure, comme on peut s'en assurer dans des aquariums. Si, en effet, on extrait le pagure de la coquille où est fixée une Sagartia, au bout de quelques heures, celle-ci se détache spontanément de la coquille vide, comme l'a constaté Faurot (34). Les pagures capturent littéralement les Sagartia quand ils en rencontrent : ces manœuvres ont été suivies en détail par Cowles (24) sur des pagures des Philippines ( $P$.deformis, $P$. asper), qui habitent des coquilles de Dolium, de Strombus et de Cassis. Ils transplantent leurs actinies quand ils changent de coquilles. L'actinie se prête à la manœuvre; elle ne se contracte pas et, après quelques instants, se détache d'elle-même; le pagure la roule alors et la 
transporte sur la coquille nouvelle. Faurot a observé que, dans tous ces cas, l'actinie n'émet jamais d'aconties, alors que cette émission se produit régulièrement sous l'effet d'excitations beaucoup moins fortes. L'association pagure-Sagartia comporte donc des combinaisons de réflexes précis.

Dans le cas de l'Adamsia, les faits sont beaucoup plus significatifs, comme il résulte des observations denombreux auteurs et notammentde FAurot (35). Ici, le pagure, Eupagurus priedeauxi, est toujours logé dans une coquille trop petite pour l'abriter; elle est moins un abri pour lui que l'organe de jonction avec l'actinie. Celle-ci, qui est toujours unique, est le véritable abri du Crustacé, proportionné à sa taille; elle lui forme un manteau souple, moulé en quelque sorte sur lui, lui permettant des mourements agiles, qui le distinguent des pagures associés aux Sagartia, beaucoup plus lourds et plus lents. La comparaison des appendices des divers pagures met en évidence l'adaptation très parfaite de ceux d'Eupagurus priedeauxi à son association avec Adamsia palliata; il ne pourrait d'ailleurs, à cause de ses mouvements, habiter une coquille profonde.

L'Adamsia, de son côté, est fixée à la coquille dans une position constante, de façon que sa bouche soit placée à la face ventrale du pagure et en arrière de la bouche de ce dernier; elle ingère ainsi souvent une grande partie des proies du pagure, sans que celui-ci oppose à cela la moindre résistance.

Dès que l'actinie est fixée, - après avoir été capturée par le pagure - elle s'étale, en subissant une très grande déformation et en sécrétant, à sa face 
plantaire concave qui prolonge la coquille, une cuticule membraneuse.

Il semble bien que l'Adamsia ne peut vivre qu'associée au pagure. Si, en effet, on enlève celuici, l'actinie ne tarde pas à se détacher spontanément. Elle se fixe alors au fond, mais ne survit pas longtemps, même si on la nourrit. L'adaptation est réciproque et très étroite pour ces deux associés et l'on aperçoit nettement des avantages pour chacun : abri et protection pour le pagure, nutrition pour l'actinie. 11 y a donc là un mutualisme indéniable entre deux espèces déterminées, et chacune a été certaine. ment modifiée par l'association, dans sa structure et son comportement. Les faits ne peuvent s'expliquer par de simples tropismes actuels. Ils mettent en jeu l'hérédité.

Cette association est l'une de celles qui ont été le mieux étudiées; elle pourrait cependant encore donner lieu à de nombreuses expériences. L'association Pagurus pilosimanus et Epizoanthus parasiticus est probablement aussi intime ; malheureusement, elle n'est pas accessible à l'expérimentation. Beaucoup de Pagurides exotiques fourniraient certainement l'occasion de remarques analogues aux précédentes .

Les pagures ne sont pas les seuls crustacés à s'associer avec des actinies. Bürgkr (2I) a observé, sur les côtes de Chili, une association analogue entre un crabe, Hepatus chilensis et Actinoloba reticulata. Sur 60 de ces crabes pêchés à Coquimbo, 4 seulement étaient isolés; tous les autres avaient le dos et la carapace recouverts par l'actinie. BünGER a séparé 
les deux animaux et les a placés dans un aquarium. Les actinies se sont d'abord fixées au fond. Mais, au bout de peu de jours, elles se sont spontanément détachées. Au contact du crabe, Bürger les a vues se fixer à une des pattes par leur pied, puis se déplacer jusqu'à ce qu'elles fussent parvenues sur le dos. Ici donc, c'est l'actinie qui a l'initiative de

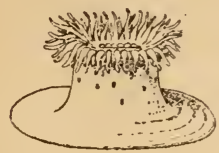

A
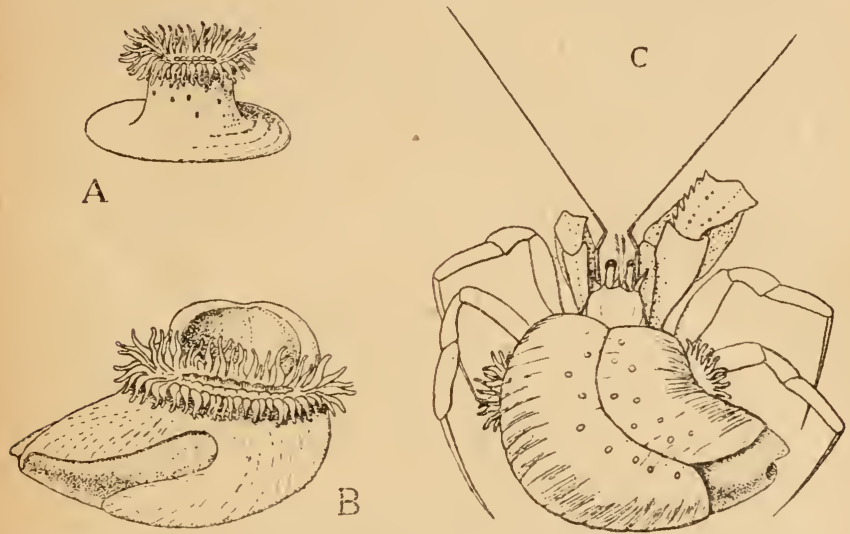

Fig. 2. - Association d'Eupagurus priedauxi et Adamsia palliata (d'après FAUrot). A L'actinie isclée. - B L'actinie fixée à une coquille de Scaphander (la bouche à la face inférieure). - C Le pagure avec l'actinie.

l'association, à l'inverse de ce qui a lieu entre actinies et pagures I).

On peut rapprocher des associations précédentes les faits très curieux offerts par certains Crabes, que

1. Actinoloba reticulata, sur les côtes de Chili, se fixe aussi à des Pecten et à des coquilles habitées par des pagures. 
l'on rencontre toujours tenant une actinie dans chacune de leurs pinces. Cette singulière association a été signalée tout d'abord aux îles Seychelles, en I88o, par Möвıus, pour Melia tesselatia. Elle a ćté retrouvée, pour cette même espèce, aux îles Maldives, par Borradatle, puis aux îles Hawaï; on voit donc. qu'il ne s'agit nullement d'un cas fortuit, mais bien d'une association normale. Duerden (29) en a fait une étude très intéressante à Hawaï, où il en a découvert un second exemple, offert par un autre crabe Polydectes cripulifera Latr. Les actinies portées par le Melia sont bien définies et semblent être les mêmes dans les trois localités citées, malgré l'éloignement. C'est une espèce du genre Bunodeopsis, ou une Sagartia. Duerden a constaté que le crabe prend indifféremment l'une ou l'autre. Les Polydectes portent une autre actinie du genre Phellia. Je me bornerai ici à résumer les faits les plus curieux observés avec les Melia. Les pinces de ce crabe sont très grêles et portées par des pattes (chélipèdes) très mobiles; les deux branches de la pince offrent, sur leurs taces internes en regard, une rangée de dents aiguës, en scie, à l'aide desquelles l'actinie est maintenue. La pince n'est qu'à demi fermée et l'actinie est tenue faiblement; mais on ne peut la détacher sans la blesser; le crabe toutefois peut le faire spontanément.

Les actinies sont dans une position fixe, la bouche tournée vers la face dorsale du crabe et les tentacules en dehors. Dès que le crabe est inquiété, il projette vivement ses pinces du côté d'où vient la surprise, en brandissant, en quelque sorte, les 
actinies comme une arme. Duerden a observé la façon dont il mange. Il se sert des pattes qui suivent la première paire (chélipèdes), pour amener les aliments à sa bouche, mais non des chélipèdes, même si on en a retiré les actinies. Si l'on offre à celles-ci une proie, telle qu'un inorceau de chair, elles se refer-
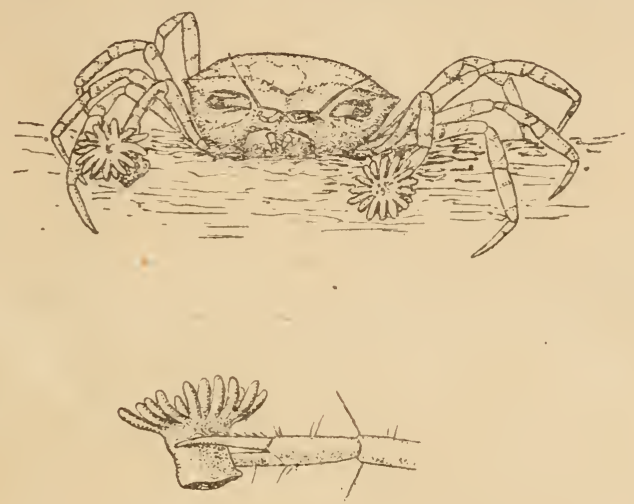

Fig. 3. - Melia tesselata tenant une actinie dans chacune de ses pinces (d'après Duerdix).

ment immédiatement sur elle, et, si le morceau est assez petit pour être englouti en un coup, elles en profitent; mais s'il est gros et fait saillie par la bouche, le crabe s'en empare sans tarder avec les autres pattes et le mange. Il est donc certain que le Crabe se nourrit pour une bonne part, avec des proies dérobées à ses actinies, après s'ètre servi de celles.ci pour les capturer (I).

I. Borradaile et Giard, indépendamment l'un de l'autre, rapprochent l'emploi que le crabe fait de ses actinies, du 
Si on enlève les actinies et qu'on les mette à l'écart dans l'aquarium où se trouve le crabe, il reste inditférent, tant que le hasard ne l'a pas amené au contact de l'actinie. Mais dès que ce contact a eu lieu, le crabe la saisit et effectue une série de manœuvres pour la détacher du fond et la placer à l'intérieur de sa pince, dans la position qui a été décrite. Il suffit mème d'un fragment de l'actinie pour déclancher la série des réflexes. Sans entrer dans d'autres détails, on voit que les intéressantes expériences de DúrDEN montrent, ici, comme pour l'association pagure Adamsia, une élaboration de réflexes très différenciés, au moins chez le crabe. Duerden n'a pas réussi à trouver isolées les actinies du Melia,Bunodeopsis et Sagartia. Par contre il a truuvè seule la Phellia. Il résulte de ses observations que l'association est beaucoup plus à l'avantage du Grabe que de l'Actinie (I).

cas d'une foimi (Ccophylla smaragdina), chez qui les ouvrières tiennent une larve entre leurs mandibules (v. Do FLEIN : Beobachtungen an den Weberameisen, Biolog. Centralbl., t: XXV, 1905, p. 497). La larve, dont les glaudes salivaires sont très développées, file un brin de soie, à l'aide duquel l'ouvrière attache des feuilles bordà bord. Elle-mème n'a plus, à l'état adulte, de glandes filières et travaille ainsi à l'aide de celles de la larve. Grard a proposé, pour les faits

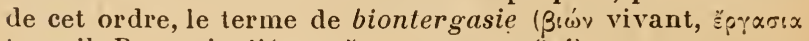
travail, Rev scientif., 1905, ${ }^{\text {er }}$ sem., p. 31 4 ).

I. Il y a un lien indéniable entre les faits qui précèdent el certains instincts des Crustacés qui ne sont plus strictement du commensalisme, mais qui doivent relever des mêmes mécanismes physiologiques, et viennent éclairer les cas de commensalisme proprement dit; je veux parler de l'instinct du déguisement. Il est particulièrement marqué chez les crahes Oxyrhynques (Maia, II yas, etc...) et est très f'acile à observer sur nos côtes. On le retrouve également 
En dehors des associations précédemment étudiées, les pagures en présentent encore communément une autre avec une éponge monaxonide, Suberites domuncula, qui recouvre les coquilles d'une masse charnue et épaisse, puis résorbe la coquille elle. même. Le pagure maintient dans l'éponge une gale. rie prolongeant la cavité de la coquille et s'ouvrant

chez les Dromies. Les faits principaux, connus depuis longtemps, ont été décrits avec précision, en I889, par AuriviLLIUs (I5), et leur étude psycho-physiologique a été dans ces dernières années l'objet des recherches approtondies de $\mathbf{R}$. MiNkiEWicz (42).

- Les objets dont se revètent les Oxyrhynques sont très variés : a!gues vertes ou rouges, Eponges, Synascidies, Hydraires, etc... mais toujours choisis de façon a obtenir l'homochromie avęc le fond sur lequel vit le crabe. On a mème vu dans un aquarium un Miäa se déguiser avec des œuf's de seiche détachés par lui, un à un, d'une grappe. Ces objets sont attachés à des poils crochus situés sur la face dorsale et le crabe les y fixe à l'aide de ses longs chélipèdes, après les avoir dilacérés. On peut l'amener à se déguiser avec des objets non vivants, tels que du papier ou des chiffons; s'ils sont de couleurs diverses, l'animal fait un tri pour obtenir un revètement homochromique au fond, ou bien, le déguisement achevé, il se rend sur un fond homochromique. Le déguisement s'opère encore, mais sans choix de couleurs, avec des crabes amputés de leurs pédoncules oculaires et anxquels on a sectionné les connectifs reliant les ganglions cérébroïdes à la chaîne nerveuse ventrale. La série des réflexes s'accomplit si le réflexe initial est déclanché. L'instinct de déguisement, conclut Mrskıewrcz, " est un enchainement de réflexes des appendices thoraciques antérieurs, provoqués par les tangoréceptions des pinces, dirigés par des tango et chémoréceptions des pièces buccales et poussćs par les tango-réceptions des crochets dorsaux flexibles vers leur but terminal $)$. Le choix des couleurs est superposé à l'instinct de déguisement et déterminé par un chromotropisme synchromatique du milieu, poussant fatalement l'animal vers certaines surfaces colorées en l'écartant des autres.

M. CauditrRY. - Le Parasitisme 
au dehors. La masse de la Suberites lui fournit un abri très sûr, en particulier contre les poulpes. Le début de cette association est d'ailleurs mal connu (I).

On voit par les exemples de commensalisme qui viennent d'être étudiés - et auxquels on en pourrail joindre beaucoup d'autres - que, sous des apparences très simples, ces associations mettent en jeu des réflexes compliqués et qui sont évidemment, de même que les particularités morphologiques, l'aboutissement d'adaptations anciennes. C'est seulement l'observation in vivo et l'expérimentation qui peuvent faire progresser nos connaissances.

Certaines de ces associations, commé celle d'Eupagurus priedauxi et d'Adamsia palliata ont un caractère nettement mutualiste ; d'autres paraissent être au profit exclusif de l'un des associés, qui pourrait être envisagé, par suite, à certains égards, comme parasite de l'autre.

1. Les Suberites sont employées aussi comme déguisement par les Dromies, qui s'en placent des morceaux sur le dos. L'éponge croît alors, en épousant la forme de la carapace de la Dromie. 


\section{CHAPITRE II}

\section{LE COMMENSALISME (suite).}

Sommatre. - Exemples tirés de la faune terrestre. - Les commensaux des Fourmis et des Termites (synoques, synechthres, symphiles). - Les symphiles: Lomechusa, Paussides, etc., Diptères, clienilles de Lycænides. - Les Pucerons et la trophobiose. - Caractères adaptatifs des symphiles. - L'esclavage chez les Fourmis; son origine (théories de Wasmann, Escmerich, Wheeler, etc...). Les plantes myrmécophiles.

La faune terrestre présente peut-être moins d'associations bien définies équivalentes aux précédentes; la plupart de celles quon pourrait citer rentrent mieux dans la catégorie du parasitisme. Il en est cependant qui sont analogues. On peut citer ainsi les rapports existant entre les Ongulés et certains Oiseaux, qui accompagnent les troupeaux, et qui viennent se poser sur les mammifères et leur enlever les tiques ou les larves d'œstres cuticoles dont ils sont porteurs. C'est ce que font les étourneaux, certaines bergeronnettes (Motacilla flava), les pies dans nos pays, les Crotophagus en Amérique, les Buphagus ou pique-bœuts on Afrique. Ce der- 
nier genre est particulièrement associé aux rhinocéros et aux grandes antilopes (I).

C'est dans la biologie des Insectes sociaux, particulièrement des fourmis et des termites, que l'on trouve le plus de faits se rattachant au commensalisme et avec une variété d'aspects considérable. Leur étude précise n'a été faite que récemment et promet encore beaucoup de résultats des plus intéressants. Wasmann ( $\left.\mathcal{B}^{8}\right)$, qui 's'y est particulièrement consacré, estimait en 1895 à r .246 le nombre des espèces myrmécophiles connues (età 2.000 en I9II), dontr.r 7 Insectes (parmi lesquels 993 Coléoptères), 60 Arachnides et 9 Crustacés. Il dénombrait en même temps rog termitophiles dont 8 j Coléoptères.

Parmi ces divers commensaux, il distinguait quatre grandes catégories :

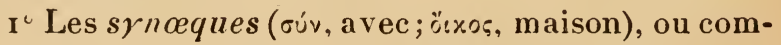
mensaux proprement-dits, partageant simplement l'habitat hypogée des fourmis et termites et trouvant à se nourrir de débris divers, des reliefs de la nourriture de leurs hôtes ou même des cadavres de

1. « La charge d'éloigner ces insectes et tiques incombe " aux pique-bœufs (Buphagus africanus) qui, dans l'Ouellé (" et le Bahr el Gazal, sonŁ particulièrement empressés auprès " des troupeaux d'antilopes. 11 y a toujours au moins un de " ces oiseaux en sentinelle pour avertir le gros gibier du ( moindre danger. Quand les petits pique-bœufs s'élèvent " dans l’air en lançant leurs notes aiguës, cela agit comme " un fouet magique, même sur les Rhinocéros. Immédiate" ment un bruit de piétinement rapide témoigne de leur " obéissance à ces niinuscules sentinelles ailées. ) (H. LANG, The white Rhinoceros of the Belgian Congo. Bull. Newa York Zøol. Soc., t. XXIII, 1920, p. 89). 
ceux-ci. Les fourmis restent indifférentes à leur égard.

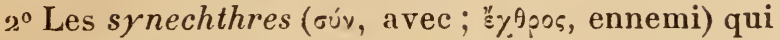
s'introduisent dans le nid en pillards, s'y nourrissant les réserves qui y sont accumulées, ou dévorant les larves. Les fourmis les attaquent et les mettent à mort ;

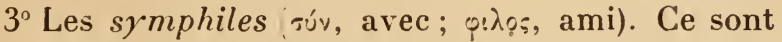
des espèces que les fourmis ou termites recherchent et mème conquièrent de haute lutte et qu'elles nourrissent. C'ette dénomination réunit les myrmécoxènes et les termitoxènes de Forel et d'Emery. Les symphiles sont d'ailleurs loin d'être toujours bienfaisants aux hôtes qui les hébergent, comme on le verra.

$4^{\circ}$ Les parasites, dont nous ferons l'étude ultérieurement.

Les synœques comprennent, dans les fourmilières, des espèces assez nombreuses : des Acariens (Trachyuropoda bostocki, Lelaps equitans), des Araignées (Micaria scintillaris, Thrreostenus biosata, Tetrilus arietinus), des Isopodes (Platyar. thrus hoffmannseggii), des Collemboles (Beckia albina), des Diptères (Ph)rllomyza formica, larves de Phorides et de Syrphides, larve limacoïde de Microdon mutabilis), des Hémiptères (Alydus calcaratus, Nabis laticentris), des Microlépidoptères, des Orthoptères (un grillon aptère Mrrmecophila, Attaphila) et de nombreux Coléoptères ; parmi ces derniers, on peut citer des Histérides (Hetcrius), des Staphylinides (Dinarda dentata, D. hagensi), des larves de Cilytra, de cétoines (Cetonia floricola.), 
etc... Ces diverses espèces, d'ailleurs, ne se rencontrent pas indifféremment dans toutes les fourmilières. La plupart sont cantonnées dans des nids d'espèces déterminées. C'est ainsi que certains Staphylinides, comme les Mimeciton et les Ecitomorpha, vivent avec les Dorylines, dont elles sont plus ou moins mimétiques. Il y a même des fourmis vivant à l'état de synœques dans les nids d'autres espèces ; c'est le cas de Formicoxenus nitidula et de Solenopsis fugax dans les nids de Formica rufa.

Les synechthres, dans les fourmilières, sont surtout certains Staphylins, comme Mrrmedonia humeralis (chez Formica rufa), M. funesta (chez Lasius fuliginosus), Quedius brevis.

Auprès des abeilles, on peut ranger dans cette catégorie les fausses teignes Galleria melonella L., Achrcea grisella F., qui vont pondre sur les rayons et dont les chenilles dévorent la cire, y perçant des galeries tapissées de fils de soie; l'Acherontia atropos, ou sphinx tête de mort, qui dévore le miel, ainsi que la Cetonia cardui.

Les symphiles sont très nombreux. Ce sont surtout des Coléoptères, appartenant à diverses familles : des Staphylinides, (Lomechusa, Atemeles, Xenodusa, etc...), des Psélaphides et en particulier des Clavigérides, des Paussides, famille complètement adaptée à la vie myrmécophile, des Histérides (Hetaerius, Trlois, Chlamrdopsis), des Cétonides, des Nitidulides. La plupart sont les hôtes spécifiques d'une espèce de fourmis ou de termites déterminée. Les fourmis les soignent, les nourrissent 
souvent à la becquée et élèvent leurs larves. D'une manière générale, ce qui attire les fourmis vers les Coléoptères, c'est qu'ils sécrètent des éthers aromatiques dont elles sont très friandes. Ces sécrétions sont produites par des glandes situées à la base de toulfes de poils, de couleur généralement jaune rougeàtre, appelés trichomes et localisés principalement sur les côtés de l'abuomen. Ces éthers dérivent plus ou moins directement du corps gras : ce ne sout pas des substances vraiment nutritives, mais les lourmis s'en délectent et lèchent avec ardeur les poils entre lesquels ils sourdent. Cela les conduit par'ois à de véritables aberrations de l'instinct.

Tel est le cas, par exemple, pour ce qui concerne les Lomechasa, un des inyrmécophiles qui ont été le mieux étudiés. Lomechusa strumosa vil dans les fourmilières de Formica sanguinea; les fourmis les recherchent, au point d'aller en enlever dans d'autres fourmilières, les nourrissent et les lèchent : elles élèvent et nourrissent leurs larres, les transportent en sûreté en cas de péril. Or, ces larves de Lomechusa sont les pires ennemis des larves de fourmis, qu'elles dévorent et les fourmis pourtant les nourrissent aux dépens de leurs propres larves. Une fourmilière de $F$. sanguinea infestée de Lomechusa dégénère et finit par disparaître. Au bout d'un certain temps, en effet, il ne s'y forme plus de femelles normales, mais des femelles plus ou moins atrophiées, plus ou moins semblables aux ouvrières (pseudogynes): finalement la fourmilière s'éteint. Les Lornechusa émigrent alor's dans une autre. ? 
voit donc qu'ils sont tout à fait funestes et cependant ils sont avidement recherchés par les fourmis. Wasmann compare assez justement cette déviation de l'instinct chez les fourmis à l'habitude du tabac, de l'opium ou de l'alcool chez l'homme.

Les Lomechusa, Atemeles et autres Aléocharides ont d'ailleurs des armes contre les Fourmis qui les attaqueraient; K. H. Jordan (65) a montré quils possèdent une glande, dont le produit se collecte dans un réservoir situé ventralement et débouchant sous le quatrième segment abdominal. Le staphylin attaqué relève l'abdomen et projette sur la fourmi la sécrétion, qui a une odeur d'acétate d'amyle et qui la stupéfie. L'acétate d'amyle, in vitro, produit le même effet. Cette glande n'est pas un organe adaptatif, car elle existe chez des Aléocharides non myrmécophiles.

Les Atemeles, dont il existe un certain nombre d'espèces, cantonnées étroitement sur des espèces distinctes de fourmis, ont, a vec celles-ci, des rapports analogues à ceux des Lomechusa, mais qui sont beaucoup moins nuisibles à leurs hôtes, parce qu'ils n'habitent pas avec eux d'une façon continue. La plupart, en effet, émigrent régulièr ement d'une four milière à une autre, vivant au printemps et en été chez des Formica et en automne et en hiver chez des Myrmica. Les Xenodusa sont des formes américaines équivalentes aux Atemeles.

Les Paussides sont des Coléoptères de taille gigantesque par rapport aux fourmis, d'un aspect très caractéristique, en particulier par leurs antennes, et profondément adaptés à la vie myrmé- 
cophile: d'après Escherich (5 5 ), ils dériveraient des Carabiques. Ce sont surtout des types tropicaux, habitant principalement les fourmilières de Pheidole; deux espèces seulement habitent la région
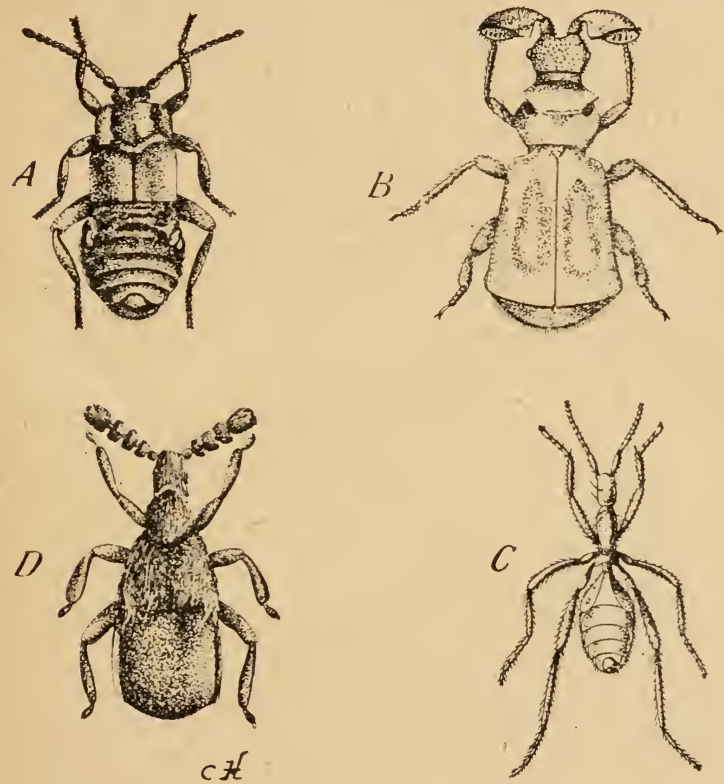

Fig. 4. - Insectes commensaux des Fourmis : A Lomechusa strumosa (d'après WheEler). - B Paussus turcicus (d'après Eschericr). - C Mimeciton pulex (d'après Wasmans). D Claviger testaceus (d'après WhekLkR).

méditerranéenne (Paussus favieri, $P$. turcicus). Ils se nourrissent de larves de fourmis. Quand ils sont inquiétés, ils produisent une explosion odorante et Peringuey pensait que ce bombardement terrifie les 
fourmis, qui, par suite, toléreraient les Paussus. En réalité, ce bombardement ne se produit jamais dans les fourmilières. Les fourmis non seulement tolèrent les Paussus, mais les lèchent sur les trichômes; elles ne les nourrissent pas. Elles soignent aussi les larves des Paussus, qui sont carnivores comme les adultes, d'après les observations de Bazving. Les Paussides bien que soignés par les Fourmis, sont des hôtes nuisibles et qui mériteraient mieux la qualification de parasites.

Les Clavigeridær' constituent un groupe très vaste, comprenant de nombreux genres et espèces; dans nos pays, Claviger testacens et $C$. longicornis vivent dans les fourmilières de Lasius flavus et $L$. niger; les larves sont encore inconnues. Ils sont l'objet de soins minutieux des fourmis, qui les nourrissent et les mettent en sûreté comme leurs propres larves, en cas de danger ; elles lèchent une sécrétion qui se produit dans une dépression dorsale de l'abdomen. Les Claviger ne paraissent pas être nuisibles aux fourmis comme les Coléoptères précédents. Cependant on a observé des Claviger testaceus, mordant à pleines mandibules dans les larves de Lasius et les tuant.

Les Hetrrius, Histérides qui vivent dans beaucoup de fourmilières indigènes (Formica fusca, $F$.rufibarbis, $F$. sanguinea), se nourrissent de cadavres de Fourmis ou d'insectes, mais ne paraissent jamais s'attaquer aux larves saines de fourmis.

Les Diptères sont représentés dans les fourmilières et termitières par une série de types profondément adaptés, ayant en particulier des ailes rudimentaires 
ou même complètement atrophiées (Psyllomyia vivant a vec les Dorylus, Commoptera, avec les Solenopsis, Ecitomyia, avecles Eciton, etc... - Termitoxenia Wasmann dans les termitières). Beaucoup de Phorides y vivent à l'état larvaire et certaines de leurs larves ont des mour's très curieuses, comme celle de Metopina pachycondyla, que Wheeler $(80)$ a trouvée au Texas, dans les fourmilières de Pachycondrla oorax. Ces larves adhèrent par un disque postérieur à une larve de la fourmi, autour de laquelle elles forment comme un collier (fig. 5) et, quand une ouvrière présente à la larve de fourmi de la nourriture, la larve de Diptère allonge son extrémité antérieure et capture la proie destinée à son hôte. Elles peuvent passer d'une larve à l'autre et finalement elles

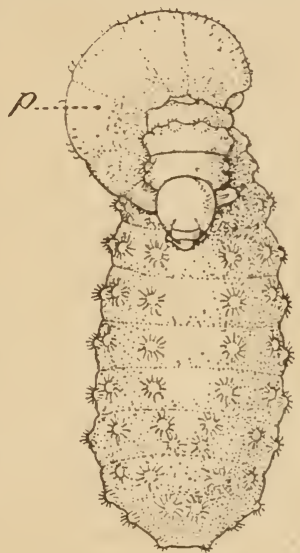

Fig. 5. - Larve de Pachy. chondyla vorax portant une larve $(p)$ de Metopina pachychondylar(d'après WHEELER). s'empupent dans un cocon de larve de fourmi. Les Pachycondrla ne les traitent pas en ennemies, mais les nettoient en mème temps que leur's propres larves. Ce comportement rappelle celui des Braula, Pupipares vivant cramponnées aux abeilles et obligeant celles-ci à dégorger des gouttelettes de miel dont elles s'emparent; il n'est pas sans analogie avec celui des Nereilepas par rapport aux 
pagures et, en somme, tend vers le parasitisme.

Parmi les Lépidoptères, les chenilles de Lycænides ont, avec les fourmis, des rapports analogues à ceux des Coléoptères cités plus haut, et qui paraissentavoir une grande généralité dans la famille. Elles commencent leur développement,en général,sur les Papilionacées, mais ne peuvent y évoluer complètement. Elles sont recherchèes et capturées par les fourmis et finissent leur vie larvaire dans les fourmilières. Elles présentent, sur l'abdomen, des glandes dėcouvertes par Gú́née : les unes impaires au. dos du $7^{\ominus}$ segment abdominal, les autres paires sur le $8^{\mathrm{e}}$; les fourmis sont très avides de la sécrétion de ces glandes qu'elles lèchent; les chenilles font alors émerger des sortes de tubes par où se fait la succion. D’après de Nicḱville, certaines fourmis élèveraient les chenilles de Lycænides en troupeaux, leur construisant des abris, où elles resteraient le jour et les conduisant au pâturage la nuit. D'autres Lycæ. nides se développent dans les galles produites par les Cremastogaster sur les acacias. Certaines espèces ont des larves carnivores, qui dévorent les larves des fourmis qui les hébergent, comme Овerthur (69) l'a constaté par exemple pour Lycana alcon et L. euphemus, et cependant elles sont recherchées par les fourmis et emmenées par elles dans leurs fourmilières. Il y a donc, là encore, des rapports analogues à ceux des Lomechusa. Il reste évidemment à observer attentivement beaucoup de faits de ce genre, différant, dans le détail, d'une espèce à l'autre.

Les rapports des fourmis et des pucerons sont 
depuis longtemps classiques; Lisvé disait déjà Aphis formicarum vacca. Huber, au début du $\mathbf{x I x}^{\bullet}$ siècle, les a étudiès en détail et ses résultats ont été souvent confirmés depuis. Il s'agit ici d'une véritable nutrition de la fourmi et non de la recherche d'une sécrétion simplement agréable. Les pucerons ne peuvent utiliser tout le sucre qu'ils extraient des plantes et en rejettent une notable partie par l'anus, sous forme de gouttelettes liquides projetées sur les feuilles. C'est ce qui constitue la miellée, connue déjà d'HÉsıove et dont la manne des Hébreux est une forme; elle a été depuis le xvirie siècle l'objet de recherches nombreuses (Réaumur, 'Tréviranus, Boussingault, Darwin, Büsgen, Forel, etc.). Huber avait déjà reconnu que les fourmis provoquent l'émission du liquide sucré, en saisissant les pucerons et leur caressant l'abłomen arec leurs antennes. Elles font sourdre ainsi doucement une gouttelette qu'elles absorbent immédiatement. C'est une véritable 'traite d'animaux domestiques. Les fourmis vont traire les pucerons sur les feuilles. Les pucerons radicicoles sont capturés et emmenés dans les fourmilières; les fourmis les élèvent et les défendent comme leurs propres larves: L'Aphis maidiradicis est transporté par beau temps sur des plantes nourricières et rentré à la fourmilière pour les nuits fraîches, ou transporté de vieilles racines sur des jeunes. Les pucerons ont une attitude passive. On a donné à ce type particulier d'association le nom de trophobicse.

La symphilie comprend dons des associations où les rapports sont très variés et loin d'être toujour's 
entièrement mutualistes. Ce sont les fourmis qui paraissent y jouer partout le rôle actif. La régularité et la constance des faits, en des localités très éloignées les unes des autres, montrent qu'il y a là, pour less espèces considérées, un genre de vie normal et nécessaire, résultat d'une véritable évolution psychique et morphologique. Wasmans $\left(\eta^{6}\right)$, à qui l'on doit les études les plus nombreuses sur la symphilie, y voit la manifestation d'un instinct spécial, dérivant, chez les fourmis, de l'instinct d'adoption. JANET (64) et Escherich (58) considèrent cette hypothèse comme inutile. Les fourmis soignent les symphiles comme leur propre progéniture. Ce sont les symphiles qui se sont adaptés aux instincts des fourmis et les ont exploitées à leur profit, en devenant parfois de véritables parasites, se laissant nourrir et faisant élever leur progéniture comme fait le coucou. Il en résulte, chez les fourmis, de véritables déviations de l'instinct, qui leur font sacrifier leur's propres larves, et qu'Escherich compare à des tares sociales, telles que que l'alcoolisme dans les sociétés humaines.

Du côté des symphiles, l'adaptation va jusqu'à des modifications morphologiques. Les Coléoptères vivant dans les fourmilières montrent des caractères propres nettement adaptatif's, dans les trichomes, dans l'appareil buccal, où l'on constate une atrophie plus ou moins marquée des palpes, chez les espèces nourries à la becquée par les fourmis. Chez les Claviger, tous les palpes sont courts; ceux des mandibules sont réduits à un seul article, alors que les Psélaphides restés indépendants ont des palpes mandibulaires extrêmement longs. Les Staphyli- 
nides Aléocharides (Lomechusa, Atemeles, Xenomedusa), qui sont nourris par les fourmis ont aussi des palpes labiaux très raccourcis et une langue large et courte ; cela est particulièrement marqué chez les espèces termitophiles: Spirachtha eurymedusa Schicedte, n'a plus que des rudiments de palpes labiaux (r). Toutefois, il existe des espèces de Termitomorpha, qui ont gardé un très long palpe mandibulaire. WASMANN ( 24 explique cette anomalie par le fait que l'insecte se sert de ce palpe pour caresser les Termites et les exciter à le nourrir, ce que les Lomechusa, Atemeles, Claviger font avec leurs antennes, sur les Fourmis.

Un autre caractère adaptatif' des symphiles est la phrsogastrie, où hypertrophie plus ou moins considérable de l'abdomen. Elle est surtout marquée chez les termitophiles, mais s'observe déjà chez les Claviger, chez les Aléocharides myrmécophiles (Lomechusa, Atemeles) et surtout chez les espèces trouvées au Brésil avec les Eciton(Ecilochara,etc...). Les Aléocharides termitophiles (Spirachtha, Ter. mitobia, Termitomorpha, etc...) ont un abdomen si fortement hypertrophié que les segments en sont à peine reconnaissables; il est, ou bien étendu dans la position normale(Ter mitomorpha), ou bien enroulé sur lui-même, avec la pointe tournée vers le thorax (Spirachtha).

Il est très significatif de voir la physogastrie se développer, en dehors des Aléocharides, chez des

I. On constate la même réduction des palpes chez les fourmis esclavagistes, qui ne se nourrissent plus que par l'aide de leurs esclaves (Anergates). 
Carabides termitophiles Glrptus sculptus, vivant en Afrique avec Termes bellicosus, etc.... Il y a là une convergence fort remarquable. Lorigine de cette physogastrie doit ètre alimentaire. On peut supposer que le gavage par les fourmis ou les termites amène une hypertrophie des corps graisseux, et cette transformation marche de pair avec les modifications des pièces buccales.

Enfin une dernière particularité adaptative réside dans la structure des antennes, qui d'ailleurs sont modifiées de façons fort variées et deviennent des organes tactiles très délicats.

Un certain nombre de symphiles, sous l'influence de ces diverses actions adaptatives, arrivent à réaliser des formes et un comportement très semblables à ceux des fourmis. WASMANN et un certain nombre d'auteurs les considèrent comme mimétiques de celles-ci (cf. Mimeciton pulex, fig. 4, p. 4I).

Aux associations précédentes il convient de rattacher celles qui sont réalisées entre espèces différentes de fourmis et qui sont généralement désignées sous le nom d'esclavage. On sait qu'un certain nombre d'espèces de fourmis ravissent des pupes appartenant à d'autres espèces et les emportent dans leurs propres fourmilières, où, après éclosion, elles jouent le ròle d'ou vrières auxiliaires. Le phènomène du rapt, désigné par Forel sous le nom de $d u$ losis, est susceptible de modalités diverses. Forec en attribue l'origine à l'instinct de pillage très développé chez les fourmis. DARwin a cherché à l'expliquer par la sélection. A l'origine, les fourmis a uraient 
enlevé des nrymphes d'autres espèces pour s'en nourrir, puis, quelques-unes des pupes, ayant échappéau massacre et obéissant à leurs instincts éducatifs, auraient fait l'élevage des larves de l'espèce ravisseuse. Ces cas, d'abord accidentels, se seraient transformés en une habitude régulière, en vertu de l'a vantage qu'ils constituaient pour la colonie. Mais, comme pour toutes les particularités sociales des fourmis, on ne voit pas bien comment a pu se transmettre et se fixer par sélection cette variation d'instincts, puisque les ouvrières sont stériles. Wasmanx (79) n'admet pas l'explication de DARwin. Il remarque que la reine, seule féconde, ne prend pas part aux expéditions des fourmis esclavagistes. Ce n'est donc pas par elle que peut ètre hérité l'instinct de rapt, et c'est cependant à partir d'elle qu'il faut chercher l'explication. Il faut tenir compte, d'une part, de ce que les espèces prises comme esclaves sont rigoureusement déterminées, et surtout, d'autre part, des circonstances dans lesquelles a lieu la fondation d'une nouvelle fourmilière.

Le cas le plus simple est celui où la reine, après le vol nuptial, s'enfonce sous terre, pond, et élève, sans aucune autre aide, ses premières ouvrières. C'est ce qui arrive dans des espèces telles que Formica fusca et $F$.rufibarbis. Il y a là évidemment, à l'origine de la colonie, une phase difficile. Aussi certaines espèces occupent-elles des nids abandonnés, ou s'installent-elles au voisinage du nid d'une autre espèce qu'elles vont piller. Ainsi font les Solenopsis, autour des nids de Messor barbarus. Ce procédé a reçu les noms de cleptobiose (WheELER) ou de lesto- 
biose (ForeL). La femelle d'autres espèces s'installe dans le nid d'une espèce différente, où elle est tolérée. C'est ce que Forel appelle la parabiose, et ainsi doivent s'expliquer un certain nombre de fourmilières mixtes ; la femelle de Formicoxenus nitidulus s'installe ainsi dans les nids de Formica rufa ou de $F$. pratensis.

Mais, chez beaucoup d'espèces, la femelle fécondée,incapable de fonder un nid à elle seule, est recueillie, après le vol nuptial, par les ouvrières d'un nid auprès duquel elle est tombée. Ainsi font, pour leur propre espèce, les ouvrières de Formica rufa et $F$.pratensis. Souvent ce sont des ouvrières d'espèces étrangères qui recueillent une femelle tombée. Les $F$. rufa adoptent ainsi des femelles de $F$. truncicola; les $F$.incerta, en Amérique, adoptent celles de $F$. consocius. Ainsi se constituent des colonies temporairement mixtes, jusqu'à ce que les ouvrières fondatrices étrangères aient disparu par extinction. Dans d'autres cas, les nids restent mixtes, parce que les ouvrières de l'espèce vont ravir des pupes de l'espèce auxiliaire fondatrice. Ainsi $F$. sanguinea ravit des larves de $F$. fusca et de $F$. rufibarbis.

De ces adoptions dériverait l'esclavagisme, suivant Wasmann. Les espèces qui ravissent des pupes pour en faire des ouvrières auxiliaires, sont de celles où le nid commence par une adoption et les ouvrières ravies ensuite sont toujour's de l'espèce ou des espèces qui ont fourni les ouvrières initiales. L'esclavage serait une déviation de l'instinct d'adoption des fourmis. La reine participerait à l'évolution de cet instinct, par les circonstances où se fait 
son adoption et ainsi on peut concevoir qu'elle en transmette les modifications.

L'évolution psychique, d'oì résulte l'escla vagisme, aboutit à une évolution morphologique. Tout ou partie de l'activité sociale passe progressivement aux ouvrières esclaves et les maitres en arrivent à être nourris parcelles-ci. Leur's pièces buccales subissent

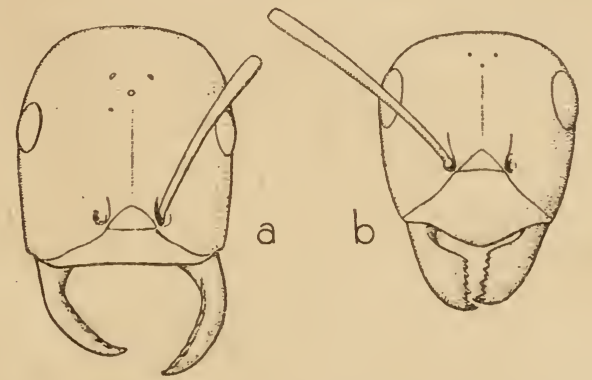

Fig. 6. - Tète et màchoires d'ouvières de Polyergus rufescens (a) et de Formica furca (b) (d'après Bononort).

corrélativement des tranśformations qui leur rendent impossible de se nourrir par eux-mêmes; ils deviennent ainsi absolument dépendants des esclaves. L'adoption primitive s'est transformée en un parasitisme social.

C'est ce qui arrive avec les Polyergus rufescens, ou lourmis amazones. Elles ont des mandibules en sabre, (fig. 6 a) qui sont des organes de combat. Elles sont très bonnes guerrières et enlèvent de vive force des pupes dont elles se feront des ouvrières. Or, les pupes ainsi enlevées appartiennent toujours aux espèces à l'aide desquelles le nid a été fondé 
(Formica fusca, F. rufibarbis). Les mandibules des Polyergus ont perdu leur bord masticateur (cf. fig. 6 b) ; l'ouvrière ne peut pas accomplir les travaux internes de la fourmilière; elle perd même l'instinct de se nourrir directement. Elle dépend de ses esclaves, dont le nombre est toujours proportionné à celui des maîtres.

Les Leptothorax emersoni sont ainsi parasites de Mrrmica brevinodis. Elles périssent quand elles n'ont pas les Mrrmica pour leur donner la becquée, en dégorgeant leur propre nourriture.

Cette évolution atteint son maximum par la disparition des ouvrières. C'est ce qui arrive chez les Anergates, dont une espèce $A$. atratulus forme en Europe des colonies obligatoirement mixtes avec Tetramorium cospitum. De même WheELer $(\delta I)$ a signalé l'absence complète d'ouvrières chez Epœcus pergandei. Mais l'esclavage peut amener, chez l'espèce soumise, des déformations tout à faịt paradoxales de l'instinct, comme celle que l'on observe chez les Monomorium salomonis, qui, réduites en esclavage par Wheeleriella santschii, tuent leur propre reine, condamnant ainsi leur colonie à périr. Pí́ron (Jo) considère cette stérilisation volontaire de la colonie parasitée comme une forme sociale de la castration parasitaire.

Wheeler $(81)$ a, sur l'origine et l'évolution de l'esclavage chez les fourmis, des conceptions assez voisines de celles de Wasmann. Il part également de la fondation des colonies, mais ne croit pas qu'il s'agisse toujours d'une adoption de la femelle par des ouvrières d'une autre espèce : la femelle de For- 
mica sanguinea, par exemple, après son vol nuptial, conquiert les nymphes qui seront les premières ouvrières de son nouveau nid. Pour Emery 160 aussi, c'est un processus violent qui est à la base : la femelle, en pénétrant dans un nid, tuerait et disperserait les ouvrières et, avec les nymphes, formerait une colonie nouvelle.

La vérité est certainement moins simple qu'aucune de ces théories générales.

On voit comment ces phénomènes se rattachent au commensalisme et qu'il est impossible 'de tracer une limite nette entre eux et le parasitisme.

Nous examinerons encore une catégorie de faits d'association, qui, sous l'influence du darwinisme, ont tenu une place assez grande dans les spéculations évolutionnistes à une période récente : je veux parler des plantes myrmécophiles. Fritz Mülcer et plus tard Schimper ont vu en elles le résultat d'une adaptation spéciale, développée par la sélection naturelle.

Elles prẻsentent deś abris, où se logent les fourmis, comme c'est le cas des Cecropia (Urticacées), ou des renflements charnus percés de cavités internes, comme diverses Rubiacées épiphytes (Myrmecodia, Hrdnophyllum), ou des épines creuses très développées et renflées, comme Acacia sphrrocephala. La plupart de ces plantes possèdent en outre de nombreux nectaires. Sur les pétioles des feuilles de Gecropia, certains corpuscules (corps 
de Müller) renferment des essences et des substances albuminoïdes. L'Acacia sphærocephala possède, à l'extrémité de ses folioles, des corpuscules succulents.

Ces divers organes fournissent aux fourmis une nourriture qui les attire et qui se renouvelle automatiquement. Aussi ces plantes sont-elles presque toujours occupées par des fourmilières. L'utilité, pour les plantes, d'être défendues par les fourmis contre des animaux détruisant le feuillage, aurait amené par sélection le développement de ces organes. Les plantes, myrmécophiles sont ainsi devenues un exemple favori dans la théorie de la sélection naturelle. Mais, en face de ces interprétations, se dressent des critiques venant d'auteurs qui ont pu observer les faits de près. Parmi celles-ci, nous résumerons les observations faites à Sao-Paulo par H. von Inering (62) sur les Cecropia (principa. lement $C$. adenopus, ou Imbauwa) et leurs fourmis symbiotes du genre Azteca.

Dans la théorie des plantes myrmécophiles, les Azteca protégeraient surtout les Cecropia contre les Atta, fourmis coupe-feuilles qui dépouillent parfois des arbres entiers de leur feuillage. L'étude des mour's des Azteca est rendue difficile par le fait qu'elles habitent dans des cavités internes des Gecropia et qu'à la moindre alerte, elles se montrent très agressives et mordent d'une façon pénible. Tous les troncs àgés d'imbauwa renferment des Azteca, mais les arbres jeunes sont loin d'en avoir toujours et, quand ils en sont dépourvus, il est à remarquer qu'ils ne soulfrent pas des Atta. Les 
Azteca ne leur sont donc pas indispensables. Elles se nourrissent surtout des parties de l'arbre en voie de croissance, du bourgeon terminal et de ceux des rameaux, ainsi que des corps de Müller, à la base des pétioles. Elles percent, à la partie supérieure des entre-nœuds, en un point de moindre résistance, la paroi de l'arbre, pour pénétrer dans des cavités où elles établissent leurs nids. L'orifice ainsi pratiqué a été appelé stoma, et. à son voisinage, se produit une prolifération réactionnelle du parenchyme, ou stomatome, riche en graisses et en sucres. Les fourmis y trouvent donc de la nourriture. Elles provoquent successivement la formation de stomatomes nouveaux, au fur et à mesure de la croissance de l'arbre. Ihering a vainement essayé de produire des stomatomes expérimentalement; la salive des fourmis semble nécessaire; il s'agit en somme d'une gaille.

Quant aux Atta, quand elles s'aventurent sur les imbaumas, elles sont effectivement chassées par les Azteca, mais elles nont aucune prédilection marquée pour ces arbres et les Asteca n'interviennent que pour défendre leurs propres nids. Elles restent d'ailleurs indiffèrentes à l'attaque d'animaux infiniment plus nuisibles au Cecropia (Chrysomélides, chenilles, Bradrpus surtout). Elles ne s'attaquent qu'à certaines espèces de fourmis et en tolèrent d'au tres. L'imbauwa est certainement l'habitat normal des Azteca, qui y trouvent des abris propices et des substances alimentaires. La fourmi exploite l'arbre et ne le protège que pour se protéger elle-même. Elle ne lui est nullement indispensable et, sui- 
vant l'expression de Inering, les Cecropia vivent sans Azteca aussi bien que les chiens sans puces. Les Azteca sont plus étroitement adaptées à l'arbre. D'après Wheeler, elles périssent quand l'arbre est abattu ; ce sont plutôt des parasites sur lui. D'une façon générale d'ailleurs, le même auteur considère que les tourmis se sont adaptées aux plantes dites myrmécophiles, mais que la réciproque n'est nullement établie. Trop des observations sur lesquelles les théories sélectionnistes reposent ont été faites hâtivement par des voyageurs .

Tout récemment, dans le même ordre d'idées, Chodat (55) a constaté, au Paraguay, que les renflements habités par des fourmis (Azteca, Pseudomyrma) sur diverses plantes (Cordia, Acacia) et consiảérés comme des adaptations myrmécophiles, étaient en réalité des galles produites par des Chalcidiens (Eurytoma), dans lesquelles les fourmis pénétraient par le trou de sortie de l'Hyménoptère adulte. Les fourmis ne font donc qu'utiliser une modification de la plante produite indépendamment d'elles et l'adaptation véritable est la corrélation entre elles et les Chalcidiens. Il serait très intéressant de chercher dans quelle mesure une explication de ce genre s'applique aux diverses plantes myrmécophiles. 


\section{CHAPITRE III}

\section{DU COMMENSALISME A L'INQUILINISME}

ET AU PARASITISME

Sommarke. - L'inquilinisme, transition au parasitisme proprement dit ; exemples divers. - Les animaux épizoaires. - Les parasites intermittents ; les animaux hématophages. - Sens général des modifications produites par le parasitisme.

Nous examinerons maintenant une nouvelle série d'associations, où l'un des animaux vit à l'intérieur de l'autre, sans cependant se nourrir vraiment à ses dépens, mais y trouvant un abri et détournant à son profit des substances nutritives captées par son partenaire. Ces cas ne sont donc pas du parasitisme véritable et on les désigne souvent sous le nom d'inquilinisme (I) (Raumparasitismus des auteurs allemands). Ils constituent une série très graduée, aboutissant au vrai parasitisme.

Un exemple classique en est fourni par les poissons du genre Fierasfer (famille des Ammodrtidce),

I. Inquilini, de incolinus, qui habite à l'intérieur. 
qui vivent généralement à l'intérieur des Holothuries [on en trouve aussi dans des Astéries (Culcita) et des Pinna], soit dans le poumon, soit même dans la cavité générale, après rupture de la paroi du poumon. Ils ne se nourrissent pas de la substance de l'Holothurie, mais de petits Crustacés qu'ils vont, de temps en temps, chasser au dehors. EMery (3o), a étudié leurs rapports avec leur hôte. Ils rentrent à son intérieur par la queue, non sans résistance de la part de l'Holothurie. Exceptionnellement, celle-ci rejette même ses viscères; mais normalement le Fieraster est toléré et l'Holothurie ne paraît souffrir que quand elle en héberge trois ou quatre. Ce que le Fierasfer cherche dans son hôte, c'est un abri. Maintenu en aquarium, sans abri, avec d'autres poissons, il est rapidement dévoré.

L. Plate $(46)$ a trouvé aux Bahamas une association analogue, entre un Poisson (Apogonichthrs strombi, long de 3 à 6 centimètres) et un Gastropode (Strombus gigas), dans la cavité palléale duquel il s'abrite, quittant celle-ci la nuit pour chercher sa nourriture.

Beaucoup de Crustacés s'abritent de mème dans les cavités palléales de Lamellibranches ; des Pontonia habitent dans des Pinna, Сн. Pérez (45) a trouvé, par couples, mâle et femelle, une crevette, Anchistus miersi, dans un Spondyle de la Mer Rouge. C'est le mode de vie générale chez les Crabes du groupe des Pinnothères. Il en existe de nombreuses espèces, la plupart vivant dans la cavité palléale des Lamellibranches, quelques-unes dans d'autres animaux (Sempen en a trouvé avec les Fierasfer 
dans les Holothuries). Ce mode de vie avait déjà attiré l'attention des anciens, qui croyaient que le crabe avertissait le mollusque de la présence des proies à ingérer. La biologie des Pinnothères mériterait d'être attentivement observée ; on admet généralement qu'ils capturent les proies passant au voisinage du Mollusque où ils se tiennent à l'affut, quand les valves sont entr'ouvertes. Coupin (25) a constaté dans leur intestin les mêmes résidus végétaux que dans celui des Moules qui les hébergent.

On pourrait citer encore de nombreux Crustacés inquilins. Semper a observé un crabe vivant dans la cavité palléale d'un Haliotis et une crevette dans la cavité branchiale d'un gros pagure. Dans diverses Eponges - surtout des Hexactinellides, - vivent des Pontonia, des Trpton, des Spongicola, des AEga, assez profondément modifiés d'ailleurs. Classique est l'exemple des Phronimes (ou tonnelier de mer), dont la femelle vit dans le manchon de colonies de Pyrosomes ou la ca vité branchiale des Salpes. Dans la cavité palléale des Lepas, vivent des Annélides du genre Hipponoe. Les Malacobdelles, Némertiens pourvus de ventouses, habitent la cavité palléale de Lamellibranches (Crprina, Mra). Dans la cavité branchiale des Telphuses, habitent régulièrement des Oligochètes (Epitelphusa catanensis), etc., etc...

L'inquilinisme passe d'une façon très graduelle au parasitisme, comme le montrent les Copépodes parasites des Ascidies. Même les formes simplement inquilines, vivant dans la cavite branchiale, subissent - au moins pour les femelles - des déformations considérables. La plupart se nourrissent 
des animacules et particules que le courant d'eau de l'ascidie amène à leur portée dans la chambre branchiale, et alors elles ont encore les appendices buccaux de formes libres (Gnathostomes; ex. : Notodelphys, Doropygus). Mais des types des mêmes séries ont émigré dans l'estomac (Enterocola) ou les tubes épicardiques (Enteropsis) et sont de véritables parasites, chez qui l'appareil buccal est transformé pour la succion d'aliments liquides empruntés à l'hôte (Siphonostomes) ; d'autres genres (Ophioseides, Ooneides), étudiés en particulier par ChatToN (334), montrent une dégradation plus complète encore.

A la frontière du parasitisme (comme l'inquilinisme), est la condition des animaux qui vivent régu lièrement à la surface d'un autre, fixés ou même non fixés. La fixation permanente à un support est un facteur important de transformation morpholo gique, dont les effets sont souvent parallèles à ceux du parasitisme. Pour beaucoup d'animaux fixés, le support ne joue strictement qu'un rôle mécanique et dès lors n'est pas déterminé. Cependant, comme les conditions ne sont pas identiques sur des supports différents, beaucoup d'animaux ont une tendance à se localiser sur certains plus ou moins déterminés. ou plutôt c'est sur ceux-là seulement qu'ils réussissent à se développer aisément.

Ces considérations valent particulièrement dans le cas des supports vivants, pour lesquels s'observe 
en général une très grande spécificité des animaux fixés, en même temps que des localisations définies. On arrive ainsi à des associations très précises et très régulières et les animaux épizoaires, comme les plantes épiphytes, forment une catégorie particulière du commensalisme.

Les exemples en sont extrèmement nombreux. Beaucoup d'Infusoires vivent ainsi sur des animaux marins ou d'eau douce et généralement sur des espèces très déterminées : c'est le cas de nombreux Vorticelliens (Cothurnia, Urceolaria,Trichodina, etc)..., Ils n'empruntent rien à l'hôte pour leur nutrition, mais utilisent le courant d'eau qu'il détermine et ingèrent les particules nutritives qui passent à leur portée. FAuré-Fremiet (33) a fait d'intéressantes constatations sur les Opercularia fixés à divers animaux d'eau douce Gammarus, Asellus, Crrelops, Notonecta). Il a vu que ces Infusoires périssent rapidement si on les détache de leur hôte, ou mème sil'on isole par exemple la patte à laquelle ils sont fixés. Ce sont les mouvements de l'hôte et l'agitation de l'eau qui en résulte qui inportent, car la plupart de ces Infusoires se maintiennent en bon état surdes pattes isolées soumises à un mouvement régulier. Les Opercularia tixées sur des hôtes distincts diffèrent spécifiquement et si l'on transfère sur un dytique celles que l'on trouve sur un notonecte, elles y végètent mal et dépérissent. Elles doivent trouver sur un hôte donné des conditions de localisation favorables, d'où résulte la spécificité de leurs associations.

Dans le groupe des Acinétiens, qui sont tous fixés, les uns à des objets inertes, les autres à des orga- 
nismes vivants, végétaux ou animaux, une assez forte proportion sont de véritables commensaux, quelques-uns tendant à l'inquilinisme ou passant au vrai parasitisme. Déjà, sur les végétaux, certaines associations sont spécifiques. Ainsi, comme le remarque B. Coluin (23), Discophrya cothurnata n'a jamais été observée ailleur's que sur les racines de Lemna. D'autres sont fixés toujours sur des coquilles de Gastropodes (Paludines, Limnées) ou sur les pattes d'un Coléoptère aquatique bien déterminé (Discophrya ferrum equinum sur Hrdrophilus piceus; D. steinii sur Dytiscus marginalis, D. cybistri sur les Cybister). Sur les Hydraires, vivent les formes très particulières comme Ophryoderdron sertularix (1); les Crustacés sont porteurs d'Acinètes très variés (Dendrosomides paguri sur les poils des pattes de pagures, Dendrocometes paradoxus sur les plaques branchiales des Gammarus, Stylocometes digitatus sur les branchies d'Asellus, etc., etc.); on en connait sur des Annélides (Ophryodendron annulatorum). Certains types ont pénétré dans les parties initiales des cavités internes d'hôtes: Trichophrya salparum, dans la cavité pharyngienne des Salpes et à l'entrée de la chambre branchiale de beaucoup d'Ascidies (2), accompagné parfois de Hrpocoma ascidiarum).

C'est dans des conditions analogues que certains Hydraires vivent sur la peau des poissons ou sur

I. Cette espèce est plutôt un vrai parasite se nourrissant des tissus externes de la Sertulaire.

2. Acineta tuberosa est souvent très abondant sur les Copépodes Ascidicoles. 
les coquilles habitées par les pagures ( $H r d r a c t i n i a$, Podocoryne); Stylactis(Podocoryne) minoi, trouvé dans l'Océan Indien, par Alcoce ( 4 ), sur Minous inermis, au voisinage de la fente operculaire, a été retrouvé dans les mêmes conditions, au Japon, par Doflein. Sur 25 o/o des Hrpsagonus quadricornis, à Puget-Sónd, Heatu (38), trouve une abondante végétation de Perigonimus pugetensis, principalement sur les nageoires et le ventre. Nudiclava monacanthi vit aussi sur un poisson des mers de l'Inde. Ichthyocodium sarcotreti a été trouvé par Jungersen ( $3 \mathrm{~g}$ ) sur un Copépode Sarcotretes scopeli, parasite lui-même d'un Scopelus glacialis.

Parmi les Bryozoaires, les Loxosoma ne vivent qu'en épizoaires sur des animaux bien définis : Géphyriens, Annélides (Aphrodite, Capitelliens, etc.). Sur un Nephropsis abyssal de l'expédition du Caudan, j'ai observé moi-même un Bryozoaire spécial du groupe des Cténostomes.

Parmi les Cirripèdes, - tous fixés au moins à des supports inertes, - il en est que l'on ne trouve que sur certains animaux, tels que les Cétacés ou les squales : les Coronula sur les Mégaptères; les Tubicinella enfoncées dans la peau des baleines. australes; les Alepas, Anelasma squalicola sur des squales; beaucoup d'espèces de Scalpellum se rencontrent sur les Hydraires, d'autres espèces du même genre sur des Bryozoaires, des Eponges.

A côté des épizoaires proprement dits fixés, il faut placer des animaux vivant aussi sur d'autres animaux mais libres et s'y nourrissant de détritus 
divers ou de déchets provenant de l'animal luimême: des Némertiens, comme Polia involuta, au milieu des œufs des crabes, se nourrissant d'œufs altérés ou morts et ne semblant pas s'attaquer aux embryons sains ; Histriobdella homari (probablement une Annélide modifiée), vivant de même entre les œufs des homards. Presque tous les Caprellides se tiennent toujours sur d'autres animaux, comme des Eponges (Halichondria), des Alcyonaires, des Ascidies, etc..., et de ce groupe dérivent les $C y a$ mus ou poux des baleines, qui vivent cramponnées sur la peau des Cétacés. Pour tous les animaux vivant dans ces conditions, il serait nécessaire d'étudier exactement les conditions de leur nutrition; certains d'entre eux sont de véritables parasites, alors que d'autres sont de simples commensaux.

$$
*^{*} *
$$

Après avoir, en quelque sorte défalqué du parasitisme proprement dit les catégories précédentes, nous trouvons encore, dans les organismes que l'on s'accorde à considérer comme vraiment parasites, des formes qui pourraient aussi bien être rangées dans l'inquilinisme et qui en dérivent en tout cas très probablement. Ce sont des parasites intestinaux, qui ne se nourrissent pas à proprement parler de la substance même de l'hôte mais du contenu intestinal, c'est-à-dire de substances étrangères en voie d'assimilation mais non encore incorporées à l'organisme. Cette distinction est évidemment subtile et les matières nutrit ves prélevées de la sorte, 
le sont incontestablement aux dépens de l'hòte; de sorte qu'on peut considérer que les animaux vivant dans ces conditions sont réellement des parasites. C'est le cas des Cestodes et personne ne contestera qu'ils soient des parasites authentiques. Mais il y a dans l'intestin d'autres organismes qui se nour. rissent de déchets inutilisables par l'hôte, ou mème qui effectuent sur les substances nutritives des transformations aidant à leur digestion. La flore bactérienne normale de l'organisme a un rôle de ce genre et PAsteur se demandait même si la vie aseptique était possible; nous verrons à la fin de ce volume comment se présente actuellement ce problème. Dans l'intestin des termites, les Trichonymphides, qui y pullulent d'une façon constante chez les ouvriers, y sont certainement inoffensifs et, d'après certains auteurs, aideraient à la digestion du bois. Les Infusoires de la panse des Ruminants et du cæcum des chevaux (Ophryoscolecide), qui se rencontrent toujour's et en quantités énormes, n'ont, en dépit de leur nombre immense, aucune action nocive et se nourrissent aux dépens des débris végétaux ingérés ou des bactéries qui se développent dans ce milieu. On a même exprimé (sans l'établir véritablement) l'opinion qu'ils aideraient a la digestion de la cellulose. En tout cas, ce sont plutôt des commensaux ou des inquilins que de véritables parasites et ils finissent par être digérés dans l'intestin grêle. 11 en est de mème pour une partie au moins des Protozoaires du gros intestin et du rectum, qui vivent en saprophytes, Opalines, Nyctotherus, certains Flagellés et xmibes $\mathbf{c x}$ : 
Chlamydophyrs stercorea, qui pullule commeamibe nue dans le rectum des chevaux et prend la structure testacée dans le crottin); de même pour des Nématodes comme les anguillules de la bouse des vaches.

L'une des sources du parasitisme véritable a dû être l'adaptation de plus en plus exclusive à une nourriture déterminée, la monophagie: Ge régime ne peut en lui-même être considéré comme du parasitisme, quoiqu'il crée des rapports nécessaires et constants entre le prédateur et la proie. De nombreux Nudibranches vivent régulièrement sur les Hydraires qu'ils broutent et dont ils s'incorporent même les nématocystes dans leurs diverticules hépatiques; des Pycnogonides se rencontrent pour la même raison régulièrement sur des Hydraires; des Lamellaria sur des Ascidies composées; Coloplana sur les Alcyonaires. La plupart des chenilles vivent sur une plante déterminée; de même les Pucerons; et de la sorte on passe graduellement aux espèces productrices de galles ou cécidogènes. dont la qualité de parasites est indiscutable. Une série aussi graduée est constituée par les animaux hématophages. Parmi les Insectes piqueurs, il en est, comme les Culicides, qui ne le sont pas exclusivement. Beaucoup, comme les Tabanides, les Simulies et les Hémiptères, restent encore franchement libres. Mais il en est qui, malgré un mode de vie apparemment libre, sont en réalité des parasites intermittents. I.es Glos- 
sines ou tsétsés, ne se nourrissent que de sang de Vertébrés pris au vaisseau, et ont subi, comme nous le verrons, dans leurs appareils digestif et reproducteur, des transformations tout à fait parallèles à celles des Pupipares, qui sont de véritables parasites, vivant en permanence sur un hôte : les Mélophages sur les brebis, les Hippobosques sur les chevaux, les Liptotena sur les cerfs, les Lynchia, Ornithomyia, etc. sur les oiseaux. D'autres groupes de Muscides offrent d'ailleurs des faits du même ordre à l'état larvaire: les Auchmeromria, vis-à-vis de l'homme et des Mammifères à peau nue (Oryctérope, Phacochère), certaines Phormia et $P$ rotocalliphora vis-à-vis des Oiseaux. Les puces, les punaises, les sangsues nous montrent des étapes avancées de l'adaptation au parasitisme, avec conservation d'un mode d'existence relativement libre. Dans les Crustacés Isopodes, les Cymothoadiens et les Pranizes constituent des séries analogues.

Dans tous ces divers cas, on se trouve en présence de certains types incontestablement parasites, mais qui sont reliés à des formes nettement libres, quoiqu'ayant un régime analogue, par des termes intermédiaires très gradués; le départ du parasitisme est difficile à déterminer. Le critérium qui se présente à l'esprit est l'établissement plus ou moins fixe sur un hòte individuel déterminé, comme c'est le cas pour les Pupipares ou les Ixodes; mais il est insuffisant et on ne peut supprimer la catégorie des parasites intermittents, qui passe très graduellement aux formes libres. 
L'inquilinisme et le parasitisme proprement dit entrainent des transformations morphologiques considérables, qui sont un des aspects les plus intéressants de leur étude, au point de vue de l'anatomie comparée et de l'évolution. Ces transtormations sont toujours en rapport avec les conditions spéciales de vie du parasite sur l'hôte et leur interprétation suppose l'analyse de ces conditions, c'est-ìdire en somme l'étude plıysiologique des parasites, étude encore peu avancée en général, et le plus souvent fort difficile.Il n'est pas étonnant que la morphologie ait,encore ici,largement précédéla physiologie.

On ne peut songer à embrasser en quelques pages toutes les modifications adaptatives que présentent les parasites ; elles sont infiniment variées et, pour en donner une idée, il vaudra mieux prendre quelques exemples significatifs en eux-mêmes et pour la comparaison avec les formes libres voisines. D'une manière générale, ces transformations se résument surtout en une simplication des organes de la vie de relation (systèmes locomoteur et sensoriel) et une hypertrophie de ceux de la nutrition (systèmes digestif et reproducteur). On est loin de pouvoir ramener toutes les dispositions réalisées à une adaptation directe; beaucoup ont dù résulter de corrélations qui, agissant d'une façon orthogénétique, ont amené des états extrêmes, sur lesquels l'action adaptative n'est plus reconnaissable: il doit en être à cet égard des formes parasites comme des formes libres; mais ici c'est une évolution secondaire, dont le point de départ est généralement aisé à reconstituer. 
En ce qui concerne les organes de la locomotion chez les parasites, on les voit, soit s'atrophier ou disparaitre, soit se différencier en appareils de fixation. Chez les Arthropodes, les articles terminaux les pattes deviennent ainsi des griffes crochues (Cramus, Crmothoïd , Epicarides, etc...). Chez les Myzostomes, groupe parasite des Crinoïdes et dérivant des Annélides, les paropodes sont complètement atrophiés et représentés seulement par une paire de soies. Les Hirudinées, qui dérivent aussi d'Annélides, ont perdu toutes traces d'appendices; cependant, chez un genre à caractères archaïques, Acanthobdella (parasite des Salmonides des fleuves et lacs russes), il subsiste des soies (cinq groupes de chaque côté, vers l'extrémité antérieure, chez A. palladina) qui indiquent l'existence antérieure des parapodes ( $\mathrm{I}$ ).

La contre-partie de la régression des appendices chez les parasites est le développement d'organes de fixation; soit, comme il a été dit déjà, par transformation des appendices eux-mêmes, soit sous forme d'organes nouveaux, surtout de ventouses et de crochets. Les Trématodes et les Cestodes, les Hiru. dinées offrent de nombreux exemples des premières et souvent, en même temps, des seconds, que l'on trouve encore dans d'autres groupes comme les Acanthocéphales.

Le système nerreux central des parasites est fré-

I. Acanthobdella possède en outre des restiges d'une cavité générale spacieuse, comme celle des Annélides proprement-dites. 
quemment réduit et il en est de même des organes sensoriels, en particulier des yeux.

Dans l'appareil digestif, on assiste, d'une manière générale, à une transformation des organes buccaux, qui deviennent le plus souvent un appareil de succion, et à une réduction plus ou moins marquée de l'intestin terminal, correspondant à ce queles matériaux ingérés par les parasites comportent peu ou point de résidus. L'appareil intestinal peut même disparaitre complètement, comme chez les Cestodes et les Acanthocéphales, où la nutrition se fait par osmose des substances assimilables élaboréés par l'hôte, à travers la paroi extérieure, ou comme chez les Rhizocéphales, où elle a lieu par un système de racines s'irradiant dans tout l'organisme de l'hôte. Chez certains Infusoires parasites (Opalines, Astomata), on assiste à une transformation de ce genre; ils n'ingèrent plus des particules solides, mais se nourrissent par osmose.

Chez la plupart des parasites et en particulier chez les hématophages, les substances ingérées s'accumulent dans les parties moyennes du tube digestif, qui se transforme en une vaste poche, où la résorption se fait graduellement. Les sangsues, les tiques, les mouches piqueuses, les punaises se gorgent ainsi à intervalles plus ou moins éloignés; de même beaucoup de Crustacés parasites (Epicarides, Gnathia) accumulent les matériaux nutritifs sucés à l'hôte, dans leurs sacs hépatiques hypertrophiés. A ces conditions de nutrition correspondent des mécanismes physiologiques particuliers, qui ne sont encore que très partiellement connus. 
C'est ainsi que les parasites hématophages possèdent, d'une façon qui semble très générale, des ferments anticoagulants, maintenant le sang ingérê à l'état liquide. Ce fait a été constaté chez les sangsues (Haycrafx' i884, Apathy 1897), où il est dû à l'action de glandes débouchant près de l'orifice buccal, dans la ventouse; chez les tiques (SABвatini I893); chez les larves d'œstres hématophages (WEINBErg I905); chez l'Ancylostomum duodenale. (L. LoEB et A.J. Sмгтн r9o4); chez une Annélide parasite, que nous étudierons plus loin (Ichthyotomus, Ersig, 1909). Et c'est là un exemple significatif, montrant la réaction adaptative semblable de l'organisme à un même régime, dans des groupes différents et des cas manifestement indépendants les uns des autres. Il doit y avoir de nombreux faits du même ordre dans la physiologie de la digestion chez les parasites.

La fonction reproductrice est la plus sensible à l'action du parasitisme et celle qui prend limportance prépondérante : nous étudierons ses principales modifications dans un chapitre spécial; bornons-nous ici à noter, d'une manière générale, l'hypertrophie de l'ovaire et la multiplication souvent - énorme du nombre des cuts, qui compense la perte d'un nombre extrêmement considérable d'embryons, résultant des difficultés d'accès à l'hôte.

Le parasitisme modifie donc très profondément l'organisme et il est courant de dire qu'il détermine sa légradation ou sa régression. De fait, il amène une simplification de beaucoup d'organes et mème leur disparition. Mais il ne faut pas perdre de vue 
que, par contre, il détermine l'hypertrophie ou la différenciation d'autres organes. Il vaut donc mieux parler d'une spécialisation sous l'influence du parasitisme que d'une dégradation : en somme certains parasites, dégradés par rapport aux formes normales du groupe auquel ils appartiennent, sont merveilleusement adaptés aux conditions tout àfait particulières dans lesquelles ils vivent, et l'évolution qu'ils ont subie à partir du type normal n'est nullement un retour en arrière, mais une transformation progressive dans une direction déterminée. Etant donnée la variété des dispositions réalisées, on resterait nécessairement dans le vague en étudiant les adaptations parasitaires d'une façon générale. Mieux vaut les examiner sur quelques exemples particuliers. 


\section{CHAPITRE IV}

\section{EXEMPLES PARTICULIERS D'ADAPTATION}

\section{AU PARASITISME}

Sommaire. - Les Annélides polychètes parasiles. - Etude spéciale d'Ichthyotomus sanguinarius, d'après les recherches d'H. EIsig. - L'adaptation au parasitisme chez les Mollusques Gastéropodes: Capulidoe (Thyca), Eulimidce (Eulima, Mucronalia, Stylifer, etc...) - Gasterosiphondeimatis. - Les Entoconchide.

L'exemple que j'étudierai d'abord nous donnera une idée des premiers effets du parasitisme. Il s'agit en effet d'un animal relativement peu modifié et appartenant à un groupe où le parasitisme est tout à fait exceptionnel, les Annélides polychètes. L'espèce en question, Ichthrotomus sanguinarius, a été découverte et minutieusement étudiée à Naples par H. Eisig (294); elle est parasite sur une Anguille, Mrrus vulgaris.

Il est intéressant de voir un début d'adaptation au parasitisme chez une Annélide, parce que ce groupe est très vraisemblablement la souche des Myzostomes et des Hirudinées, qui sontentièrement 
composés de parasites et profondément modifiés; on pourra donc imaginer comment ils ont commencé à se transformer. Il y a d'ailleurs, en dehors d'Ichthyotomus, quelques autres faits de parasitisme connus chez les Polychètes: dans la famille des Tuniciens, sur lesquels nous reviendrons plus ${ }^{\circ}$ loin et dans celle des Syllidiens. A. Treadwell a brièvement signalé, sous le nom d'Haplosyllis cephalata, une forme trouvée, fixée par le pharynx aux cirres d'un Tunicien déjà conservé dans l'alcool. F.-A. Potrs (2.97) a décrit, sous ie nom de Parasitosyllis, une Annélide observée dans les mêmes conditions sur des Annélides et Némertes provenant de Zanzibar; son organisation semble normale, mais son pharynx dévaginé est intimement soudé à la paroi du corps de l'hôte, dont il n'a pas été possible de le détacher. Il semble donc que, dans ces deux cas, il s'agisse d'une fixation permanente à un hôte par la région pharyngienne (I); mais il serait indispensable qu'ils fussent étudiés sur des matériaux abondants et in vivo. C'est ce qu'Ersig a pu faire, dans d'excellentes conditions, pour Ichthrotomus sanguinarius.

L'animal (l'adulte est long de $ๆ$ à ro $\mathrm{mm}$.), fixé solidement sur les nageoires - surtout sur la dorsale - du Mrrus, a l'apparence d'une Annélide normale, dont les parapodes sont bien développés

I. Les Syllidiens sont des Annélides carnassières, attaquant leur proie en dévaginant leur pharynx et perforant la paroi du corps !Cf. Malaquin, Recherches sur les Syllidiens. Mém. Soc. Sciences et Arts de Lille, 1893, p. 246). 
- et c'est son appareil fixateur qui mérite avant tout d'être étudié de près.

C'est un système de deux stylets, sortant de la bouche et tournant l'un autour de l'autre par des surfaces articulaires en divergeant (fig.8). Leur portion distale, enfoncée dans la peau de l'hôte, a une

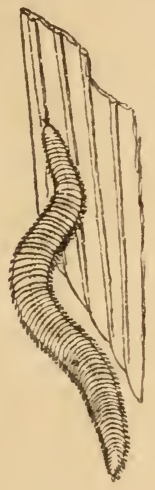

Fig 7

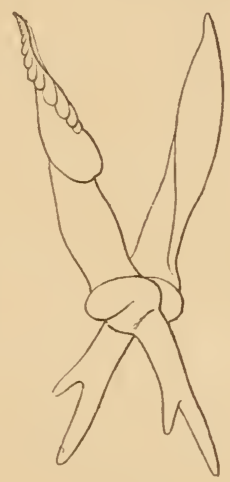

Fig. 8

Ichthyotomus sanguinarius, Les stylets fixateurs d'Ichfixé à la nageoire de Mrrus vulgaris (d'après EIsIG).

thyotomus (d'après EIsig).

forme en cuiller à bord muni de denticulations qui les retiennent solidement. L'animal pique avec ses stylets rapprochés ; il les écarte ensuite l'un de l'autre, ce qui dilacère la peau et la paroi des petits vaisseaux Il est très difficile de détacher un Ichthrotomus de son hôte sans blesser celui-ci ; la position d'écartement assure la fixation. Elle correspond en même temps à l'état de repos des muscles moteurs; l'animal est donc fixé d'une façon passive et doit 
faire un effort de contraction musculaire pour se dégager. 11 y a donc là un appareil de fixation mécaniquement très perfectionné et très spécial.

On doit se demander comment il s'est formé. Estce par une transformation continue d'un appareil existant chez les Syllidiens libres ou autrement? A l'entrée de l'œsophage, beaucoup de Syllidiens présentent une dent ou une couronne de dents, mais rien qui approche de l'appareil d'Ichthrotomus, sauf, semble-t-il, chez un Syllidien signalé par Schmarda, sous le nom de Gnathosyllis diplodonta et muni de deux dents qui pourraient avoir quelque analogie arec lui. Malheureusement la description en est plus que sommaire et cette forme n'a pas été retrouvée. La mécanisme de la réalisation de ce dispositif est mystérieuse : on ne peut guère admettre une explication de nature lamarckienne; ces stylets sont des formations non vivantes, qui ont d'emblée leur'structure définitive ; leur fonctionnement ne peut donc pas influer sur leur forme ; l'aninal doit les utiliser tels qu'ils sont : d'autre part, on ne peut raisonnablement admettre, comme un effet de pur hasard, la réalisation brusque d'un appareil aussi compliqué et aussi bien adapté à la fixation. Le problème restera obscur jusqu'à ce qu'on ait trouvé des formes voisines possédant un appareil analogue mais moins différencié. Or, nous n'avons présentement aucune donnée de ce genre, en dehors de l'espèce de Schmarda. Et ce simple exemple montre comment se posent la plupart des problèmes morphologiques de l'adaptation au parasitísme; il montre en mème temps que le parasitisme est loin 
de mener uniquement à des régressions ou des dégradations.

L'adaptation d'Ichthrolomus se traduit par d'autres caractères, en particulier dans la région antérieure, qui est en voie de se transformer en une ventouse. Les stylets, en dilacérant la peau de l'anguille, produisent une hémorragie au point de fixation. Au moment où il se gorge de sang, on voit l'animal s'appliquer contre la peau de l'hôte par toute sa partie antérieure qui devient concave, tandis qu'en temps ordinaire elle est convexe. Cette partie, formant temporairement ventouse, est la tête, qui, chez les Annélides, porte des appendices spéciaux à fonction surtout sensorielle, antennes, palpes, etc.... et auxquels correspondent, à la surface même de la peau, des aires nerveuses bien définies. Chez les Syllidiens, dont Ichthrotomus se rapproche manifestement, il y a ainsi dorsalement trois antennes (une médiane et deux latérales) et ventralement deux palpes. Or, sur la tête d'Ichthyotomus (fig. 9), Eisig a retrouvé les aires nerveuses correspondant à ces diver's appendices, mais les appendices eux-mêmes ont disparu et les aires nerveuses sont comprises dans la zone formant ventouse. On saisit donc bien, là encore, la modification de l'extrémité antérieure de l'animal, corrélative de son mode de vie; elle est ici manifestement de nature régressive, mais elle constitue en même temps une différenciation appropriée à ce genre de vie ; et elle représente bien une étape de la transformation réalisée chez les Hirudinées, où la ventonse est devenue permanente et où la structure primitive de 
la tête annélidienne n'a plus laissé de traces. Ichthrotomus est un des exemples rappelés plus haut de ces parasites hématophages,qui rendent le sang ingéré par eux incoagulable. EIsıg a fait à ce sujet des observations et expériences très précises. Alors que le sang simplement extrait des vaisseaux du poisson se coagule très vite, celui qui est ingéré par le ver reste liquide. L'incoagulabilité est due à l'action de la sécrétion de glandes volumineuses, les glandes hémophiles, au nombre de deux paires, qui débouchent au dehors, dans la partie de la région antérieure formant ventouse. Leur sécrétion se mélange au sang, avant même que celui-ci ne soit arrivé dans le pharynx. EIsıg a établi, par des expériences directes, leur action anti-coagulante. Grâce à cela, le sang reste liquide et est constamment brassé dans le tube digestif. Outre les conséquences que ce fait peut entraîner pour l'assimilation, Eisig y voit une adaptation d'ordre respiratoire. En effet, l'intestin envoie des diverticules latéraux volumineux dans chacun des segments de l'Annélide et qui s'étendent jusque dans les parapodes et les cirres, contrairement à ce que présentent les Annélides normales. Par contre, Ichthyotomus n'a ni vaisseaux, ni branchies. La respiration des tissus semble donc être assurée par le brassage du liquide intra-intestinal, suivant la conception du phlébentérisme de Quatrefages.

La présence des glandes hémophiles est un caractèreadaptatif important; ce ne sont vraisemblablement pas des formations entièrement nouvelles. Les autres Syllidiens, possèdent, sur la tête, des 
glandes cutanées qui leur sont probablement homologues et aux dépens desquelles elles se sont sans doute différenciées, en s'hypertrophiant et en acquérant la propriété hémophile corrélativement à la nutrition parasitaire. On peut imaginer que ce déve-

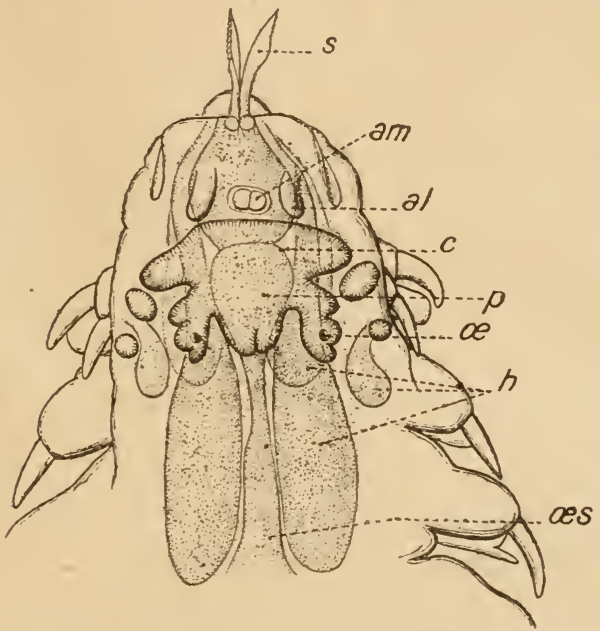

Fig. 9. - Région antérieure d'lchthrotomus (d'après Ersig): a $m$ antenne médiane, $a l$ antenne latérale (rudimentaires), $c$ cerveau, $h$ glandes hémophiles, $œ$ œil, $œ s$ œsophage, $p$ pharynx, $s$ stylets fixateurs.

loppement a eu lieu progressivement, ou que cette propriété existait chez certaines formes à l'état de préadaptation ; ce seraient alors ces formes préadaptées qui auraient été particulièrement aptes à devenir parasites. Nous n'avons pas de données pour trancher entre ces deux hypothèses. La seconde est de l'ordre de celles qui ont été volontier's formulées 
récemment, à propos de faits nombreux d'évolution. La première me scmble infiniment préférable. Elle se rattache à la production des anti-corps et on peut très bien supposer que l'établissement progressif d'un régime hématophage de plus en plus exclusif ait provoqué dans l'organisme des modifications de certaines sécrétions glandulaires, qui se traduisent par des propriétés anti-coagulantes.

Outre les glandes hémophiles de la région céphalique, Ichthrotomus présente, sur tous les segments, des organes de même structure et ayant vraisemblablement la même signification, quoiqu'en fait ils ne semblent pas pouvoir être fonctionnels. Leur présence n'est sans doute qu'une manifestation des corrélations qui relient les diverses parties de l'organisme.

Eisig a relevé encore d'autres traces de l'action du parasitisme sur cette Annélide. La musculature générale des parapodes est réduite. Les yeux sont petits et placés sous la peau, directement sur le cerveau et en état de régression. Le pharynx diffère de celui des Syllidiens normaux et correspond à un état embryonnaire. L'appareil génital est nuanifestement hypertrophié. Ainsi donc toute l'organisation a subi l'influence du parasitisme. Mais l'animal conserve encore le faciès d'une Annélide libre et d'ailleurs il peut changer de place sur l'hôte et se fixer à nouveau sur la même anguille ou sur une autre. Nous trouvons là un exemple très intéressant d'un organisme qui est en train de se transformer. L'étude très complète qui en a été faite par Ersig montre 
aussi combien est fructueuse l'association des données morphologiques et physiologiques. Mème dans un cas aussi complètement fouillé, le mécanisme par lequel ont été réalisées les transformations reste cependant obscur, et, si certaines particularités comme l'hémophilie semblent pouvoir être aisément rattachées à l'activité fonctionnelle de l'animal, il en est d'autres, comme la diffèrenciation des stylets, qui sont beaucoup plus embarrassantes, à moins qu'elles n'aient été le point de départ initial dont les autres ont découlé.

Les Mollusques sont, comme les Annélides, un groupe où le parasitisme est tout à fait exceptionnel, mais qui nous en montre une série de cas très graduée jusqu'à un degré d'extrème régression, d'autant plus significative que les Mollusques coristituent des animaux très élevés en organisation. Cet exemple permet donc de concevoir par analogie la dérivation des groupes entièrement et profondément modifiés par le parasitisme. Il nous montre, en outre, qu'une pareille régression ne se fait pas suivant une série linéaire unique, mais bien par une série de rameaux simultanès et distincts. Malheureusement, ces parasites, presque tous exotiques, n'ont puêtre étudiés jusqu'ici dans de bonines conditions et in viøo, comme dans le cas précédent.

Les Mollusques forment un des embranchements les plus élevés et les mieux définis du règne animal, 
avec des variantes secondaires nombreuses, qui en font l'un des champs d'études les plus intéressants pour l'anatomie comparée. Leur éthologie est des plus variées, mais ce sont toujours des animaux libres. Les Lamellibranches (ou Pélécypodes) offrent seulement quelques cas de commensalisme (I) passant plus ou moins, pour certains, à l'inquilinisme. Les Unionides, ou Moules d'eau douce, passent, au cours du développement, par une phase parasitaire (Glochidium) qui sera étudiée plus loin. Les autres cas de parasitisme, chez les Mollusques, appartiennent à la classe des Gastropodes.

Pelseneer (349), dans ces dernières années, en a signalé plusieurs chez les Prramidellida, où d'ailleurs la radula est réduite ou absente, ce qui implique un changement radical d'alimentation. Il a vu une Odostomia des mers de Chine, perforant de sa trompe le manteau d'une Telline; une autre espèce du même genre a les mêmes rapports avec l'huitre perlière (Meleagrina margaritifera). Il a montré enfin que des Odostomia de nos côtes vivent dans des conditions similaires : $O$. rissoides aux dépens de la Moule commune, $O$. pallida aux dépens des Pecten. Elle enfoncent leur longue trompe par l'entrebaillement des valves pour aller sucer sur le man-

x. Montacuta avec des Spatangues et Synaptes, Ephippodonta avec des Axius, Lepton avec des Gébies, Scioberetia avec un Oursin. On a décrit quelques types parasites des Synaptes : ex. Entovalva (Vokctzkow) dans l'œesophage de Synapta ooplax, Synapticola (Malard). Herpin a signalé une forme assez énigmatique qu'il a trouvée à Cherbourg dans ces Holothuries, mais qui est encore très insuffisamment connue. 
teau de ces Lamellibranches; leur radula a disparu, le reste de leur organisation est peu modifiée.

Deux autres Gastropodes très singuliers ont été récemment signalés sur les Echinodermes: Ctenosculum hawaiense, déterminant la formation d'une sorte de galle sur les bras des Brisinga, et Asterophila japonica, parasite interne des bras d'un Pedicellaster des mers du Japon. Nous nous bornons à mentionner ces deux types dont l'interprétation reste fort obscure.

La série que nous voulons étudier est formée par des Prosobranches parasites d'Echinodermes et appartenant aux familles des Ćapulido, Eulimida et Entoconchidae; cette dernière n'étant peut-être qu'une dérivation de la seconde. Elles renferment ensemble actuellement une trentaine de types dont l'anatomie a été plus ou moins étudiée et qui se résument dans le tableau de la page suivante.

Capulidae. - Ce sont des Prosobranches tænioglosses à coquille très faiblement enroulée ou en forme de simple cône incurvé. Le genre Thrca vit en parasite sur diverses astéries. Cette adaptation est probablement très ancienne, car on a trouvé sur des Crinoïdes des temps primaires des formes voisines (Platyceras). Les Thyca sont peu modifiés et montrent que l'intensité des transformations subies n'est pas forcément en raison du temps écoulé.

La figure Io B relative à Thyca ectoconcha donne une idée de l'organisation de ce genre. Elle montre, dans l'ensemble, un Gastropode dont l'anatomie est encore normale. Les modifications portent sur la région péribuccale et le pied. Ce dernier est réduit 
et ne présente plus d'opercule. La région péribuccale est développée en un large disque(pseudo.pied), par lequel l'animal adhère à l'hôte en faisant plus ou moins ventouse. Au centre fait saillie une trompe, qui s'enfonce à travers les téguments de l'Etoile de mer. Peu développée chez $T$. ectoconcha, elle est extrêmement longue (trois fois environ la longueur du corps) chez $T$. cristallina. La radula a

\begin{tabular}{|c|c|c|c|c|}
\hline Familles & Genres & 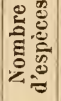 & Localités & Ilòtes \\
\hline Capulida & Thyca & 5 & Océan Indien & Astéries (Linckia) \\
\hline & Platyceras & & & $\begin{array}{l}\text { Fossile (Silurien), } \\
\text { - Trias) sur (Crinoides }\end{array}$ \\
\hline Eulimida & $\begin{array}{l}\text { Eulima (I) } \\
\text { Robillardia }\end{array}$ & $\begin{array}{l}3 \\
\mathbf{I}\end{array}$ & $\begin{array}{l}\text { Pacifique, Océan } \\
\text { Indien, } \\
\text { Océan Indien }\end{array}$ & $\begin{array}{l}\text { Crinoïdeset Astéries } \\
\text { Oursin }\end{array}$ \\
\hline \multirow{5}{*}{$\begin{array}{l}\text { Entocon- } \\
\text { chidee }\end{array}$} & Mucronalia & 2 & $\begin{array}{l}\text { Archipel Malais, } \\
\text { Océan Indien }\end{array}$ & $\begin{array}{l}\text { Oursins, Ophiures, } \\
\text { Astéries, Holothu- } \\
\text { ries. }\end{array}$ \\
\hline & Stylifer (2) & 4 & $\begin{array}{l}\text { Archipel Malais, } \\
\text { Ceylan }\end{array}$ & Astéries et Oursins \\
\hline & $\begin{array}{l}\text { Megadenus } \\
\text { Rosenia } \\
\text { Pelseneeria } \\
\text { Gasterosiphon } \\
\text { Enterovenos }\end{array}$ & $\begin{array}{l}2 \\
\mathrm{I} \\
3 \\
1 \\
1\end{array}$ & $\begin{array}{l}\text { Bahama, Zanzibar } \\
\text { Mer du Nord } \\
\text { Acores } \\
\text { Océan Indien } \\
\text { Norvège }\end{array}$ & $\begin{array}{l}\text { Holothuries } \\
\text { Oursin } \\
\text { Oursins } \\
\text { Holothurie } \\
\text { Holothurie }\end{array}$ \\
\hline & Entoconcha & 2 & Trieste, Philippi- & Holothuries \\
\hline & Entocolax: & 2 & $\begin{array}{l}\text { Mes. } \\
\text { Chili }\end{array}$ & Holothuries \\
\hline$?$ & $\begin{array}{l}\text { Asterophilus } \\
\text { Ctenosculum }\end{array}$ & $\begin{array}{l}\text { I } \\
\text { I }\end{array}$ & $\begin{array}{l}\text { Japon } \\
\text { Hawaï }\end{array}$ & $\begin{array}{l}\text { Astéries } \\
\text { Astéries }\end{array}$ \\
\hline
\end{tabular}

I. Il y a en outre d'assez nombreuses espèces d'Eulima qui paraissent être libres.

2. Plusieurs especes de ce genire ont été anciennement signalées, par les malacologistes, en dehors de celles dont le parasitisme a été récemment reconnu. 
complètement disparu, ce qui indique une nutrition par succion de liquide. Les espèces à longue trompe ont aussi d'énormes glandes salivaires, tandis que l'intestin et le foie y sont réduits.
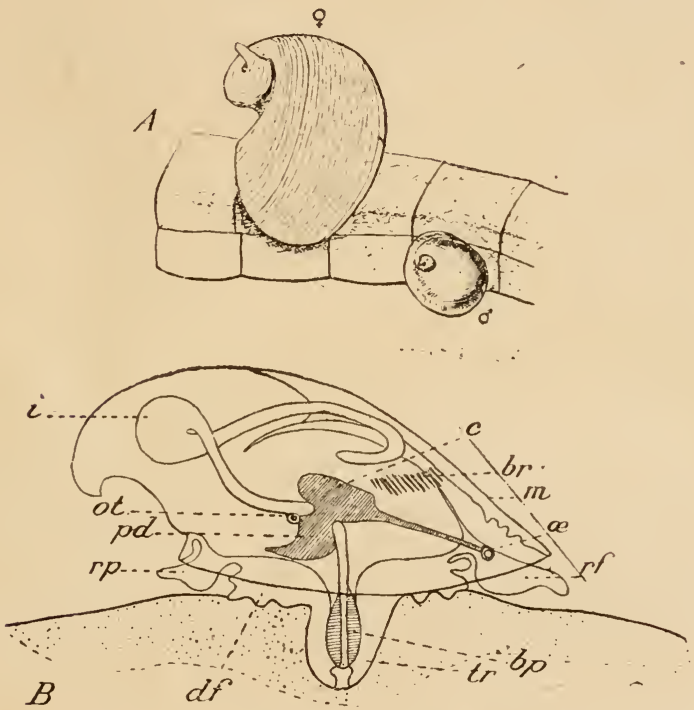

Fig. 10.- A Thyca stellasteris, dimorphisme sexuel (d'après Koenler et Vaney). - B Anatomie de Thyca ectoconcha (d'après $\mathrm{P}$. et $\mathrm{F}$. SARAzin): $b r$ branchie, $c$ cerveau, $i$ intestin, $m$ manteau, $\propto$ œil, ot otocyste, $p d$ ganglion pédieux. $r p$ pied, $r f$ repli frontal, df pseudo-ried; $b p$ pharynx tr trompe.

Thyca stellasteris, bien étudié par KäHLER et VANEY, est l'espèce la moins modifiée; sa trompe est rudimentaire; il y a un opercule. L'animal doit se déplacer sur l'hôte. Il y a des individus de deux 
tailles, qui semblent correspondre aux deux sexes (les mâles étant plus petits).

Les diverses espèces de Thyca ne se rangent pas, pour leurs déformations, en une série linéaire.

Eulimidae. - Ce sont aussi des Tænioglosses voisins des Pyramidellidae, à coquille turriculée offrant plusieurs tours de spire, et ne possédant pas de radula en général.

Le genre Eulima est représenté par d'assez nombreuses espèces de petite taille, dont les coquilles sont communes sur les fonds littoraux de nos côtcs. Une partie de ces espèces doit vivre librement, commeles genres voisins (Niso, Scalenostoma, Hoplopteron). Certaines, comme $E$. polita, ont encore une radula. E. distorta, trouvé sur les côtes de Norvège, est commensal et peut-être parasite dans une Holothurie; il n'a plus de radula. SEMPER, aux Philippines, a trouvé un Eulima rampant à la face interne de l'intestin d'une Holothurie. Trois espèces franchement parasites ont été signalées jusqu'à ce jour : l'une fixée à une Crinoïde abyssal (P'tilocri$n u s)$, les deux autres à des Astéries. Seul $E$. equestris a été étudié anatomiquement par Kähler et VANey. Il envoie à l'intérieur de son hôte (Stellaster) une longue trompe, plongeant dans la cavité générale et par laquelle il suce. L'anatomie générale de ce type est peu modifiee; toutefois le pied est très réduit ; les sexes sont séparés. Une étude biologique et anatomique précise des divers Eulima serait certainement très intéressante, parce que ce geure et les voisins contiennent à la fois des espèces libres, des espèces commensales et des espèces para- 
sites et constituent le point de départ des genres de la série suivante, sur lesquels le parasitisme a plus nettement mis son empreinte.

Jusqu'ici, malheureusement, tous ces genres, en raison de leur habitat exotique, et de leur rareté, n'ont pu être étudiés anatomiquement et biologiquement comme il conviendrait.

Pelseneeria et Rosenia (I) sont des Eulimidœe vivant sur des oursins et dépourvus de radula. L'une des espèces $(R$. st Jlifera) a pu ètre observée vivante, sur des oursins de la mer du Nord. Elle se déplace entre les piquants de son hôte, mais ne le quitle pas et y dépose ses reufs. Les trois espèces décrites par Kanler et VANey et qui proviennent des dragages de la Princesse Alice, ont une trompe enfoncée à travers le test de l'oursin. Chez $P$. profunda, la bouche est entourée d'une large collerette à bords irréguliers et déchiquetés, qui recouvre en partie la coquille et que nous allons trouver, plus ou moins développée, dans les autres genres, sous le nom de pseudopallium. C'est une acquisition nouvelle et évidemment adaptative, qui paraît dériver de l'épipodium. Le pied reste assez bien représenté, mais il est dépourvu d'opercule. Il n'y a pas de radula. Les Pelseneeria et Rosenia sont hermaphrodites. L'ensemble de leur anatomie, sauf les traits qui viennent d'être mentionnés, est peu modifiée.

Le genre Megadenus n'est représenté jusqu'ici que par deux espèces : $M$. holothuricola et $M$. voltzkowi, qui vivent dans l'organe arborescent d'holo-

I. Vaney propose de fusionner ces deux genres. 
thuries. Il y a une longue trompe non rétractile, perforant la paroi de l'organe et pénétrant profondément dans la cavité générale. Il n'y a pas de radula. Il s'agit donc incontestablement d'un vrai parasitisme; la nutrition se fait par succion du liquide cavitaire de l'hôte. Le pied n'a plus d'opercule. Autour de la bouche, s'étend un pseudopallium qui recouvre en partie la coquille. L'anatomie interne n'est guère modifiée. A la différence des Pelseneeria, les sexes sont séparés et on trouve ces animaux par couples, mâle et femelle, de tailles inégales.

Les Mucronalia (fig. II , qui offrent actuellement le plus grand nombre d'espèces, ont encore, comme les genres précédents, une coquille bien développée et porcellanée, terminée à l'apex par quelques tours formant un petit mucron cylindrique. Ici, l'opercule a persisté sur le pied, qui toutefois est plus ou moins réduit. Il y a une longue trompe, dépourvue de radula et s'enfonçant dans la cavité générale de l'hôte. Le pseudopallium est peu différencié. Les sexes sont séparés. L'anatomie reste sensiblement normale. Il n'est pas impossible que les Mucronalia soient fixés d'une façon invariable en un point de leur hôle.

Mucronalia variabilis, parasite de Srnapta ooplax, à Zanzibar, a été trouvé, tantôt dans le tube digestif, tantôt, à l'extérieur, sur la peau. C'est une espèce très variable, très primitive à certains égards, très modifiée à d'autres et qui doit occuper une place particulière. Ainsi - et ceci a un intérèt spécial pour les formes suivantes - le tube digestif 
montre une régression importante. La trompe perce la paroi intestinale de la Synapte et l'animal se nourrit en aspirant le liquide colomique de l'bòte. Il n'y a pas de radula ni de glandes salivaires. Il n'y a ni estomac ni foie; à l'csophage ne fait suite qu'une région courte qui se termine d'une façon aveugle, sans orifice anal. La branchie, elle aussi, a subi une forte régression. Les organes sensoriels subsistent, mais les yeux, très variables, tendent à s'enfoncer sous la peau. L'animal est hermaphrodite. Ces divers caractères sont très discordants, comme l'èthologie de l'animal; certains s'expliquent par la possibilitè qu'il a gardée de vivre à l'extẻrieur, d'autres sont en harmonie avec son habitat à l'intérieur de son hôte.

On voit en tout cas, dans ce genre Mucronalia, combien les

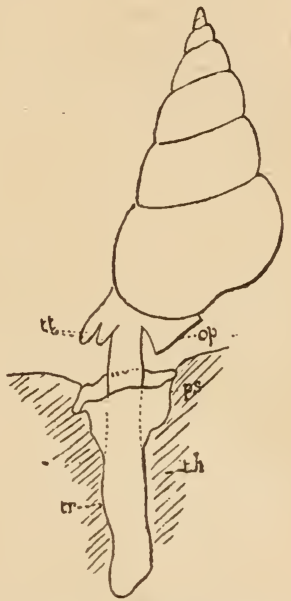

Fig. I . - Mucronalia palmipedis (d'après KanLER et VANEY) op opercule, ps pseudopallium, $t t$ tentacules, $t r$ trompe. transformations sont diverses suivant les espèces et loin de constituer une série unique et simple.

Le genre $S t y-l i f e r$ se rattache de fort près aux précédents et en particulier aux Mucronalia, avec lesquels le caractère distinctif le plus net est l'absence d'un opercule. Toutefois ici la coquille est mince et simplement cornée; chez certaines des espèces au 
moins (S. celebensis, $S$. linckice), le pseudopallium prend un grand développement et la recouvre à peu près complètement. L'animal tout entier s'y trouve alors enfoui. Une trompe plus ou moins longue et dépourvue de radula pénètre dans le cœlome de l'hôte, où elle s'étale parfois en un large renflement terminal. Le pied est très réduit et sans opercule. Le tube digestif montre une régression qui se traduit surtout dans le foie rudimentaire ou même absent. Les quatre espèces connues offrent des divergences considérables ; l'une ( $S$. sibog $\propto$ ) est hermaphrodite, les autres semblent avoir les sexes séparés.

Dans l'ensemble, ce genre est intéressant, en particulier par le progrès dans le développement du pseudopallium et la régression du pied. Son anatomie reste, cependant, en somme, encore assez normale.

Les divers genres qui viennent ainsi d'être passés en revue sont voisins les uns des autres et représentent des variantes multiples et en sens divers du type Eulima. Le parasitisme y a partout - à des degrés divers - provoqué la formation d'un pseudopallium et réduit le pied; il a influé sur le tube digestif, en faisant disparaître la radula et parfois en réduisant le foie. Mais l'anatomie fondamentale d'un Prosobranche est partout conservée.

Genre Gastrosiphon. - L'action modifiante du parasitisme devient infiniment plus saisissante avec ce genre, dont deux exemplaires ont été trouvés par Koinler et Vaney dans une holothurie abyssale de l'Océan Indien, Deima blakei; il a l'extrème inté- 
rêt de relier, de la façon la plus claire, les Eulimidae qui précèdent aux Entoconchidœe que nous verrons ensuite.

Gastrosiphon deimatis (fig. 13) est un parasite

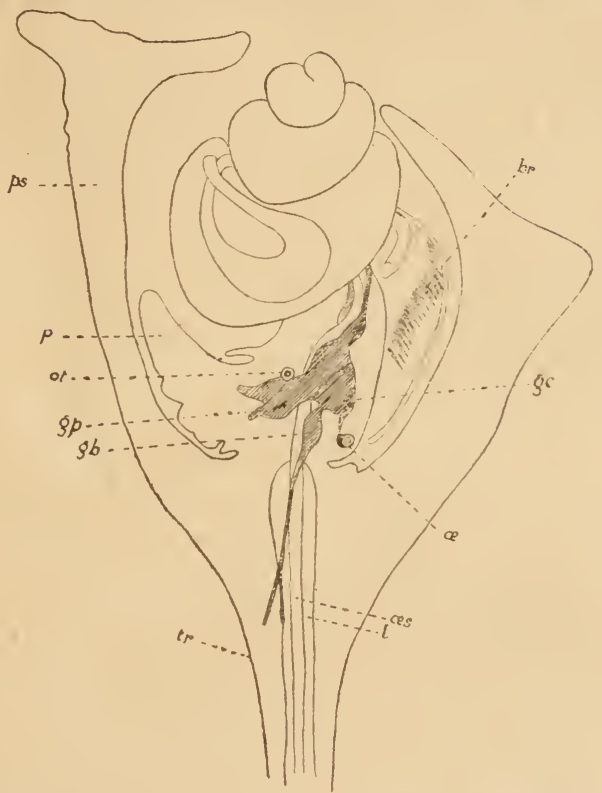

Fig. 12. - Anatomie de Stylifer linckia (d'après P. et F. SARAziv); $b r$ branchie, gb ganglion buccal, gc ganglion cérébroïde, œ œil, ot otocyste, as œsophage, $p$ pied, $p s$ pseudopallium, $t r$ trompe.

interne, mais qui reste en communication avec le dehors par un fin orifice ménagé dans la peau de l'holothurie. En ouvrant la cavité générale de celleci, on voit partir de cet orifice un tube mince, le 
siphon, mesurant environ ro millimètres de longueur, aboutissant à un renflement ovoïde de 5 à ro millimètres de long, qui se continue par un second tube mince et très long ( $104 \mathrm{~mm}$. de long sur o mm. 7 de diamètre), lequel vient se fixer, par son extrémité, au vaisseau marginal de l'intestin de l'holothurie. Ce dernier tube n'est autre chose que la trompe des genres précédents extrêmement développée; l'animal se nourrit en aspirant le sang de l'hôte.

Si l'on ouvre le renflement intermédiaire aux deux tubes minces, siphon et trompe, on trouve, à son intérieur, un Gastropode aisément reconnaissable quoiqu'en régression manifeste. La coquille n'existe plus, mais il y a encore un tortillon viscéral. 11 reste des vestiges du pied. On ne voit plus trace des tentacules céphaliques, ni du manteau proprement dit, ni des branchies, des reins et du cœur. Le système nerveux central est conservé au completet condensé. L'œsophage conduit dans une cavité stomacale, d'où partent des tubes ramifiés constituant l'hépatopancréas.' Il n'y a ni intestin, ni anus. L'animal est hermaphrodite. Ovaire et testicule sont deux glandes distinctes, dont les conduits toutefois se réunissent. Autour de la masse viscérale proprement dite, la cavité du renflement qui l'abrite est remplie des embryons en voie de développement. En somme, la paroi dece renflement n'est autre chose que le pseudopallium, qui a pris un développement énorme. Chez Stylifer linckice, il enveloppait l'animal qui y était enfoui et n'émergeait plus à la surface de l'hôte que par un étroit orifice.Ici, le pseudo- 
pallium a continué à se développer et s'est refermé au-dessus de la coquille en un tube étroit, le siphon. L'animal lui-même est littéralement plongé dans la cavité générale de l'holothurie, restant relié à l'extérieur par le tube siphonal. La trompe, en s'allon-
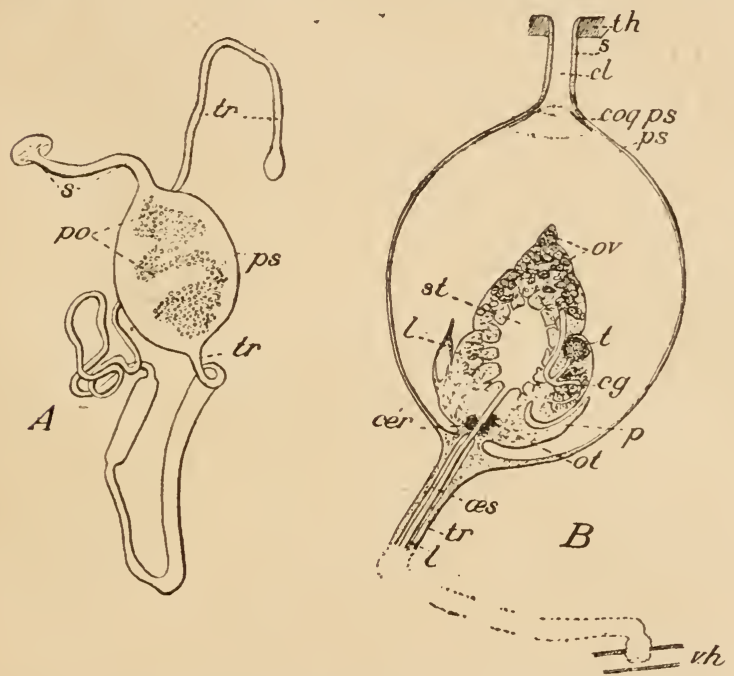

Fig. 13. - Gastrosiphon deimatis (d'après Köhler et VANRy,

$A$ Ensemble du parasite, $B$ Anatomie: $p o$ paquets d'œufs, $p s$ pseudopallium, $s$ siphon, $t r$ trompe; $e s$ œsophage, $c e r$ cerveau, $l$ lacune sanguine, ot otocyste, $p$ pied, $c g$ oviducte, $t$ testicule. ov ovaire, st estomac, coq-ps calcification coquillière pseudopalléale, th tégument de l'hòte.

geant énormément, est allẻe enfoncer son extrémité lans le vaisseau marginal.

On a vu les transformations anatomiques considérables qui ont accompagné cette évolution du pseudopallium. Mais, somme toute, le Mollusque 
reste encore très reconnaissable et se rattache nettement aux Eulimidar; on conçoit aisément sa dérivation des types précédemment examinés.

Entoconchidae. - Le genre Gastrosiphon est peut-être plus intéressant encore, en ce qu'il fournit une base solide à l'interprétation des types infiniment plus dégradés, dont on connaît aujourd'hui trois genres et quatre espèces. A vrai dire, ScнгеMENZ avait fourni de ces types, avant la découverte de Gastrosiphon, une interprétation qui est exacte dans son ensemble, mais qui était purement hypothétique; l'existence de Gastrosiphon lui apporte l'appui solide d'un fait.

La dégradation de ces Mollusques est si grande qu'elle fut cause d'une erreur d'interprétation qui reste historiquement significative. En I85 I, J. MüL-LER (406), étudiant à Trieste les glandes génitales de Synapta digitata, trouvait, à leur voisinage, chez certains individus, des tubes longs et non ramifiés, renfermant des embryons et des larves Veliger de Gastropodes. Il donna à ces larves le nom d'Entoconcha mirabilis, mais expliqua leur présence par une hỳpothèse des plus singulières, suggérée par l'idée qu'on se faisait à ce moment des générations alternantes. Il imagina, en effet, qu'il était en présence d'un cas de ce processus entre Mollusques et Holothuries, la Synapte produisant elle-même des larves de Gastropodes (I). Il méconnut l'explication

I. H жaKel a fait une erreur analogue, à propos des Méduses (Cunina) qui se développent en parasites dans d'autres Méduses, et qu'il avait considérées comme appartenant au cycle de ces dernières. 
très simple, le parasitisme, tant chez les tubes où se produisaient les larves Veliger, manquait tout point de repère permettant de caractériser un Mollusque; d'ailleurs, à cette époque, aucun des exemples précédents n'était connu. Ce fut Baur, en 186r, qui reprit l'étude des Synaptes de Trieste et montra qu'il s'agissait d'un simple fait de parasitisme.

Depuis cette époque, deux genres analogues à Entoconcha ont été découverts dans des holothu ries: Entocolax Voigt, dont deux espèces ont éte trouvées dans des Synaptes de la mer de Behring et de Patagonie et Enteroxenos Bornevie, dans des Stichopus tremulus des còtes de Norvège. Cette dernière esjèce a pu être complètement étudiée, même au point de vue cytologique.

La dégradation de ces trois types (fig. 14) est extrême. Ce sont de simples tubes vermiformes, où l'on ne retrouve pour ainsi dire plus trace de l'organisation des mollusiques; seules les larves peuvent permettre l'identification du groupe.

Entocolax est fixé par une de ses extrémités à la peau. Une portion tubulaire initiale se renfle en une vésicule, à laquelle fait suite un tube étroit et long, flottant librement dans la cavité générale, où il s'ouvre à son extrémité. Ce tube n'est autre que la trompe, qui, à sa portion proximale, s'élargit en une sorte d'estomac aveugle; celui-ci vient butter, à la base du renflement, contre une masse de tiśsus où se différencient l'ovaire, l'oviducte et l'utérus. Cet organe génital femelle fait saillie dans la cavité interne de la partie renflée du parasite; les cuf́s se 
déversent dans cette cavité où ils se développent. Aujourd'hui que nous connaissons Gastrosiphon, le renflement et le tube qui le relie à la peau s'interprètent par son intermédiaire et sont évidemment un pseudopallium très développé. Mais la
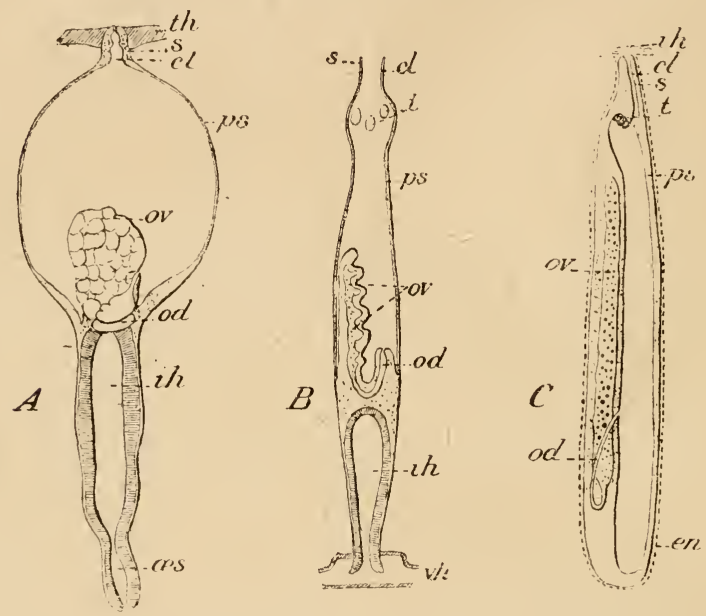

Fig. I4. - Organisation d'Entocolax (A), d'Entoconcha(B) et d'Enteroxenos $(C)$ (d'après VANEx): $c l$ canal cilié, ih intestin hépatique, od oviducte, ns œsophage, $p s$ pseudopallium, $s$ siphon, $t$ testicule; en tunique péritonéale de l'hôte (enveloppant Enterovenos), oh vaisseau ventral de l'intestin de l'hôte.

masse viscérale, qui, chez Gastrosiphon, à l'intérieur' du pseudopallium, contenait encore les organes typiques d'un Gastropode, est réduite ici à l'ovaire. On ne connait malheureusément ces remarquables parasites que par un seul exemplaire d'Entocolnx lndwigi et deux d'Entocolax schiemenzi. 
Eutoconcha a fourni des matériaux relativement abondants à J. MülLER et à BAur, mais devrait être réétudié avec le secours de la technique moderne. Il se présente (fig. I 5 ) sous forme de minces tubes cylindriques, sans aucun renflement et atteignant jusqu'à 80 millimètres de longueur; ils sont fixés par une de leur's extrémités au vaisseau ventral de la synapte. On peut distinguer, à partir de ce point, trois parties: la première est la trompe; la bouche du parasite plonge dans le vaisseau de son hòte; l'appareil digestif est réduit à un simple tube, qui s'étend sur un tiers environ de la longueur totale et se termine en cæcum. Au bout de ce premier tiers, vient une cloison renfermant l'ovaire et séparant la cavité digestive d'une autre cavité, qui s'étend sur toute la partie distale et dans laquelle on truuve des em. bryons et des larves. Elle correspond évidemment au renflement et au siphon de $G^{\prime}$ as-

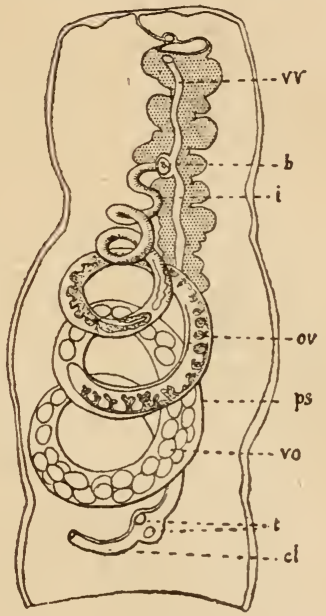

Fig. 15. - Entoconcha mirabilis (d'après BAUR) et ses rapports avec l'hôte : $b$ bouche (fixée au vaisseau ventral, $v$, de l'intestin de l'hôte), $i$ intestin, ov ovaire, $p s$ pseudopallium, vo paquets d'œufs en voie de développement, $t$ testicule, $c l$ canal cilié. trosiphon et d'Entocolax, c'est-à-dire au pseudopallium. Mais ici, au moins autant qu'on peut en juger sur des descriptions datant de 1861 , la régression 
organique a été encore plus complète. Il ne reste plus, des viscères du mollusque, que l'ovaire: on considère comme un testicule un groupe de vésicules faisant saillie dans le siphon vers son extrémité distale.

Quant à l'Enteroxenos, les formes adultes sont dés

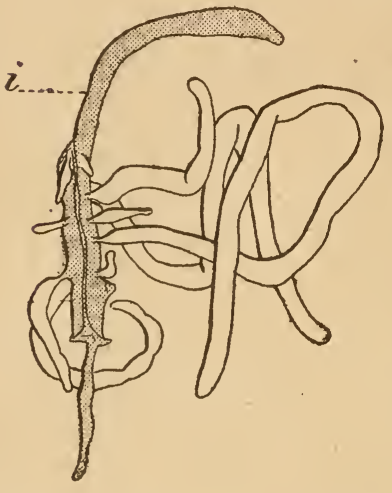

Fig. I6.- Portion d'intestin de Stichopus portant des Enteroxenos de diverses tailles (d'après BonNevie). tubes de 100 à rŏo millimètres de long, libres dans la cavité générale de l'holothurie ; les individus jeunes sont fixésà la face extérieure de la région antérieure de l'intestin (fig. I6). II a mème été trouvé des stades très jeunes, complètement inclus dans la paroi de l'œsophage. C'est le plus dégradé de tous ces Gastropodes parasites. Le tube, en effet,ne présentequ'une seule cavité axiale sur toute sa longueur ; elle est terminée en cæcum du côté distal et s'ouvre par un mince canal situé du côté proximal. L'ovaire est dans la paroi du canal central, le testicule à une des extrémités, comme chez Entoconcha. Iln'y aplus ici ni trompe,ni tube digestif distincts, au moins aux stades étudiés. Toute la longueur de l'animal semble correspondre au pseudopallium. Le parasite est réduit à un sac à embryons, ne montrant plus trace de l'organisation primitive du mollusque. 
Par contre, les larves (fig. I 7) de ces trois types si dégradés révèlent leur nature immédiatement. Ce sont des Veliger typiques, avec coquille enroulée, relum, tortillon viscéral, pied, opercule, système nerreux et otocyste. Le type ancestral s'est complètement conservé dans le développement.

Nous ne connaissons actuellement que quatre espèces et trois genres d'Entoconchidce. Il en existe
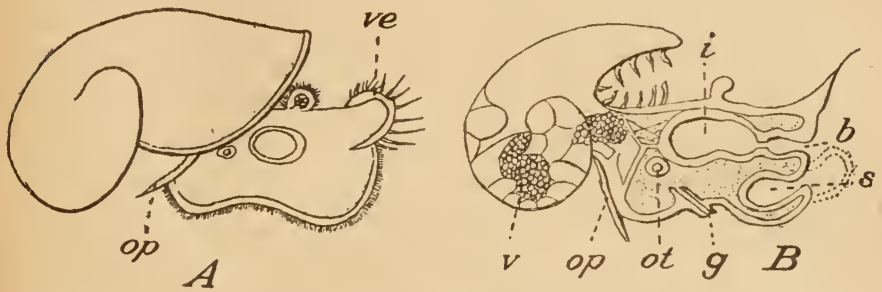

Fig. 17. - Larve veliger d'Entoconcha. A Extérieur, B Coupe optique longitudinale (d'après BAUR): $b$ bouche, $g$ glande pédieuse, $i$ intestin, op opercule, ot otocyste, $s$ invagination sacciforme, $v$ vitellus résiduel,ve velum.

vraisemblablement d'autres. Ces trois genres, tout en offrant une assez grande similitude générale, diffèrent cependant beaucoup dans leur organisation et leurs rapports avec l'hôte. On ne peut les considèrer comme dérivant les uns des autres; ils appartiennent plutôt à des séries distinctes, ayant évolué indépendamment et que les conditions analogues du parasitisme ont amené à une conoergence générale. Le cas de Gastrosiphon permet de penser qu'ils dérivent des Eulimidce. Mais,à partir des Thyca,il a pu se former des types aussi dégradés et semblables. Ainsi, un groupe restreint, comme celui des Gastro- 
podes parasites, nous montre des transformations considérables et à des degrés divers et nous les montre s'opérant, à chaque étape, sur des séries multiples, indépendantes les unes des autres. Il nous montre aussi, en même temps que s'accomplit la régression de certains organes, le développement compensateur de certains autres. C'est le cas ici du pseudopallium, qui est en somme un exemple d'adaptation progressive et de perfectionnement, étant donné le genre de vie de ces mollusques.

Les formes actuellement connues suffisent à exciter un intérêt très vif, mais il n'est pas douteux que d'autres restent à découvrir, qui permettront une notable augmentation de nos connaissances sur cette remarquable évolution ( 1 ).

I. Pour plus de détails voir les études d'ensemble de VANey ( $41 J)$ et Nierstrasz ( $40 J)$. 


\section{CHAPITRE V}

\section{L'ADAPTATION AU PARASITISME CHEZ LES CRUSTACÉS}

Sommaire. - Les Gnathiidœ (Anceus et Praniza). - Les Cymothoïda.

Les Isopodes Epicarides. - Phases de leur dévéloppement. - Les principales familles : Bopyridce, Entoniscidce, Dajida, Cryptoniscidae. - Dualité de constitution de la cavité incubatrice dans le groupe. -- Herma phrodisme successif des Cirytoniscide.

Les Rhizocéphales. - Evolution de la sacculine. - Larves Nauplius et Cypris. - La phase de sacculine interne (travanX de Y.Delage et G. SMithi). - La différenciation de la sacculine externe. - Le genre Thompsonia. - Multiplication asexuce par bourgeonnement (Thompsonia, Peltogaster sócialis).

Les Copépodes parasites. - Le genre Xenocœloma; rapports ana tomiques et physiologiques avec l'hòte; évolution.

Nous emprunterons de nouveaux exemples de l'action du parasitisme aux Crustacés; leur morphologie quasi-géométrique rend très frappantes les déformations qu'ils subissent et le parasitisme y reste également exceptionnel et significatif.

Nous considérerons en premier lieu les Isopodes, groupe en somme très homogène et où, sur une trentaine de familles, trois offrent des parasites: les 
Gnathiida, les Crmothoidae et les Epicarides ; nous insisterons surtout sur ces derniers.

Les Gnathiidce sont une famille aberrante, remarquable par son dimorphisme sexuel très accentué, qui a fait longtemps prendre les deux sexes pour deux genres distincts, Anceus (le mâle) et Praniza (la femelle). E. Hesse, en 1864 , a établi les rapports réels de ces deux types et de leur commune forme larvaire. Les adultes vivent librement, mais ont cessé de se nourrir; leurs pièces buccales ont disparu. La femelle (Praniza) n'est plus qu'une enveloppe pleine d'embryons, mais ayant gardé son système nerveux, ses organes sensoriels et sa musculature. Le mâle (Anceus) se distingue par de puissantes mandibules. Les larves (Praniza) sont des parasites intermittents des poissons, dont elles sucent le sang; leurs pièces buccales sont transformées en stylets piqueurs. Le sang dont elles se gorgent s'accumule dans les sacs hépatiques distendus, il y reste fluide et est progressivement résorbé; il doit y avoir ici aussi une action anticoagulante, qui n'a pas encore été mise en évidence. Les Gnathiidoe forment un groupe isolé.

Les Crinothoidr (s. lato) contiennent une dizaine de familles dont deux (AEgidæ, Cymothoidæ, s. str). montrent des adaptations au parasitisme. Les AEgidæ sont plutôt commensaux ou inquilins que vraiment parasites (ex. AEga spongiophila dans Euplectella aspergillum). Beaucoup d'espèces vivent sur la peau des poissons et s'y cramponnent par leurs pattes antérieures à articles terminaux crochus; les pattes postérieures restent franchement ambulatoires; les pièces buccales sont disposées 
pour percer, indiquant une tendance au parasitisme. Cette tendance est plus accentuée chez les Crmothoida qui sont sédentaires sur la peau des Poissons. Un type même, Ichthyoxenus (dont on connaît actuellement quatre espèces), s'enfonce dans une cavité pratiquée à travers la paroi de l'hôte et, faisant
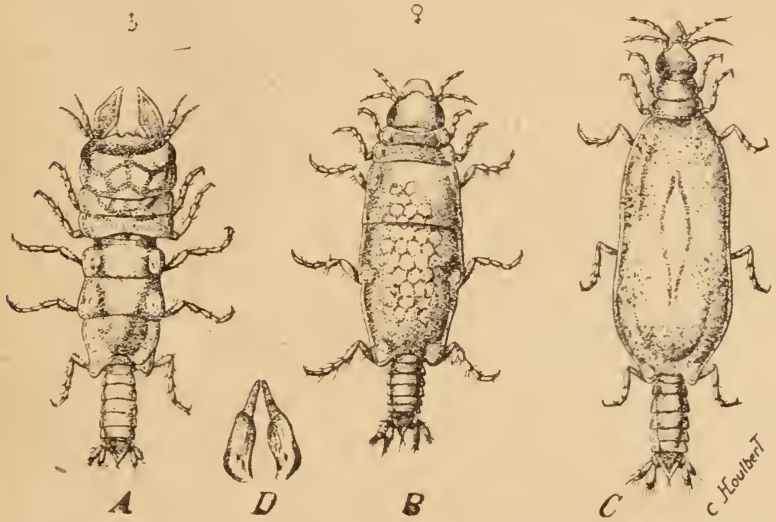

Fig. 18. - Gnathia maxillaris : A màle adulte (Anceus),

B femelle adulte (Praniza); C larve (Pranisa), D Mandibules de la larve (d'après G. O. SARs).

hernie dans la cavité générale, ne communique plus a vec le dehor's que par un étroit orifice; à l'intérieur de ce sac, on trouve toujour's un couple, mâle et femelle, qui ont dû y pénétrer jeunes et y ont subi leur croissance. Les Gymothoidae, en général, sont hermaphrodites successifs et cette particularité doit être une conséquence du parasitisme. L'ensemble de leur organisation est peu moditiée.

Chez les Epicarides, parasites d'autres Crustacés, 
le parasitisme a produit au contraire des modifications considérables et extrêmement variées, très intéressantes au point de vue de l'évolution, parce qu'elles sont parallèles à la diversité des hôtes. Il s'est différencié une série de groupes, par adaptation au parasitisme sur des familles diverses d'hòtes.

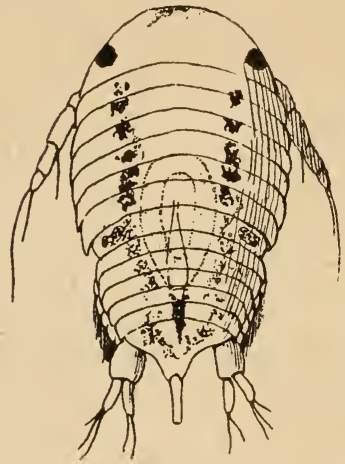

Fig. 19. - Larve épicaridienne de Cancricepon elegans (d'après GIARD et BonNigr).
L'homogénéité du groupe résulte avant tout de l'uniformité des formes larvaires etc'est d'elles qu iil faut partir.

Les œufs sont incubés, comme chez tous les Isopodes et éclosent avec tous les segments et appendices (sauf la septième paire de pattes thoraciques) bien différenciés. Cette première larve (dite larve épicaridienne, fig. 19) ressemble à un petit sphérome ou Cymothoa à pattes crochues; elle a l'aspect d'un Isopode libre, mais dont les pièces buccales indiquent déjà nettement la vie parasitaire.Celles-ci, en effet, ont leur structure définitive de stylets piqueurs et l'ensemble est disposé pour percer et sucer.

Dès qu'elles sont mises en liberté, ces larves, comme j'ai eu l'occasion de le vérifier, vont se fixer sur des Copépodes pélagiques (Acartia, etc.) et subissent une mue, à la suite de laquelle leur chitine 
reste molle; leurs pattes ont par suite un aspect plus ou moins rudimentaire. Ces stades, fixés sur des Copépodes (fig. 20) qu'ils sucent, ont été décrits sous le nom de Microniscas et considérés longtemps comme destypesautonomes. G. O. Sars a, le premier, reconnu qu'ils étaient une phase larvaire, commune à tous les Epicarides. Ils se transforment peu à peu en une forme larvaire nouvelle, ayant cette fois sept paires de pattes thoraciques, un corps allongé, une chitine rigide et des a ppendices bien articulés, que l'on appelle la larve cryptoniscienne. Cette larve quitte le Copépode où elleavait été fixée à l'étal de Microniscus. Le parasitisme sur les Copépodes est donc temporaire, comme celui des Praniza sur les Poissons.

La larve cryptoniscienne nage vigoureusement; on la

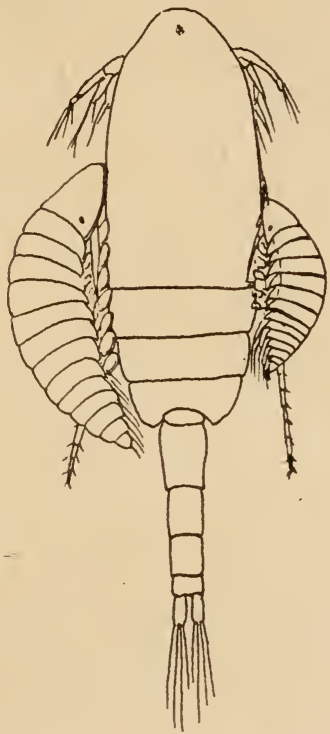

Fig. 20. - Stade Microniscus, sur un Calanus elongatus, d'après G. O. SARS. trouve communément dans les pèches pélagiques. Elle n'est cependant que très transitoire et a pour rôle la recherche de l'hôte définif auquel elle se fixera.

Cet hòte est toujours un Crustacé et, d'une manière générale, une espèce strictement déterminée. 
A. Giard et J. Bonnier, à qui l'on doit les recherches les plus importantes sur les Epicarides, considèrent comme une loi rigoureuse la spécificité du parasitisme de ces Isopodes. Ils considèrent, a prior $i$, comme distincts des Epicarides trouvés sur des hôtes différents, même s'ils ne peuvent mettre en évidence des caractères distinctifs entre eux. Cette opinion est combattue par des carcinologistes comme G.O.SARs, H. J. Hansen et nous y reviendrons; même s'il y a quelques restrictions à y apporter, elle renferme certainement une très grande part de vérité.

Jusqu'au stade de larve cryptoniscienne inclus, tout le groupe des Epicarides montre une extrême homogénéité,qui prouve son unité fondamentale : on distingue cependant, à ce stade, les diver'ses familles, mais d'après des particularités tout à fait secondaires. A partir de la fixation à l'hôte définitif, au contraire, une diversité extrême se manifeste, témoignant de l'influence morphogène des conditions du parasitisme. D'une manière générale, chaque famille d'Epicarides est localisée sur un ordre donné de Crustacés. On peut y distinguer quatre grands groupes :

$\mathrm{I}^{\circ}$ Les Bopjride (Bopyriens s. str. et Ioniens) sur les Décapodes ;

$2^{\circ}$ Les Entoniscida sur les Brachyoures el Anumoures;

3. Les Dajidae sur les Schizopodes;

$4^{\circ}$ Les Cryptoniscida, groupe naturel, qui se sub. divise en tamilles, dont chacune a une localisation bien définie. J. Bonnier (325) distinguait, dans les Gryptoniscida : les Podasconide sur les Amphi- 
podes, les Cabiropsidae sur les Isopodes (et quelques-uns en particulier sur les Bopyrida), les Cumoniscidce sur les Cumacés, les CJproniscidce sur les Ostracodes, les Hemioniscidae sur les Cirripèdes, les Liriopsidœ sur les Rhizocéphales, d'où certains, comme les Danalia, sont repassés sur les Crabes, hôtes des Rhizocéphales. Au total, les Cryptonisci$d c e$ se sont diversifiés de façons extrêmement variées, en mème temps qu'ils s'établissaient sur des hôtes divers.

Les Bopirydce sont, dans l'ensemble, les moins modifiés et forment un groupe naturel sur les Décapodes. Les Bopyres et les Ioniens siègent dans la cavité branchiale de leurs hòtes ; toutle monde connaît la bosse latérale que produit un Bopyre sur une crevette (Palaemon). Les Phryius et les Athelges siègent sur l'abdomen et sont assez différents. Sur le Bopyre femelle, on retrouve aisément l'Isopode. Il est élargi; mais tous les segments sont restés reconnaissables et ont conservé leurs appendices, péreiopodes crochus et pléopodes respiratoires lamelleux : ces derniers, très développés, sont abondamment pennés et même ramifiés chezles Ioniens. Entre ces pléopodes, on trouve toujours un màle nain et grêle, dont tous les segments sont bien distincts et qui a gardé des péreiopodes, mais dont les pléopodes ont disparu. Chez tous les Bopyridae, on constate une dissymétrie marquée, corrélative de leur fixation latérale sur l'hôte et qui atteint l'individu d'une façon complémentaire, suivant qu'il siège à droite ou à gauche. Chez les Phryxus (parasites sur l'abdomen de diverses crevettes), cette dissymétrie est 
extrêmement forte et va jusqu'à la disparition de tous les appendices de l'un des côtés. On voit par là combien la déformation du parasite dépend des conditions du parasitisme. Il serait cependant intéressant de prouver par des expériences directes que le sens de la dissymétrie d'un individu résulte du côté où il est fixé sur son hôte; car on peut soutenir que la larve choisit le côté où elle se fixe d'après une particularité de sa structure individuelle qui préjuge du sens de son évolution ultérieure. On sait. par exemple, que le sens de la dissymétrie des Mollusques gastropodes s'exprime dejà dès l'œuf par l'orientation des fuseaux de division cellulaire. Malheureusement cette expérience facile à concevoir est pratiquement très difficile à réaliser.

Les Bopyridce, comme les autres Epicarides, percent la paroi de leur hòte à l'aide de leurs mandibules ou stylets, terminés par une petite lame denticulée et sucent son sang. L'intestin terminal n'est plus fonctionnel et les substances aspirées s'accumulent dans la cavité des sacs hépatiques qui deviennent énormes; là elles sont progressivement absorbées et dialysées, pour aller s'accumuler, sous forme de réserves graisseuses, dans un tissu spécial, ou pour constituer la substance des œufs. Ventralement, les segments thoraciques portent des lamelles incubatrices ou oostégites, relativement peu développés chez les Bopyres, bien davantage chez les Ioniens : elles délimitent une cavité, dans laquelle se développent les embryons jusqu'à l'éclosion au stade de larve épicaridienne.

Les Entoniscidie constituent le groupe certaine- 
ment le plus différencié des Epicarides, en même temps que le plus voisin des Bopyridce ; leur diffèrenciation est une conséquence manifeste des conditions de leur localisation sur leurs hôtes. Ils sont, en effet, complètement plongés dans la ca vité viscérale de celui-ci (fig. 2I). En réalité, cependant, ainsi que l'ont montré GIARd et BoNNiER (340), dans leur magnifique monographie du groupe, ils doivent être considérés, morphologi quement et physiologiquement,comme des parasites externes. En effet, ils ne sont pas directement au contact des viscères des Crabes qui les hébergent, mais ils sont enveloppés entièrement par une mem-

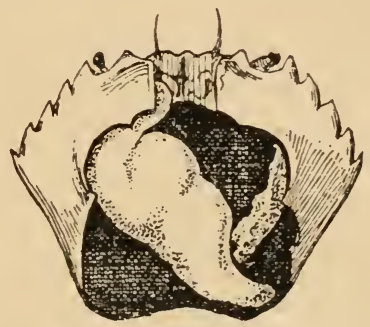
brane mince qui les en sépare; ce n'est autre chose qu'un sac,qu'ils repoussent devant eux, au fur et à mesure de leur croissance et qui est formé par la paroi séparant la cavité branchiale de l'hôte de sa cavité viscérale. Il font donc progressivement hernie dans cette dernière, à partir dela première; ce sac reste toujours en communication avec la cavité branchiale de l'hôte, c'est-à-dire avec l'extérieur, par un étroit canal à sa base; par là pénètre l'eau servant à la respiration du parasite et à celle de ses embryons.

A l'état adulte, le type Isopode est méconnais- 
sable chez l'Entoniscien. Il n'y a plus de segmentation visible, ni d'appendices; le corps même est enveloppé par des lobes énormes, qui ne sont autre chose que des oostégites. Sur l'abdomen, des appendices abondamment festonnés et frangés sont les pléopodes respiratoires.

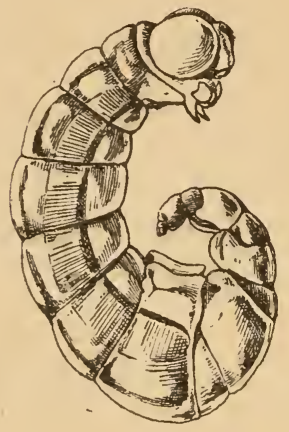

Fig. 22

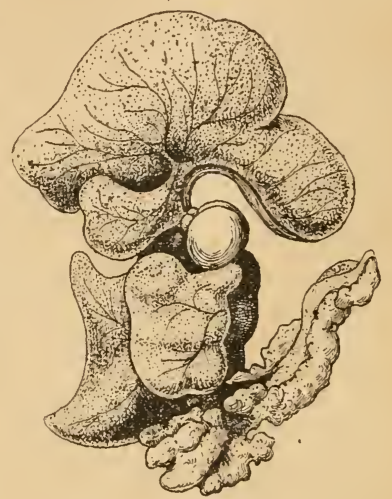

Fig. 23

Portunion mcenadis; femelle très jeune, au début de sa métamorphose (stade asticot, d'après GiARD et BoNNIER).

Portunion Kossmanni ; femelle adulte, avec la cavité incubatrice remplie d'embryons (d'après GiaRD et BONNIER).

Pour comprendre la morphologie étrange de cette femelle auilte, il faut en trouver des stades jeunes (fig.22), dits stades asticot, et ceux, un peu plus âgés, où débutent les oostégites et le développement des pléopodes; les péreiopodes ont disparu de bonne heure; c'est à partir de ce stade vermiforme que, par le développement des oostégites, se réalise l'adulte si déconcertant au premier abord. Les Entoniscisdce 
sont un des exemples les plus frappants de l'ampleur des transformations produites par le parasitisme(fig. '23). Plongé dans la cavité viscérale de son hôte,l'Entoniscus se contracte d'une façon ry thmique et produit ainsi un courant d'eau régulier, qui assure sa respiration et celle de ses larves. Par son appareil buccal, conformécomme chez les Bopyrida, il perce en un point la mince paroi qui l'isole de la cavité viscérale de son hôte et, grâce à un appareil de succion très différencié et pulsatile, il aspire le liquide de cette cavité. Ici non plus, il n'y a plus d'intestin terminal fonctionnel; et les substances assimilables s'accumulent dans les sacs hépatiques fortement distendus.

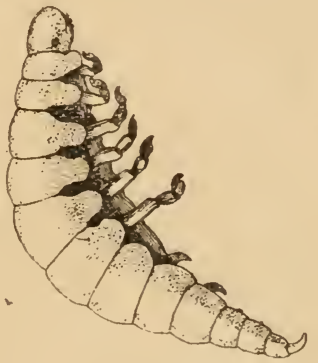

Fig. 24. - Portunion Kossmanni,mâle adulte,fortement grossi (d'après Giard et Bonnier).

Quant au måle (fig. 24), il est tout à fait nain, long d'un millimètre à peine et très difficile à découvrir dans le dédale des oostégites et au milieu de la ponte. Il est toujours accompagné d'un certain nombre de larves cryptonisciennes, chez lesquelles les testicules sont déjà formés et qui, d'après GIARD et Bonnicr, fonctionnent commes mâles complémentaires, ou qui, peut-être, sont destinés à se transformer en des mâles proprement dits, pour assurer la fécondation des pontes successives de la femelle. En tout cas, abritée comme l'est la femelle dans le crabe il est remarquable que toujours un certain nombre de larves sachent la découvrir. 
Les Dajidce sont une famille ayant des caractères propres très marqués et qui est localisée sur les Schizopodes, où ils occupent d'ailleurs des'positions assez variées.

D’une manière générale, chez eux, les segments postérieurs du thorax (deux à quatre suivant les genres) s'hypertrophient, mais perdent leurs péreiopodes, tandis que les premiers les gardent, groupés en arc à la partie antérieure; les oostégites de ces premiers segments restent rudimentaires; ceux des derniers, au contraire, sont de grande taille. L'abdomen est très réduit et dépourvu de pléopodes. Le mâle y vit blotti, comme chez les Bopyridœ. L'incubation des œufs se fait ici dans des conditions nouvelles. Les oostégites ne jouent plus qu'un rôle virtuel ; les œuts se développent dans deux grands sacs, formant les parties latérales du corps et dont les rapports n'ont jamais été étudiés avec précision. 11 me paraît probable que cette cavité incubatrice est à l'intérieur du corps même des Dajides et qu'elle doit se former par des replis latéraux. S'il en est ainsi, ce groupe annonce ce que nous allons trouver chez les Cryptoniscida. En tous cas, il se distingue nettement des deux familles précédentes.

Les Cryptoniscida, qui se subdivisent d'une façon très naturelle en une série de sous-familles ayant chacune un groupe d'hôtes défini, offrent, par rapport aux types ci-dessus, une extrême diversité dans leurs déformations en même temps qu'une énorme régression de tous leurs organes à l'état adulte. Ils se présentent sous les formes les plus déconcertantes, ne rappelant plus en rien un Isopode, ni même un 
Crustacé ; ce sont de simples sacs de formes bizarres, définies dans chaque cas, pleines d'embryons, sans métamérie ni appendices, dépourvus de bouche et n'offrant que des vestiges du tube digestif, souvent ne conservant que d'infimes vestiges de système nerveux. Rien de plus différent entre eux que les divers Cryptonisciens. Chez Hemioniscus, qui vit dans les Balanes (Balanus balanoides), la tête et les quatre premiers segments thoraciques, avec leurs appendices, gardent rigoureusement leur structure larvaire, tandis que le reste du corps devient un sac lobé, de taille considérable, sans appendices ni segments distincts, et le nom d'Hemioniscus exprime très bien ce bouleversement qui respecte la moitié antérieure du corps. Chez un Cabiropsidce parasite d'un sphérome, Ancyroniscus bonnieri fig. 25), parasite de Dynamene bidentata, l'abdomen pénètre dans la cavité viscérale de l'hôte, tandis que le thorax reste à l'extérieur, dans la cavité incubatrice de cet hôte, et, dans ce cas, le parasite se nourrit non aux dépens de l'hôte lui-même, mais aux dépens des œufs de cet hôte en voie de développement et qu'il gobe; aussine se fixe-t-il jamais que sur des femelles en train ou venant de pondre. Chaque genre a des rapports spéciaux avec son hôte et une déformation propre correspondante.

Parmi les Cryptoniscida, un certain nombre sont parasites au second degré ou hyperparasites, étant fixés sur des Crustacés, déjà eux-mèmes parasites. Tels sont les Liriopsidoe, parasites des Rhizocéphales (Danalia et Enthylacus sur Sacculina; Cryptoniscus et Liriopsis sur des Peltogaster) et cer- 
tains Cabiropsida fixés sur de leurs congénères Epicarides (Gnomoniscus sur Podascon, Cabirops sur Bopjrus).

Sous cette extrême diversité, les Cryptoniscidae ont néanmoins des traits spéciaux, caractéristiques et constants dans tout le groupe.

A la différence de Boprridae et Entoniscidae, ils ne pondent qu'une fois et leur existence de parasites se subdivise en deux phases très nettes: une phase dejeunesse ou de croissance, où ils se nourrissent aux dépens de l'hôte, en accumulant rapidement une énorme quantité de substances extraites de cet hôte, dans leurs larges sacs hépatiques dilatés; elles se résorberont progressivement et serviront à édifier l'ovaire; une seconde phase, où ils ont cessé de se nourrir et pondu et où ils incubent leurs œufs dans une cavité incubatrice interne, qui envahit la totalité de leur cavité générale. Le développement de cette cavité a été suivi d'une faşon précise chez Hemioniscus balani (Caullery et Mesnil, 33 I); à des détails près, elle se forme dans les mêmes conditions chez tous les Grrptoniscidae. En s'épanouissant, elle refoule tous les organes, qui sont réduits à des débris non fonctionnels. En général, à ces stades, il n'y a plus ni bouche, ni tube digestif. ni système nerveux. L'animal n'est plus qu'une enveloppe vivante, contenant des embryons, ne se nourrissant plus, mais continuant cependant à se contracter à une cadence réglée. Il est bon de remarquer que le même fait se produit, dans d'autres cas, chez des Crustacés libres, ou beaucoup moins modifiés par le parasitisme : nous l'avons signalé précédemment chez 
les Gnathia (Pranizes) et chez les Sphéromides.

La cavité incubatrice est close; elle ne s'ouvre que tout à la fin de l'incubation par une fente longi-
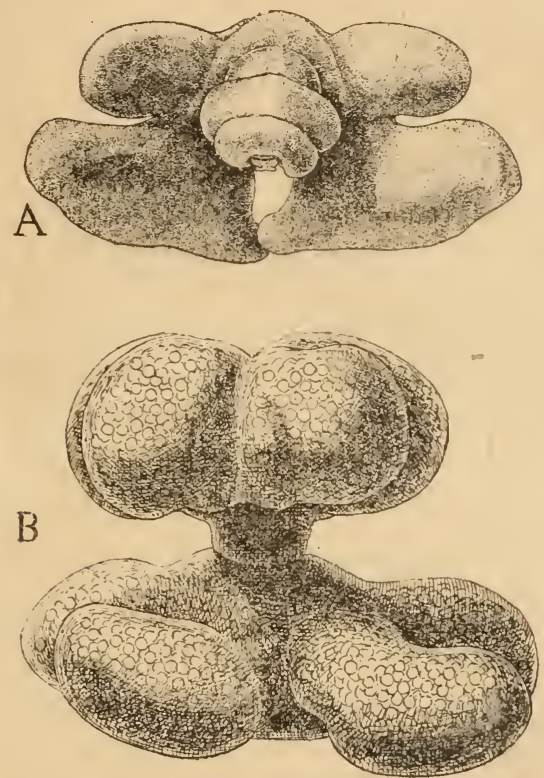

Fig. 25.- Ancyroniscus bonnieri (d'après Cauller et MesNIL). $A$ Femelle sub-adulte (avant la ponte); les deux paires de lobes inférieurs appartenant à l'abdomen sont logés dans la cavité viscérale de l'hôte. $-B$ Femelle adulte ayant pondu et réduite à un sac lobé el clos, rempli d'embryons.

tudinale ventrale, au moment où les larves mûres sont complètement formées et prêtes à éclore ; il n'y a pas d'oostégites, ou du moins il n'en subsiste que des traces chez quelques, types. On voit les diffé- 
rences très accentuées qui séparent les Gryptoniscidce des autres Epicarides, au point de vue des conditions de développement d'es œufs et qui les rapprochent les uns des autres, en dépit de leur profonde diversité d'aspect : les Dajidae constituent peut-être un trait d'union avec les Bopyridce.

Un autre trait important et spécial à ce groupe, qui a été établi en toute précision sur Hemioniscus et les Liriopsidce et qui est très vraisemblablement très général, est leur hermaphrodisme successif. Tous les individus deviennent des mâles fonctionnels à l'état de larve cryptoniscienne et se transforment ensuite en femelles. On ne rencontre jamais, chez les Cryptonisciens, les mâles spéciaux des autres groupes, ayant subi une évolution st une dégradation propres. Il y a donc ici un régime sexuel spécial, semblable d'ailleur's à celui que présentent les $C y$ mothoidce. La fécondation des femelles se produit tout au début de leur transformation, très peu de temps après qu'elles se sont fixées à l'hôte et les spermatozoïdes restent dans les voies génitales, en attendant la maturité des ovaires et la ponte des œufs.

Tels sont, brièvement résumés, quelques-uns des traits généraux qu'offre le parasitisme des Epicarides. Il y a là, comme on le voit. un exemple très instructif de l'action du parasitisme sur l'évolution d'un groupe.

On voit, en particulier, combien un groupe nettement homogène s'est diversifié en s'adaptant à vivre aux dépens de divers groupes de Cirustacés. Chaque famille d'hôtes a été le point de départ d'une évo- 
lution nouvelle distincte, et, dans un groupe donné d'hôtes, des types extrêmement voisins se sont partois extrêmement diversifiés suivant les rapports contractés avec les hôtes. C'est ce que montre, par exemple, la comparaison de deux genres de Cabiropsidae tels que Clypeoniscus G. et B. (sur Idothea) et Ancyroniscus G. et M. (sur Dynamene). Leurs larves, aux stades successifs, sont identiques et pouriant, à l'état adulte, les deux genres diffèrent radicalement. De mème, les genres Hemioniscus (sur Balanus balanoides) et Crinoniscus (sur Bala. nus perforatus). Mais les larves montrent les affinités originelles étroites de ces formes, si différentes au premier abord. Sous l'influence d'un facteur externe, le parasitisme, dans un groupe homogène, il s'est déroulé une érolution particulière extrêmement riche, conditionnée, d'une part, par les circonstances propres à chaque cas de parasitisme, et d'autre part par la constitution et les propriétés internes des diverses espèces.

Cette dernière considération s'applique, en particulier, à la divergence qui oppose, pour les conditions de l'incubation, les Bopyridae et les Entoniscidce aux Crrptoniscidce, auxquels il faut joindre probablement les Dajidce. Dans les premiers, la cavité incubatrice est extérieure et formée par des oostégites; chez les seconds, elle est interne et les oostégites sont rudimentaires ou absents. Il est très vraisemblable que cette différence entre les deux groupes est antérieure au parasitisme. Si homogène que fuit certainement le groupe des ancêtres libres immédiats des Epicarides, il devait présenter ce 
double mode d'incubation, qui n'a dû ensuite que se maintenir dans les conditions nouvelles de la vie parasitaire. On trouve, en effet, ce double mode d'incubation dans des familles libres et homogènes de Crustacés, et en particulier d'Isopodes. Il en est ainsi chez les Spheromidce, famille des plus nettement homogènes, où certains genres (Dynamene) ont une cavité incubatrice externe, limitée, comme d'ordinaire, par des oostégites et d'autres genres (Cymodoce) ont, au contraire, une cavité incubatrice interne comme les Cryptonisciens.

Les Epicarides sont, dans l'ensemble des Iso. podes, un groupe nettement distinct et circonscrit. Les phases primitives de leur transformation en parasites ont complètement disparu, ainsi qu'en tèmoigne l'appareil buccal tout à fait modifié chez tous les Epicarides et à tous leurs stades. Les circonstances initiales du parasitisme, les facteurs qui l'ont déterminé restent entièrement dans l'ombre. L'étude de ces parasites montre seulement, d'une façon très frappante, la diversification multiple d'un groupe certainement très homogène à ses débuts.

Les Rhizocéphales fournissent, parmi les Crustacés, un autre exemple frappant de l'intensité des transformations produites par le parasitisme. Le type le plus classique de ce groupe est le genre Sacculina, parasite des Crabes et des Anomoures. Il se présente comme un sac charnu (fig. 26), fixé transversalement à la face ventrale de l'abdomen et écartant 
celle-ci de la face ventrale du céphalothorax. Ce sac s'ouvre à son somrnet libre par un orifice médian, conduisant dans une cavité aplatie, dite cavité palléale, qui s'étend tout autour d'une masse viscérale centrale charnue et qui, chez l'adulte, est remplie

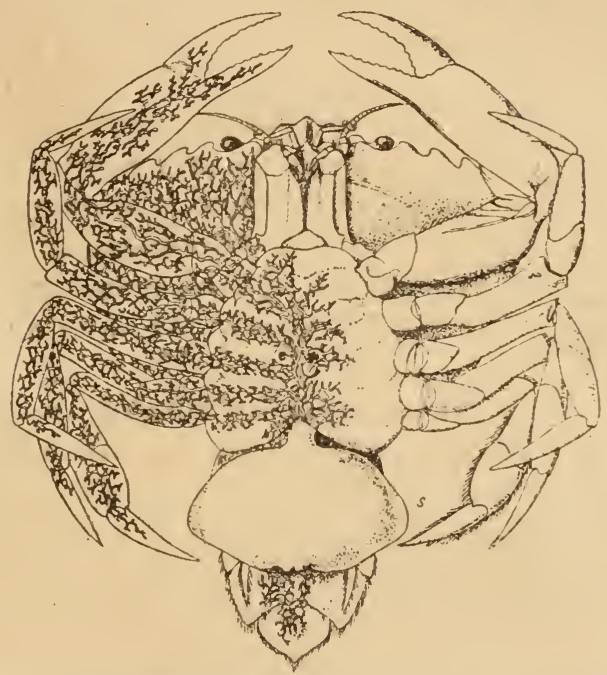

Fig. 26. - Crabe portant une Sacculine $S$; le système radi. culaire est représenté du còté gauche de la figure (d'après BoAs).

d'embryons en voie de développement. La masse viscérale est constituée presque en totalité par l'ovaire pair; il y a en outre une paire de testicules peu volumineux et un ganglion nerveux. Cet ensemble d'organes, ex térieur à l'hôte, ne constitue pas toute la sacculine; il faut $\mathrm{y}$ ajouter une portion interne forrnée par un système de racines s'irradiant 
et se ramifiant dans tout le crabe. C'est par elles que la sacculine assimile, comme une plante, aux dépens de son hôte et qu'elle édifie une série de pontes successives. Ces quelques données montrent combien la sacculine est dégradée, dépourvue d'appendices, de tube digestit, d'organes sensoriels, etc... Ses affinités mêmes ne pourraient pas être établies d'après l'adulte.

Les Pagures portent des parasites voisins des Sacculines, les Peltogaster; on connaît encore quelques autres genres de Rhizocéphaies: Parthenopea sur les Gébies et Callianasses, Lernoeodiscus sur les Galathées et Porcellanes, Thompsonia (Thrlacoplethus) sur des Crabes (Melia, Thalamita) et des Alpheus.

Le développement révèle les affinités des Rhizocéphales, qui sont des Crustacés se rattachant aux Cirrhipèdes, groupe comp̣osé de formes fixées (Balanes, Anatifes, etc.) En effet, les larves qui sortent du manteau de la sacculine sont, à leur éclosion, des Nauplius, présentant des cornes frontales latérales, comme ceux des Cirrhipèdes (fig. 27 I). De plus, après quatre mues, se succédant en cinq jours, ce Nauplius s'est transformé en une larve dite Crpris (fig.2J II), également caractéristique des Cirrhipèdes. Ces deux formes larvaires ne laissent donc aucun doute sur la position zoologique des Rhizocéphales. Toutefois elles diffèrent par quelques points des formes correspondantes des Cirrhipèdes: ni l'une ni l'autre n'a de tube digestıf; elles sont constituées intérieurement par une masse de tissu chargé de graisse, sans autre différenciation d'organes qu'une 
tache visuelle; il y a là une modification due à l'action du parasitisme, comme nous en avons constaté une sur la larve épicaridienne des Epicarides, dans la structure de l'appareil buccal.

Les larves Crpris des Cirrhipèdes se fixent au support où elles achèveront leur évolution, par leur antennule et il est facile de voir les organes de la larve devenir' ceux de l'adulte. Celle des sacculines se fixe de même au crabe et, par analogie, on a admis tout d'abord que le système radiculaire dérivait de la région antérieure ou céphalique, d'où le nom de Rhizocéphales donné au groupe. Il semblait évident aussi que la fixation de la Crpris devait avoir lieu à l'endroit où se trouve le parasite adulte, sous l'abdomen du crabe dans le cas de la sacculine ; celle-ci devait résulter directement de la transformation in situ de la Crpris. Mais on ne trouve jamais de sacculines dont la taille soit de l'ordre de grandeur de celle des larves Cypris (o mm., 2); les plus petites ont de 2 à 3 millimètres, soit dix fois plus. En réalité, entre la larve Cypris et les sacculines les plus petites que l'on puisse observer fixées sur l'abdomen des Crabes, se trouve interposée une série de phases tout à fait inattendues et surprenantes, dont on doit la découverte à Y. DrLAGE $(337)$, et qui ne peuvent ètre que le résultat d'une longue évolution sous l'influence du parasitisme. L'obscurité subsiste seulement sur les phases par lesquelles une semblable évolution a été réalisée comme sur les causes précises qui l'ont déterminée.

La Crpris, après avoir nagé pendant quelques jour's, se fixe, par une de ses antermes, sur un jeune 
crabe (un Carcinus manas de 4 à $7 \mathrm{~mm}$.) ; cette fixation n'a lieu qu'à l'obscurité; on peut la provoquer, de jour, en chambre obscure. Mais elle n'a nullement lieu, comme on avait été naturellement amené à le supposer, au point où plus tard se trouvera la sacculine. Les Crpris se fixent en un point quelconque de la surface du crabe; mais c'est seulement en certains points qu'elle peut réussir, en particulier à la base d'un poil de la carapace. Dès la fixation effectuée, la Crpris commence à se transformer (fig. 27, III); le contenu interne se contracte en une masse cellulaire vésiculeuse assez compacte et la carapace, avec les pattes larvaires, se détache et est rejetée ; la masse interne, devenue extéricure (fig. 2 IV), s'est recouverte d'une nouvelle et mince couche de chitine. Dans la partie antérieure de cette masse cellulaire, voisine du point de fixation, se différencie un tube interne mince, chitineux, en forme de dard, qui pénètre, en s'engageant dans l'antenne par où s'est faite la fixation, à travers lé tégument du crabe, aminci à l'articulation du poil et, par cette sorte de trocart, la masse cellulaire cypridienne s'inocule en quelque sorte elle-même dans la cavité viscérale du crabe. DELAGE a appelé ce stade larve kentrogone.

La Crpris s'est ainsi transformée en une petite masse cellulaire nue et indifférenciée, qui est maintenant à l'intérieur du crabe; il y a donc eu une régression énorme, à partir des stades libres et surtout à partir de la cypris ancestrale, dans laquelle étaient déjà ébauchés tous les organes essentiels du Cirrhipède adulte. 
La sacculine va rester parasite interne dans le crabe pendant une période très longue, que DeLAGE

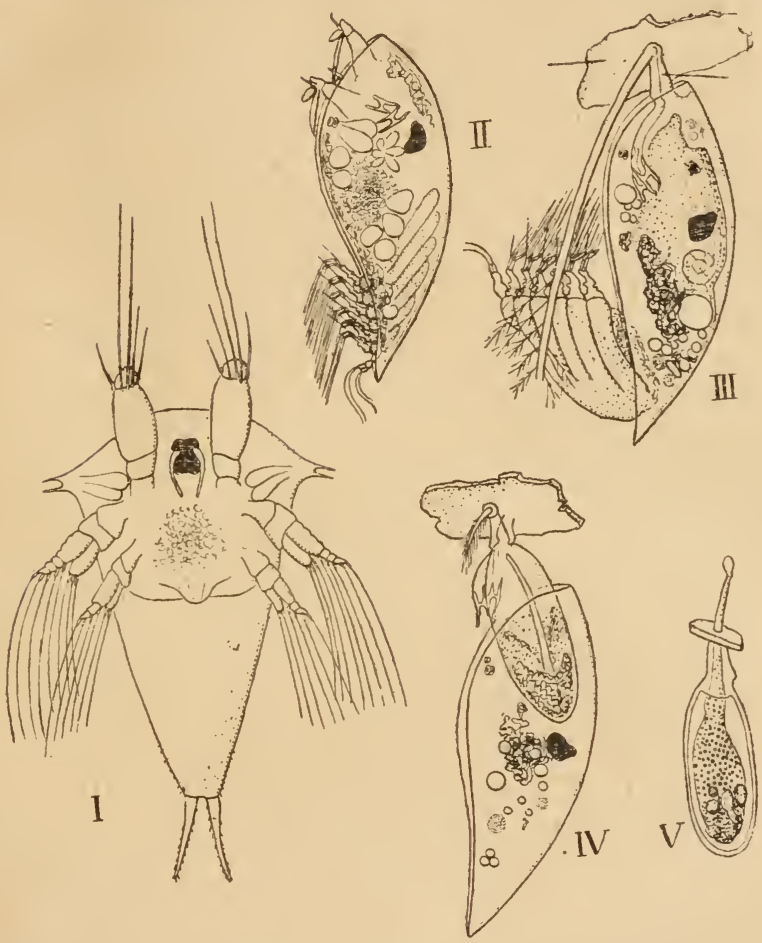

Fig. 27. - Evolution larvaire de la Sacculine (d'après Y.Delage).I Nauplius ; II Cypris libre ; III Cypris fixée à la base d'un poil de crabe et ayant commencè sa régression ; IV fin de la régression de la Cypris; V stade kentrogone.

évalue à environ vingt mois et pendant laquelle le crabe effectue sa croissance. Son histoire, pendant 
cette période, a été éclaircie par G. Sмгтн (I), qui a vérifié (352) et définitivement mis hors de doute, en Igo6, les données de DELaGE, contestées, notamment par GraRd, en raison deleur étrangeté. La Sacculine interne, indiflérenciée, eflectue une migration régulière dans le crabe, depuis son point d'inoculation, qui est quelconque, jusqu'au point fixe, sur l'abdomen, où l'on trouve la sacculine externe. Swrth a réussi, pour la sacculine d'Inachus mauritanicus (I. scorpio), à la trouver aux diverses étapes de cette migration, qui s'effectue surtout le long de l'intestin, depuis le point antérieur où débouchent les cæcums pairs, jusqu'en face du cæcum abdominal impair, où elle s'arrête (fig. $2 \mathrm{~S}$ ) Elle constitue, pendant cette période, une masse déformable, lobée, qui pousse des prolongements, début d.u système radiculaire. A un moment donné, vers la fin de la migration, se différencie, dans la partie centrale, d'où partent les premières racines, une sorte de tumeur ou nucleas qui est le début de la Sacculine proprement dite. Le parasite, arrivé dans l'abdomen de son hôte, se dispose finalement à la face ventrale de l'intestin, en face du cæcum postérieur impair. Dans le nucléus se forment, par une différenciation nouvelle, comme l'a montré Smịt et non pas, comme le supposait DelaGe, aux dépens d'ébauches déjà présentes sur la Cypris), les organes définitifs (cavité palléale, glandes génitales, ganglions nerveux, etc.). Ainsi se constitue la saccaline

1. Groffrey Smith, qui s'était classé parmi les meilleurs biologistes de sa génération, en Angleterre, a été tué en rgro, à la bataille de la Somme. 
interne. Elle est appliquée contre la paroi ventrale de l'abdomen du crabe et détermine, à son contact, une nécrose des muscles pariétaux et de l'ectoderme, puis un ramollissement de la chitine, suivant un petit disque de 2 à 3 millimètres. Ce disque finit par céder, ou bien le crabe mue et la sacculine se troure
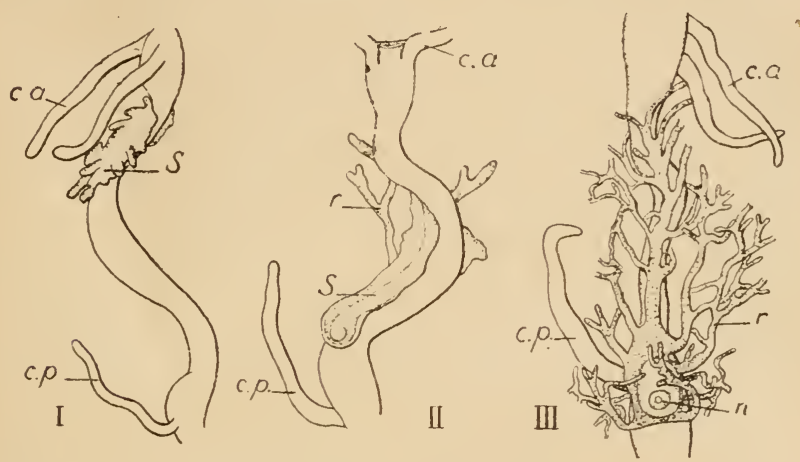

Fig. 28. - Stades internes de la sacculine $s$, en voie de migration le long de l'intestin du crabe et différenciant le système radiculaire $r$; $c a$ cæcums antérieurs, $c p$ cæcum postérieur de l'intestin du crabe, $n$ nucleus (future sacculine externe) (d’après Geoffrey Sмгтн).

maintenant externe; elle grossit alors rapidement.

On a constaté une évolution parallèle chez les Peltogaster Sснімкеwitch, Sмiтn); dans les autres genres, beaucoup plus rares, le dèveloppement n'a pas encore été étudié.

Les processus qui constituent le développement de la sacculine interne: dédifférenciation et migration, puis différenciation nouvelle, ne peuvent être que le résultat d'une évolution progressive, plus ou 
moins rapide, dont les étapes successives nous restent encore entièrement inconnues. Peut-être les genres autres que Sacculina et Peltogaster, dont le développement n'a pu encore être étudié, nous apporteront-ils là-dessus des lumières (I).

Coutière (336) avait $\mathrm{cru}$ trouver une forme primitive de Rhizocéphales à développement direct et sans migration à l'intérieur de l'hôte, dans un genre grégaire qu'il a appelé Thlyacoplethus et qu'il avait trouvé sur des Alphéides. Chaque individu, pensait Courière, devait se dévelcpper au point où on le trouve et l'état grégaire devait résulter de la fixation d'un grand nombre de Crpris sur le même hôte. Ce genre est, en réalité, identique aux Thompsonia (fig.29) précédemment décrits et les recherches récentes de F.-A. Potrs (35o) ont montré que c'était, au contraire, un type encore plus modifié que les autres et ayant acquis, sous l'action du parasitisme, un processus nouveau et particu. lièrement intéressant, la multiplication asexuée.

Les Thompsonia ne sont pas les seuls Rhizo-

I. Sмгтн, fait remarquer qu'un Cirrhipède, Anelasma squalicola, fixé sur la peau d'un Squale (Spinax) présente des prolongements radiculaires s'enfonçant dans le tégument de l'hôte: mais ce ne sont là que des organes de fixation et l'animal,à la différence des Rhizocéphales, a un tube digestif très développé. Il ne peut nullement être considéré comme un Rhizocéphale. D'autre part, Sмrтu considère comme étant probablement un Rhizocéphale primitif et peut-être dépourvu de racines, un parasite fixé à la face ventrale diun Isopode (Calathura brachiata). Cet animal, encore très mal connu, et qui a reçu le nom de Duplorbis calathurce, n'a malheureusement été rencontré qu'une fois au Groenland. 
céphales grégaires. Les Pagures de nos còtes et particulièrement, dans la Méditerranée, Eupagurus priedeauxi et $E$. meticulosus, portent parfois un Peltogaster qui n'est jamais isolé, mais toujour's par groupes de dix à vingt individus, paraissant du même âge, Peltogaster socialis Kossm. Surth avait déjà émis l'idée que ces multiples individus pouvaient résulter du bourgeonnement d'un stade interne indifférencié; mais il n'a vait pu le démontrer, ayant toujours trouvé que chacun de ces individus était pourvu d'un système radiculaire propre, indépendant des autres, et pouvait par suite dériver d'une larve cypris particulière.

Chez les Thompsonia, la grégarité est beaucoup plus accentuée, et souvent dépasse cent et même atteint deux centsindividus (fig. 29). Ces types n'ont été trouvés jusqu'ici que sous les tropiques et surtout dans le Pacifique, sur des Crabes (Melia, Thalamita, Pilumnus, Actcea), sur des Pagures, des Diptychus et sur des Alphéides. Ils sont fixés dans les points les plus variés, à la carapace et aux pattes. L'étude anatomique de ces individus montre une organisation beaucoup plus simple que chez la sacculine. Ici tous les individus se dressent sur un unique système radiculaire qui leur est commun à tous, ce qui fail supposer qu'ils y sont nés par bourgeonnement. Potrs a constaté, sur un Alpheus, que tous ces individus externes sont rejetés à chaque mue de l'hôte, après avoir émis leurs embryons (il ne semble se faire ici qu'une ponte unique) et qu'il en repousse une génération nouvelle sur le système radiculaire à l'intérieur de l'hòte, par un bourgeonnement, comme 
des volées successives de champignons de couche se développent sur le mycélium. La supposition de Smitu est donc vérifiée et il est très probable qu'elle s'applique effectivement au Peltogaster socialis; mais, dans ce dernier cas, il doit y avoir, soit fragmentation précoce et définitive du stade interne qui

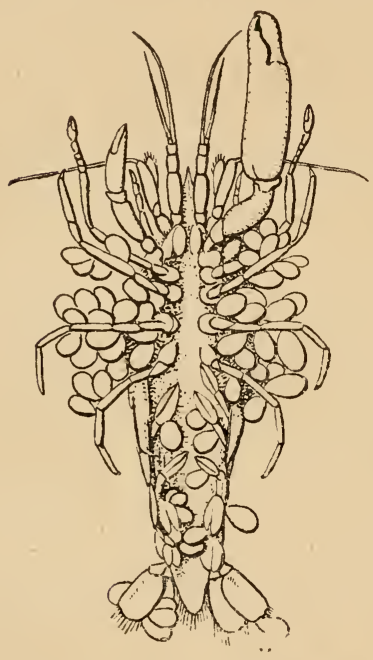

Fig. 99. - Thompsonia sp. sur Synalpheus brucci(d'après F. A. Роттеs). succède à la Cypris, soit un bourgeonnement qui se rapproche d'une polyembryonie.

Ainsi, chez les Rhizocéphales, le parasitisme, après avoir amené l'intercalation d'une phase interne d'indifférenciation cellulaire et la nutrition radiculaire que nous avons constatée chez la sacculine, a, en outre, déterminé, gràce à cette indifférenciation, un processus de multiplication asexuée tout à fait surprenant dans un groupe tel que les Crustacés. Ces animaux, qui appartiennent aux plus différenciés du règne animal, quant à l'individualité et au fonctionnement organique, se trouvent ramenés par le parasitisme à un mode de vie et de propagation semblable à celui des Métazoaires les plus inférieurs, Cœlentérés et même Spongiaires, rappelant même plus encore les Végétaux. 
Nous ajouterons aux données qui précèdent quelques faits empruntés aux Copépodes. Cet ordre est, parmi les Crustacés, celui chez lequel les faits de parasitisme sont les plus étendus et les plus variés. Il y a des Copépodes parasites sur presque tous les groupes d'animaux marins (Alcyonaires, Actinies, Annélides, Crustacés, Mollusques, Tuniciers, Poissons, Cétacés, etc.) et sur les Poissons d'eau douce; ils oflrent tous les modes du parasitisme : exterue, intestinal, cœlomique même, et tous les degrés d'adaptation, depuis une réduction plus ou moins grande des appendices jusqu’à leur disparition totale, le corps étant réduit à un sac de forme plus ou moins bizarre. Il y a, en général, un dimorphisme sexuel extrèmement marqué comme chez les Bopyridés ; le mâle reste fréquemment libre ou semi-libre, alor's que la femelle est franchement parasite : il est nain par rapport à elle ; chez beaucoup d'espèces, il vit à demeure sur elle. La femelle est hypertrophiée et produit une série de pontes. La nutrition a lieu, comme chez les Epicarides, par succion et aspiration des sucs de l'hôte (sang, ou lymphe cœlomique) dans l'intestin. Le nombre des genres et espèces connus est extrêmement considérable.

Je me bornerai ici à résumer l'histoire d'une forme exceptionnellement dégradée et qui, par ses rapports anatomiques avec l'hôte, a subi des transformations de l'importance de celles de la sacculine, le 
genre Xenocoloma (333), parasite d'une Annélide du genre Polvcirrus ; il se rattache peut être au groupe des Herprllobiidae, parasite des Annélides et qui renferme des formes extrêmement modifiées (I).

A première vue, Xenoccloma est simplement un parasite externe, formant un sac cylindrique au flanc de son hôte, dépourvu de tout appendice, céphalique ou autre, reconnaissable comme Copépode à des sacs ovigères et à ses larves Nauplius. $\mathrm{Au}$ microscope, on constate que le sac se raccorde avec la paroi de l'Annélide sans aucune discontinuité de tissu. L'étude histologique de coupes sériées, longitudinales et transversales, montre immédiatement qu'en réalité Xenocœloma n'est pas un parasite externe, mais qu'il est recouvert entièrement par l'ectoderme du Polrcirrus, et ne com. munique avec le dehors que par l'orifice terminal, d'où sortent les deux cordons ovigères : il est logé, en somme, dans une hernie de la peau de l'hôte. Mais sa structure devient paradoxale, en ce que c'est l'ectoderme de l'hôte qui sert de paroi externe au parasite, le tégument de celui-ci ayant disparu. Par contre, la musculature pariétale striée a été conservée et est même fort développée en un réseau qui s'insère sous l'épithélium annélidien. Il y a une soudure et une solidarité parfaites des tissus de l'Annélide et du Crustacé .

I. Les Annélides polychètes hébergent d'ailleurs divers genres de Copépodes particulièrement dégradés, tels que les Flabellicola, trouvés par Gravier sur Siphonostoma diplochaitos et divers types signalés du Groenland (Saccopsis, Crypsiclomus, etc.), mais cncore très mal connus. 
On ne trouve plus trace de la région céphalique ni du système nerveux du Copépode. Son axe, sur les deux tiers environ de la longueur, est occupé par une cavité qui s'ouvre directement dans la cavité générale de l'Annélide et qui est tapissée par l'endothélium péritonéal de celle-ci ; c'est donc, en réalité, un diverticule du cœlome de l'hòte (d'où le nom de Xenocolo$m a)$ : cet endothélium est appliqué contre une paroi appartenant au Crustacé, constituant la paroi propre de la cavité axiale et qui peut-ètre représente son tube digestif.

On voit combien est intense la pénétration réciproque du parasite et de l'hôte; une partie des

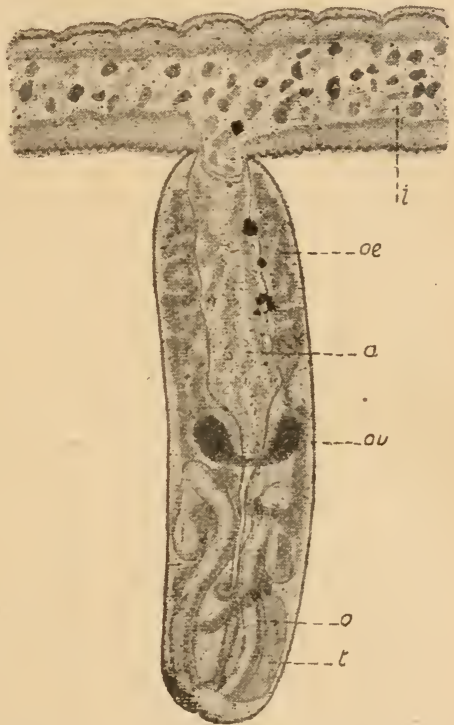

Fig. 3o. - Xenocceloma brumpti, fixé à un Polvcirrus arenivorus; $i$ intestin de l'hôte rempli de sable; $a$ cavité axiale du Copépode, $o$ oviducle, ov ovaire, $x$ oocytes en voie de maturation, $t$ testicules (d'après Caullery el Mesnil). tissus du second étant radicalement incorporés au premier, morphologiquement et fonctionnellement. C'est un exemple jusqu'ici unique et qui indique une adaptation extrême. On peut considérer, à un cer- 
tain point de vue, que cette disposition est l'inverse de celle qu'offre la sacculine. Chez elle, en effet, c'est le parasite qui pénètre dans l'hôte par ses racines ; ici c'est l'hôtequi enveloppe le parasite par son ectoderme et qui pénètre en lui par son endothćlium péritonéal et son cœlorne. De l'organisme du Copépode, qui est assez volumineux $(5.6 \mathrm{~mm}$. de longueur), il ne reste plus, en somme, quel'appareil génital, qui est comme greffé sur l'Annélide. L'ovaire produit incessamment des œufs, qui mûrissent dans des oviductes, remplissant presque toute la masse du parasite et débouchant finalement au dehors dans une cavité atriale. qui s'ouvre par l'orifice terminal du sac ci-dessus mentionné. Ovaires et oviductes ont d'ailleurs la conformation qui se retrouve dans des Copépodes moins déformés. Mais Xenocoloma présente un nouveau paradoxe, c'est qu'à la différence de tous les Copépodes connus, il est hermaphrodite ; l'extrémité du corps est occupée par deux volumineux testicules, qui produisent des spermatozoïdes gigantesques ( $\mathrm{mm}$. 5 de longueur) et s'ouvrent dans une vésicule séminale médiane, d'où ces spermatozoïdes sont évacués par des spermiductes qui débouchent à l'extrémité distale des oviductes; il y a autofécondation; les mâles semblent avoir complètement disparu.

Les oufs se développent en donnant un Nauplius typique, mais complètement dépourou de tube di. gestif. Il n'a pas été possible jusqu'ici de suivre les larves, depuis leur éclosion jusquà lemr fixation sur l'hôte. Il est probable que celte dernière n'a lieu, comme chez les autres Copépodes, qu'après une 
période de vie libre et des mues. Les plus jeunes stades observés sur les Polycirrus, à peine plus grands que les Nauplius, et qui devaient être peu postérieurs à la fixation, montraient déjà l'ébauche des divers organes de l'adulte et en particulier celle de l'ovaire. Les testicules ne se développent que beaucoup plus tardivement (I).

A ce moment, la tumeur parasitaire sous-ectodermique est close de toutes parts. Sa structure est déjà extrêmement complexe et il est impossible d'y retrouver l'organisation des autres Copépodes. Il y a lieu de penser que, comme dans le cas de la sacculine, elle résulte d'une différenciation nouvelle, résultat de l'adaptation propre de ce type, et largement indépendante de l'organisation de la larve libre.

Sous l'influence de cette tumeur, la musculature pariétale de l'Annélide, contre laquelle elle s'appuie à sa face profonde, est écartée et résorbée; la tumeur vient alors au contact de l'endothélium péritonéal et se rompt, si bien que cet endothélium vient s'étaler à l'intérieur. Ainsi se réalisent les connexions si spéciales qui ont été constatées chez l'adulte. Le reste n'est plus qu'affaire de croissance.

Ce parasite offre, comme on voit, dans un cas tout différent de la sacculine, des transformations qui ne sont pas moins remarquables, à la fois par

I. Ce fait est important, car il prouve d'une façon formelle que les spermatozoïdes existant chez l'adulte ne peuvent provenir d'un mâle, qui se serait accouplé à la femelle avant la fixation de celle-ci, pendant une phase de vie libre, ainsi que cela a lieu par exemple pour la Lernée. 
l'importance des régressions subies et par l'établissement de connexions particulièrement intimes avec l'hôte. On peut dire ici que le parasite est véritablement incorporé à l'hôte, certains organes devenant réellement mixtes, dans leur structure et dans leur fonctionnement.

On remarquera, en mème temps, dans cecas et dans celui de la sacculine, que, s'il y a une extrême régression, il y a en même temps production de différenciations adaptatives des plus parfaites pour assurer la nutrition et le fonctionnement du parasite sur son hôte, de sorte qu'au total, il vaut mieux concevoir les transformations subies par ces organismes, sous l'influence du parasitisme, comme une spécialisation plutôt que comme une simple dégradation. 


\section{CHAPITRE VI}

\section{LE PARASITISME PROVISOIRE OU PROTÉLIEN}

Sommarr. - Définition. - Le parasitisme larvaire des Monstrillidce : Signification des appendices absorbants Le parasilisme placentaire (GIARD): adaptations parasitaires ne portant que sur des organes provisoires ou des annexes et n'atteignant pas les organes définitifs. - Le cycle évolutif des Orthonectides. - Les Euniciens parasites. - La phase parasitaire des larves d'Unionidae (Glochidium) sur les Poissons. - Les Gordiens.

Les Insectes entomophages; leur importance dans la nature et leur rôle dans l'équilibre des espèces. - Leur utilisation aux Etats-Unis dans la luttre contre les Insectes nuisibles. - Principales conditions de développement. Formes larvaires spéciales (larve cyclopoïde des Platy. gaster, Planidium, larve primaire d'Eucoila, etc...). Action sur l'hôte.

Dans les exemples qui viennent d'être étudiés et qui correspondent au cas général, - la vie parasitaire commence après une phase initiale de vie libre et est définitive. Après avoir atteint l'hôte, l'organisme subit des modifications adaptatives ou régressives permanentes. Il est cependant des cas exceptionnels, - mais dont les recherches récentes ont augmenté le nombre, - où, au contraire, le parasitisme n'est qu'une phase provisoire de jeunesse, 
conduisant à un état adulte libre dont l'organisation est normale. Les modifications parfois très profondes que présente l'animal jeune ne sont que des adaptations transitoires n'ayant qu'un retentissement faible ou nul sur la structure définitive. 11 y a là un ordre de faits remarquable et d'allure paradoxale, qui prouve combien complexe est l'action du parasitisme; on peut le dénommer parasitisme provisoire ou si l'on veut, d'un terme spécial, parasitisme protélien ( $\pi \rho \circ$ avant, $\tau \varepsilon \lambda \varepsilon$ cios adulte). Nous consacrerons à son étude le présent chapitre.

Monstrillides. - Nous en trouvons un premier et frappant exemple, parmi les Copépodes, dans la famille des Monstrillidae. A l'état adulte, ils sont hautement différenciés pour la vie pélagique et la nage rapide (fig. $3_{2}, \mathrm{I}$ ) : ils ont un oeil nauplien, brillant comme une gemme et de robustes rames thoraciques; ils offrent un dimorphisme sexuel accentué, le måle est plus petit que la femelle. Leùr tube digestif est atrophié et réduit à un mince cordon non fonctionnel et il n'y a plus d'appendices buccaux. L'ani. mal ne se nourrit pas : c'est, en somme, ce qui arrive pour les Pranizes, qui sont précisément parasites protéliens; mais cette atrophie du tube digestif et la cessation de la nutrition peuvent se présenter aussi, indépendamment de tout parasitisme, chez l'adulte de certains types, comme chezlesSphéromes (Dynamene bidentata), chez les Annélides (I) et chez les

I. Ex. : les formes épitoques, Dodecaceria concharum. Cf. Caullery et Mesnil, Les formes épitoques et l'évolution des Cirratuliens (Ann. Univ. Lyon, fasc., XXXVIII, 1898). 
Insectes. L'adulte, ou imago, n'est qu'un vecteur de dissémination des produits génitaux mûrs; il n'a plus à assimiler. C'est le cas des Monstrillides.

On ne trouve jamais de Monstrillides jeunes dans

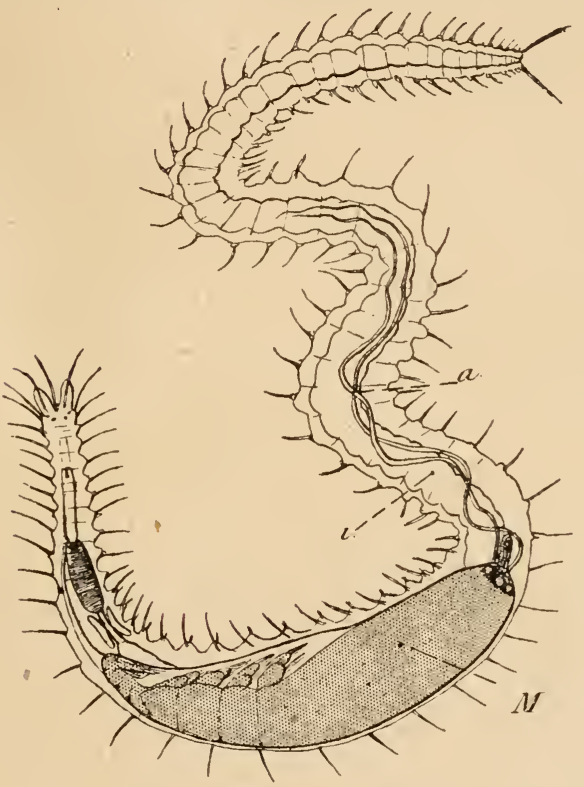

Fig. 3r. - Monstrillide $M$ parasite dans le vaisseau dorsal de Syllis gracilis ; remarquer la longueur considérable des appendices absorbants $a ; i$ intestin de l'Annélide (d'après Caullery et Mesnil 33o).

les pêches pélagiques ; iln'y a que des adultes parfaits, comme des imagos d'Insectes holomotaboles. La raison en est qu'ils sont parasites pendant toute leur croissance, ainsi que l'a constaté Giard, en 
I896(338) sur des matériaux recueillis par F.MEsNıL; il s'agissait d'un Thaumaleus, qui se trouvait, en effet, parasite à l'intérieur d'une Annélide Poly゙dora giardi. Le parasite était contenu dans un fourreau, que Grard assimila à la membrane d'enveloppe des Entonisciens et il crut que l'endoparasitisme n'était qu'apparent, qu'en réalité le Monstrillide faisait hernie à l'intérieur de l'hôte, en restant en communication avec le dehors. D'autres Monstrillides ont été trouvés depuis, parasites dans des Syllidiens (fig. 3I) et des Salmacines (1). En réalité, comme l'a reconnu Malaquin(346), ce sont de véritables parasites internes, logés dans le système vasculaire de l'hôte, sans communication avec le dehors et ne sortant qu'à l'état complètement adulte. C'est là la raison pour laquelle on ne trouve jamais de jeunes dans les pèches pélagiques.

Voici le résumé de leur développement, qui a été suivi par Malaquin sur Homocera dance, parasite des Salmacines. L'œuf se développe jusqu'au stade nauplius dans un sac ovigère porté postérieurement par la temelle (fig. 32, I). Le nauplius (tig. 32, II) est dépourou de tube digestif et sa troisième paire d'appendices est réduite à une paire de crochets. Il nage activement, puis pénètre à travers le tégument dans une salmacine; il mue alors, rejetant tégument et appendices et se réduisant (comme dans le cas de la sacculine) à un amas cellulaire indifférencié (fig. $3_{2}$, III). Sous cette forme, il parvient, sans doute par cheminement amiboïde, dans le vaisseau

i. Pelseneer ( $19 \mathrm{r} 3$ ) en a même trouvé une espèce parasite dans un Mollusque (Odostomia rissoides). 
longitudinal de l'Annélide. Là, il s'entoure d'une cuticule chitineuse, ayant la valeur d'une mue. A
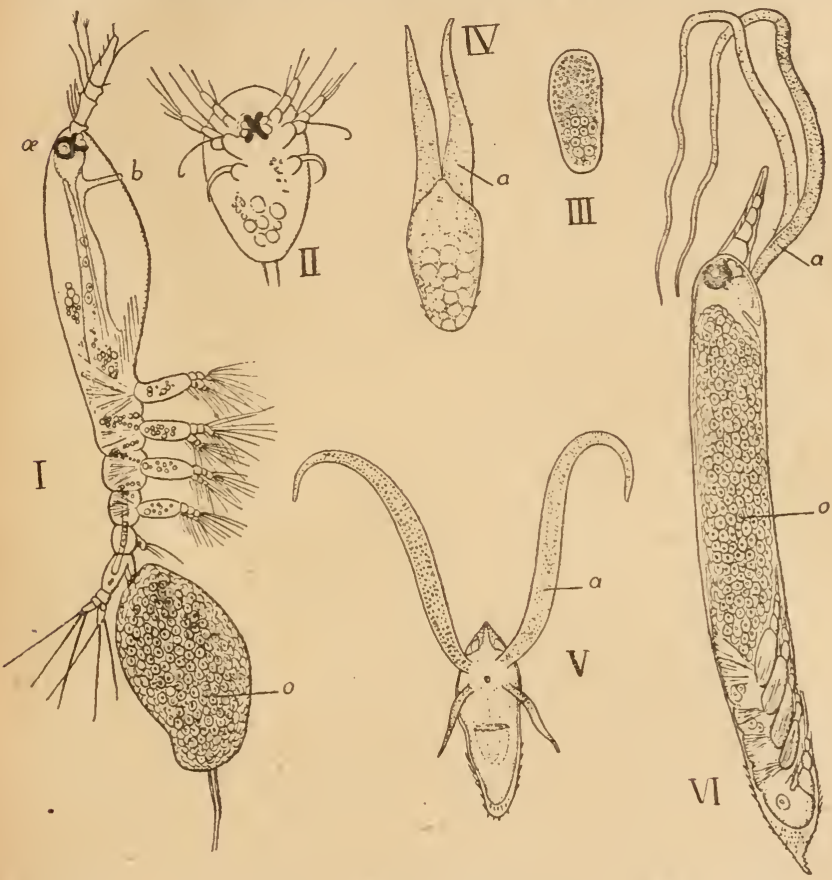

Fig. 32. - Evolution des Monstrillides (d'après MaLaquix). I Homocera dance, femelle adulte portant sa ponte o; II Nauplius libre; III Stade de masse cellulaire indifférenciée, dans le vaisseau de l'hôte ; IV Développement des appendices absorbants; V Larve à deux paires d'appendices absorbants; VI Stade vers la fin de la période parasitaire; le Monstrillide est complètement différencié à l'intérieur du fourreau larvaire.

l'extrémité antérieure, se développent deux lobes inarticulés (fig. 32, IV), qui s'allongent en deux longs 
appendices intravasculaires ; ils jouent le rôle d'appendices absorbants, comme les racines de la sacculine. Chez les espèces parasites des Polydores et des Syllis, il n'y a qu'une paire de ces appendices; chez Monstrilla dance des Salmacines, il y en a deux (fig. $32, \mathrm{~V}$ ); chez Monstrilla helgolandica, parasite d'Odostomia rissoides, il y en a trois paires. La signification morphologique de ces appendices est un problème intéressant: sont-ce des formations adaptatiyes entièrement nouvelles? ou bien sont-ce les appendices métanaupliens (mandibules et maxilles, qui n'existent plus chez l'adulte) transformés en appareils d'absorption?

La première cuticule chitineuse formée autour du parasite est rejetée et remplacée par une autre, qui formera une enveloppe extensible, persistant pendant tout le reste du développement ; elle est garnie postérieurement de rangées de petites épines et constitue le fourreau inexactement interprété par GIARD.

Dans ce fourreau et se nourrissant par absorption, au moyen des appendices qui viennent d'être décrits, le Monstrillide adulte se différencie progressivement avec tous ses organes et appendices (fig. $3_{2}, \mathrm{VI}$ ) et ses glandes génitales. Une fois complètement forıé, il sort de son fourreau et de l'hôte à l'état parfait, comme un papillon sort de la chrysalide; sa vie pélagique commence ; les sexes se rencontrent, la femelle pond et porte ses œufs jus(ju’à ce que les nauplius éclosent, sans se nourrir.

Telle est l'évolution individuelle d'un Monstrillide. 
Elle nous offre un endoparasitisme aussi intense que possible, débutant par une régression totale, se continuant par une nutrition osmotique radiculaire et rappelant à ce double point de vue la sacculine. Ici encore, nous ne connaissons aucune étape de la réalisation d'une adaptation si particulière ; elle a dù cependant résulter'd'une longue évolution. Seulement, loin de consacrer une régression définitive comme chez les Rhizocéphales et Xenocoloma, il n'y a là qu'une dégradation provisoire, qui n'a aucun retentissement sur l'adulte. On pourrait objecter que l'adulte des ancêtres de la sacculine, Cirripède fixé, était bien différent des Copépodes pélagiques, ancêtres des Monstrillides, et que cette différence suffit à expliquer le sort différent des deux parasites actuels. Mais Xenocoloma est un Copépode comme les Monstrillides dont les ancêtres étaient libres à l'état adulte et l'objection ne vaut pas pour lui. Au reste, le cas des Monstrillides est loin d'être isolé.

En réalité, l'évolution d'un parasite dépend, en premier lieu, des connexions qui s'établissent entre son hòte et lui. On peut imaginer que ce qui a conservé aux Monstrillides leur état adulte inaltéré est que l'adaptation parasitaire s'est faite chez eux par des organes provisoires spéciaux, dont l'organisation adulte est restée indépendante, les appendices absorbants; ou bien si, comme je le pense, ce sont des appendices métanaupliens modifiés, le résultat de cette adaptation a été la perte de ces appendices par l'adulte, et cela sans doute a entraîné l'atrophie de la bouche et du tube digestif. Mais, ce sacrifice 
fait, en quelque sorte, tout le reste de l'organisation définitive se construit, pour ainsi dire, à l'abri du parasitisme, indépendamment de lui, tandis que, chez Xenocoloma, c'est la totalité de l'organisme jeune qui est adaptée au parasitisme et définitivement dégradée.

Giard a comparé, d'une façon très suggestive et, à mon sens, très juste, ce genre de parasitisme à la placentation, telle qu'on la trouve chez les Mammifères, les Salpes et d'autres animaux: la comparaison s'applique d'ailleurs à plusieur's des cas qui vont suivre. Le parasitisme placentaire se distingue de la placentation embryonuaire normale en ce que celle-ci est une greffe sur un individu de même espèce au lieu de se faire sur une espèce étrangère. Physiologiquement, les appendices absorbants d'un Monstrillide sont l'équivalent des villosités d'un placenta de Mammifère, et les embryons de ces dernier's se nourrissent par le placenta, en véritables parasites de la mère ; ce qui ne les empêche pas d'aboutir à un état définitif qui ne se ressent pas de ce parasitisme temporaire. Or, ici encore, ce parasitisme s'est opéré par un organe annexe, tandis que l'embryon proprement dit se constituait, de toutes pièces, pour la vie libre. On peut compléter cette comparaison en y opposant le cas de Xenocœloma. Celui-ci réalise bien aussi une placentation sur son hôte. Rien n'est plus comparable en effet à un placenta que sa cavité axiale, où sont intimement accolés, comme en une gigantesque villosité mixte, maternelle et placentaire, l'endothélium péritonéal de l’Annélide et le tissu du Crustacé. Mais ici la pla- 
centation, au lieu de se réaliser par un annexe, s'établit aux dépens des organes essentiels de l'individu, qui sont ainsi irrémédiablement utilisés. Il n'y a plus de matériaux disponibles pour construire l'adulte normal. On conçoit ainsi, non seulement qu'il n'y ait pas une contradiction irréductible entre les deux cas, mais qu'ils puissent être reliés par des transitions. Dans beaucoup de cas de parasitisme protélien, que nous allons passer en revue, l'animal éclot en quelque sorte à l'état d'imago parfaite (I), avec ses organes sexuels complètement mûrs et n'a plus, comme les Monstrillides, qu'a disséminer immédiatement ses œufs, sans avoir rien à élaborer.

Les Crustacés présentent un autre cas qui peut être rapproché de celui des Monstrillides en ce qu'il est limité à la période de croissance : celui des Gnathia (Pranizes), dont il a été question plus haut. Il est d'ailleurs peu accentué et n'a de retentissement que sur les pièces buccales et l'appareil digestif. On peut noter que les pièces buccales qui ont subi les transformations adaptatives à la phase parasite disparaissent chez l'adulte .

Orthonectides. - (On peut ranger dans le parasitisme protélien le cas des Orthonectides. Considérons en effet le cycle de Rhopalura ophiocoma, qui est le plus complètement connu et partons de la larve.

I. On peut encore dire que des types comme les Monstrillides se comportent comme les Insectes holométaboles. Le parasitisme n'atteint que des organes larvaires, laissant les organes définitifs évoluer comme aux dépens des disques imaginaux. 
Ces larves ciliées, qui s'échappent de la femelle libre, pénètrent dans les fentes génitales d'Amphiura squamata et donnent naissance, dans divers tissus de l'ophiure, à des plasmodes où se différencient des cellules germes, qui, en évoluant, deviennent les Rhopalura mâles ou femelles. Ceux-ci constituent, en fait, une nouvelle génération, pour laquelle le plasmode joue le rôle de placenta. Ils écloront, comme les Monstrillides, à l'état adulte, pour mener une vie libre,'en vue de laquelle ils sont manifestement organisés. L'Orthonectide adulte a bien plutôt l'allure d'un animal libre que d'un parasite. Sa puissante ciliation lui permet une nage rapide dans le milieu extérieur. Une étude histologique plus complète qu'elle n'a été faite, $\mathbf{y}$ décèlera sans doute un anneau nerveux. Ce qui lui manque, c'est l'appareil digestif, comme aux Monstrillides, et sans doute parce que la vie adulte est ici plus éphémère encore et uniquement consacrée à la production et à la dissémination des larves. En effet, les deux sexes, lors de leur sortie de l'hôte, sont parfaitements mûrs; après quelques instants, l'accouplement se fait en nage rapide (GAULLery et Lıvallée, 25g) et les œufs fécondés se développent immédiatement. Au bout de vingt-quatre heures environ, les larves ciliées éclosent et vont fermer le cycle en infectant une nouvelle Ophiure. On peut admettre que l'absence de tube digestif chez les Orthonectides n'a pas été déterminée simplement par une dégradation due au parasitisme, mais aussi et peut-être surtout par le fait que l'animal n'a pas à se nourrir pendant sa très courte vie adulte 
libre. Des deux Igénérations qui alternent régulièrement, dans le cycle, c'est la génération asexuée formée par les plasmodes qui est réellement para-

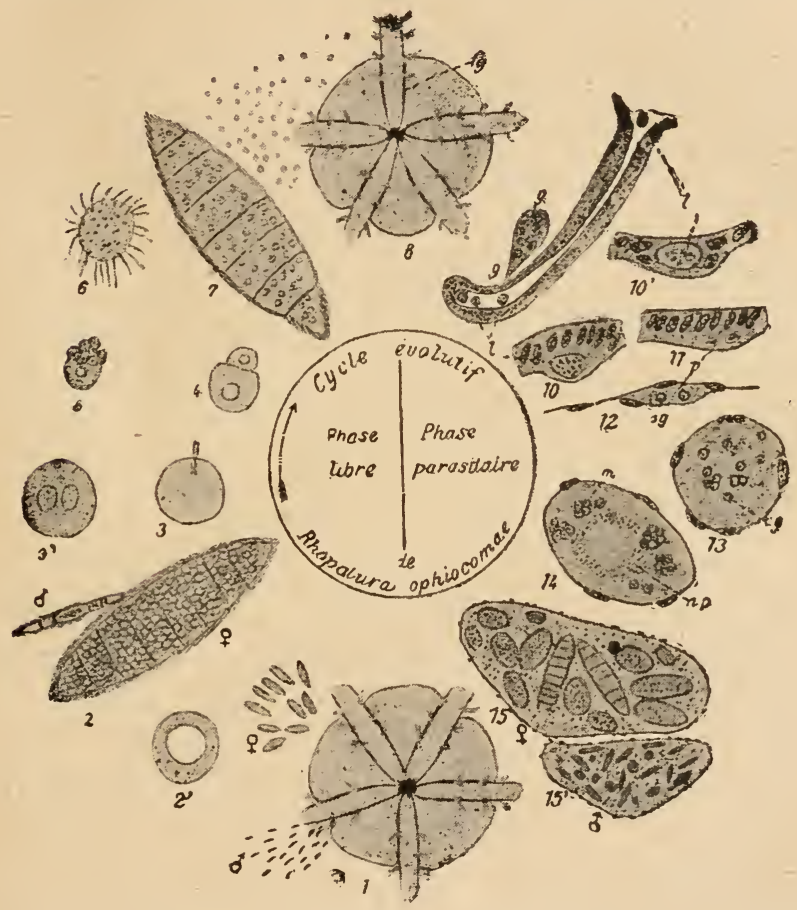

Fig. 33. - Cycle évolutif de Rhopalura ophiocomae. I Emission des adultes $u_{\star}$ et $\overparen{\beta}$ hors de l'hôte (Amphiura squamata), 2 fécondation, 2' oocyte mur, 3 émission des globules polaires, 3' fécondation (stade des pronuclei vésiculeux), 4.5 segmentation, 6 larve ciliée, 7 émission des larves ciliées, 8-9 leur pénétration dans l'ophiure, 10-14 stades initiaux des plasmodes et différenciation des cellules germes, 15 plasmodes $G_{\star}$ et $९$. 
site. La génération sexuée peut être assez naturellement considérée comme se développant à l'aide d'une sorte de placentation et comme ayant une vie propre essentiellement éphémère.

Euniciens parasites. - Un certain nombre d'Euniciens se développent jusqu'à la taille adulte en endoparasites d'autres Annélides, ou Invertébrés, sans montrer aucune autre trace de régression qu'une certaine simplification des mâchoires. Voici les cas actuellement connus :

$\mathrm{I}^{\circ}$ Oligognathus bonelliøe (SPEngeL, 296) se développant dans la Bonellie et y atteignant ro centimètres de long et plus de 200 segments (Naples;.

$2^{\circ}$ Hematocleptes terebellidis Wiren (r886), dans le vaisseau longitudinal (cf. Monstrillides) de Terebellides stromi (Groenland).

3. Labrorostratus parasiticus (SAIN'T-Joseph, 298), dans divers Syllidiens, en particulier dans Odontosrllis ctenostoma ; Manche).

$4^{\circ}$ Oligognathus parasiticus (Cerruti, rgog), dans Spio mecznikovianus (Naples).

$5^{\circ}$ Labidognathus parasiticus (GAullery, 293), dans un Térébellien de l'expédition du Siboga (archipel malais).

$6^{\circ} \mathrm{Il}$ semble qu'une autre espèce a été rencontrée, dans les mêmes conditions, dans une Marphyse, par KосH (1847).

C'est donc un mode de développement qui est assez répandu chez les Euniciens.

Le parasite arrive souvent à être aussi long que l'hôte où il vit. Malģré l'intensité de ce parasitisme, 
l'Annélide reste normale et doit sortir de son hîte au moment de se reproduire. Elle y pénètre certainement de bonne heure (un des Labrorostratus observés par de SAINT-Joserir n'a vait que neuf segments sans parapodes ni soies); elle accomplit don: en parasite toute sa croissance, sans subir de régression.

Unionidæ.-Les Lamellibranches de cette famille, ou moules d'eau douce (genres Unio, Anodonta. Margaritana) passent également par une phase de parasitisme protélien intense, qui ne laisse pas de traces sur l'adulte. Les oufs sont incubés entre les feuillets branchiaux maternels et donnent naissance à une forme larvaire, dite Glochidium, de structure tout à fait spéciale. Elle a une coquille à deux valves, présentant dans le plan de symétrie une paire de longues dents et latéralement des épines accessoires (fig. 34 $a-b$ ). Le manteau est tapissé d'un épithélium très spécial, avec des touffes de poils sensitifs. La masse viscérale est tout à fait rudimentaire: il n'y a pas de tube digestif. Au centre, s'élève un long et mince tentacule mobile, que l'on voit se mouroir entre les valves. Les Glochidium ainsi constitués sont émis au dehors et flottent. Lerdig, en I866, a découvert qu'ils deviennent parasites sur des Poissons (Cyprinida). Quand un Glochidium, en effet, arrive au contact d'un Cyprinide (souvent, par exemple, en étant absorbé avec l'eau servant à la respiration), sous l'action d'un réflexe tactile du filament.ci-dessus décrit, les valves tendent à se refermer et les dents 
qu'elles présentent pénètrent dans les tissus du Poisson, surtout sur les feuillets branchiaux (fig. 34, c). On en trouve aisément à la saison convenable dans la nature et il est très facile d'infecter expérimentalement des Cyprinides ou des Batraciens. L'hôte réagit très rapidement à la présence du parasite
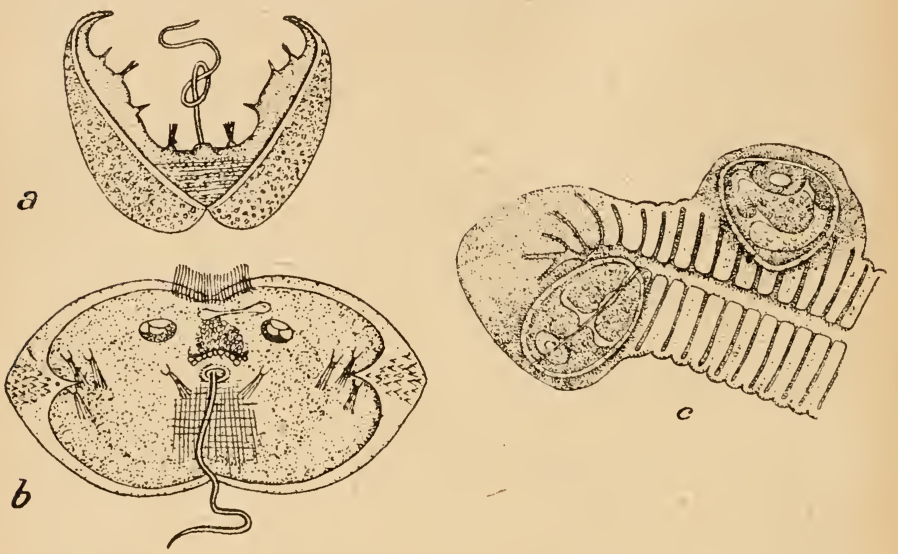

Fig. 34. - Glochidium, $a$ et $b$, stade libre en coupe optique et par la face interne (d'après Flemming); $c$ deux Glochidium enkystés dans une lamelle branchiale de Cyprin (d'après HARMs).

(nous reviendrons plus loin sur ce phénomène), en l'enveloppant dans un kyste épais et vascularisé. Les cellules du manteau, comme l'a montré FAUSSEK, quoique de nature ectodermique, se comportent comme d'actifs phagocytes, digérant, áu contact, les tissus de l'hôte et assurant ainsi la nutrition du Glochidium, qui n'a pas encore de tube digestif. Le tissu kystique vasculaire de l'hôte éveille une com- 
paraison avec un placenta. Dans ces conditions de nutrition, s'élaborent peu à peu les organes définitifs de la jeune Unio (tube digestif et bouche, pied, rein, etc.), la coquille définitive se forme peu à peu autour de la coquille larvaire. Après un délai qui dépend de la température ( 80 jours à $8^{\circ}-10^{\circ}$, 2 I jours à $16^{\circ}-18^{\circ}, 12$ jours à $20^{\circ}$, d'après Harms 402 ), le jeune Mollusque sort du kyste, qu'il rompt à l'aide de son pied, quitte le poisson et tombe sur le fond où s'effectuera sa croissance.

Nous avons donc encore ici un parasitisme intense et temporaire, préparé par une adaptation préalable, qui comporte la différenciation d'organes spéciaux, à côté de la régression momentanée des organes normaux. Les rapports a vec l'hôte, à la période parasitaire, offrent physiologiquement des analogies frappantes avec un placenta et la nutrition se fait par l'activité métabolique d'organes annexes (manteau larvaire). Les organes définitifs (tube digestif, etc.) restent en dehors du parasitisme; on peut donc concevoir qu'ils se réalisent sous la forme normale ; le tube digestif, persiste à la différence du cas des Monstrillides, évidemment parce que le parasitisme cesse de très bonne heure et que toute la croissance de l'animal se fait à l'état libre ( $\mathbf{r}$ ).

Gordiens. - Ces V Vers, qui se rattachent intime-

I. Une Aviculide marine du genre Philobrya, a une larve analogue aux Glochidium, mais son développement n'est pas connu.

La larve des Unionides sud-américaines, dite Lasidium, est assez différente des Glochidium; on ne sait pas, d'une façon certaine, si elle a une phase parasite des Poissons. 
ment aux Nématodes, se développent en parasites à travers deux hôtes successifs et deviennent libres à l'état adulte. Ils n'ont plus alors de tube digestif fonctionnel. Leur cas est évidemment le même que celui des Orthonectides, des Monstrillides, des formes épitoques d'Annélides, etc...

Insectes Entomophages. - L'exemple du parasitisme protélien le plus considérable et qui, loin de constituer comme les précédents des exceptions curieuses mais très localisées, est un phénomène d'une grande généralité et d'une importance capitale pour l'équilibre des espèces dans la nature, nous est tourni par les Insectes Entomophages, les Hyménoptères en premier lieu, les Diptères ensuite. Soit dès l'œuf, soit à partir d'un stade larvaire plus ou moins précoce, ils se développent en parasites à l'intérieur ou sur d'autres Inisectes, pour éclore à l'état d'imagos libres et nullement modifiées par le parasitisme préalable. Ici encore, l'imago n'est en général qu'une phase brève, uniquement employée à la dissémination des œufs et, dans bien des cas, elle ne prend aucune nourriture; le tube digestif est même souvent conformé de telle sorte qu'il est impossible à l'animal de se nourrir.

La place que tient dans la nature ce mode de parasitisme résulte du nombre des seules espèces d'Hyménoptères qui le présentent : il y en a 200.000 et peut-être davantage, d'après SHARP, réparties dans dix familles (I). Les Diptères, sans atteindre à

I. Les Cynipida, Proctrotrypida, Chalcidida, 1chneumonida, Braconidce sont les plus importantes. 
de pareils effectifs, et en n'étant pas limités comme hôtes aux Insectes, sont aussi légion; ce sont des Muscides (I). Nous ne connaissons encore de l'histoire de ce parasitisme que de maigres bribes, indiquant une variété d'aspects considérable et des processus d'un intérêt capital pour la Biologie. Chaque espèce a pour victimes des espèces plus ou moins strictement déterminées et toute victime périt sans se reproduire. On voit immédiatement le rôle que joue un phénomène de cette importance. Dès qu'un de ces Hyménoptères entomophages vient à se multiplier - et les centaines d'œufs que pondent ces minuscules Insectes permettent, dans des conditions favorables, cette multiplication d'une façon très rapide, - l'espèce qu'il parasite est décimée. Si, d'ailleurs inversement, cette espèce s'est multipliée d'une façon exceptionnelle, elle offre immédiatement à l'entomophage des proies nombreuses qui favorisent sa reproduction. Les Insectes Entomophages sont ainsi l'agent régulateur naturel, de beaucoup le plus efficace, de la multiplication d'un très grand nombre d'Insectes, avant tout des Lépidoptères et aussi des Coléoptères. En particulier, ils constituent un facteur de première importance dans la lutte contre les Insectes nuisibles; ils sont en effet la barrière la plus puissante contre leur propagation excessive.

Aussi, et cela vaut la peine d'être indiqué ici, quoique ne rentrant pas, à proprement parler, dans notre sujet actuel, s'efforce-t-on maintenant de les

I. Anthomyida, Tachinidce, Dexiidce, Sarcophagidce, CEstridas. 
utiliser à ce point de vue, d'une façon expérimentale et directe. C'est le service entomologique des EtatsUnis qui a fait de ce procédé une méthode régulière. Dans les conditions naturelles, il s'établit automatiquement, entre les espèces composant une faune, un équilibre assez stable et qu'il est difficile et dangereux de rompre. Mais à notre époque, l'intensité des communications et des échanges, entre pays et continents éloignés les uns des autres, apporte constamment aux équilibres naturels des perturbations graves. L'introduction accidentelle d'un Insecte nouveau, dans une faune où il n'existait pas, peut avoir de très graves conséquences, alors même que, dans son pays d'origine, il était relativement inoffensif. Le Phylloxera de la vigne, introduit d'Amérique en Europe, a fourni de cela un exemple terrible. Inversement de très nombreux Insectes européens ou asiatiques, introduits aux Etats-Unis, y ont trouvé de favorables conditions de propagation, qui les ont transformés en de redoutables fléaux ( $\mathrm{t}$ ).

Tel a été le cas de deux Bombyciens, dont les dégâts en Europe sont supportables et qui, aux Etats-Unis, sont devenus très rapidement de terribles dévastateurs : Liparis (Ocneria) dispar (Gypsy-moth) - et Liparis(Porthesia) chrysorrhoea (Cul-doré, Brown-tail moth). Le point de départ de l'invasion du Gypsy-moth en Amérique est dans

1. On sait, par ailleurs, que, de même, l'introduction de plantes et d'animaux d'Europe en Australie et en NouvelleZélande a eu des conséquences désastreuses pour de nombreux éléments de la faune et de la flore indigènes de ces régions isolées, où s'étaient réalisés des équilibres indépendants. 
quelques chenilles échappées d'un élevage que faisait, à Medtord, près Boston, vers I868, l'entomologiste Trouvelot. Il avait fait venir cette espèce d'Europe pour étudier des croisements avec des formes américaines. Enquelques années, le Liparis dispar s'était multiplié, au point de détruire des forêts entières et la végétation arborescente des villes de l'Etat de Massachusetts et des Etats voisins. La lutte contre ces Insectes s'est traduite par des dépenses annuelles de plusieurs millions de dollars et maintenant elle est basée avant tout sur la mise en œuvre du parasitisme des Insectes entomophages.

Déjà, en I886, Riley avait triomphé d'une cochenille exotique, qui dévastait les vergers d'orangers de la Calitornie, Icerva purchasi, en introduisant et naturalisant dans le pays une cochenille australienne, Novius cardinalis, qui d'ailleurs n'est pas un parasite, mais se nourrit de l'Icerva : la même expérience a été refaite, avec un succès constant, en diverses contrées. Riley avait appliquéle mème principe en opposant au papillon blanc du chou, Pieris brassica, cette fois un Hyménoptère entomophage, Apanteles glomeratus et en combattant la cochenille de l'olivier, Lecanium olece, par l'intervention d'un Chalcidien, qui est parasite au Cap, Scutellista cyanea. L'une des raisons principales de la pullulation énorme d'un Insecte nouvellement introduit dans un pays comme les EtatsUnis, est qu'il y parvient sans être accompagné du cortège des parasites qui, dans le pays d'origine, enrayent sa multiplication. En introduisant expéri- 
mentalement ces parasites, on doit donc rétablir, l'équilibre. Partant de ce principe, pour combattre le Gypsy-Moth et le Brown-Tail-Moth, on est venu faire en Europe une étude approfondie de tous les parasites de ces deux espèces; puis on a introduit en Amérique, par centaines de mille, des chenilles et des chrysalides de ces deux espèces, provenant d'Europe et du Japon, pour y rechercher ces parasites, les multiplier dans des laboratoires spéciaux et les acclimater ensuite dans la nature (I). On ne connait pas moins de 27 espèces d'Hyménoptères et de 25 Diptères, qui, en Europe, s'attaquent aux chenilles de Liparis dispar. La chenille d'un Géométride, Cheimatobia brunnea, est parasitée, en Europe, par 63 Hyménoptères.

Mais une lutte de ce genre ménage bien des surprises. A côté des parasites qui détruisent une espèce nuisible, conformément aux intentions de l'expérimentateur, il y a des parasites de ces parasites ou hyperparasites, qui, en s'attaquant aux premiers, les déciment et par suite favorisent indirectement la propagation de l'ennemi. Les parasites sont des - auxiliaires, les hyperparasites sont des adversaires. Or, on les introduit simultanément. Le bilan de l'opération dépendra donc de la prédominance des uns sur les autres, une fois l'acclimatation réalisée.

I. Pour l'histoire de cette lutte, voir Howard et Fiske, The importation into the United-States of the parasites of the grpsy-moth and the brown-tail-moth (U.S. Dept. of Agriculture; Bureau of Entomotologr, Bull. $\left.\mathrm{n}^{\circ} 9 \mathrm{I}, \mathrm{I} 91 \mathrm{I}\right)$ et P. Marchal, Les Sciences biologiques appliquées à l'agriculture et la lutte contre les ennemis des plantes aux Etats. Unis, Paris (Lhomme), 1916. 
Quelquefois aussi, dans les conditions nouvelles, un parasite se transforme en hyperparasite. Ainsi, un Chalcidien, Pteromalus egregius, parasite européen de Porthesia chrysorrhoea, pond aussi ses œufs dans les larves d'un Braconide, Apanteles lacticolor, qui est lui-mème un parasite du Liparis. Il arrive aussi que des espèces américaines, parasites de chenilles indigènes, se sont transformées, à la suite d'introduction d'Hyménoptères européens, en hyperparasites sur ces Hyménoptères, devenant ainsi elles-mèmes nuisibles. L'A panteles fulvipes, Braconide introduit d'Europe comme parasite utile, s'est trouvé attaqué aux Etats-Unis par I6 espèces américaines, devenant hyperparasites sur lui et enrayanı ainsi sa multiplication souhaitée.

On voit combien important et complexe est le rôle des Insectes Entomophages dans l'équilibre entre les espèces et à quelle échelle gigantesque agit ce facteur, combien par suite cette catégorie de parasites offre d'intérêt, à. la tois pour la Biologie générale et pour ses applications. La lutte engagée aux Etats-Unis, sous la direction du Bureau of Entomology contre le Gypsy-Moth, a apporté à la Biologie des documents d'une importance capitale qui ne pouvaient être réunis que grâce à d'énormes ressources en matériel, outillage et personnel.

Mais revenons à l'examen du parasitisme des Insectes entomophages en lui-même. Il est évident qu'un phénomène de cette envergure comporte un nombre considérable de modalités qui ne peuvent être passées en revue ici en détail. Elles se ramènent aux grandes catégories suivantes: 
$I^{\circ}$ Les œufs du parasite sont pondus dans le milieu extérieur et la larve, une fois éclose, atteint activement sa victime, sur qui elle vit en parasite externe; $2^{\circ}$ L'œuf étant pondu dans les mêmes conditions, la larve pénètre à l'intérieur de sa victime où s'accomplit son développement, en parasite interne ;

$3^{\circ}$ Les oufs sont pondus par l'entomophage directement dans sa victime et ils y accomplissent tout leur développement; on peut distinguer dans cette catégorie les cas où la ponte a lieu dans une larve (chenille) plus ou moins avancée, ou dans un ouf non encore développé.

Le développement des Insectes entomophages, malgré qu'il ait été déjà l'objet de nombreux travaux, ne nous est encore connu que d'une façon très insuffisante. Les imagos se révèlent plus aisément, parce que, très souvent, l'élevage d'une larve, d'une chenille par exemple, au lieu du papillon attendu, amène l'éclosion, aux dépens de la chrysalide, de l'Hyménoptère ou du Diptère parasites. Mais il est peu d'espèces dont on ait suivi toute l'évolution et nous devons attendre de ces études beaucoup de données intéressantes.

Les circonstances de la ponte, souvent difficiles à observer d'ailleurs, posent des problèmes d'importance générale très grande. Par quel moyen l'entomophage reconnait-il la présence de la larve ou de l'œuf sur lequel il va pondre et où sa progéniture trouve les conditions favorables à son développement? Quel moyen, par exemple, révèle aux Ichneumonides ou aux Braconides la présence d'une larve sylophage sous l'écorce d'un rameau ou d'un tronc? 
Et cependant l'Hyménoptère sait trouver, à cuup sûr, le point où, en forant avec sa tarrière, il déposera son œuf, juste au contact de la larve. invisible du dehors, qu'il veut parasiter. Ainsi les Thalessa. lunator atteignent, dans l'intérieur du bois, la larve de Sirex gigas. Ainsi, comme l'ont décrit avec précision Prcard et Licitenstein $(376)$, un Braconide, Sycosoter lavagnei, dépose son ouf, en forant une branche de figuier, sur la larve d'un Scolytide, $H_{y}$ poborus ficus, qui vit à l'intérieur du bois. De l'œuf ainsi déposé, éclòt une larve qui reste immobile sur l'hôte, sans pénétrer à son intérieur : elle perce, à l'aide de ses mandibules acérées, la peau de la larve d'Hrpoborus et aspire le liquide cavitaire dont elle se nourrit, en vidant peu à peu sa victime. qui continue cependant à se nourrir elle. même. Il est vrai que cet instinct est loin d'être infaillible et beaucoup d'Insectes font parfois des erreurs systématiques au détriment de leur progéniture. Ainsi Pteromalus egregius, qui pond dans les chenilles de Liparis chrysorrhcea, dépose fréquemment ses œufs sur des peaux vides de la chenille, où ils sont perdus. Il y a ainsi, d'une façon générale, beaucoup de larves égarées par des erreurs des femelles lors de la ponte (I).

1. Le développement des larves d'Insectes entomophages dans d'autres Insectes amėne la nécessité pour les premiers de sortir du corps des seconds à l'éclusion de l'imago, et cela estréalisé parfois par des dispositionsqui semblent être des adaptations précises. Ainsi Künckel D'Herculats a observé qu'un Diptère Bombylide (Srstropus conopoïdes), qui se développe dans la chenille de Sibine bonaerensis et ae trouve enfermé dans le cocon de la ehrysalide, en sort 
Les formes larvaires des Insectes Entomophages sont souvent des plus inattendues et des plus difficiles à expliquer. Telles sont celles des Platygaster, Proctotrypides qui pondent dans les larves de Cécidomyies et dont le développement a été étudié d'abord par Ganin, puis plus récemment par MARCHAL (3 J9). La première larve est toute différente deslarves vermiformes habituelles chez les Hyménoptères. Elle est fortement chitinisée, avec une région céphalique énorme et distincte, un abdomen étroit. Elle rappelle un Copépode et a été appelée, pour cette raison laroe cyclopoïde. Elle a des mandibules énormes. Sa filiation sera vraisemblablement plus claire quand on connattra mieux le développement des espèces où la larve est primitivement libre et ne pénètre que plus ou moins tard dans son hôte. 'Telles sont, par exemple, les larves, dites Planidium, découvertes par WhEELER ( I 9J), qui appartiennent à des Chalcidiens (Orasema, Perilampus) et qui pénètrent dans des larves de Tachinaires, situées parfois elles-mêmes à l'intérieur des chenilles. Elles ont une structure très différente de la larve vermiforme habituelle. La première larve des Hyménoptères parasites doit, au reste, être très variable. J'en figure quelques-unes ici, dont celle d'Eucoila keilini, trouvée par Keilin, dans une larve de Pegomyia (Diptères).

par le même procédé que la chrysalide elle-même, en découpant, à l'aide d'une pointe située sur la tête, et par un mouvement de giration, une rondelle dans le cocon. Le parasite a donc dù acquérir un organe semblable à celui de l'hôte. KüNckel donne à ce parallélisme le nom d'homaopraxie (de öproío semblable $\pi \rho \alpha \xi ! \zeta$ action). 
La difficultéà comprendre ces formes larvaires tient surtout à ce qu'elles ne sont manifestementpas en rapport avec les conditions actuelles où on les trouve ; Et pourtant, l'œuf dont elles proviennent est adapté à ces conditions, dans sa structure et son premier développement. Il est très pauvre en vitellus; sa segmentation est totale; ce qui correspond au fait
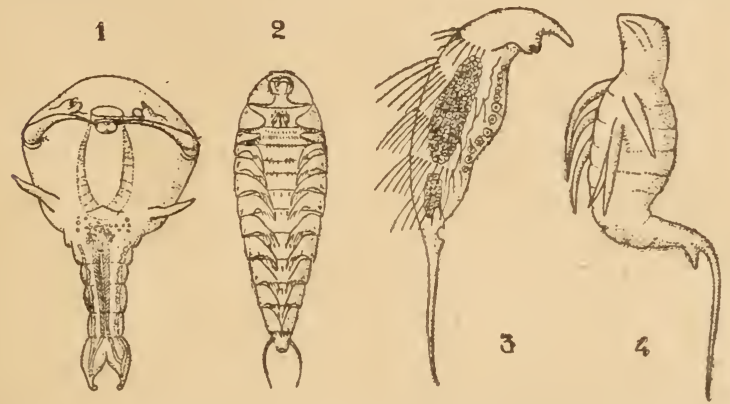

Fig. 35. - Larves primaires de divers Hyménoptères entomophages: Platygaster (Trichacis remulus) (d'après MARchal), 2 Planidium de Perilampus (d'après H.-S.S.Sirth), 3 Teleas (d'après Ayers), 4 Eucoïla keilini (d'après Kerlun).

que la larve trouvera immédiatement, hor's d'ellemême, de quoi se nourrir. Une forme larvaire ancestrale a sans doute été conservée ici, par une éclosion à un stade très précoce, le la même façon que l'imago libre est conservée au terme de la vie larvaire.

En général, ces larves entomophages vivent sur ou dans leurs hôtes, sans en détruire les organes essentiels, ni mème, comme on l'a cru parfois, sans dévorer le corps gras. Au début du développement. jusqu'à l'éclosion de la larve, elles sont fréquemment 
entourées d'un épithélium provenant de l'hôte et qui les en isole. A l'intérieur de cette enveloppe, la segmentation de l'œuf sépare, dès le debut, l'embryon proprement dit et de gros noyaux végétatifs très colorables, qui se fragmentent et jouent évi.demment un rôle trophique important. On retrouve donc là, au moins pour le début du développement, une disposition organique constituant un appareil interposé pour la nutrition et rappelant une placentation. Cela doit jouer un grand rôle dans la conservaticn des formes larvaires initiales dont il vient d'être question. Quand les larves sont écloses et mobiles dans l'intérieur de l'hôte, elles absorbent, par succion, le liquide de sa cavité générale, qui renferme les substances tirées dela nourriture végétale de cet hôte et élaborées par lui. Leur développement serait sans doute enrayé, si seulement l'hôte cessait de se nourrir. Aussi cet hôte peut-il être considéré comme un simple transformateur intermédiaire des matières nutritives pendant la croissance de la larve, et comme les organes imaginaux sont, pour la plupart, des néoformations qui, chez tous les Insectes holométaboles, ne participent nullement à la vie fonctionnelle larvaire, on conçoit qu'en tout état de cause, le parasitisme de la larve soit sans action sur eux et conduise à une imago semblable à celle des Insectes à larves libres. Par là le cas présent se rattache à ceux examinés précédemment, comme, par exemple, les Monstrillides.

On s'explique aussi que, dans des familles comme les Cynipides, à côté des formes entomophages, il en existe d'autres, très voisines, qui sont gallicoles. 
Elles provoquent sur les végétaux (surtout sur les Chênes), dans des conditions que nous verrons plus loin, la formation de galles, où la plante accumule des réserves et des sucs dont elles se nourrissent. Elles prennent alors directement à la plante ce que les formes entomophages absorbent indirectement et à un état déjà élaboré, dans le corps d'un hôte. On conçoit queles diverses espèces d'un même type aient pu s'adapter à l'un ou à l'autre régime, beaucoup moins différents en réalité qu'en apparence. Mais il n'y a là encore qu'une analogie vague et il est évident que l'étude physiologique précise de la nutrition, tant chez les formes parasites que chez les formes gallicoles, offrirait un très grand intérêt.

Dans tout ce qui précède, on n'a eu en vue que les Insectes entomophages, mais un certain nombre de types se développent d'ume façon analogue en parasites dans les végétaux et dans des animaux autres que des Insectes. On troure des larves de Diptères parasites dans des groupes extrêmement variés. A l'occasion de l'étude du développément de Pollenia rudis, mouche très vulgaire, dont il a découvert la vie larvaire dans les vésicules séminales d'un lombric (Allolobophora chlorotica), KEILiN $(374)$ a passé en revue les traits généraux du parasitisme des larves des Cyclorhaphes. Un certain nombre de ces Diptères offrent un intérêt spécial comme parasites des Vertébrés et en particulier des Mammifères et de l'homme. Le chapitre des mriases est intéressant par la variété qu'il révèle dans les conditions de ce parasitisme. 


\section{CHAPITRE VII}

\section{LES PARASITES HÉTÉROXÈNES ET LEURS MIGRATIONS}

Sommaire. - Définition. - Cestodes : oncosphères et cysticerques. - Cycle et hôtes successifs des Bothriocéphales. - Trématodes : miracidium et sporocyste; cercaire et métacercaire. Cycle des Schistosonum (Bilharsia), etc, etc. - Némathelminthes : Spiroplère, Trichine, Filaires, Gordiens, Acanthocéphales. - Protozoaịres : Grégarines (Aggregata, Nematopsis). - Hémosporidies (Plasmodium, Hémogrégarines, ete...), Hémoflagellés (Trypanosomes, Piroplasmes, Leishmania). - Le problème de l'hôte définitif dans le cas des Protozoaires hétéroxènes.

On voit suffisamment, par l'étude des chapitres précédents, que la circonstance capitale de la vie d'un parasite est la rencontre de l'hôte. Faute de trouver, au moment voulu, l'hôte convenable - et celui-ci est le plus souvent une espèce étroitement définie - le jeune parasite, embryon ou larve, meurt. Il se perd ainsi un nombre énorme d'individus, qui ne font pas la rencontre propice, et nous verrons comment cette perte immense de germes est compensée. Mais il est un certain nombre de para- 
sites pour qui le cycle évolutif est plus compliqué et plus risqué encore; ce sont ceux qui ne peuvent l'accomplir qu'en passant successivement par deux hôtes : le premier, transitoire, appelé hôte prosisoire, ou hôte intermédiaire, où ils restent à un ètat imparfait; le second, appelé hôte définitif, où ils atteignent l'état adulte. Il y a même quelques parasites qui doivent passer par trois hôtes successifs. Ces changements d'hôtes sont appelés migrations et les parasites qui les présentent sont dits hétéroxènes.

Le fait des migrations complique beaucoup l'étude des parasites; car il est extrêmement difficile, en général,de les identifier à leurs phases successives, ou bien, les rencontrant dans l'un des deux hòtes, de déterminer quel est l'autre. Pour ces raisons, l'histoire des migrations des parasites offre un intérêt spécial et nous passerons en revue les divers cas qui en sont connus, glissant rapidement sur ceux qui sont classiques et insistant davantage sur d'autres plus récemment découverts.

Cestodes. - Le cas de migrations des parasites le plus anciennement découvert est celui des Cestodes. Il a été élucidé vers le milieu du $\mathrm{x}_{1 x^{\mathrm{e}}}{ }^{\mathrm{s}}$ siècle. Jusquelà, on considérait encore comme deux types zoologique distincts, d'une part, les Tænias rubannés siégeant dans l'intestin des Vertébrés et d'autre part, les vers crstiques vésiculeux, siégeant dans des organes profonds, tels que le péritoine, les muscles, le foie, le cerveau et qu'aujourd'hui nous appelons cysticerques. Küchenmeıster et l'. J. 
Vas Beneden ont, le; premiers, expérimentalement démontré que les cysticerques sont simplement un stade de l'évolution des tænias; et que la trans. formation des uns dans les autres se fait à la faveur d'un changernent d'hôte. Le cysticerque siège dans un hôte provisoire et devient tænia quand il est ingéré, avec tout ou partie de cet hôte provisoire par l'hôte définitif. Faute de cette condition nécessaire, il reste indéfiniment à l'état de cysticerque et finit par dégénérer.

Aujourd'hui, le cycle évolutif des Cestodes est classique et a été suivi effectivement sur un assez grand nombre d'espèces. Résumons-le sur le cas de Taenia solium. L'œuf se développe dans l'utérus du segment, ou proglottis, du Tænia où il s'est formé, jusqu'au stade d'embryon munide six crochets groupés en trois paires, et dit embrron hexacanthe ou oncosphère. Il est évacué hors de l'hôte avec les proglottis. S'il vient alors à être ingéré par un Mammifère, - le Porc est l'hôte typique, mais ce peuvent être d'autres espèces - la coque de l'ouf se rompt sous l'influence du suc gastrique et l'oncosphère est mis en liberté.A l'aide de ses crochets, il traverse la paroi intestinale, pénètre dans les vaisseaux sanguins et lymphatiques et est entraîné dans la circulation générale. Finalement, au niveau des capillaires, il se fixe dans le tissu conjonctif des muscles, y gonfle en un vésicule ét passe ainsi à l'état decysticerque, Cysticercus cellulosce. Sur cette vésicule, au bout de quelques semaines, se forme une invagination, dans laquelle se differencie le scolex, c'est-à-dire ce qu'on est convenu d'appeler la 
tête du futur tænia. Mais le développement s'arrêtelà et le cysticerque peut rester à cet état pendant des mois et mèmes des années. L'infestation des muscles du porc par des cysticerques constitue la ladrerie de cet animal. Si de la viande ladre est absorbée par un Mammifère approprié, tel que l'homme, le cysticerque estlibéré, le scolex se dévagine, se fixe à la muqueuse intestinale, s'allonge et se strobilise en un tænia adulte.

On trouve dans les traités de zoologie et de parasitologie la description du cycle de nombreuses espèces. Je me borne ici à donner à titre documentaire un tableau (p. r66) qui en résume quelques-uns.

Chacun de ces cycles offre des particularités. Les hôtes provisoires sont très variés et ce ne fut pas sans occasionner des surprises et des méprises. P. J. Van Beneden avait effectué à Paris, devant une commission, des expériences tendant à prouver l'identité spécifique des Cysticercus pisiformis et de Tania serrata. A de jeunes chiens nourris exclusivement avec du lait, il avait fait ingérer les cysticerques du lapin. A l'autopsie, il fut surpris de constater qu'en plus du Tania serrata, les chiens renfermaient des Diprlidium caninum. Aujourd'hui, le fait s'explique aisément, parce que, tout en étant nourris exclusivement de lait, les chiens s'étaient cependant infestés de l'autre espèce par leurs poux et leurs puces, auxquels on n'avait pas pris garde.

Le cycle se complique quelquefois en ce qu'au lieu d'un seul hôte provisoire il y en a deux et tel est le cas des Bothriecéphales, dont l'histoire complète n'a 


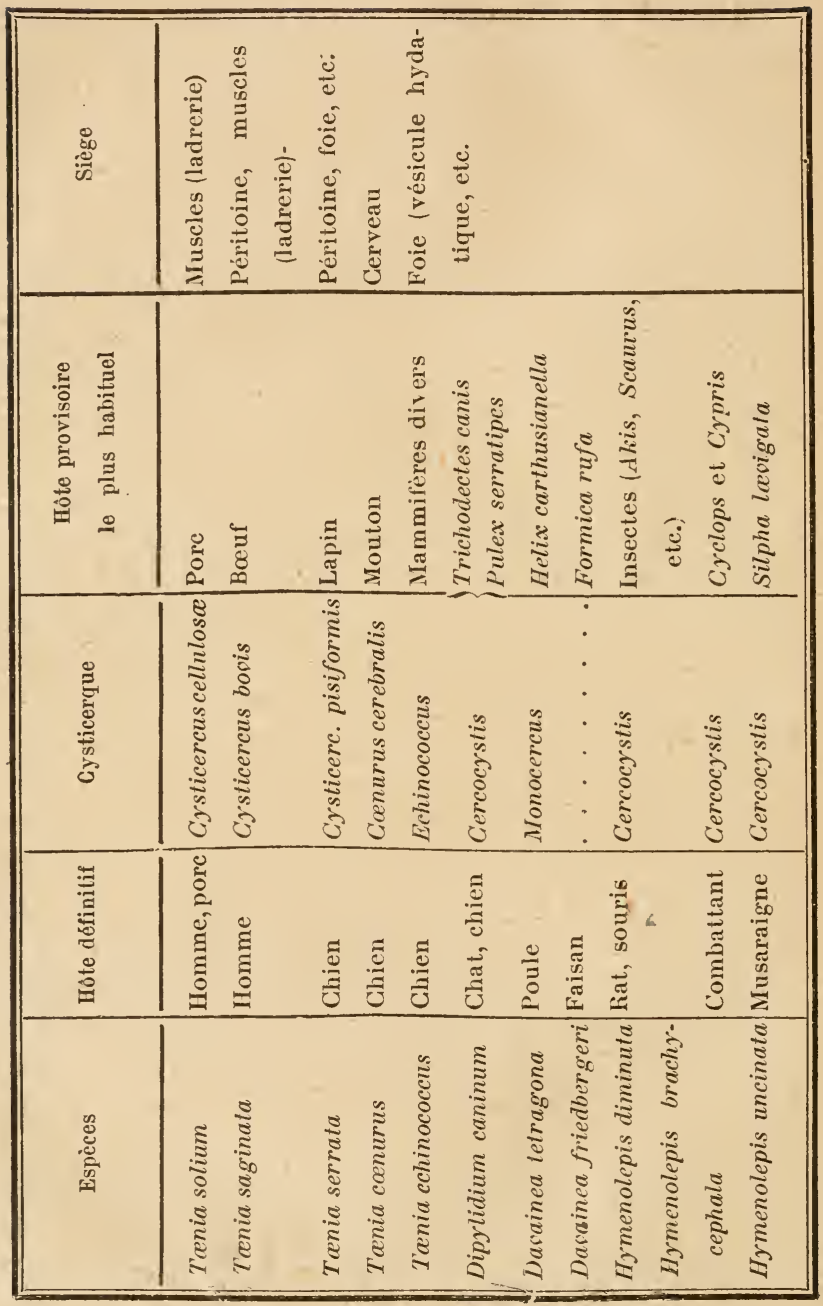


été élucidée que tout récemment, par les travaux de F. Rosen (289).

On connaissait depuis longtemps la larve du Bothriocéphale qui infeste l'homme. C'est un ver allongé, blanchâtre, dit larve plérocercoïde (I), qui vit dans les viscères ou les muscles de divers poissons (Brochet, Salmonides) et l'homme s'infeste en absorbant ces poissons insuffisamment cuits (2) et en particulier, leur's œufs (caviar). Mais on ignorait comment se fait le passage de l'œuf à cette larve. Les œuf's de Bothriocéphale ne se développent qu'une fois rejetés dans le milieu extérieur et très lentement, - en plusieurs mois, dans l'eau courante, en dix à quinze jours à 3o-35 degrés. L'embryon hexacante est recouvert ici.d'un long revêtement ciliaire ; il éclôt et vit librement dans l'eau, sous forme de larve nageuse ou coracidie (fig. 36, a). Les recherches de Rosen viennent de montrer que cette coracidie doit être ingérée par un premier hôte provisoire, qui est un Copépode (Grclops strennuus ou Diaptomus gracilis). Elle passe dans la cavité générale (3) de celui-ci et s'y transforme en une forme larvaire, dite larve procercoüde (fig. $36, b, c$ ). C'est en avalant des Copépodes renfermant ces larves que les poissons, brochets ou salmonides, s’infestent à

x. Elle correspond à l'état définitif des Cestodes les plus primitifs, ou Ciestodaires, tels que l'Archigetes.

2. Le Bothriocéphale, en raison de cela, se rencontre surtout dans la région des lacs suisses et italiens et en Finlande.

3. La transformation ne réussit que dans certaines espèces de Copépodes; dans d'autres, comme Cyclops viridis, les coracidies sont digéréeś. 
leur tour de la larve plérocercoïde, préalablement connue. Il y a donc ici deux hôtes provisoires -

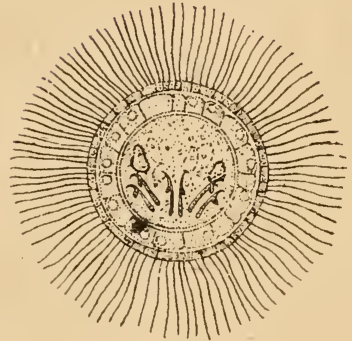

a

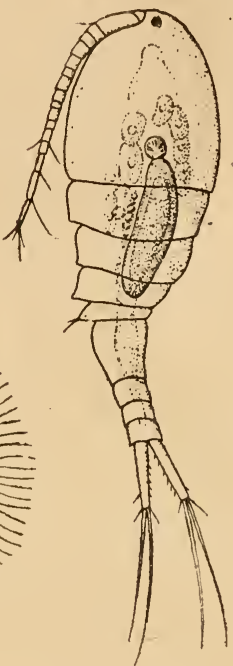

6

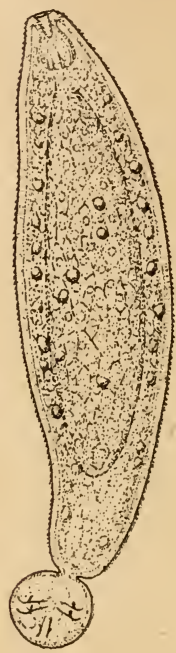

c

Fig. 36. - Formes larvaires de Bothriocephalus latus (d'après Rosen) : $a$ larve libre (Coracidie), b Cyclops infesté par la larve procercoïde, $c$.

copépode et poisson - avant l'hôte définitif (I). Il ne faut donc pas s'étonner que le Bothriocéphale

r. Rosen a mis expérimentalemeni en évidence la même évolution pour Triaenophorus nodulosus, Bothriocéphalide qui, à l'état adulte, vit dans le Brochet (hôtes provisoires : Cyclops et perche); pour Abothrium infundibuliforme, parasite de la truite (Trutta lacustris), dont la coracidie n'est pas ciliée (hôtes provisoires : Cyclops et perche) et enfin pour la ligule (Ligula simplicissima), qui, à l'état alulte, siege dans l'intestin d'oiseaux aquatiques (Colym. 
doive produire des œufs en nombre immense : sa taille est couramment de 8 mètres de long et atteint jusqu'à rŏ mètres, avec plusieurs milliers de proglottis.

Inversement au cas des Bothriocephalida, certains Cestodes, probablement par une adaptation secondaire, se développent directement sans hòte intermédiaire. C'est ce que Grassi et Rovelli (275) ont établi pour un tœnia des Rongeurs, Hymenolepis traterna Stiles (=H. murina Dujardin) et Calaxnfuccio, pour l'Hrmenolepis nana de homme. Les embryons bexacanthes se transforment, dans la lumière de l'intestin, en cysticercoïdes, qui ne prennent pas la structure vésiculeuse des cysticerques, se fixent directement à la paroi intestinaleet deviennent directement des tænias adultes.

L'étude expérimentale lu cycle évolutif des Cestodes offre encore énormément de problèmes parti culiers à résoudre. Nous n'avons de connaissances précises que sur une proportion relativement très faible des espèces existantes.

Trématodes. - D'une manière gènérale, les animaux de ce groupe, qui sont parasites externes, se développent entièrement sur un seul hôte et on les - oppose à ce titre (monogénétiques) à ceux qui sont endoparasites et effectuent des migrations compliquées de phases de multiplication (digénétiques).

Le cycle de ces derniers n'est connu, d'une façon

bus, Mergus, Anas), et qui, après un stade de coracidie ciliée, passe aussi par un Cyclops et un poisson (goujon, brème, gardon). Les œuf's de la ligule tombent dans l'eau avec les excréments de l'oiseau. 
précise, que pour un très petit nombre d'espèces, mais ses traits généraux semblent très constants. L'hôte provisoire est un Mollusque, où l'animal passe par les états de sporocyste, rédie et cercaire $(\mathrm{x})$. Le cas classique, le premier qui ait été élucidé, est le Distomum (Fasciola) hepaticum, la grande douve du foie du mouton; les œufs, très nombreux, sont évacués avec les excréments du mouton et se développent lentement (deux à trois semaines à $25^{\circ}$, beaucoup plus longtemps à basse température) en une larve ciliée, dite miracidium, qui éclot dans l'eau, y nage quelque temps. librement, jusqu'à ce qu'elle rencontre une petite espèce de Pulmoné, Limnea truncatula. C'est dans cette espèce seulement, du moins en Europe, que l'évolution ultérieure du miracidium peut s'accomplir complètement; dans Limnea stagnalis, elle commence mais ne s'achève pas. Le miracidium se fixedans le poumon de la limnée, s'y transforme en sporocyste, à l'intérieur duquel se forment les rédies, qui émigrent dans le foie et y produisent, soit immédiatement des cercaires, soit d'abord une nouvelle génération de rédies. Les cercaires mûrs sortent de la limnée, nagent quelques heures, puis s'enkystent après s'être fixés à un brin d'herbe. Quand le kyste est avalé par. un herbivore, il se rompt dans l'estomac et le jeune distome, mis en liberté,gagne les voies biliaires où il devient adulte.

On ne connaît actuellement le cycle complet que pour un nombre relativement restreint d'espèces.

I. V. chapitre suiv. p. 202. 
En voici quelques-unes résumées, à titre de document, dans un tableau (p. 1 22). $^{2}$.

Pour certaines formes extrêmement communes, comme Distomum lanceolatum (petite douve du foie du mouton), l'hôte provisoire n'a pu être encore déterminé.

On connaît de même beaucoup de sporocystes et de cercaires dont l'adulte est ignoré.

La phase de rédi e est parfois supprimée. C'est ce qui arrive pour Distomum macrostomum, parasite d'oiseaux (Pics, etc...), dont le très remarquable sporocyste, Leucochloridium paradoxum vit dans la succinée (Succinea putris .ll s'y ramifie en tubes, dont l'un vient distendre les tentacules du mollusque et s'y hypertrophie en un gros tube pulsatile au soleil et vivement coloré. Cette particularité attire le regard des Oiseaux qui se jettent sur les succinées parasitées, les dévorent et s'infestent. Or, dans ces sporocystes, il se forme directement des cercaires.

Chez beaucoup d'espèces, les cercaires, au lieu de s'enkyster à l'extérieur, comme ceux de Distomum hepaticum, pénètrent dans un second hôte provisoire, chez lequel ils s'enkystent dans la cavité générale, en attendant qu'ils soient ingérés avec lui par l'hôte définitif. On donne le nom de métacercaire à cette phase du cycle: les métacercaires sont très répandus, en particulier chez les Annélides polychètes; l'arénicole des pècheurs, par exemple, en renferme très communément un, appartenant au genre Echinostomum (caractérisé par une série de crochets disposés comme en pèlerine) et ces kystes sont recou- 


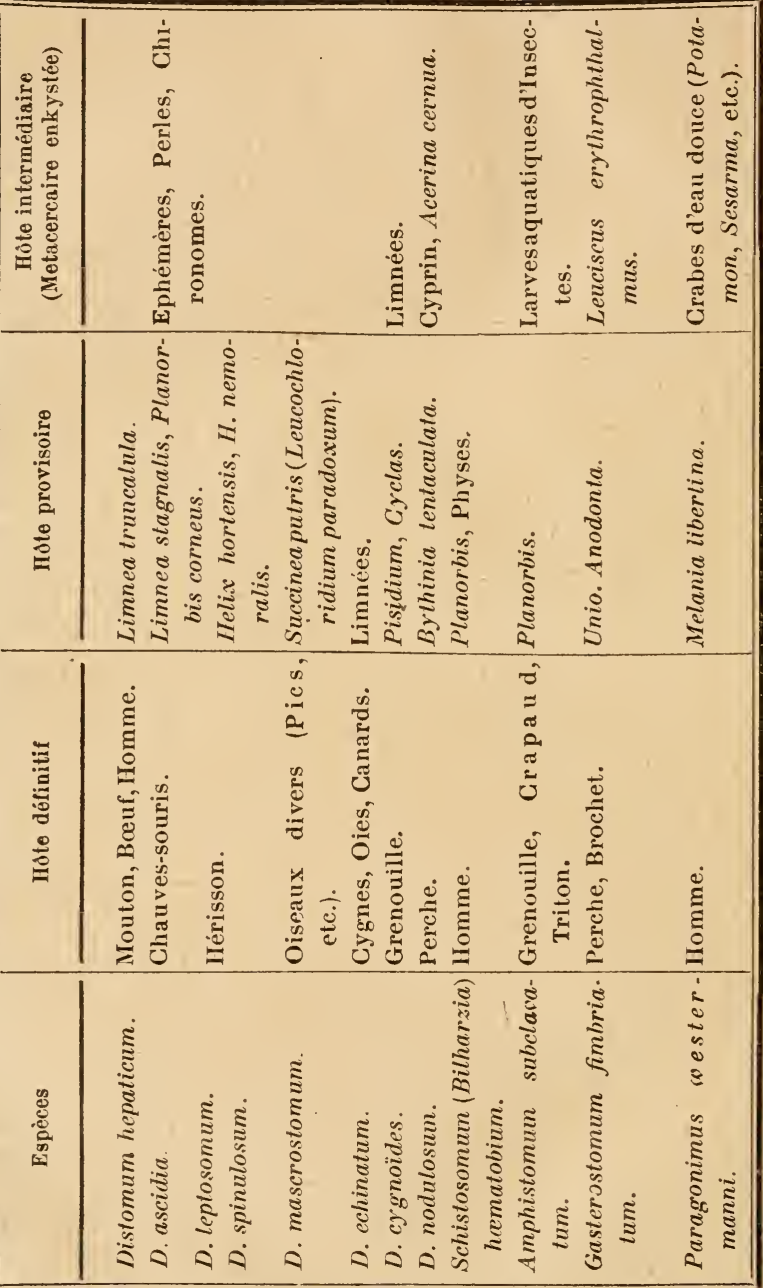


verts d'un épais manteau de phagocytes de l'annélide. Beaucoup de ces métacercaires sont des individus égarés qui n'arriveront pas à maturité, faute d'être ingérés par l'hôte définitif.

C'est seulement dans ces tout dernières années qu'a été reconstituéle cycle de deux espèces de Distomes, qui causentà l'homme des maladies redoutables; ces cycles sont intéressants par les variantes qu'ils offrent par rapport au cas général.

L'un est celui qui cause une affection répandue dans les pays chauds, la bilharziose. C'est le médecin Bilharz qui, en Egypte, a reconnu qu'elle était due à un Trématode vivant dans le système veineux, Schistosomum (= Bilharsia, = Gynacophorus) hoematobium. Il offre la curjeuse particularité d'être, seul parmi tous les Trématodes, une forme à sexes séparés et le mâle porte constamment la femelle jeune dans une gouttière ventrale (I). Le mode d'infestation par ce parasite est resté inconnu jusque tout récemment; on avait remarqué que la maladie atteignait de préférence les hommes travaillant dans l'eau, comme les ouvriers des rizières. Looss, guide par ses recherches surl'Ancylostome, concluait à une pénétration directe du miracidium dans la peau immergée. C'est en I913, au Japon, que Miyairi et Suzuki (285) découvrirent le cycle de ce Trématode; il est en réalité tout à fait parallèle à celui du Distomum hepaticum. Les

I. On connaît actuellement trois espèces de ce genre, chez l'homme ( $S$. haematobium, $S$. mansoni et $S$.japonicum) et cinq chez divers mammifères domestiques. On les distingue par la forme des oufs. 
résultats des auteurs japonais ont été rapidement confirmés par Leiper ( 282$)$ en Egypte, par Iturbe et Gonzar.ez (284) au Vénézuéla et par Lutz (279) au Brésil.

Les œufs sont rejetés au dehors avec l'urine ou les excréments (suivant l'espèce) et renferment à ce moment un miracidium cilié, qui éclot quand l'œuf arrive dans l'eau pure. Il pénètre alors dans un hôte intermédiaire, planorbe ou physe : l'infestation se fait surtout par les tentacules du mollusque. Le miracidium évolue en sporocyste dans le tentacule qui se gonfle. Après une vingtaine de jours, les sporocystes primaires, arrivés à maturité, crèvent dans le tentacule, en donnant issue à de nombreuses masses cellulaires indifférenciées, qui vont former, dans les divers viscères du planorbe (foie, glande génitale), des sporocystes secondaires, où se différencient de très nombreux cercaires à queue fourchue. Ces cercaires sortent du planorbe, sous l'influence de la chaleur et d'une lumière solaire vive. Ils viennent alors à la surface de l'eau et y flottent, suspendus par la queue. L'homme s'infeste, soit par le simple contact de la peau en se baignant, soit en buvant l'eau contaminée. Lès cercaires traversent, suivant le cas, la peau ou la muqueuse buccale ou œsophagienne. La pénétration est rapide; il suffit d'une dizaine de minutes. L'infestation expérimentale a été réalisée méthodiquement sur des Rongeurs, par la peau rasée. Les eaux stagnantes peuplées d'une riche végétation et habités par les planorbes et les physes sont donc dangereuses, surtout après une période d'insolation. 
L autre parasite humain passe par une phase de métacercaire dans un second hôte provisoire; c'est le Paragonimus westermanni, qui occasionne en Extrême-Orient (I) une grave affection, la Distomatose pulmonaire. Le distome adulte, localisé
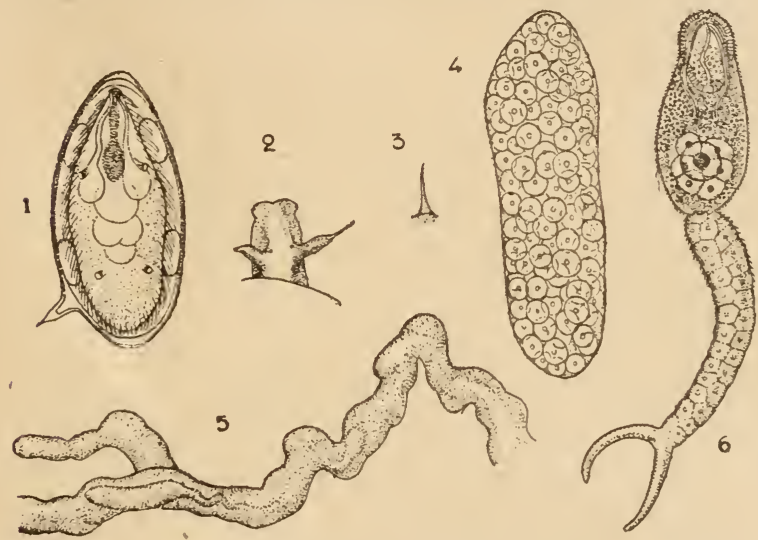

Fig. 37. - Développement de Schistosomum (Bilharsia) mansoni (d’après Lutz), $I$ œuf normal renfermant l'embryon cilié, 2 tentacules infestés (et renflés) de Planorbis olivaceus, 3 tentacule normal, $f$ sporocyste secondaire, 5 id. plus développé, 6 cercaire à queue fourchue.

dans les poumons, occasionne des hémoptysies redoutables. Or l'homme s'infeste en absorbant les cercaires enkystés (ou métacercaires) qui se trouvent dans des crabes d'eau douce (Potamon obtusipes, Sesarma de haani, Eriocheir japonicus); ceux-ci sont contaminés parfois dans la proportion

1. Elle atteint à Formose jusqu'à ro o/o des habitants, dans certaines parties montagneuses de l'ile. 
de 100 o/o. Ces crabes sont le second hôte provisoire du distome, le premier étant une Melania (M. libertina).

Nématodes. - Dans ce groupe, un certain nombre de parasites sont aussi hétéroxènes. Le Spiroptera obtusa de la souris commence son évolution dans les vers de farine (larves de Tenebrio molitor). Les Acuariidce, en général, sont d'abord parasites dans des insectes coprophages, puis dans des mam. mifères. Spirocerca sanguınolenta et Physocephalus sexalatus ont ainsi, pour hôtes successifs, l'Ateuchus sacer et le chien ou le chacal.

Les Ollulanus du Chat vivent à l'état de larves chez la souris; les Cucullanus elegans de la Perche ont pour premier hôte des Cyclops ou des larves d'Agrion; un Ichthyonema des Uranoscopes parasite d'abord des Sagitta.

La Trichine (Trichinella spiralis) s'enkyste dans les muscles des mammitères (porc, sanglier, rat, etc.), et peut y rester vivante, sans se développer, pendant plusieurs années. Quand les muscles infestés sont mangés par un autre mammifère ou par l'homme, ces trichines sont mises en liberté dans l'estomac; achèvent d'y mûrir, s'accouplent dans l'intestin grêle, y pondent et leur's larves franchissent la paroi intestinale, puis,entraînées dans la circulation, vont finalement s'enkyster dans les muscles du nouvel hôte.

Les filaires accomplissent des migrations compliquées, qui ne sont connues qu'en partie.

La Filaire de Médine (Filaria medinensis), qui 
vit dans le tissu sous-cutané de l'homme et atteint jusqu'à I mètre de longueur (sur r-2 millimètres de largeur), a pour hôte provisoire un Copépode Cr. clops coronatus; elle y pénètre par la bouche et le tube digestif et passe de là dans la cavité générale (Roubaud, 3 I 2). L'homme s'infeste en avalant ces Crustacés, mais il est nécessaire que le ver y ait subi une évolution qui est assez longue. L'infestation expérimentale a été obtenue sur des singes.

Toute une série de filaires qui vivent à l'état adulte dans les organes profonds, notamment dans les vaisseaux lymphatiques, et dont les embryons (microfilaires), entourés d'une gaîne, circulent dans le sang, ont un rycle analogue. Telles sont Filaria bancrofti ( $F$. nocturna), dont les larves circulent la nuit et qui cause des maladies redoutables, $F$. loa ( $F$. diurna), $F$. perstans, $F$. oolvulus, etc.

Seul est complètement connu, pour les Filaires de l'homme, le cycle de $F$.bancrofti, découvert en I87\%, par P. MANson (I). L'hôte intermédiaire est un moustique, qui avale les microfilaires avec le sang. Dans l'estomac de l'insecte, ces microfilaires se dèbarrassent de leur gaine, passent dans la cavité générale et dans les muscles et subissent là une évolution dine quinzaine dejours, au bout de laquelle leurs organes sont achevés. Elles émigrent alors dans les diverses parties du corps du moustique et

I. Cette découverte, outre son intérêt propre, a celui d'avoil été le point de départ des recherches qui ont abouti ultérieurelitent à la connaissance ducycle de l'hématozoaire du paludisme. Elle est historiquement l'origine de toute la série si fructueuse des travaux sur les maladies parasitaires du sang. 
viennent s'accumuler dans la lèvre inférieure. Au moment où le moustique pique, elles se trouvent déposées sur la peau, à travers laquelle elles passent activement, sans devoir utiliser la piqûre, car elles peuvent traverser la peau saine.

La Filaria immitis du cour du chien est transmise aussi par des Culicides; le mécanisme est le même que pour $F$. brancrofti, sauf que les jeunes filaires vont achever leur développement dans les tubes de Malpighi du moustique. La $F$. grassii du chien passe par une tique du genre Rhipicephalus.

Les Gordius, types aberrants de Nématodes, subissent aussi des migrations complexes. En voici le résumé très succinct pour Gordius tolosanus. Les adultes se rencontrent libres dans l'eau, en avril.Ils pondent et leurs larves, qui se développent en un mois environ, pénètrent dans des larves aquatiques d'Insectes (Sialis, Whemera, Tanypus, Corethra, Chironomus), ou dans des Poissons, ou eucore dans des vers (Enchriraus). Elles s'enkystent dans les muscles de ces hôtes intermédiaires et y restent jusqu'après la métamorphose, s'ils'agit d'Insectes. Elles achèvent leur développement quand ce premier hôte est avalé par l'hôte définitif, généralement un Coléoptère (Pterostichus niger ou divers Carabides), où elles constituent la seconde larve, qui grandit et, au printemps suivant, perce la paroi de l'hôte et parvient ainsi à l'état adulte, dans l'eau où on trouve le ver. Pour que que cette dernière condition soit réalisée, il faut que les Pterostichus, animaux 
essentiellement terrestres, soient amenés à l'eau, soit par hasard, soit par un tropisme non encore analysé. Les Gordius libres achèvent de mûrir leurs glandes génitales et pondent leurs œufs; le nombre extrêmement élevé de ceux-ci compense la perte considérable des larves (I).

Les $A$ canthocéphales, parasites à l'état adulte dans lintestin des Vertébrés, auquel ils sont fixés par une trompe garnie de nombreuses rangées de crochets et complètement dépourvus de tube digestif, passent à l'état larvaire par un hôte provisoire, variant avec les espèces : Crustacé (Asellus, Gammarus, etc...) ou Insecte (Blaps, Cetonia), ou Poisson.

Les Linguatulides, groupe gćnèralement rattaché aux Arachnides, évoluent aussi avec des migrations. Liadulte habite les voies respiratoires des Mammifères et des Serpents. Les larves sont enkystées dans les viscères d'autres Mammifères, généralement herbivores.

Protozoaires. - Les migrations, avec passage par des hôtes provisoires, ne sont pas moins répandues chez les Protozoaires que chez les Métazoaires, ainsi que l'on montré les travaux récents, surtout chez les Sporozoaires et les Flagellés.

ז. Les Nectonema marins, trouvés nageant à la surface et qui ont une structure voisine de celle des Gordius, ont peut-être un cycle analogue, mais qui est encore complètement inconnu. 
Parmi les (irégarines, Léger et Du boscq (23 $I$ ) ont démontré, d'une façon indiscutable, que les Grégarines cœlomiques des Crustacés qui forment le genre Aggregata, ne sont autres que la partie schizogonique d'un cycle, dont la sporogonie s'effectue chez les Céphalopodes et y constitue les Klossia ou Eucoccidium, jusque-là considérés comme les Coccidies. En faisant ingérer à des Portunus et des Inachus des sporozoïtes de l'Eucoccidiam eberthi de la Seiche, ils sont provoqué, chez ces Crabes, une infection intense d'Aggregata etils ont pu en suivre tous les stades.

De même les Grégarines intestinales des Crustacés Décapodes, Homards et Crabes, connues sous le nom de Porospora, dont les sporozoïtes sont à nu, ne représentent qu'une fraction asexuée du cycle, dont la partie sexuée se produit chez des Mollusques lamellibranches (Tapes, Solen, Tellina, Mrtilus, Cardium, Donax) et y constitue les parasites décrits sous le nom de Nematopsis. En faisant ingérer des Nematopsis à des Portunus, LÉger et Duboscq (235-236) ont obtenu toute l'évolution des Porospora (cf. fig. 38).

C'est surtout chez les Hémosporidies et les Hémoflagellés, que les migrations présentent une importance capitale, en raison du rôle pathogène de beaucoup de ces parasites. L'étude de ces migrations a été un des principaux objets de recherches zoologiques, au début du $x x^{\circ}$ siècle. D'une manière générale, chez les Vertébrés, les Hémosporidies se multiplient par voie asexuée (schizogonie) et différencient leurs éléments sexués (gamétocytes), mais sans 
que la formation des gamètes proprement-dits s'achève. Cet achèvement n'a lieu que quand les gamétocytes sortent du vaisseau sanguin du Vertébré. En examinant au microscope du sang de Mammifères ou d'Oiseaux infestés, on voit, au bout de
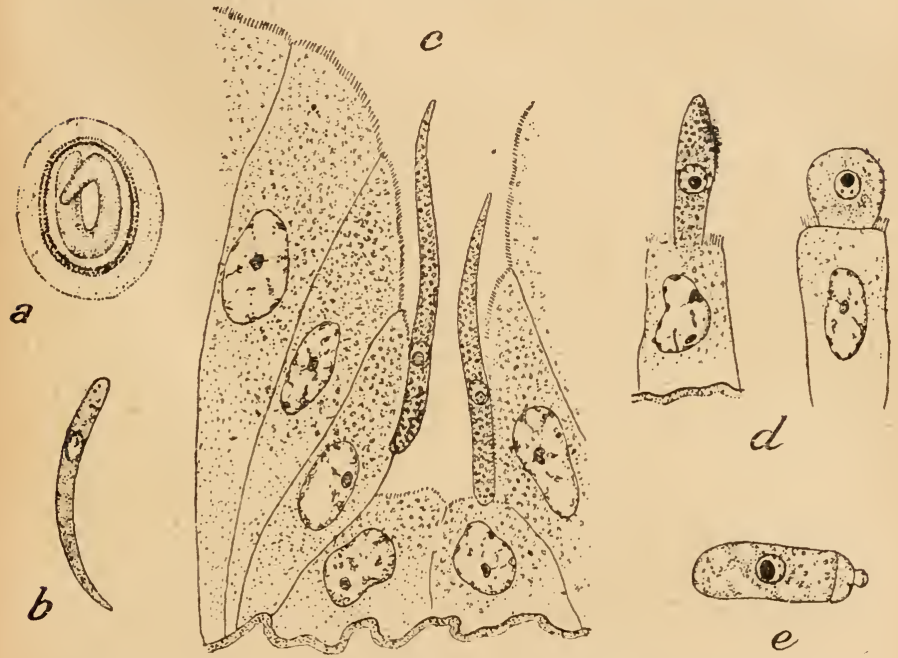

Fig. 38. - Cycle de Porospora portunidarum (d'après Léger et Dubosco) : a Stade Nematopsis (dans les branchies de Cardium edule), $b$ sporozoïte de Nematopsis venant d'éclore (dans le tube digestif de Portunus depurator, $c$-e sporozoïtes fixés à des cellules intestinales et évoluant en sporadins.

quelques instants, les gamétocytes mâles émettre rapidement quelques longs flagelles, qui se détachent et ne sont autre chose que les microgamètes: on a assez longtemps pris ceux-ci pour des formes de dégénérescence. Le premier Mc Callum, sur l'Haemo. 
proteus columba du Pigeon, a vu. sous le microscope, ces flagelles féconder des gamètes femelles. Dans les conditions naturelles, cet achèvement des gamètes et leur fusion se produisent dans l'estomac d'un Invertébré piqueur, moustique, sangsue, tique, etc... Dans ce nouvel hôte, s'accomplit la seconde partie du cycle, qui aboutit à des germes très nombreux, inoculés au Vertébré par la piqûre de l'hôte invertébré.

R. Ross (243) a, le premier, fait connaître ce cycle, en 1898 , pour les Proteosoma des oiseaux, dont la gamogonie a lieu dans des Culex. Peu après, les recherches de Grassı (223) et de ses élèves l'ont reconstitué avec précision pour les parasites tout à fait voisins(Plasmodium), qui déterminent le paludisme humain; ici le second hôte est un autre genre de Culicide (Anopheles).

Résumons rapidement les faits aujourd'hui classiques, relatifs au Plasmodium. Les parásites se multiplient par schizogonie dans les globules sanguins de l'homme (formes en rosette) et y élaborent du pigment mélanique. Après un certain nombre de générations de ce genre, ils produisent des éléments d'une forme spéciale (croissants) qui sont des gamétocytes et qui n'évolueront pas da vantage dans les vaisseaux humains: mais, s'ils sont absorbés par un Anopheles avec le sang, sitôt arrivés dans l'estomac des moustiques, les gamétocytes femelles, ou macrogamètes, s'arrondissent; les gamétocytes mâles émettent rapidement des flagelles ou microgamètes, qui vont féconder les macrogamètes. Le zygote formé est vermiforme et mobile (oocinète).Il frauchit 
la paroi de l'estomac du moustique et s'enkyste (oocyste), en faisant hernie à la surface externe de la paroi stomacale, dans la cavité générale.

Dans ces oocystes, se différencient, en nombre immense, des sporozoïtes filiformes et mobiles, qui se répandent dans tout le corps de l'anophèle et envahissent les glandes salivaires. Ils seront inoculés à l'homme quand l'anophèle piquera. lue mécanisme de transmission est, comme on voit, assez analogue à celui de Filaria bancrofti.

L'Hamoproteus columbee du pigeon passe par une mouche pupipare (Lynchia maura) qui vit dans le pigeon: mais, dans ce cas,la partie du cycle qui s'accornplit dans l'invertébré,se réduit à la copulation desgamètes; l'oocyste ne sort pas de l'estomac del'Insecte et estinoculé au pigeon avant d'a voir'évolué. L'Hamoproteus noctuce de la chevêche se transmettrait, d'après Schaudivx (246) par des Culex(I).

Les Hémogrégarines, que l'on rencontre surtout dans le sang des Vertébrés à sang froid, ont un cycle analogue. L hôte invertébré est généralement une Hirudinée (pour les Hamogregarina) ou un Acarien (Lypon)ssus saurarum pour Karyolysus lacertarum). L'Hepatozoon perniciosum du rat a pour hôte invertébré un Acarien (Lelaps echidninus) parasite sur le rat. Le Leucocytozoon canis, une tique (Rhipicephalus sanguineus).

r. Les recherches de Schaudiry sur ce dernier parasite (I904) avaient eu un très grand retentissement, parce que l'auteur y avait été conduit à admettre l'identité des Hémosporidies, des lfémoflagellés et des Spirochètes. Mais ces conclusions devaient reposer sur la mécnnnaissance d'infections mixtes et sont caduques aujourd'liui. 
Les Hémoflagellés se transmettent dans des conditions semblables aux Hémosporidies et l'étude de ces conditions est actuellement un problème d'une importance exceptionnelle, en raison des formes pathogènes ; il est d'ailleurs très complexe. Aujourd'hui, on peut considérer comme établi qu'il y a deux catégories dans cette transmission. Dans l'une, l'invertébré transmetteur mérite véritablement le nom d'hôte, parce qu'il y a évolution du Flagellé à son intérieur avant la réinoculation et celle-ci n'est possible qu'après que cette évolution s'est accomplie ; dans l'autre catégorie, l'invertébré n'est qu'un agent mécanique de transmission passive. Dans le premier cas, les virus transmis sont spécifiques, dans le second ils sont quelconques.

Les Invertébrés transmetteurs d'Hémoflagellés sont naturellement des espèces hématophages, en premier lieu des Insectes piqueur's, soit des Diptères (Mouches, Glossines, Stomoxys, Tabanides, Simulies, Phlëbotomes et Moustiques), des Poux et des Puces, des Hémiptères, des Tiques, des Sangsues.

Les Glossines, ou Mouches tsétsé, sont les agents vecteurs des trypanosomiases les plus importantes, par leur caractère pathogène, en premier lieu du nagana ( $T$. brucei) et de la maladie du sommeil ( $T$. gambiense), et aussi d'autres Trypanosomiases comme la souma ( $T$. cazalboui), ou celle à $T$. pecaudi, etc. Leur rôle a été mis en évidence, d'abord par Bruce, en r 894 ; dans des expériences précises sur le nagana,il a prouvé que l'agent de sa transmis. sion ètait Glossina morsitans et que le gros gibier atricain était le réservoir de virus. Trypanosoma 
gambiense, virus de la maladie du sommeil, est transmis surtout par Gl. palpalis ; mais, en certaines régions (Rhodesia), on trouve un autre trypanosome humain ( $T r$. rhodesiense) transmis par Gl. morsitans. Tr. cazalboui est transmis par les diverses espèces de glossines. Dans tous ces cas, les glos. sines sont de véritables hôtes, dans lesquels s'effectue une évolution, dont les modalités sont diverses avec les espèces. D'après certains auteurs, cette évolution aurait lieu exclusivement dans la trompe ; d'après d'autres elle s'accomplirait dans l'estomac, doù les trypanosomes repasseraient, après un certain délai, soit dans la trompe, soit dans les glandes salivaires (ce serait le cas pour les trypanosomes humains). Cette évolution cn elle-même est encore mal élucidée. Косн avait observé un dimorphisme qui fait soriger à des gamétocytes, mais la réalité du phénomène de sexualité n'a pas été démontrée.

Trypanosoma lewisi, forme non pathogène du rat, accomplit de même un cycle évolutif dans une puce Ceratophyllus fasciaíus et peut-être dans un pou Huematopinus spinulosus. T. theileri, des Bovidés du Transvaal, serait transmis par une hippobosque. Schizotrypanum cruzi, agent de la trypanosomiase humaine sud-américaine, a pour hôte intermédiaire un Hémiptère de la famille des Réduvides (Conorrhinus megistus), a vec une évolution analogue à celles qui se produisent chez les Glossines. Les Trypanosomes des Vertébrés aquatiques se transmettent par des sangsues (Hemiclepsis pour Tr. granulosum de l'anguille, Pontobdella pour T. raje, Helo- 
bdella pour T. inopinatum de la Grenouille, etc...), comme cela résulte des recherches de LÉger et de Brumpt.

Mais, pour d'autres Trypanosomiases, les Invertébrés ne sont que des agents mécaniques de transmission. Ce serait le cas pour le surra ( $T$. evansi), transmis par les stomoxes et les taons, pour le debab du chameau $T$. berberum), transmis par les taons. Les stomoxes propageraient d'ailleurs aussi des trypanosomiases pour lesquelles les glossines sont les hôtes spécifiques, ainsi que Boufrari l'a montré nettement pour la souma (T. cazalboui). De même les moustiques peuvent opérer cette transmission.

Trypanosoma equiperdum, agent de la Dourine du cheval, se transmet directement à travers les muqueuses, dans le coït, à la différence de tous les autres trypanosomes (I). Mais on a pu l'inoculer expérimentalement par des insectes.

Les Leishmanioses (1. canine, kala-azar humain, bouton d'Orient, leishmaniose sud-américaine, etc.), dont les agents sont aussi des Flagellés (Leishmania), doivent être transmises par des insectes ; mais on n'a pas encore établi avec certitude. les hôtes normaux de ces Flagellés et les conditions de leur rôle. Les puces semblent être parmi les vecteurs les plus probables.

La transmission des piroplasmoses (ou babé-

I. Kосн croit cependant, d'après des faits de contagion conjugale, que le $T$. gambiense peut se transmettre de mèine. 
sioses) est au contraire mieux connue et leurs convoyeurs sont des Acariens, les tiques (Ixodida), qui sont de véritables hôtes, dans lesquels le parasite accomplit une évolution et chez qui même il passe d'une génération à l'autre par les œufs. Ces Acariens transmettent d'ailleur's une série d'autres virus.

Les mécanismes précis des transmissions des divers parasites sont loin d'être uniformes et restent souvent encore très discutables : inoculation proprement dite par l'invertébré suceúr, dépôt sur la peau et pénétration active ou passive du parasite, le dépôt ayant lieu, soit par la salive, soit par les excréments, le passage se faisant, soit à travers la peau saine, soit à la faveur d'excoriations.

Une question spéciale se pose à propos des migrations des Protozoaires parasites. Pour les Métazoaires, il est évident que l'hỏte définitif est celui où le parasite atteint sa maturité génitale. Pour les Protozoaires, le critérium est beaucoup moins net, les phénomènes de sexualité s'accomplissant souvent par parties dans chacun des deux hôtes, ou n'étant pas connus. On ne connaît pas, au moins jusqu'ici, d'une façon sûre, la sexualité des trypanosomes, et, pour les Hémosporidies, les gamètes se différencient réellement dans le sang du Vertébré, à l'état de gamétocytes, mais ne s'achèvent et ne se fusionnent que chez l'Invertébré hématophage. Dans ces conditions, quel est l'hôte définitif ou fondamental ? Deux théories sont en présence. Certains biologistes, comme L. LÉGER, considèrent, par exemple, que les trypanosomes ont été originairement des parasiles intestinaux dinsectes non piqueurs, à l'état de 
Crithidia et de Leptomonas et qu'ils se sont modifiés chez les insectes piqueurs et hématophages, en s'adaptant au milieu intérieur des Vertébrés; Roubaud s'est rallié à ces idees. Minchin au au contraire, considère le Vertébré comme l'hôte fondamental, chez qui les Tryponosomes auraient été des parasites originairement intestinaux, puis sanguicoles; ensuite ils seraient passés dans les Insectes hématophages. Mrsnil s'est rallié récem ment à la dernière-hypothèse, en considération des faits assez nombreux où l'on a constaté maintenant le passage de Flagellés intestinaux dans le sang, en dehors des cas pathologiques.

Pour les Hémosporidies, cette seconde hypothèse semble la plus naturelle; elles dériveraient de coccidies originairement intestinales et devenues sanguicoles : les coccidies proprement dites offrent, dans leur siège et même dans leur cycle évolutif, des types qui indiquent la possibilité de cette transformation. Le passaḡe par les Culicides serait une complication secondaire du cycle. Les Vertébrés seraient donc les hôtes principaux.

Cette dernière épithète convient d'ailleurs ici mieux que celle d'hôte définitif (ou provisoire). Si la thèse de LÉGEr est admise pour les Hémoflagellés, on voit que les migrations, après s'être constituées secondairement, peuvent finalement disparaître comme dans le cas de la dourine, et cela doit être rapproché de la suppression de la migration que nous avons vue chez certains $H$ rmenolepis, où le tænia se développe sans hôte intermédiaire et où cette forme d'évoluti on est évidemment secoudaire. 
Les parasites végétaux offrent, comme ceux du règne animal, des cas de migrations sur des hôtes successifs, plus ou moins indispensables pour que s'accomplisse l'ensemble de leur cycle. L'exemple classique est celui qu'offrent certaines Urédinées, dont le sporophyte (avec les urédospores et les téleutospores) vit sur un hôte et le gamétophyte (avec les œcidiospores et les spermogonies) sur un autre. Pour la Puccinia graminis, ou rouille du blé, le premier des hôtes est une graminée (et en particulier le blé), le gamétophyte, au contraire, vit sur l'évine-vinette. 


\section{CHAPITRE VIII}

\section{LES MODIFICATIONS ADAPTATIVES DE LA REPRODUCTION CHEZ LES PARASITES}

Sommarre. - Fréquence de l'hermaphrodisme, ou rapprochement permanent des sexes avec exagération du dimorphisme sexuel. - Elévation considérable du nombre des œufs.

Intercalation de processus de multiplication au cours du développement : schizogonie des Sporozoaires. - Agamogonie des Dicyémides. - Plasmodes des Orthonectides. - Bourgeonnement larvaire chez les Ccelentérés parasites. - Cestodes : strobilisation, pluralité des scolex sur certains cysticerques. - Trématodes : formation des rédies et cercaires. - Rhizocephales : bourgeonnement chez les Thompsonia et chez Peltogaster socialis. - Polyembryonie chez des Hyménoptères entomophages.

Rapport entre ces processus et l'effacement de l'individualité physiologique. - Analogie avec les animaux fixés.

Les exemples étudiés dans les chapitres précédents montrent combien le parasitisme modifie tous les systèmes d'organes ; l'appareil reproducteur est un de ceux qui sont le plus constamment et le plus profondément touchés. La fonction reproductrice subit chez la généralité des parasites une hypertrophie considérable; aux processus normaux de reproduction s'en ajoutent fréquemment d'autres, qui vien- 
nent encore les renforcer. Sans introduire aucune tendance finaliste, on peut dire qu'en fait la reproduction est l'aboutissant de toutes les fonctions de l'organisme; mais, chez les formes libres, l'activité de l'individu s'exerce, dans une large mesure, indépendamment d'elle et, chez les êtres supérieurs, elle leur survit mème. Au contraire, chez les parasites, cette fonction est prépondérante, tout lui est subordonné ; rien n'est conservé, peut-on dire, que dans la mesure où cela aide à la reproduction.

La vie parasitaire limite les conditions où la fonction de reproduction peut s'exercer, en rivant le parasite à l'hôte et restreignant ainsi la possibilité de rencontre des sexes. D'autre part, elle introduit dans le développement une condition majeure, celle de rencontrer l'hôte nécessaire, à une phase déterminée ; de ces deux données découlent les particularités essentielles de la reproduction des parasites.

A la première correspondent les modifications habituelles de la sexualité chez les parasites; elles se ramènent à deux types principaux : l'hermaphrodisme et l'exagération du dimorphisme sexuel.

L'hermaphrodisme est une condition très fréquente chez les parasites, soit qu'il existe déjà chez les formes ancestrales libres et soit par conséquent primitif, soit qu'il apparaisse comme secondaire et résultant du parasitisme. On peut considérer ainsi comme un hermaphrodisme primitif, celui des Trématodes el Cestodos, des Rhizocéphales, des Hirudi- 
nées même (les Oligochètes sont déjà hermaphrodites). Mais, dans la plupart des autres groupes, l'hermaphrodisme est secondaire,comme cela résulte de la comparaison avec les formes voisines. Chez les Myzostomes, qui dérivent certainement des Poly. chètes, l'hermaphrodisme a đû s'établir ou au moins se renforcer (car il existe à l'état plus ou moins rudimentaire chez un certain nombre de Polychètes) par le parasitisme. Parmi les Crustacés Isopodes, qui sont essentiellement gonochoriques (I), les Cymothoadiens sonthermaphrodites successifs, ainsi que les Cryptonisciens parmi les Epicarides, et c'est là manifestement une condition secondaire. Parmi les Orthonectides à sexes séparés et dimorphes, l'hermaphrodisme s'introduit comme une modification également secondaire (Rhopalura julini et R. pelseneeri, Stcecharthrum giardi). Parmi les Nématodes normalement gonochoriques, les parasites présentent un certain nombre de types hermaphrodites (Rhabdonema nigrorenosum,Bradynema rigidum, Allantonema). Chez les Gastropodes prosobranches, où le gonochorisme est la règle, le parasitisme entraìne, au moins fréquemment, comme nous l'avons vu, l'hermaphrodisme et l'entraîne surtout chez les formes fortement dégradées (Ento. conchida).

L'hermaphrodisme n'est d'ailleurs une simplification pour la reproduction des parasites que s'il y a autofécondation et c'est le cas dans un certain nombre de groupes, comme les Cestodes, les Rhizocéphales, les Orthonectides hermaphrodites, etc. Mais

1. C'est-à-dire à sexes séparés. 
l'hermaphrodisme successif aboutit à une utilisation de tous les individus pour la production des œufs et, par suite, se trouve être une disposition favorable à l'espèce; il arrive d'ailleurs à converger avec la seconde des conditions dont il a été parlé plus haut, l'exagération du dimorphisme sexuel, àu point qu'il a été et qu'il reste encore parfois difficile de trancher à laquelle des deux dispositions on a affaire. Liexagération du dimorphisme sexuel consiste presque toujours dans le gigantisme de la femelle par rapport au mâle. L'inégalité inverse est une exception rare (Bilharsia). Mais, des deux façons, les sexes vivent réunis; en général donc, le mâle nain vit sur la femelle. Ainsi la rencontre des sexes est assurée. D’ailleurs la réunion permanente des sexes s'observe même chez des parasites peu modifiés et à dimorphisme sexuel faible, notamment chez beaucoup de Crustacés (Ichthyoxenus), mème chez de simples commensaux ou inquilins $v$. chap. I). C'est la réunion permanente des sexes qui est le trait vraiment caractéristique et fondamental; mais on peut dire que de là a découlé le dimorphisme sexuel et le nanisme du mâle. Ces phénomènes se retrouvent d'ailleurs, pour les mêmes raisons, chez des êtres simplements fixés. On pourrait dresser de longues listes de parasites à dimorphisme sexuel intense et à sexes vivant associés en permanence : c'est le cas de la généralité des Epicarides (Bopyrida, Entoniscida, Dajid $\propto$ ), de presque tous les Copépodes parasites (sauf Xenocceloma, qui est hermaphrodite avec autofécondation), de divers Nématodes parasites (ex.: Syngamus trachealis).

iI. Caullerr. - Le Parasitisme 
Chez les Cryptonisciens et une partie des Myzostomes, l'apparence est la même et il a fallu des démonstrations précises pour prouver qu'il y avait en vérité hermaphrodisme. A la phase mâle, l'animal est nain et vit sur de grosses femelles, forme en laquelle il se transformera après avoir tonctionné comme mâle. Pratiquement c'est un mâle nain. Dans le cas particulier des Myzostomes, on a trouvé tous les passages, de l'hermaphrodisme protandrique avec présence contemporaine des deux glandes inégalement évoluées, à un hermaphrodisme véritablement successif, et les mâles ont été longtemps regardés comme des individus spéciaux indépendants des femelles (I).

La transformation véritablement caractéristique de la sexualité chez les parasites est donc le rapprochement permanent des sexes, assurant la fécondation : soit dans le gonochorisme avec nanisme du mâle, soit dans l'hermaphrodisme, parun hermaphrodisme successif équivalent, ou bien par l'établissement d'un hermaphrodisme comportant l'autofécondation.

$$
* *
$$

I. On a décrit chez certains parasites (Myzostomes, Entoniscida), comme d'ailleurs chez des types fixés (Cirroripèdes), des màles complémentaires, distincts des individus hermaphrodites. Il est nécessaire, dans clıaque cas, d'être sûr que ces mâles n'évoluent pas ensuite en femelles; ainsil'existence des mâles complémentaiı'es des Myzostomes n'est géuéralement plus admise maintenant. Celle des mâles d'Entonisciens, admise par GiArd et Bonnier, exigerait une étude nouvelle. Les larves cryptonisciennes, qu'ils ont considérées comme telles, sont peut-être simplement des états jeunes de mâles ordinaires. 
La nécessité d'atteindre, au moment voulu du développement, l'hôte favorable, et, pour les formes effectuant des migrations, celle de parvenir successivement dans les divers hôtes, a, sur les parasites, un retentissement plus marqué encore que celle d'assurer la fécondation des œufs. Il découle en effet de ces circonstances une perte énorme de larves ou d'embryons, qui, dans les conditions kabituelles de reproduction, entrainerait rapidement la disparition des espèces. Les formes parasites n'ont donc pu se, maintenir que par des dispositions compensatrices de cette mortalité extrême des jeunes individus.

La plus simple et la plus répandue de ces dispositions est un accroissement considérable du nombre des œufs produits. L'accroissement de fécondité est une particularité très générale chez les parasites, et c'est à lui qu'est due, pour une forte part, l'hypertrophie de la femelle par rapport au mâle. On aura une idée nette de cet accroissement de fécondité, en comparant le contenu de la cavité incubatrice d'un Epicaride - énormément développée et où les embryons se chiffrent par milliers - à celui de la cavité incubatrice d'un Isopode normal, comme un sphérome, où il y en aura à peine une centaine ou deux. Une sacculine, une lernée, Xenocoeloma, émettent constamment des pontes copieuses : les cordons ovigères des Copépodes parasites sont beaucoup plus longs que ceux des formes normales. La production d'œuf́s par les Nématodes parasites est énorme. On a calculé, il y a déjà longtemps, que l'Ascaris lumbricoides de l'homme émettait annuel- 
lement 64 millions d'œufs, représentant r 700 fois son poids; la reine d'abeilles, qui est considérée comme douée d'une fécondité tout à fait exceptionnelle, ne produit par an que 3 fois son poids d'œufs. Chez Spharalaria bombi, nématode parasite des Bourdons, il se produit, sur la femelle même, une extroversion de l'utérus, qui forme un sac énorme, auquel le corps de la femelle reste fixé comme un minuscule appendice (fig. 39 , A-C) et qui renferme des embryons extrêmement nombreux; les genres voisins Allantonema et Attractonema offrent des dispositions de même ordre. Les Trématodes et Cestodes pondent des œufs de façon continue et on évalue à 80 millions ceux émis en un an par le Tania solium.

Mais l'augmentation du nombre des œufs n'est pas le seul moyen, par où soit assurée la compensation de la perte élevée d'embryons et de larves. Dans un assez grand nombre de groupes, il s'intercale, au cours de l'évolution de l'individu, une phase de multiplication relevant, soit de la parthénogenèse, soit du bourgeonnement. Nous allons en passer en revue les principaux exemples.

Protozoaires. - Chez beaucoup de types parasites, et notamment de Sporozoaires (coccidies, hémosporidies, schizogrégarines, etc...), à la phase initiale del'infestation de l'hôte, il y a production, par voie asexuée, d'un très grand nombre d'individus. C'est ce qu'on appelle la schizogonic. C'est une phase de multiplication intense, après laquelle a lier la phase sexiblle on gamogonie, an cours de 
laquelle a lieu la propagation d'un hôte à l'autre.

Dicyémides. - Ces animaux pullulent. comme on sait, dans le rein des Céphalopodes, qu'ils doivent infester très peu après leur sortie de l'œuf. Chez les
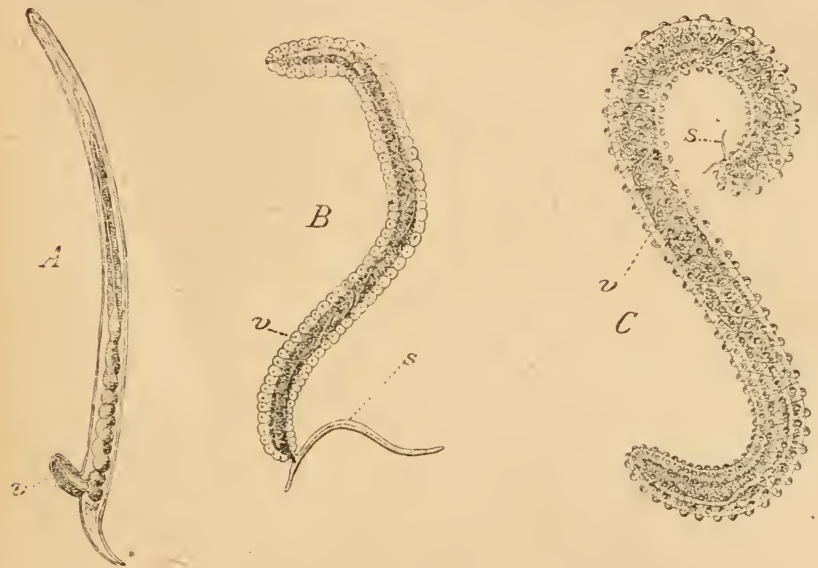

Fig. 39. - Spharularia bombi. A, femelle jeune; début de l'extroversion de l'utérus $(G=50)$. - B stade plus avancé; le corps $s$ de la femelle est très petit par rapport à l'utérus extroversé $\bullet(G=9)$. $-C$, stade terminal ; le corps $s$ de la femelle n'est plus qu'un minuscule appendice sur l'utérus $\vartheta$, où se développent les embryons $(G=5)$ (d'après Leucikart).

Céphalopodes jeunes, ils semblent se multiplier, à l'état d'individus allongés, dits vermiformes ou nématogènes, pendani de nombreuses générations, par voie uniquement asexuée, comme dans la schizogonie précédente. Les cellules germes de la cellule axialc, n'offrent, en effet, aucune trace de féconda- 
tion, ni d'émission des globules polaires et semblent bien être des agamontes, le processus étant une agamogonie (équivalente à la schizogonie). Chez les Céphalopodes adultes au contraire, où l'infection est ancienne, on trouve, d'une façon plus ou moins exclusive, des rhombogènes, qui donnent naissance, dans leur cellule axiale, à des individus spéciaux, dits infusoriformes, aux dépẻns des cellules germes détachées de groupes pluricellulaires dits infusorigènes; et ces éléments, comme l'a montré Hartmans (263), sont des œufs qui émettent uu globule polaire et sont fécondés. La production des infusoriformes résulte donc d'un processus sexué, d'une gamogonie; les cellules des infusorigènes sont des gamontes.

La signification des infusoriformes ne peut être considérée comme définitivement établie. HAnTMann, s'appuyant surtout sur une observation de Keppen, qui a figuré des spermatozoïdes, les considère comme des mâles. Mais, si l'on adopte cette interprétation, le cycle devient des plus paradoxaux, car la fécondation n'aurait lieu que pour la production des mâles. L'existence réelle d'une spermatogenèse dans ces infusoriformes reste à établir. L'autre interprétation, la plus vraisemblable, est que l'infusoriforme est la forme pectrice de l'infection d'un Céphalopode à l'autre; avec elle cadre le fait qu'il résiste au milieu extérieur,ce qui n'est pas le cas des individus vermiformes. Les observations récentes de LAmeere (264) tendent à cette seconde interprétation. Pour trancher définitivemeut la question, de nouvelles observations et expériences sont néces. 
saires, dans lesquelles on essaierait de suivre les transformations des cellules intérieures des infusoriformes, hors du Céphalopode où ils se sont formés et où on tâcherait d'infester de jeunes Céphalopodes sortant de l'œuf. Bien qu'on n'y ait pas réussi jusqu'à présent, la chose ne doit nullement être considérée comme impossible.

Quoi qu'il en soit, le cycle des Dicyémides comportel'intercalation d'ùne longue période de multiplication agamogénétique.

Orthonectides. - Il existe dans leur cycle évolutif une phase de multiplication asexuée chez l'hôte. Considérons, en effet, le cas de Rhopalura ophiocoma, qui est le mieux connu. Les larves issues des œufs fécondés pénètrent dans les fentes génitales de l'ophiure (Amphiura squamata). Elles donnent naissance à des germes intracellulaires uni-ou binucléés, qui deviennent des plasmodes, dans lesquels les noyaux se multiplient et où se différencient, à leurs dépens, des cellules germes, origine des individus sexués, mâles ou femelles. Ces plasmodes constituent une véritable agamogénèse, comme celle des Dicyémides Chacune des larves qui a réussi à atteindre l'hôte donne naissance, dans cet hôte, à de très nombreux individus, et ainsi se trouve compensée la perte de larves qui ne sont pas arrivées à bon port (Gf. fig. 33, p. r 45 ).

Ccelentérés. - Dans ce groupe, la multiplication asexuée est très générale. Son existence chez les parasites n'est donc pas significative. Toutefois il est 
intéressant de noter que, parmi les rares parasites qu'il renferme, il en est plusieurs qui montrent une multiplication asexuée précoce. Tel est le cas de Polypodium hrdriforme, parasite des œufs d'esturgeon, au milieu desquels il forme des tubes qui se résolvent en nombreux bourgeons, chacun de ceuxci devenant un polype hydroïde. Le bourgeonnement larvaire se manifeste aussi chez les Narcoméduses parasites (Cunina, Cunoctantha, etc.) : la larve Planula vit en parasite dans le inanubrium et le système gastro-vasculaire d'autres méduses Géryonides (Carmarina, etc.) et, à un stade très précoce (à peine plus différencié que la planula), donne naissance à une série de bourgeons.

Ceslodes. - Le ténia est souvent considéré comme une chaine d'individus résultant d'une strobilisation. Chaque proglottis renferme en effet la collection d'organes pouvant caractériser un individu et comparable à l'ensemble constitué par les Cestodes inférieurs ou Cestodaires (Amphilina, Gyrocotyle, Caryopinyllceus, parasites des poissons. Archigetes, parasite de Tubifex rivulorum, n'est sans doute que la larve de Carrophylloeus). Les nouveaux anneaux se forment dans la partie initiale du scolex, au voisinage de la zone de fixation à l'hôte, appelée ordinairement la tête du Tcenia. Mais l'étude, soit d'Archigetes, soit des cysticercoïdes des Hrmenolepis et types voisins, montre, par la position des crochets provenant de l'embryon hexacanthe, que le point de fixation des ténias et des Cestodes en général est leur extrémité posté- 
rieure, et que c'est à celle-ci qu'a lieu la formation de segments nouveaux chez les Cestodes.

L'interprétation de la segmentation du corps du ténia en proglottis, comme une multiplication d'individus, reste sujette à des discussions, qui, au f'ond, sont plus verbales que réelles. En fait, au point de vue qui nous occupe, la strobilisation se présente avant tout comme un processus qui favorise très efficacement la production d'un nombre d'œufs considérable. Surtout, une fois le Cestode implanté sur son hôte, cette production a lieu d'une façon continue, pendant une période extrêmement longue, où les proglottis mûrissent et se détachent successivement (I). La totalité de la ponte n'est donc pas soumise au hasard d'une émission unique d'embryons, circonstance très propre à assurer la conservation de l'espèce et que l'on retrouve chez les Trématodes et beaucoup de Nématodes.

Mais les Cestodes offrent un autre mode de multiplication intercalé au cours de l'évolution de l'individu issu de l'œuf. C'est celui où le cysticerque, au lieu de produire un seul scolex̃, en produit une série; d'une larve hexacanthe unique dérive alors un nombre de ténias plus ou moins élevé. Le processus est réalisé par des modes très divers : chez

I. Ce processus peut être rapproché de la schizogenèse de divers ()ligochètes (Lumbriculus, Chcetogaster, Naïs, etc.) et surtout de la schizogamie des Syllidiens, en particulier des Autolytus et des Myrianides, qui, physiologiquement, correspond assez bien à la formation des proglottis et assure aussi une dissémination successive des produits génitaux. Giard avait groupé les faits de ce genre sous le nom assez expressif d'autotomie génératrice. 
le Taenia nilotica (de Cursorius europaus), il se forme des invaginations multiples de la paroi du cysticerque (Polycercus), qui vit dans les Lombrics. De même, dans le cas depuis longtemps classique du $\boldsymbol{T}$. canurus, dont le cysticerque a pour localisation habituelle le cerveau du mouton. Ce processus atteint son maximum chez l'Echinocoque, où, comme on sait, le cysticerque bourgeonne des résicules secondaires (vésicules filles) et parfois même des vésicules petites-filles, chacune de celles-ci se com. portant comme un coenure et produisant plusieurs scolex. Il y a là une possibilité de multiplication très considérable, en même temps que d'essaimage dans des organes très variés. Un cysticerque des Glomeris (Staphylocystis), au lieu de bouryeonner des scolex parinvaginations, produit extérieurement et par ramification en grappe,une série de vésicules cystiques secondaires, dont chacune produit un scolex.

Il y a d'ailleurs un certain balancement entre ces processus de multiplication et le développement ultérieur du ténia. "Chez l'Echinocoque, où la multiplication des scolex est très puissante, le ténia luimême est très réduit, n offrant que trois ou quatre proglottis : quoique ceux-ci se reforment de taçon continue, la production d'œufs doit être plus restreinte que chez les grands ténias. Par contre, le Tania echinococcus est éminemment grégaire, ce qui se conçoit étant donné l'évolution de son cysticerque.

Trématodes. - Les Trématodes endoparasites qui 
sont hétéroxènes sont en mème temps digénétiques et les phénomènes de multiplication au cours du développement sont classiques.

Ils se produisent à l'état de sporocyste dans lequel se différencient de nombreuses rédies, dont il peut exister. plusieures générations; ces rédies donnent naissance elles-mêmes finalement à de nombreux cercaires.

Il y a lieu de chercher la signification exacte des germes d'où proviennent les rédies ou les cercaires : y a-t-il là un bourgeonnement interne asexué ou une parthénogénèse larvaire (progénétique)? C'est cette dernière interprétation qui tend à ètre acceptée aujourd'hui. Dans le sporocyste de Distomum duplicatum parasite des anodontes, Reuss ( 288 ) aurait vu les rédies provenir d'une cellule unique,émettant un corpuscule qu'il considère comme un globule polaire. Elle aurait donc la valeur d'un oocyte. La confirmation la plus précise de cette opinion est due à $\mathrm{CARY}_{\mathrm{AR}}(270)$, qui a étudié le Diplodiscus sub-. clavatus parasite de divers Batraciens. Toutefois les figures données par ces auteurs ne sont pas entièrement convaincantes et, en tout cas, on est loin de pouvoir retrouver l'équivalent de ce qu'ils décrivent chez la plupart des espèces. R. DoLLFus (272) qui n'a pu vérifier les taits annoncés par Reuss et CARy, propose de considérer les cellules internes des sporcystes et des rédies comme appartenant à la lignée germinale du Trématode, qui se continuerait sans interruption jusqu'au Cercaire. La formation des rédies et des cercaires est assimilée par lui à une polyembryonie répétée, c'est-à-dire à un 
bourgeonnement. Mais le propre du tissu germinal est d'évoluer, préalablement à la formation d'une nouvelle génération, en oocytes et spermatocytes avec phénomènes de réduction chromatique. Dans la polyembryonie, dont nous allons voir des exemples, les faits s'interprètent beaucoup plus naturellement cornme correspondant à un processus asexué, c'est-à-dire indćpendamment de la notion de tissu germinal. En réalité, la question réclame encore des recherches.

Rhizocéphales. - Nous avons vu précédemment que, chez certains de ces parasites si profondément modifiés, il se produit une multiplication asexuée typique, qui est particulièrement remarquable dans le groupe des Crustacés.

Sur le système radiculaire des Thompsonia, au lieu qu'il se différencie un seul nucléus, comme chez les sacculines, il s'en forme un nombre considérable, qui tombent périodiquement et se régénèrent. Nous ne reviendrons pas davantage sur la description de ce processus. Il équivaut à la production d'un grand nombre de scolex par le cysticerque d'un coenure ou d'un échinocoque. Et l'on retrouve ici le balancement que nous avons signalé pour ces Cestodes. L'organisation d'un individu de Thompsonia est simplifiée par rapport à celle de la sacculine. Il n'y a plus ni cavité palléale, ni ganglion nerveux, ni même de testicules et il ne se produit qu'une seule ponte, dont le développement doit être parthénogénétique (I).

1. Les larves éclosent directement au stade Cypris. 
Chez Peltogaster socialis, il y a, très vraisemblablement, une fragmentation précoce du stade indifférencié interne. Il s'agit donc d'un bourgeonnement, ou si l'on veut d'une polyembryonie et ce processus n'est pas spécial à cette espèce puisqu'il à été retrouvé dans des formes distinctes du Pacifique (Peltogasterella socialis).

Les phénomènes de multiplication asexuée existent donc chez les Rizocéphales avec une certaine variété dans leur réalisation, et l'on n'en connaît vraisemblablement pas encore toutes les manifestations.

Polyembryonie des Hyménoptères Entomophages. - Ce processus si remarquable, étant donnée la place des Hyménoptères dans la classification, a été

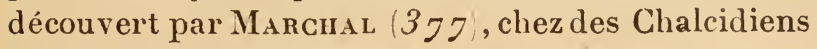
et des Proctotrypides.

Il a été étudié en détail par lui, chez Encyrtus (Ageniaspis) fuscicollis, parasite des chenilles d'Hyponomeute (Hrponomeata cognatellus, H. mahalellus et $H$. padellus). L'ceuf de ce Chalcidien est pondu dans celui du papillon, en juillet-août etsubit seulement un début de développement a vant l'hiver; puis tout s'arrête, pour repartir vers le mois d'aviril. L'œuf du parasite est entouré, dès le commencement de son évolution, par une paroi épithéliale appartenant à l'hôte. Il se différencie, dès le début, un gros noyau très riche en chromatine, le paranucle:s, qui jouera un rôle végétatif et trophique et de petits noyaux peu colorables (fig. $40, A$ ), qui sont les noyaux embryonnaires proprement dits. Le paranucléus 
subit un développement énorme, se lobe et se divise en une infinité de fragments, tandis que les noyaux embryonnaires donnent naissance de bonne heure à de petits groupes cellulaires distincts moruliformes, dont chacun devient un embryon (fig. 4o, B). Il s'en individualise une centaine. Ces embryons se déve-

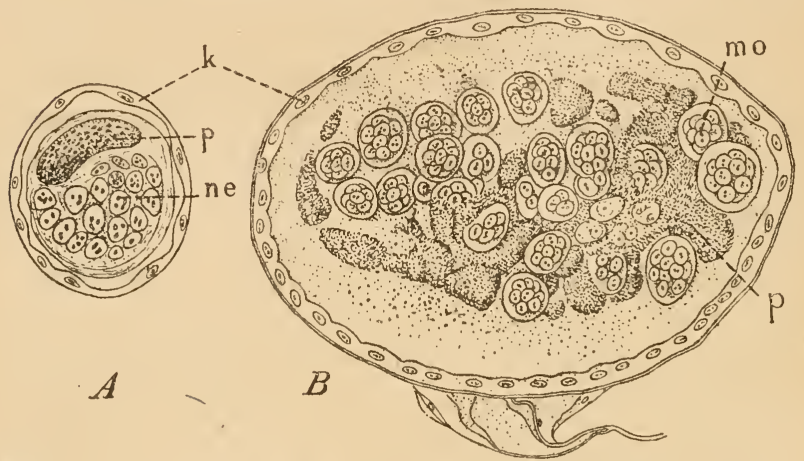

Fig. 4o. - Polyembryonie d'Encyrtus fuscicollis (d'après Marchal): $p$ paranucléus, ne noyaux embryonnaires, mo amas moruliformes donnant les divers individus; $k$ enveloppe kystique épithéliale produite par l'hôte (Hyponomelita).

loppent - comme chez les Orthonectides, - au sein d'une masse cytoplasmique semée de fragments du paranucléus et qui se charge de graisse. Elle joue le rôle à la fois d'amnios et de feuillet trophique. L'œuf primitif s'est transformé peu à peu, dans son ensemble, en un long tube, où les embryons sont disposés en file et qui continue à être enveloppé par le kyste épithélial de l'hôte.

En somme, la différenciation des embryons est 
extrèmement précoce et rappelle beaucoup celle des Orthonectides dans les plasmodes, ou des rédies et des cercaires dans les sporocystes des Trématodes.

La polyembryonie est un phénomène exceptionnel chez les Hyménoptères parasites, mais dont il doit exister pourtant bon nombre d'exemples. MarchaL l'a retrouvé chez une autre Encyrtide, Ageniaspis testaceiceps, parasite des chenilles de Lithocolletis, chez un Proctotrypide, Polygnotus minutus, qui se développe dans le sac gastrique de Cecidomria destructor et de $G$. avence. Chez ce Polygnotus, chaque ouf donne une quinzaine d'embryons.

Silvestri (394) a reconnu la polyembryonie chez Lithomastix truncatellus (I), parasite des chenilles de Plusia gamma et ici un seul œuf produit environ r.ooo larves, sans compter un certain nombre de larves abortives, appelées par Silvestri larpes asexuées; celles-ci sont dépourvues d'ébauche génitale et dégénèrent sans ja mais se métamorphoser (2). Le détail des processus, chez Lithomastix, paraît assez différent du cas d'Encyrtus .

Enfin, dans ces'dernières années, Patterson (383) a trouvé et étudié un certain nombre de cas de polyembryonie chez des Chalcidiens voisins des Encyrtus : Copidosoma (3) gelechice, parasite de Gnori-

I. Grard $(3 \zeta I)$ avait annoncé qu'elle devait exister chez cette espèce, dès la découverte de Marchal.

2. Cela tendrait à faire supposer qu'au début ces larves ne contiennent pas de cellule appartenant à la lignée germinale et à faire admettre par suite que les groupes cellulaires initiaux renferment normalement à la fois des éléments somatiques et des éléments germinaux.

3. Nom générique synonyme de Lithomastix. 
moschema salinaris ; Paracopidosomopsis floridanus, parasite de la chenille de la Piéride du chou (Autographa brassicce); Platygaster rubi, parasite des larves de deux Diptères vivant sur des conitères (Sabina). Chez Paracopidosomopsis, il a retrouvé les larves asexuées de Silvestri, dont WheELER avait mis en doutel'existence et il a prouvé, par des élevages faits à l'abri de toute autre infection, qu'elles ne pouvaient pas être les larves d'un autre insecte parasite, tel qu'un Ichneumonide, comme WHEELER en a vait fait la supposition (I).

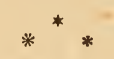

Il résulte de l'exposé succinct qui précède que les processus de multiplieation des individus, au cours du développement de l'œut, sont à la fois fréquents et très variés chez les parasites. Le résultat de ces

r. Ces dernières recherches de Patrerson remettent en question la portée de la polyembryonie dans le problème du déterminisme du sexe. Dans les cas précédemment signalés, en effet, - Bugnion l'avait noté dans Encyrtus fuscicollis, avant lestravaux de MARGHAL - tous les individus issus d'un même œuf étaient de même sexe. Le sexe paraissait donc déter iné dès le début du développement et cela était confirmé par la polyembryonie des tatous chez les Mammifères. De même,chez Lithomastix truncatellus, Sicvestri a constaté que les œufs fécondés donnent naissance à des femelles et les œuf́s non fécondés exclusivement à des màles. Il n'en est plus de même chez les Encyrtides étudiés par Pattrason. Paracopidosomopsis, par exemple, a fourni, sur 177 pontes étudiẻes, 154 où il y a mélange des sexes (soit 84 o/o) et l'analyse des faits montreque cela ne peut plus s'expliquer par le développement simultané de plusieurs œufs de sexes différents dans le même hôte. 
processus est si manifestement favorable à la perpétuation de l'espèce, en compensant la destruction d'un grand nombre de larves qui n'atteignent pas l'hôte nécessaire, que l'esprit est très attiré ver's une interprétation téléologique. Il y a là, de toute évidence, des adaptations. Mais le problème est de savoir comment elles ont été réalisées et comment ces modifications du développement individuel sont venues assurer la propagation de l'espèce.

En rejetant a priori l'interprétation téléologique, il reste deux possibilités: o u bien ce sont là des préadaptations conservées et développées par la sélection naturelle; ou bien - et c'est la solution à laquelle je me rallie - ces processus se sont manifestés en vertu des conditions où l'œuf des parasites s'est trouvé se développer, mais sans liaison nécessaire avec le parasitisme et avec les nécessités de la conservation de l'espèce.

Nous remarquons, en effet, qu'aucun des processus qui viennent d'ètre passés en revue n'est propre au parasitisme, mais que presque tous se retrourent dans des cas où les conditions éthologiques sont plus ou moins parallèles, en particulier chez des animaux qui vivent fixés. Nous avons déjà eu l'occasion de faire des rapprochements entre ceux-ci et les parasites. Les animaux fixés montrent une tendance extrêmement prononcée à la multiplication asexuée. Elle résulte, en somme, chez eux, de l'effacement et de la dissociation de l'individualité. Chez les animaux libres, qu'on peut considérer comme ayant une éthologie normale, l'individualité associe deux caractéristiques essentielles: l'une d'ordre physiologique, 
l'individu est un complexe d'organes se suffisant fonctionnellement mais indivisible ; l'autre d'ordre morphologique, l'individu est l'ensemble indivisible des tissus provenant du développement d'un œuf. Le développement réalise les conditions nécessaires et suffisantes pour la formation du complexe organique individuel ; entre les parties s'établissent des corrélations rigoureuses et nécessaires.

Le changement des conditions résultant de la vie fixée consiste avant tout à modifier ces corrélations, dont certaines perdent leur caractère obligatoire, tandis que d'autres deviennent possibles. De là une dissociation de l'individualité, qui est commune à tous les organismes fixés. Or les conditions de la vie fixée sont réalisées chez de nombreux parasites, qui, en fait, sont fixés.

En outre, les conditions spéciales de la nutrition, chez eux, sont une autre cause de transformation des corrèlations et par suite de l'effacement de l'individualité et l'on peut expliquer, par une argumentation réciproque, l'existence, en dehors des parasites, de certains processus de multiplication embryonnaire qui doivent aussi relever de la nutrition.

Tel est le cas de la polyembryonie et des processus qui doivent en être rapprochés (formation des rédies et cercaires, production des individus sexués chez les Orthonectides). Nous les retrouvons chez des animaux non parasites, où l'œuf se développe dans un milieu nutritif analogue à celui qu'un parasite trouve dans son hôte. C'est le cas des Bryozoaires cyclostomes, chez qui la polyembryonie a été dè- 
couverte par S. F. Harmer, avant même de l'être chez les Hyménoptères par Marghal. L'œuf des Crisia, Lichenopora, Tubulipora, etc., se développe dans une ovicelle qui joue le rôle de chambre nutritive, en réalisant des conditions analogues à celles que rencontre l'œuf d'un Encyrtus dans une chenille. La polyembryonie de certains Mammifères est certainement en rapport a vec la greffe très précoce de l'œuf sur la paroi utérine et les conditions de nutrition qui en résultent.

Mais il est bien évident que les faits de multiplication embryonnaire qu'offrent les parasites ne sont pas expliqués par une analogie superficielle de ce genre, pas plus que réciproquement ne le seraient ceux des formes libres. Il en résulte seulement qu'ils ne doivent pas être envisagés comme dérivant nécessairement $d u$ parasitisme proprement dit considéré comme une entité, ni comme répondant à la nécessité mystique de la conservation de l'espèce. On les voit se manifester en dehors du parasitisme dans des conditions plus ou moins analogues.

Dans chaque cas, ils relèvent d'un déterminisme spécial actuel et surtout passé. Marchat, pour la polyembryonie des Encyrtus et Polygnotus, a cherché à l'analyser. Il s'est efforcé de trouver dans les conditions auxquelles sont soumis les œufs de ces parasites des circonstances qui amènent la réalisation expérimentale de la polyembryonie, par la blastotomie. Il croit apercevoir une circonstance de ce genre, pour les Polygnotus, dont l'œuf, dans l'estomac des larves de Cécidomyies, est soumis à des variations osmotiques très brusques, en même 
temps qu'à un brassage énergique. Il rapproche d'autre part la polyembryonie des Encyrtus du fait que leur développement s'arrête pendant l'hiver et que le morcellement en embryons se manifeste au printemps, c'est-à-dire au moment où la chenillehôte recommence à se nourrir, ce qui entraîne aussi de brusques variations osmotiques dans le milieu où le parasite est plongé. Mais ce ne sont là que des indications encore très précaires.

Les résultats obtenus dans ces dernières années relativement à la culture des tissus me paraissent également très suggestifs, en montrant combien l'évolution d'une catégorie d'éléments donnée peut être modifiée quand on réussit à substituer, aux conditions normales de l'organisme, des conditions vraiment nouvelles. Plusieurs des processus de multiplication asexuée qu'offrent les parasites doivent être la conséquence d'une expérience de même ordre réalisée par la nature et ils doivent être envisagés en dehors de toute idée téléologique. Chaque organisme a réagi, à sa façon propre, en vertu de sa constitution, c'est-à dire des facteurs internes; ce qui, joint à la variété des conditions extérieures résultant du parasitisme, a produit la diversité des cas que nous constatons. 


\section{CHAPITRE IX}

\section{LA SPÉCIFICITÉ PARASITAIRE \\ ET LES MODES DIVERS DE L'INFESTATION DE L'HOTE}

Sommarre. - Exemples de spécificité rigoureuse: Grégarines, Crustacés, etc... - Théorie de Grand et Boxviek. Idées différentes de G.-O. Sars et H.-J. Haxsrax. - Cas de spécificité moins précise: Trématodes et Cestodes. L'hôte normal et les hòtes accidentels. - Réservoirs de virus. - La théorie de la prophylavie trophique ou des écrans protecteurs (Roubaud). - Changement d'équilibre entre les hòtes et les parasites: exemples des Insectes eutomophages aux Etats-Unis. - La spécificité est une propriété relative et le résultat d'une évolution.

La spécificité et les conditions d'accès à l'hòte. - Exemples divers.- Pénétration dermique : Hémosporidies, Filaires, Ancylostomes, Sacculines, etc. - Migration d'Ascaris lumbricoides. - Les divers nodes d'infestation par les larves de Tachinaires et les myiases. - Propagation de parasites par l'œuf et transmission héréditaire.

L'une des caractéristiques du parasitisme et déjà du commensalisme est la spécificité de ces associations ; elles ont lieu toujours entre espèces déterminées. C'est là une constatation de portée générale, mais elle comporte des modalités que nous allons passer en revue. La spécificité parasitaire n'est pas 
en effet une propriété absolue, expression d'une harmonie préétablie entre hòte et parasite ; elle est relative et contingente.

Il y a certainement des cas nombreux et même des groupes étendus, où la spécificité parasitaire est très stricte. C'est celui des Sporozoaires et en particulier des Grégarines. Chaque hôte a, en général, ses grégarines propres. Nous en avons constaté, Mesnil et moimême, un exemple très significatif sur Dodecaceria concharum. Dans les plaques de Lithothamnion polymorphum où vit cette Annélide, on la trouve sous trois formes, que nous avons désignées par $A, B, C$ (peut-être $B$ est-elle une espèce distincte de $A$ et $\mathrm{C}$, mais en tout cas très voisine); le régime alimentaire de ces trois formes est exactement le même. Or, la forme B renterme, d'une façon absolument constante, une grégarine colomique, Gonospora longissima, qu'on ne trouve jamais chez A et C. Dans une famille donnée, on trouvera fréquemment, chez les diverses espèces, des grégarines de formes semblables, mais qui sont spécifiquement distinctes. Telles sont les Anchorina dans les Capi. tellida. LÉger et Duboscq (232) font la même remarque pour les grégarines des Myriapodes: “ les Pte" rocephalus se trouvent, disent-ils, seulement chez " les Scolopendres, les Dactylophorus chez les "Cryptops, les Rhopalona chez les Géophiles. Mais " ce qu'il semble encore, c'est que chaque espèce de " Scolopendre a son espèce de Ptérocéphale et 
" même une simple variété de Scolopendre aura sa (" grégarine spéciale. ) E. Hesse (224) arrive à des conclusions analogues pour les Monocystidées des Lombrics.Les Coccidies et Hémosporidies sont aussi, en général, très étroitement liées à un hôte déterminé. En général, les Hématozoaires que l'on trouve dans la nature peuvent être définis par l'espèce où on les rencontre. Toutefois, au laboratoire, il est parfois possible d'inoculer avec succès des hôtes voisins. Divers groupes de Métazoaires parasites offrent les mêmes caractères de spécificité. Tels sont les Orthonectides et, dans une large mesure, les Dicyémides.

Les Crustacés parasites sont aussi des hôtes très spécifiques. Grard et Borvier regardaient la spécificité des hỏtes des Epicarides comme absolue. Mème en l'absence de caractères morphologiques distincts, pouvant être appréciés, ils donnent des noms spécifiques différents à deux Épicarides trouvés sur des hôtes distincts. Cette conception est critiquée par des carcinologistes descripteurs, tels que G.-O Sars et H.-J. HANSEn, comme trop absolue; ce dernier va évidemment trop loin en sens inverse, puisque, dans un mémoire récent (342), il réunit en une seule espèce (Cumœechus insignis) trois Epicarides trouvés sur trois genres de Crustacés distincts; les femelles, sont semblables, mais Hansen lui-mème signale des différences entre les mâles trouvés sur les divers hôtes. J. Bonnier, en discutant la question, a fait valoir en faveur de la spécificité des arguments importants. Il cite, par exemple, le cas d'un Entoniscien de Portunus holsatus, Portunion frais$s e i$, pour lequel Giard et lui firent une espèce nou- 
velle, tout en ne pouvant la distinguer par des caractères précis d'autres Portunion, mais parcequ'elle se rencontrait sur une espèce donnée de Portunus ( $P$. holsatus). Or, plus tard, ils constatèrent que le mâle de ce Portunion est tout à fait distinct, tellement qu'ils firent de cette espèce le type d'un genre spécial Priapion (en raison de la grande longueur du pénis). - Recevant de Naples un lot de Callianasses parasitées par des Epicarides et considérées comme appartenant à une seule espèce, les mêmes auteur's constatèrent que les parasites étaient dedeux tailles différentes : examinant alors les hôtes avec soin, ils découvrirent que ceux-ci appartenaient à deux espèces voisines, máis distinctes (Callianassa subterranea, $C$. truncata), chacune portant l'une des catégories de parasites. - Ayant pratiqué la recherche d'Epicarides sur de très nombreux individus de divers hôtes, ils ont vu que, de deux espèces voisines vivant côte à côte et dans les mêmes conditions, l'une seulement est parasitée. Ainsi, à Wimereux, Porcellana platycheles renferme souvent un Pleurocrypta, alors que $P$. longicornis n'en a jamais. Ces observations, faites sur de grands nombres et dans la nature, ont une valeur spéciale, très supérieure aux conclusions tirées de rares exemplaires de musée.

-Pour affirmer avec sûreté l'identité de deux Epicarides semblables trouvés sur des hôtes $\mathrm{A}$ et $\mathrm{B}$, il faudrait pouvoir élever les larves et infester avec celles d'un élevage indifféremment les deux hôtes. Pratiquement cela est impossible. En appliquant le critérium de GIARD et Bonnier, on peut conserver 
des doutes sur la réalité de la distinction entre deux espèces, mais, comme le remarque Bonvier, une erreur de ce genre est préférable à l'erreur inverse; car, en réunissant indûment deux espèces, on supprime toute idée de comparaison attentive entre elles.

Les Copépodes parasites présentent une spécificité en général stricte. Cela est vrai pour les espèces parasites des poissons, des ascidies, des annélides (Monstrillides, Tenocceloma, Staurosoma parasiticum sur Anemonia sulcata, etc.). Pour les Rhizocéphales, Giard appliquait la mème règle de spécificité, déterminant les sacculines d'après leurs hôtes; cette pratique n'a généralement pas été suivie, mais elle ne pourrait être véritablement condamnée qu’après des expériences positives d'infestation expérimentale sur plusieurs hôtes avec les nauplius d'une mème sacculine, expérience qui pratiquement est très difficile à réaliser.

Dans les organismes inférieurs (Protozoaires, Bactéries, la spécifité parasitaire peut être très stricte, sans qu'elle se traduise par des caractères morphologiques appréciables chez le parasite ; c'est ainsi que Laveran et Mesnil 22 J) ont été amenés à distinguer des trypanosomes pathogènes morphologiquement semblables par des propriétés d'immunisation réciproque chez un animal donné. Cela montre que le critérium morphologique peut être insuffisant pour la séparation des formes parasites et est de nature à renlorcer la notion générale de spécifité parasitaire. 
Il y a donc, dans bien des cas, une spécificité rigoureuse des parasites. Par contre il est avéré que d'autres parasites se rencontrent sur une série d'hôtes distincts; la spécificité peut même se présenter différemment.pour un même parasite, suivant qu'il s'agira de l'hôte provisoire ou de l'hôte définitif, dans le cas des parasites hétéroxènes.

Ainsi, chez les Trématodes, le mollusque hôte du sporocyste est généralement assez rigoureusement spécifique. Pour Distomum hepaticam en Europe, c'est à peu près exclusivement Limnea truncatula Müll ( $L$. minuta Drap.); des expériences directes ont montré que dans $L$. stagnalis, par exemple, le miracidium ne subissait qu'un début d'évolution : mais, en d'autres régions que l'Europe, $L$. truncatula est remplacée comme hôte de ce miracidium par d'autres espèces: $L$. viator en Amérique du Sud, L. humilis en Amérique du Nord, etc... Des faits du même ordre viennent d'être constatés pour les Schistosomum; le miracidium de S. mansoni a pour hôte, $P$. guadalupensis aux Antilles, $P$. olipaceus et $P$. centimetralis au Brésil. Mais l'hôte définitif des Trématodes est beaucoup moins bien bien défini. Distomum hepaticum se trouve chez toute une série de Mammifères. On a pu de même infester diverses espèces avec des cercaires de Schistosomum.

Chez les Cestodes, la spécificité semble aussi plus étroite pour le cysticerque ou le cysticercoïde que pour l'adulte; il y a pourtant beaucoup d'espèces dont les cysticerques peu vent évoluer dans des hôtes nombreux. C'est le cas de l'Echinocoque notam- 
ment.Inversement, la spécificité de l'hôte peut être rigoureuse pour l'adulte. C'est ce que montrent les expériences récentes de Joyeux (280) sur les Hrmenolepis des Rongeurs et de l'homme. L'Hymenolepis nana de l'homme ne se distingue par aucun caractère morphologique précis de l'Hymenolepis du rat et de divers Muridés $H$. traterna ( $=H$. murina Duj.). Or, tandis qu'on infeste aisément des rats avec des oufs d'Hymenolepis provenant de leurs congénères, on échoue constamment en faisant absorber à ces animaux des œufs de l'Hymenolepis humain. Il semble donc bien y avoir là deux espèces quasi-identiques morphologiquement et localisées sur des hòtes différents .

La spécificité apparaîtra souvent moins stricte au laboratoire que dans la nature. Ainsi, alors que les Hémosporidies sont généralement spécifiques dans la nature, on peut inoculer certaines d'entre elles à des espèces diverses. La spécificité naturelle peut tenir à ce que les conditions d'infestation ne se trouvent pas remplies pour d'autres hôtes.

D'autres fois, une infection peut être réalisée sur des hôtes divers, mais elle ne s'y maintiendra pas.

Ainsi, dans les conditions naturelles, les puces et les poux sont assez étroitement cantonnés sur un hôte déterminé ou sur un petit nombre d'hôtes voisins les uns des autres, quoique ce ne soit pas là une donnée absolue. La puce de l'homme (Pulex irritans) se rencontre sur divers Mammitères (chien, chat, renard, chacal, rat, eheval, etc.). On peut d'ailleurs, au laboratoire, nourrir une puce déterminée sur divers Mammifères. 
Toutefois, comme l'a constaté Joy eux ( 280 ), si l'on institue un élevage de puces sur un hôte, qui n'est pas l'hôte normal, on constate bientôt que la reproduction se fait mal et que l'élevage périclite plus ou moins rapidement. En d'autres termes, dans des cas de ce genre, il y a un hôte normal, où les conditions sont plus favorables et c'est ce qui fait que, dans la nature, le parasite ne se rencontre, dans la règle, que sur lui. LÉGer et DuboscQ $(23 I)$ sont arrivés à cette notion pour les Aggregata des crabes. L'infestation des Portunus avec des spores tirées des Céphalopodes réussit bien mieux que celle des autres genres, où cependant on peut l'obtenir.

Dans ses expériences sur les Bothriocéphales, Rosen (289) a obtenu le developpement des onchosphères dans plusieurs espèces de Crclops et de Diaptomus. Mais c'est chez les Cyclops et en particulier chez Cyclops strennuus que le développement s'accomplit le mieux.

L'hôte normal dans la nature n'est cependant pas nécessairement celui où le parasite se développe le plus activement. On peut, avec Woodcock, admettre pour les espèces pathogènes, que les animaux où elles déterminent des infections aiguës sont des hôtes exceptionnels et non les hòtes normaux. Ceux-ci doivent tolérer le parasite en vertu de l'accoutumance, et avoir acquis vis-à-vis de lui une immunité relative, à l'inverse de ceux-là. C'est ainsi qu'il faudrait interpréter les Trypanosomiases très virulentes pour les animaux domestiques ou pour l'homme. Trypanosoma brucei, par exemple, l'agent du nagana, maladie fatale à la plupart des animaus 
domestiques, chien, âne, cheval, bovidés (I), ne doit pas ètre considéré comme un parasite normal de ces espèces. Ses hòtes naturels sont le gros gibier sauvage, comme les antilopes, où il existe sans déterminer de troubles graves. C'est quand le développement de la colonisation a amené l'introduction par l'homme d'animaux réceptifs que le parasite a atteint ces espèces qui n'étaient pas adaptées à lui. Le surra pour le bétail, la trypanosomiase humaine doivent être considérés sans doute comme des exemples analogues. Ainsi, pour ces parasites, la spécificite est très relative, puisqu'ils peuvent exister dans des espèces très diverses. Vus du point de vue humain de la prophylaxie, les hôtes naturels de ces espèces pathogènes constituent ce qu'on appelle un réserooir de virus. Dans le cas du nagana, ce réservoir est constitué par le gros gibier, en particulier par les antilopes; pour le mal de Caderas du cheval dans l'Amérique du Sud, dû à Trypanosoma equinum, le réservoir de virus paraît être un gros Rongeur, Hrdrochærus caprbara, qui d'ailleurs en meurt.

La spécificité des agents transmetteurs de ces divers parasites du sang est également très variée. Ainsi le parasite malarique humain est transmis par les Anopheles, mais non par les Culex, son évolution ne pouvant se faire que dans les premiers et inversement, les Proteosoma des oiseaux, voisins des Plasmodium, évoluent dans les Culex. Parmi les diverses espèces d'Anophèles, il en est qui s'infestent plus facilement que d'autres.

x. L'homrue n'est pas réceptif à ce trypanosome. 


$$
*^{*} *
$$

Si l'on se place au point de vue pratique de la lutte contre ces parasites pathogènes, la question a de multiples aspects, bien mis en évidence par RouBAUD ( $I 83$ ), et qui ne manquent pas de paraître paradoxaux. Certaines de ces conclusions se rattachent assez étroitement à l'analyse de la spécificité parasitaire et doivent être résumées ici. En outre, en raison de l'ingéniosité et de l'intérêt de ces vues, inspirées par une étude des faits pratiquée dans la nature, je m'y étendrai assez longuement.

La destruction, soit du réservoir de virus, soit de l'agent transmetteur, quand par exemple c'est un insecte piqueur, comme une glossine ou un anophèle, peut être une impossibilité. D'autre part, l'examen des faits naturels conduit à constater que, pour certaines infections au moins, ces destructions ne sont nullement indispensables. Ainsi l'endémie palustre a diminué progressivement en France et a à peu près disparu, sans que pour cela les anophèles aient dû être exterminés. On a pu redouter que la guerre ramenant en France de nombreux paludéens, il ne s'y développât du paludisme. Or en cherchant les anophèles, on a constaté qu'ils sont extrêmement répandus en France et ils n'ont jamais dù être rares : cependant l'endémie a disparu. C'est qu'elle ne dépendait pas uniquement de la présence des anophèles, mais d'autres facteurs, comme les conditions d'habitabilité, de culture du sol, etc...

Pour expliquer des faits de ce genre et pour 
résoudre les problèmes pratiques de prophylaxie, RouBAUD en arrive à la conception générale qu'il appelle la méthode trophique, ou de nutrition protectrice, ou encore de prophylaxie trophique. Elle consiste à satisfaire les besoins de l'espèce convoyant le parasite redouté, en la détournant de l'homme ou de tel animal domestique. Il conçoit cette méthode comme plus facilement applicable dans les pays neufs pour l'activité humaine, où les équilibres fauniques n'ont pas encore acquis une solide stabilité par rapport à cette activité, comme dansles vieux pays, où tous les équilibres sont depuis longtemps établis. Dans les régions neuves, les transformations du milieu que l'homme accomplit ou provoque, les espèces qu'il y introduit, consciemment ou inconsciemment, crèent de nouveaux rapports.

Ainsi, au Sénégal, un termite, qui ravage les cultures d'arachides, n'est nullement un parasite spécifique de cette espèce ; en dehors de la zone des cultures, il s'attaque à des végétaux variés; sa localisation sur les graines d'arachides serait dûe, suivant Roubacd, à ce qu'il y trouve encore quelques réserves d'eau, alors que le sol environnant est complètement desséché. En maintenant une certaine humidité au sol, dans la période où le termite envahit les graines encore vertes, c'est-à-dire en satisfaisant à ses besoins, on le détournera de l'arachide ; ce qui sera plus aisé que de chercher à exterminer le termite lui-même. La sécheresse, dans certaines zones des pays tropicaux, serait, de même, la cause qui attirerait tant de mouches sur les yeux de l'homme 
et des animaux, où elles peuvent boire les larmes, ce serait par suite la cause indirecte des ophthalmies fréquentes et graves dans ces régions. D'où la suggestion de détourner les mouches des hommes en leur offrant de l'eau.

De mème, l'homme pourrait se protéger contre les Insectes piqueurs, en leur fournissant des proies qu'ils préfèrent. Le gros bétail ou les chevaux, par exemple, sont bien plus attaqués que l'homme, dans les bois, par les taons ou les glossines. Le porc est, d'après Roubaud, un animal qui offre les mêmes possibilités de nutrition que l'homme à beaucoup de parasites et spécialement à ceux qui vivent sur la peau, son épiderme étant nu comme celui de l'homme. Cette simple condition permet la réussite de la pénétration chez lui de beaucoup de parasites arrêtés par le revêtement pileux d'autres espèces. Inversement d'ailleurs, cette similitude a amené à l'homme des parasites qui, originairement, devaient être propres au porc ou à d'autres mammifères à peau nue.

Les Auchméromyies, ou vers des cases, actuellement adaptées à la race noire, ont dû, à l'origine, être des parasites de Mammifères à peau nue, comme les Phacochères ou les Oryctéropes, sur lesquels vivent, dans les mèmes conditions, les Chæromyies, et Roubaud a vu ces dernières se répandre dans les habitations humaines. De même, une tique, l'Ornithodorus moubata, agent de propagation de la Tickfever, semble, d'aprèsles observations faites au Congo belge, être naturellement en Afrique un parasite des Mammifères à peau nue, comme les Phacochères, 
dans le terrier desquels on la trouve et s'ètre portée vers l'homme, à mesure que son hôte naturel se raréfiait. Ed. et Ex. Sergent ont tait, dans le même ordre d'idées, en Algérie, une observation très intéressante sur l'Ckstre du mouton. Elle s'attaque aux yeux et aux narines des bergers, en Kabylie, produisant la myiase connue sous le nom de Thimni, (Tamné chez les Touaregs et retrouvée depuis en des régions très diverses. Or, la fréquence de l'affection chez l'homme varie en raison inverse de la densité ovine locale. L'homme n'est pas attaqué quand la population ovine suffit à assurer la ponte normale de l'œestre.

De même, la fréquence locale de la maladie du sommeil en Afrique n'est nullement en rapport avec celle des glossines; l'inverse mème est souvent vrai, ce que Roubaud explique par le fait que les hôtes normaux des glossines sont les gros mammifères et non l'homme. Elles pullulent dans les forèts où le gros gibier est abondant et ne s'y attaquent pas normalement à l'homme. Pour les déceler en un point, l'un des meilleurs moyens est d'exposer un ảne ou un cheval comme piège. Là où ces hôtes naturels manquent, les Glossines rares se rabattent sur l'homme; c'estsur ces points que leur's parasites se propageront le mieux à l'homme, en dépit de la rareté de la mouche.

En ce qui concerne la décroissance progressive et la disparition de l'endémie palustre en France et dans d'autres pays de l'Europe, alors que les Anophèles n'y sont nullement devenus rares, RouBAUD, à la suite d'études faites spécialement à ce sujet

M. Caullery. - Le Parasitisme 
dans le Marais vendéen et aux environs de Paris, explique ainsi les faits qui avaient été précédemment constatés par Ed. et Et. Sergent. En Vendée, - pays palustre, les anophèles pénètrent dans les maisons, d'où ils sont absents en Ile-de-France. Ce qui est typique, c'est leur présence dans les étables. Il y en a dans les deux cas. Mais ils pullulent dans les étables vendéennes, en raison de l'étendue des marais qui amène un formidable développement de larves. Il en résulte que les anophèles ne trouvant pas une population de bestiaux suffisante pour assurer leur alimentation envahissent les maisons, alors qu'aux environs de Paris le bétail leur suffit et qu'ils ne recherchent pas l'homme. Le bétail est done un écran protecteur pour l'homme et l'assainissement réalisé au xIx ${ }^{e}$ siècle se comprend aisément. La culture, le drainage, la suppression des marais a diminué la population anophélienne, à qui le bétail devenu plus nombreux a offert des proies suffisantes. L'homme s'est trouvé ainsi naturellement hors de son atteinte. Le problème de la prophylaxie se trouve ramené, suivant l'heureuse expression de RouBAUD, à un équilibre alimentaire dans la faune environnante. Il semble résulter, en outre, des observations faites aux environs de Paris, qu'adaptés à se nourrir sur le bétail, les anophèles cessent de s'attaquer à l'homme.

Ces idées très ingénieuses, et qui fournissent à tout le moins un programme précis d'expériences prophylactiques, ont, pour les questions qui sont envisagées ici, l'intérêt particulier d'avoir été suggérées par l'observation directe de la nature et surtout 
celui de faire apparaître la spécificité parasitaire comme une propriété relative. Elles cadrent bien avec la conception de l'hôte normal précédemment exposée. Il n'y a pas, entre les espèces, des rapports rigides préétablis, mais des équilibres plus ou moins stables et plus ou moins faciles à ébranler. En vertu de cette conception lamarckienne, le milieu reprend dans ce problème la place qui lui revient et les faits mêmes de spécificité absolue s'encadrent naturellement, comme des cas limites d'équilibres parfaitement stabilisés.

Par leur énorme extension et leur contact immédiat a rec le milieu naturel, les recherches dentomologie appliquée entreprises par le Bureau d'Entomologie des Etats-Unis ont fourni aussi à la question de la spécificité parasitaire des documents très importants, en ce qui concerne les Insectes ento. mophages. Il a été institué, en effet, comme nous l'avons vu, pour les Insectes les plus redoutables, des enquêtes d'une ampleur sans précédent et, comme les parasites de ces insectes ont apparu comme un des moyens de lutte les plus efficacas, le problème de la spécificité parasitaire s'est trouvé naturellement envisagé .

Pour chaque Insecte nuisible, le Bureau d'Entomologie collationne spécialement la liste et les mours de ses parasites, et des parasites de ces derniers ou hyperparasites. les premiers auxiliaires, les seconds adversaires de l'homme. En constituant ces dossiers, on saperçoit de la complexité des rapports qui commandent l'expansion naturelle des espèces. 
Prenons, par exemple, les études faites sur un charançon du cotonnier, Anthonomus grandis, qui s'est récemment étendu et a été énergiquement combattu. On avait reconnu déjà, en IgI3, l'existence de 54 espèces parasites de cet Insecte. Sur un tableau relatif à 25 de ces parasites (et dont on trouvera la reproduction dans le livre déjà cité de $\mathrm{P}$. MARGhal), on constate que, leur spécificité est très inégale, au moins en l'état présent de nos connaissances. Cinq d'entre eux sont connus pour parasiter respectivement de 18 à 12 espèces différentes; tandis que ro a utres ne sont encore connus absolument que sur Anthonomus grandis et 5 en même temps sur une seconde espère.

Dans des recherches relatives à deux Charançons de la Luzerne, Hrpera punctata et Phytonomus posticus, W. R. Thompson $(396)$ a constaté des faits qui plaident en faveur d'une spécificité parasitaire assez étroite. En effet, ces deux espèces vivent dans les mêmes champ̣s et dans des conditions très analogues. Or, sur neuf parasites du Phytonomus, deux seulement se retrouvent dans l'Hrpera.

Les renseignements les plus variés et les plus importants ont été obtenus dans les recherches faites à propos de Liparis dispar (Gypsy-moth) et de Liparis chrysorrhae (Brown-tail-moth), dont il a déjà été question. Les parasites européens de ces espèces, introduits volontairement aux Etats-Unis, s'y sont trouvés dans des conditions nouvelles. Considérons les Tachinaires ; leur spécificité est très variée. Certaines espèces n'ont été rencontrées jusqu'ici que dans Liparis dispar, tandis que Garcelia excisa est 
connu, en outre, sur 24 hôtes différents, et Compsilura concinna sur 51, 'Tachina laroarum, sur 39 .

Le cas de Parexorista chelonice offre un intérêt particulier. On trouve cette mouche à la fois en Amérique et en Europe, où elle se développe dans des insectes assez variés et en particulier dans Liparis chrysorrhcea. Or, la race américaine de la mouche n'attaque jamais la chenille de ce papillon ; on a reconnu qu'elle n'est pas immunisée contre les propriétés urticantes de la chenille. Il se trouve que lintroduction de la race européenne de Parexorista n'a pas été efticace, parce qu'il s'est produit une hybridation avec la race américaine et que les hybrides se comportent, vis-à-vis de la chenille, comme la race américaine et non comme la race européenne.

L'ensemble des faits qui précèdent montre qu'on ne peut considérer la spécificité réciproque des parasites et de leurs hôtes comme une propriété absolue et uniforme. Elle est évidemment une des caractéristiques fondamentales du parasitisme; mais elle est essentiellement relative el se présente à des degrés extrêmement variés. Il y a certainement beaucoup de cas où elle est très stricte, un parasite donné ne se rencontrant rigoureusement que dans une seule espèce d'hôtes. Mais il est non moins incontestable que beaucoup de parasites infestent, dans les conditions naturelles, plusieurs espèces différentes d'hôtes et parfois même un nombre assez considérable. La spécificité doit donc être considérée spécialement pour chaque forme parasite.

Il faut, en outre, distinguer entre la spécificité de 
fait et de principe. La première est celle qui nous fournit l'observation simple des faits naturels, la seconde celle qui résulte de l'expérimentation. La limitation d'un parasite sur un hôte unique dans la nature peut tenir simplement à ce que ne sont pas réalisées les conditions auxquelles il pénètrerait dans d'autres hôtes, mais non à ce qu'il ne serait pas capable de s'y développer. Nous avons cité plus haut des parasites qui sont localisés sur les Mammifères à peau nue et dont on a pu aisément infester des Mammifères à peau couverte de poils, à la simple condition de raser ceux-ci partiellement. Par contre, il existe réellement des parasites - surtout internes, - qui ne peuvent s'accommoder que du milieu intérieur d'une seule espèce, à laquelle ils sont adaptés. C'est le cas notamment de l'hématozoaire humain $\mathrm{du}$ paludisme, qu'on ne peut cultiver sur aucune autre espèce animale (I).

Même dans les cas où l'infestation expérimentale est obtenue sur plusieurs espèces, on constate, ainsi que nous l'avons vu plus haut pour divers exemples, qu'elle réussit mieux sur certaines espèces que sur d'autres. On est conduit à distinguer ainsi des hôtes normaux et des hôtes exceptionnels. C'est à cette distinction que se rattache la localisation habituelle étroite des parasites dans la nature, sur un hôte déterminé ou sur un petit nombre d'hôtes. D'ailleurs, toutes les fois quel'observation des faits natu-

I. Sauf cependant peut-être des singes anthropomorphes. Mesnil et Roubaud $(2 f I)$ ont en etfet réussi à infester un chimpanzé. On trouvera dans leur mémoire un exposé de la spécificité des divers Plasmodium. 
rels a lieu à une échelle suffisante, on rencontre des parasites égarés dans des hôtes exceptionnels. Cela est particulièrement vrai des parasites à migrations comme les Trématodes et les Cestodes. Beaucoup de cysticerques ou de métacercaires s'enkystent dans des hòtes qui ne seront jamais la proie d'un animal où pourra ètre atteint l'état adulte de ces parasites.

La spécificité résulte aussi, ainsi que l'indique fort bien Roubaud, d'une adaptation progressive des parasites et de leurs hôtes, d'un équilibre de plus en plus stable dans les faunes anciennement constituées. De nouveaux équilibres et de nouvelles associations parasitaires se réalisent quand une faune est perturbée par l'apport de formes nouvelles.

Tous ces problèmes ont leurs équivalents dans la bactériologie, où l'étude expérimentale des microbes pathogènes a permis de les aborder sur une vaste échelle. L'étude expérimentale de la syphilis, par exemple, telle qu'elle a été faite dans les quinze dernières années, a montré que cette infection, considérée autrelois comme rigoureusement spécifique de l'homme, pouvait ètre communiquée à de nombreuses espèces, mais qu'elle était loin d'y éveluer de même. Il va de soi que la plupart des données générales de la bactériologie s'appliquent au parasitisme et que c'est seulement pour des raisons d'opportunité que nous les avons laissées de côté ici.

L'ensemble des constatations précédentes nous conduit donc, en dernière analyse, à considérer la spécificité des parasites comme très réelle, mais d'ordre relatif et comme le résultat d'une évolution; elle 
dépend des conditions extrinsèques rencontrées dans le passé et le présent par les espèces en présence, nullement d'une harmonie préalable; il ne peut être question de voir dans les parasites des formes conçues spécialement par la Providence comme complément à la vie d'hôtes déterminés.

L'un des éléments importants du problème de la spécificité parasitaire réside dans les conditions d'accès des parasites à leur hôte et de pénétration à son intérieur. L'étude de ces conditions est donc un complément de la question précédente. Il va de soi qu'on ne peut passer en revue tous les modes de pénétration des parasites. Chaque espèce a le sien propre. Mais quelques exemples donneront une idée de la variété et de l'intérêt de ces processus et du rôle qu'ils peuvent jouer quant à la spécificité parasitaire.

C'est pour les parasites internes que la question existe surtout, quoique pour les externes la question d'accès soit également intér'essante. On peut distinguer deux grands modes d'infestation: l'infestation passive et l'infestation active de la part du parasite.

L'infestation passive a lieu, soit par ingestion de spores ou d'œuf's, soit par celle d'un hôte provisoire renfermant le parasite, soit par inoculation à la faveur d'une piqûre par un organisme vecteur. S'il y a ingestion d'œufs, de spores ou de kystes, le germe est généralement mis en liberté par action des sucs digestifs de l'hôte sur les enveloppes protectrices et 
cette action comporte une certaine spécificité qui a èté mise en évidence, par exemple, avec les Sporozoaires. Les spores de grégarines, ou de myxosporidies ne s'ouvrent que sous l'influence du suc gastrique de certains hòtes ou tout au moins s'ou. vrent mieux. Le germe mis en liberté doit pouvoir résister à l'action de ces sucs, et, là encore, il y a une spécificité généralement étroite. Entre la mise en liberté du germe ou de la larve ingérée et son arrivée à son siège définitif, oì se fera son évolution, se placent souvent des trajets compliqués.

L'inoculation directe dans le milieu intétieur de l'hòte est le mode de transmission le plus parfait. On peut en prendre comme exemple le parasite du paludisme (Plasmodium malarice). Il passe de l'homme au culicide (Anopheles) par succion, subit dans le moustique une évolution compliquée, qui se termine par la localisation des germes dans les glandes salivaires et la trompe; ces germes sont inoculés ensuite directement à l'homme. La plupart des Hémosporidies se transmettent d'une façon analogue par les diver's hồtes intermédiaires, moustiques, sangsues, etc...

Mais cette adaptation complète n'est pas toujours réalisée. Ainsi, pour la Filaria bancrofti, les larves qui ont évolué dans les Moustiques ne pénètrent pas dans la trompe, mais s'accumulent dans la lèvre inférieure de l'insecte. $\mathrm{Au}$ moment où celui-ci pique, elles sont simplement dėposées sur la peau et elles $\mathrm{y}$ tont effraction activement. Ici donc, il y a transport passif jusqu'à l'hôte et pénétration active à son intérieur. Les choses se passent de 
même dans un certain nombre de cas, où les Invertébrés hématophages sont des vecteurs de virus. Celui-ci est déposé par eux sur la peau avec la salive ou même avec les excréments, et pénètre ensuite,à la faveur d'une solution de continuité,excoriation ou piqùre de l'Insecte; ce serait là le mode de pénétration d'un certain nombre de microbes, comme le bacille pesteux, divers spirochètes, en particulier celui de la fièvre récurrente qui viendrait au contact de la peau surtout par l'écrasement du pou. On voit ainsi la variété des mécanismes que met en jeu la transmission des parasites par des hôtes intermédiaires.

Les voies et modes de pénétration des parasites ne comportant pas d'hôte intermédiaire sont parfois beaucoup moins simples que l'on ne le supposerait, ainsi que nous pourrons nous en rendre compte par quelques exemples. Celui de la sacculine est typique à cet égard et la réalité est tout à fait différente de ce que l'on pouvait supposer $a$ priori. Pour beaucoup de parasites internes d'Invertébrés, la voie de pénétration est inconnue. On ne sait pas comment arrivent dans leur hôte des formes comme Fecampia ou les Euniciens parasites des Annélides. On n'a pas observé la pénétration des Dicyémides dans le rein des Céphalopodes. L'un des groupes qui offre les faits les plus rariés et les plus inattendus est celui des Nématodes, dont les genres de vie saprophyte et parasite et les localisations dans les hôtes offrent une extrême diversité. Nous avons vu déjà ce que l'on sait sur les Filaires du sang. Il y a encore un certain nombre de ces 
parasites dont le mode de pénétration est inconnu. On ne sait pas davantage comment pénètrent des parasites, comme les strongles du rein du chien et de divers mammifères (Eustrongylus visceralis). Mais, mème pour les Nématodes intestinaux, qui semblent devoir pénétrer par simple ingestion et se dérelopper directement dans l'intestin, la réalité est parfois beaucoup plus complexe.

Tel estle cas de l'Ancylostomum duodenale, l'agent de l'anémie des mineurs. On a cru longtemps qu'il était ingéré, soit avec l'eau, soit avec des aliments souillés par les mains. Il résulte des recherches de Looss (305), confirmées de divers côtés, que ce ne doit pas être la voie la plus habituelle. Les œufs évacués avec les fèces se développent dans le milieu extérieur, pourvu que la température soit assez élevée (d'où la localisation de ce parasite dans les pays chauds et les mines); les larves pénètrent dans le corps de l'homme généralement à travers la peau. Looss a été amené à le constater sur lui-même accidentellement, dans des conditions où la contamination per os devait être exclue et il l'a méthodiquement vérifié. Des larves d'Ancylostome, déposées sur la peau humide, y pénètrent en quelques minutes; il l'a constaté notamment sur une jambe infestée une heure avant l'amputation.

Dans des expériences sur des chiens et des singes (avec Ancylostomum duodenale et $A$. caninum), les larves étant déposées sur la peau rasée, il a pu reconstituer toutes les phases de leur pénétration et leur trajet ultérieur. Elles produisent localement, en pénétranț, du prurit et de la rougeur et, à doses 
massives, un œdème temporaire. Elles passent dans les vaisseaux sanguins et lymphatiques, où une partie est détruite par phagocytose dans les ganglions lymphatiques. Par la voie veineuse, elles arrivent au cœur, de là passent au poumon, dont on peut, en quelques jours, provoquer des infestations massives. Du poumon,elles passent à la trachée, gagnent l'œsophage et se rendent enfin à l'intestin. Dans le milieu extérieur, ces larves sont très sensibles à la dessiccation; quelques minutes à sec suffisent à les tuer, ce qui se réalise le plus souvent sur les aliments. Sur la peau mouillée et surtout à la faveur de la sueur, elles trouvent des conditions favorables. Dans les galeries des mines, elles montent facilement sur les parois humides, d'où elles passent sur les mains des mineurs. Cet exemple est très significatif de la complexité qu'offre parfois le mécanisme de pénétration des parasites.

Le Strongyloides stercoralis suit un trajet semblable, ainsi probablement que d'autres Nématodes. LüHe rapporte, à propos des expériences de Looss, qu'à l'autopsie d'une panthère, il avait trouvé le poumon plein de Nématodes résultant vraisemblablement d une migration analogue.

L'Ascaris lumbricoides, ce parasite banal de l'intestin, a une histoire non moins compliquée, d'après des travaux récents. Stewart (3I 4 ), puis Ransom et Forstel ( 3 IO) (confirmés encore par Yoshida ( 3 I g) sur des rats, souris, porcelets, lapins et cobayes) ont montré que les larves, sortant d'œufs ingérés per os, ne se développent pas directement dans l'intestin, mais passent dans la circulation 
intestinale et accomplissent dès lors un circuit analogue à celui de l'Ancylostome, en passant en particulier par le poumon. En faisanl ingérer à des porcelets de deux semaines des doses massives d'œufs d'Ascaris lumbricoides, Ranson et F'oster ont déterminé, en huit jours, chez ces animaux, des pneumonies mortelles; le poumon se montrait, à l'autopsie, rempli de jeunes Ascaris, tandis que les témoins étaient bien portants. Au bout de dix jours, on trouve les vers dans la bouche et l'œsophage. Chez le rat et la souris, les choses commencent de même, mais l'infestation ne s'achève pas et s'arrète à la bouche. Le porc et l'homme sont les hôtes normaux; chez le mouton, qui doit être un hôte accidentel, on a obtenu l'infestation intestinale. Des expériences de ce genre montrent l'élasticité de la notion de spécificité parasitaire .

Elles indiquent, en outre,combien de découvertes intéressantes restent à faire dans le domaine du parasitisme, relativement aux conditions de pénétration dans l'hôte.

De l'histoire de l'Ancylostome, on rapprochera naturellemeut celle des Schistosomum (Bilharzia) précédemment résumée et où le cercaire passe aussi par la peau.

Les larves de mouches, qui offrent une variété con . sidérable dans leur éthologie, depuis le saprophytisme jusqu'au parasitisme strict, montrent aussi, dans les conditions d'accès à l'hôte, des faits extrêmement instructifs.

Les Tachinaires, dont les larves entomophages jouent un si grand rôle, comme il a déjà été dit, par- 
viennent à l'hôte de façons extrêmement diverses que Townsend $(398)$ a étudiées et qu'il classe de la façon suivante.

$I^{\circ}$ Ponte des reufs sur des feuilles, où ils sont ingérés par l'hôte. - La larve éclôt dans le tube digestif de celui-ci et passe dans la cavité générale où elle se développera dans le tissu adipeux. Les œufs de ces espèces sont petits, foncés, et n'éclosent que sous l'influence du liquide intestinal de l'hôte (ex: Crossocosmia sericaria parasite du ver à soie ; Blepharipoda scutellata parasite de Liparis dispar, etc.

$2^{\circ}$ Ponte des oufs sur l'hôte. - La larve pondue, par exemple sur une chenille jeune, y éclôt plus ou moins vite et pénètre à l'intérieur. A son dernier stade larvaire, elle perfore la paroi, de dedans en dehors, pour se ménager un orifice respiratoire. Ce mode est le plus anciennement connu (ex.: Thrixion halidayanum étudié par Panter, Parexorista chelonice parasite de Liparis chrysorrhaa).

$3^{\circ}$ Ponte de larves écloses, déposées sur la peau de l'hôte (Dexiida).

$4^{\circ}$ I'onte de larves sous la peau de l'hôte. - La femelle, à l'aide d'une tarière, pique la chenille et introduit la larve sous le tégument (ex.: Dexodes nigripes, Compsilura concinnata, parasites de Liparis chrysorrhcea et L. dispar).

$5^{\circ}$ Ponte de larves sur des feuilles ou des liges. Cas d'Eupeleteria magnicornis, qui dépose ses larves sur des rameaux, où elle a reconnu (probablement par l'odorat) la présence de chenilles et sur le trajet de celles-ci pour retourner au nid. La 
larve s'accroche à la chenille au passage et $\mathrm{y}$ pénètre (I).

Dans le détail, on constate de curieuses particularités adaptatives des œufs ou des larves des Tachinaires, en rapport a vec ces diverses conditions.

Je signale ainsi le cas de Pollenia rudis, très bien étudié par Kerrur (374). Ici, l'œul' est pondu sur le sol. La larve, après l'éclosion, pénètre dans un lombric (All lobophora chlorotica) par les orifices des vésicules séminales, dans lesquelles elle passe l'hiver et le printemps. Au mois de mai, elle gagne, en creusant une galerie dans les tissus de l'hôte, l'extrémité antérieure de celui-ci, y déterminant une perforation, par où sort son extrémité postérieure avec les orifices respiratoires.

Les mouches à larves parasitesdes Vertébrés (myiases) offrent des faits multiples et des plus intéressants. Certaines sont plutôt saprophytes que parasites, vivant dans les ulcérations, sans doute aux dépens des bactéries qui s'y cultivent. Elles montrent les débuts de l'adaptation au parasitisme. Certaines de ces larves ne sont nullement spécifiques, d'autres tendent à se spécialiser en produisant des myiases très définies ; telle Pycnosoma bezzianum qui pond ses œufs sur les poils des Bovidés et Equidés; la larve s'enfonce ensuite dans la peau et y détermine des ulcères; jamais la mouche ne pond sur des ulcè-

r. Les Nyctéribies, qui vivent sur les chauves-souris, pondent aussi des larves prètes à s'empuper au voisinage des Roussettes, sur des branches, mais non sur l'animal luimème,comme l'ont décrit Rodhain et BequaERT (386) pour C.yclopodia greeffi. 
res déjà formés.Telles aussi Lucilia argrrocephala, L. sericata .

Certaines espèces ont des larves hématophages, vivant au contact de l'hôte et le rejoignant,de façon intermitiente, pour lui sucer le sang. C'est le cas des Auchméromyies, bien étudié par Roubaud $(389$ ). La larve, ou ver des cases, est liée biologiquement, comme il a été dit déjà, à la race noire; l'espèce ne se maintient que chez les peuplades sédentaires, couchant directement sur le sol des cases. La larve, inerte le jour, sort de terre la nuit, pour aller sucer le sang des dormeurs. On ne la trouve pas chez les populations nomades. Les Chœromyies des terriers de Phacochère et d'Oryctérope sont adaptées de même à ces animaux, qui ont la peau nue comme l'homme. Et il existe une série de mouches vivant de la même façon dans les nids des oiseaux aux dépens des jeunes, Phormia sordida,P. (Protocalliphora) azurea, Passeromyia heterochceta.

D'autres mouches productrices de myiases pondent sur le sol et les larves atteignent activement l'hôte dans lequel elles pénètrent. Telle est Cordylóbia anthropophaga, dont la larve, ou ver du Cayor (1), produit dans l'épaisseur de la peau de l'hôte (rat, chien et accessoirement l'homme), des tumeurs furonculeuses munies d'un orifice permanent, par où elles respirent.

Certaines atteignent l'hôte d'une façon indirecte très curieuse en étant véhiculées par un autre

I. La larve de Lund, qui vit dans des conditions analogues, appartient à une autre espèce, Cordylobia (Stasisia) rodhaini 
insecte. C'est le cas de Dermatobia hominis, dont la larve ou oer macaque, produit dans l'Amérique du Sud une myiase cutanée. Elle va pondre ses oufs sur des Insectes (Stomoxes, et surtout un Culicide, Janthinosoma lutzi), au moment où ils piquent des chevaux. L'insecte et particulièrement le Janthinosoma est le vecteur par lequel la larve arrive sur l'homme(v. 38I).

D'autres pondent directement sur l'hôte, en particulier l'œstre du mouton (CEstrus ovis), qui pond au vol sur les narines ou l'œil et évolue dans les fosses nasales (I), produisant le faux tournis. L'œstre du cheval (Gastrophilus equi) dépose ses œufs sur les poils, dans des points où le cheval peut se lécher. Le choc produit par les lèvres. lors du léchage, détermine l'ouverture de l'œuf et la mise en liberté de la larve, qui, arrivée dans la bouche de l'hôte, s'enfonce dans l'épiderme, comme l'a montré RouBAUD ( $3 g I)$ et chemine, parl'cesophage, jusqu'à l'estomac, où elle effectue sa croissance, fixée à la paroi. Elle est rejetée au moment de la pupaison, avec le crottin. L'œstre du bœuf (Hrpoderma bovis), qui produit des tumeurs sous-cutanées, placées sur le dos, au voisinage de la colonne vertébrale, ne s'y développe pas sur place, mais pénètre dans les mêmes conditions que l'œstre du cheval, et chemine

x. Diverses mouches se développent ainsi dans les cavités naso-pharyngiennes: Lucilia bufonivora, dans celles de Batraciens (Crapaud, Salamandre), Chrysomyia macellaria sur l'homme (à Buenos-Ayres, on a observé un cas de myiase probablement due à cette mouche, dans lequel on a extrait 265 larves). 
le long de l'œsophage dans la paroi, puis suit le diaphragme, traverse la colonne vertébrale et finalement arrive à la peau, sur le dos, où elle détermine une tumeur sous-cutanée. La larve mûre sortira à la faveur de l'ulcération de la tumeur. Certains oiseaux (pies, sansonnets, bergeronnettes) énucléent très fréquemment ces larves pour les dévorer en débridant la tumeur.

Ces divers exemples montrent combien la localisation définitive du parasite est insuffisante pour renseigner, par elle-même, sur la façon dont se fait l'infestation.

Une autre catégorie de faits, relativement au mode de pénétration des parasites, est constituée par les cas où l'infestation est héréditaire et transmise par l'œuf. On en connait actuellement un certain nombre d'exemples relatifs à des Protozoaires ou des Bactéries et Protophytes. Le cas le plus classique est celui des Microsporidies et en particulier de la Pêbrine du ver à soie (Nosema bombrcis). C'est en ayant reconnu la contamination de l'œuf par les corpuscules que Pasteur a imaginé la méthode du grainage, qui permet d'établir des élevages sains. Le mode de contamination direct est la voie buccale, le ver mangeant des feuilles souillées par des excréments porteurs des spores du parasite. Celles-ci éclosent dans son tube digestif et la microsporidie pénètre dans l'épithélium intestinal, puis dans les divers tissus qu'elle envahit, atteignant finalement l'ovaire. Il en est de même très probablement de beaucoup d'autres microsporidies; Mesnil par exemple a constaté la présence de spores de $\mathrm{Non}$. 
sema incurvata dans les oufs de Daphnia obtusa.

Les Piroplasmes se transmettent aussi dans les tiques, d'une génération à l'autre, par l'infestation de l'œut. Theiler a même constaté quel'infection pouvait persister sans apport de parasites nouveaux pendant deux générations. C'est grâce à cette transmission héréditaire que se propage la piroplasmose bovine ; car certaines tiques (Boophilus annulatus, $B$. decoloratus) ne quittent plus le breuf sur lequel elles se sont fixées à l'état de larve et où elles se sont inlectées. La transmission ne peut donc se faire que par les tiques filles; et on a d'ailleur's trouvé les Piroplasmes dans les œufs. La même transmission héréditaire a lieu, pour la piroplasmose canine par Rhipicephalus sanguineus. Les tiques, et en particulier les Argas, transmettent héréditairement aussi des spirochètes (I).

Brumrt a annoncé de même la transmission héréditaire de Trypanosoma inopinatum de la grenouille verte, dans la sangsue, hôte intermédiaire (Helobdella algira). Les sangsues, nées d'une mère infestée et ne l'ayant jamais été elles-mêmes, ont des trypanosomes dans la trompe et les cæcums gastriques. Mais la présence dans l'œuf lui-même n'a pas été constatée.

Enfin la transmission héréditaire par l'œuf joue un rôle capital dans des infections qui ont une portée considérable, comme nous le verrons; il s'agit des levures qui existent d'une façon constante dans

I. Le spirochète de la syphilis se transmet aussı neréditairement. 
divers groupes d'Insectes et notamment chez les $\mathrm{Pu}$ cerons (corps verts, pseudova, pseudovitellus). Nous nous bornons à les mentionner maintenant, et les étudierons à propos de la symbiose.

N.-B. - Les idées de Roubaud sur la prophylaxie trophique (p. 223) se sont trouvées confirmées dans un important travail, paru pendant l'impression de ce volume et dù à C. Wesenberg-Lund (Contr. to the biology of the danish Culicidae. Copenhague, Dansk. Vid. Selsk. Skr., I 92I).:Cet auteur est arrivé, en effet, dans l'ignorance complète des recherches de Roubaud, à peu près exactement aux mêmes conclusions en ce qui concerne la biologie des Anophèles (adaptation secondaire au bétail) et la disparition du paludisme au Danemark. 


\section{CHAPITRE $\mathrm{X}$}

\section{ACTIONS RÉCIPROQUES DU PARASITE}

\section{ET DE L'HOTE}

Sommare. - Parasites et corps étrangers. - Membranes anhystes ou cellulaires tendant à isoler les parasites. Réactions d'ordre phagocylaire. - Parasites normaux et anormaux. - Produits solubles. Antiferments élaborés par les parasites intestinaux. - Toxines parasitaires. Eosinophilie et anti-corps spécifiques chez l'hôte.-Action du parasite sur le métabolisme général de l'hôte (cas de la sacculine).

Castration parasitaire. - Exemples divers chez les animaux et les végétaux.

Cas spéciaux de réaction de l'hôte à un parasite (ver du Cayor, Glochidium. - Sporozoaires divers, etc.).

Les galles aninales (thrlacies) et végétales (cécidies). Essais de reproduction expérimentale des cécidies).

L'action des parasites sur leurs hôtes est un problème extrêmement vaste, qui comprend en somme toutes les maladies infectieuses, avec les questions qu'elles soulèvent, comme en particulier l'immunité. Il ne peut être question de les traiter ici. Elles ont leur place d'ailleurs dans d'autres sections de l'Encyclopédie. En se bornant aux parasites non bactériens, il est évident que cette action dépend 
beaucoup des circonstances du parasitisme. Beaucoup de parasites, pratiquement inoffensifs en petit nombre, deviennent redoutables et mèmes mortels en cas d'infestation massive. Ainsi quelques trichines n'occasionnent que des troubles restreints, tandis qu'une ingestion de ces Nématodes en grand nombre détermine une inaladie très rapidement mortelle. On pourrait citer des exemples analogues pour les Trématodes. Le hérisson, par exemple, en. renferme qui, dans les conaitions ordinaires, sont inoffensifs, Distomum leptosomum, D. spinulosum, et dont les sporocystes vivent dans Helix hortensis et $H$. nemoralis. Mais, en nourrissant des hérissons avec des Helix infestés, Hoffmann (2 78 ) a déterminé chez eux une infestation massive et mortelle. ('haque parasite détermine dans des conditions de ce genre, des accidents spécifiques que nous laissons aussi de côté.

En considérant les infestations qui ne sont pas aiguës, on peut dire qu'un parasite, particulièrement un parasite interne, une fois établi sur son hôte, forme avec lui un système fonctionnel en équilibre, qui s'oppose à l'ensemble du milieu extérieur. C'est ce que Giard (4I5) exprimait par le terme de complexe hétérophysairé, chacun des deux organismes étant un complexe homophysaire. L'équilibre ainsi conçu résulte d'actions et réactions mutuelles, dont nous allons examiner les principales.

$$
*^{*} *
$$

Le parasite étant avant tout un corps etranger 
introduit accidentellement dans l'hôte, on peut s'attendre à voir celui-ci tendre à l'éliminer, ou au moins à l'isoler du milieu intérieur par une barrière anhyste ou cellulaire, comme cela a lieu autour des corps inertes. On peut en effet citer un certain nombre d'exemples de cet ordre. Les larves des trichines, dans les muscles, sont entourées par une membrane kystique généralement calcifiée. La production des perles, chez les Mollusques margaritigènes, semble ètre, au moins dans une large mesure, une réaction du même ordre, car, au centre de la plupart des perles, on trouve un parasite, le plus souvent une larve de Trématode ou de Cestode. L'épithélium palléal, à son contact, a sécrété une couche de nacre qui l'a isolée. Cette réaction se continue par la formation de couches concentriques, dont l'accumulation constitue la perle, perle de nacre si le processus reste extérieur, au contact de la coquille, perle fine, si le processus s'accomplit dans la masse viscérale du mollusque. L'origine parasitaire des perles reconnue en 1852 par de Ficippi chez les Anodontes, a été l'objet assez récemment de travaux nombreux, notamment de Seurat ( 185 ) à Tahiti, de Herduan et Hornell, à Ceylan, de L. Jameson ( $I$ フ 7 ), sur les moules de nos côtes (Billiers, Morbihan), de R. Dubois, Grard, etc...

Lá production d'une membrane dienveloppe cellulaire autour du parasite est un phénomène asseż rare, au moins dans le cas des parasites normaux; alors que des amobocytes s'accumulent très rapidement autour des corps étrangers inertes, la plupart des parasites normaux vivant dans le miliew. 
intérieur, restent indemnes. Ainsi, les grégarines cœlomiques, comme l'a remarqué Cúńtot (221), ne sont jamais enveloppées d'amœbocytes, au moins tant qu'elles sont à l'état végétatif.

L'enveloppement se produit dès qu'elles s'enkystent, ou même se préparent à l'enkystement. C'est ce que LÉGER (228) a mis en évidence avec une parfaite netteté pour Lithocystis schneideri,grégarine vivant dans le colome d'un oursin, Echinocardium cordatum. Autour deskystes, les a mœbocytes forment, par contre, des amas énormes, noirâtres (I). Les métacercaires de Trématodes, enkystés par exemple dans des Annélides, sont aussi entourés d'un épais manteau d'amœbocytes. De même les Nématodes enkystés dans le cœlome des Lombrics, les larves de Pollenia rudis, en hiver, pendant leur période d'inertie, sont également enveloppées. Mais quand ces divers parasites sont à l'état d'activité, ils ne sont pas attaqués. Il semble que les parasites normaux possèdent une immunité vis-à-vis des amœbocytes ou phagocytes. C'est ce qui a lieu, en particulier, d'une façon générale, pour les parasites entomophages. Mais, avec des parasites anormaux, il semble en ètre autrement. Timberlake ( $I 88$ ), par exemple, fait pondre, dans Liparis chrysorrhcea, un Hyménoptère Limnerium validum, qui normalement para-

I. Nous avons, Mesnil et moi-même, constaté cependant l'enveloppement par des phagocytes d'une grégarine cœlomique du Dodecaceria concharum (forme B), Gonospora longissima). Mais il est possible que les cas où nous avons observé ce phénomène étaient le prélude de l'enkystement de cette grégarine. 
site Hrphantria cunea. Or, malgré que des œufs très nombreux aient été pondus, il n'a trouvé que très peu de larves dans les chenilles. La plupart étaient détruites ou fortement attaquées par des phagocytes. W.-R. Thompson $(396)$ a constaté des faits de
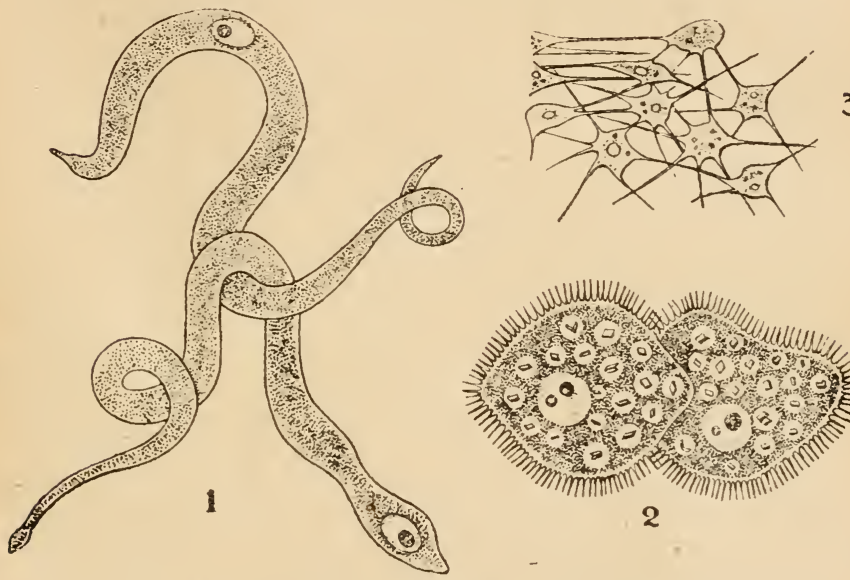

Fig. 41. - Lithocystis schneideri: I Stade de grégarine libre et mobile (deux individus enlacés) et sans revêtement phagocytaire, dans le liquide colomique de l'Oursin (Echinocardium cordatum) $;-{ }_{2}$ Prélude de l'enkystement de deux individus accouplés et contractés et déjà recouverts d'un manchon de phagocytes; - 3 quelques-uns de ces phagocytes à un fort grossissement (d'après LÉGER).

même ordre avec une Tachinaire, normalement parasite de Liparis dispar, Sturmia scutellata. Cette mouche pond sur des feuilles ses œufs, qui sont ensuite ingérés par la chenille et éclosent dans le tube digestif, d'où les larves passent dans le cœlome. Thompson a fait avaler ces oufs de Stur- 
mia, sur des feuilles, à diverses chenilles; les larves se sont développées dans des Lasiocampidce, mais non dans les chenilles de Vanessa urtice et Parorgyia antiqua, dans lesquelles on les a retrouvées phagocytées. Malheureusement, dans ces divers cas, on n'a pas pu préciser si les phagocytes avaient attaqué des larves saines, ou seulement des larves mortes ou déjà fortement atteintes dans leur vitalité.

Au total, il semble que les parasites normaux ne provoquent pas, d'une manıère générale, de réaction phagocy taire, ou qu'ils inhibent celle-ci par des secré tions appropriées, que ne possèdent pas les parasites anormaux. L'absence de réaction aux parasites normaux est donc sans doute le résultat d'une adaptation d'ordre sécrétoire. C'est par un mécanisme du même ordre que l'on peut concevoir la possibilité, pour le parasite, de subsister dans l'intestin ou le milieu intérieur de l'hôte. Il doit pouvoir résister aux ferments ou autres corps actifs de ce milieu. Le problème a été abordé pour les parasites intestinaux qui ne sont pas digérés. D'après Dastre et Stassano $(x \supset 3)$, les tænias résisteraient par la production d'une antikinase, neutralisant la kinase intestinale et par suite empêchant indirectement l'action de la trypsine. D'après Weinland ( 194 ), la substance produite par le parasite serait une antitrypsine.

L'action apparente de beaucoup de parasites sur leur hòte est faible, extrèmement faible même, quand 
on songe à la masse énorme de beaucoup de ces parasites par rapport à l'hôte et à la part qu'ils doivent prélever sur la nutrition de celui-ci.

Souvent ils détournent des réserves : ainsi les Entomophages n'empêchent pas les chenilles d'évoluer et de se chrysalider, mais elles n'ont plus les maté. riaux disponibles pour effectuer leur métamorphose-

C'est par des substances toxiques que l'action de beaucoup de parasites se fait surtout sentir.La réaction fébrile dans le paludisme, par ex emple, se produit quand, après chaque phase de multiplication, les toxines élaborées sont mises en liberté dans le sang, par rupture des globules où a lieu la schizogonie.

L'A scaris megalocephala renferme, dans le liquide péri-intestinal, une substance toxique, qui provoque, au contact, une irritation vive de la cornée et de la muqueuse nasopharyngienne et il est arrivé souvent que des zoologistes, après avoir manié ces ascaris, en aient éprouvé les effets. Weinberg (rg3) a montré, en recueillantle liquide péri-intestinal aseptiquement et l'injectant à des cobayes, quec'est bien l'agent irritant et qu'il est très toxique (une dose de o mmc., 5 tuerapidement un cobaye).L'instillation de ce liquide dans l'œil du cheval provoque une réaction violente, mais non constante. D'après les recherches de WeInBERG, les chevaux insensibles sont en général porteurs d'un grand nombre de ces vers. Il y a donc lieu de penser qu'il s'établit une immunisation contre cette toxine ascaridienne. D'ailleurs les chevaux fortement infestés sont souvent amaigris et leur sérum renferme des anticorps spécifiques (I).

I. La sarcosporidie du mouton renferme une toxine, 1a 
L'Ancylostome duodénal provoque, comme on sait, une anémie pernicieuse et souvent mortelle, mais dont le mécanisme n'est pas établi. Elle a été longtemps attribuée aux hémorragies provoquées par le ver et L. Läb et A. J . Smith (I J9) ont montré, que ces vers secrètent une substance anti-coagulante paraissant en rapport avec une nutrition hémophage. Cependant, d'après Looss $(3 \circ 6)$ ils se nourrissent non de sang, mais de débris de la muqueuse et les hémorragies ont un caractère accidentel. L'action de ces vers serait duc à une toxine. L'anémie provoquée par le Bothriocéphale serait aussi le résultat de l'action d'une toxine, mais qui ne semble être mise en liberté et par suite agissante, que quand le ver est malade ou mort, et qu'elle peut alors diffuser.

Dans ces divers cas, la réaction de l'hôte à ces toxines se manifeste par des altérations du sang. La plupart de ces parasites déterminent en effet une éosinophilie plus ou moins intense, constatée chez les porteurs d'échinocoques, d'ancylostomes, de filaires, de trichines, de myiases dermiques, etc...On provoque d'ailleurs cette éosinophilie en injectant à un cobaye des extraits de ces divers parasites.

On a pu aussi déceler, dans le sérum des hôtes de ces parasites, des anti-corps spécifiques (lysines, précipitines, anti-corps anaphylactiques) et l'existence deces anticorps peut devenir un moyen de diagnostic, comme l'a montré Weinberg ( 192$)$, dans le cas de l'échinocoque. Il faut toutefois tenir compte,

sarcocystine, isolée et étudiée par LAverax et MesniL $(I J 8)$; elle est très active sur le lapin qu'elle tue à très petite dose, mais elle n'agit qu'à peine sur le mouton. 
dans tous ces cas, de l'action possible de bactéries introduites par les parasites, à la faveur des lésions qu'ils déterminent et se mettre à l'abri de cette cause d'erreur.

Certains parasites ont une action profonde sur la nutrition de l'hôte, en modifiant d'une manière notable son métabolisme. Wheeler (I 97) a signalé un fait très curieux de ce genre, chez une fourmi américaine Pheidole commutata. Les ouvrières parasitées pardes Mermis sonthypertrophiées ; l'abdomen a un volume plus de huit fois supérieur à la normale; la tête, le thorax et tous les organes sont aussi hypertrophiés. Ces individus sont désignés par WhEeler sous le nom de macroërgates. Cette hypertrophie est évidemmentle résultat d'une surcroissance larvaire, amenée par une surnutrition, sous l'influence du parasite. Les larves parasitées doivent être nourries d'une façon appropriée par les ouvrières.

La sacculine amène aussi une modification sensible du métabolisme du crabe qu'elle infeste, ainsi qu'il résulte des recherches de G. Sмітн ( 18 7). La sacculine élabore, dans son système de racines, aux dépens du sang du crabe, des substances de réserve, qui, chez les crabes femelles, se seraient déposées dans les ovaires. Le chimisme du sang diftère notablement dans les deux sexes des crabes. Chez Carcinus manas, le sang normal est sensiblement incolore, sauf à l'approche de la mue où il est rosé. Chez la femelle, il est jaune à l'approche de la maturité de l'ovaire ; 
ces deux teintes tiennent respectivement à la présence dans ce sang de tétronérythrine et de lutéine. La teneur du sang en graisse est 0,198 o/o chez les femelles à sang jaune, de 0,086 o/o chez les mâles à sang rose et de $0,0590 / 0$ chez les mâles à sang incolore. Comme le sang, le foie présente des variations considérables et parallèles de la teneur en graisse, qui varie de 4 à $120 / 0$, la proportion la plus considérable se trouvant chezles femelles où l'ovaire est voisin de la maturité. Or, les crabes des deux sexes, porteurs de sacculine, ont toujours un foie très riche en graisse et leur sang est rosé ou jaune pâle. Le sang des mâles sacculinés renferme un fort excès de graisse par rapport à la normale et se rapproche de la composition de celui de la femelle. Ainsi, la sacculine détermine chez son hôte, quel qu'en soit le sexe, la réalisation du métabolisme caractéristique des femelles (I). Ces modifications ont sur le crabe un retentissement morphologique, qui a été mis en évidence par Grand (4I5) et considéré par lui comme un effet très fréquent du parasitisme, sous le nom de castration parasitaire.

Il y a, en réalité, dans la castration parasitaire, telie que la conçoit GiARd, deux ordres de faits : d'une part la castration proprement dite, c'est-à-dire une atrophie plus ou moins complète des glandes génitales, sous l'influence du parasite; d'autre part, une altération corrélative des caractères sexuels

I. La sacculine exerce en somme sur le métabolisme de l'hôte une action équivalente à l'ovaire et détournevers elle même les substances assimilées. Kailin (3J4) a proposé le nom de nutrition déviatrice pour les faits de ce genre, très répandus chez des Insectes entomophages. 
secondaires, amenant la production d'individus d'allure plus ou moins intersexuelle.

Giard a distingué la castration directe et la castration indirecte. Dans la première, le parasite se développe dans les organes génitaux eux-mêmes, en se substituant à eux; ainsi une CEstride, Cuterebra einasculator, se développe dans le testicule d'un écureuil (Tamias listeri), un distome (Distomum megastomum) détruit les glandes génitales d'un crabe (Portunus depurator); beaucoup de sporocystes et de rédies de Trématodes envahissent et détruisent les glandes hermaphrodites ou unisexuées des mollusques qu'ils infestent, Pulmonés ou Prosobranches. Amphiura squamata est stérilisée par l'orthonectide (Rhopalura ophiocomce) qu'elle héberge; il se développe au voisinage immédiat des ovaires, dont le développement est arrêté, mais les testicules de cette espèce hermaphrodite se développent. La sacculine enraye le développement des glandes génitales des crabes, ovaires ou testicules, mais la castration n'est pas toujours totale, en particulier pour le mâle.

Beaucoup plus fréquente est la castration parasitaire indirecte, résultant d'une action à distance. On l'observe très généralement sur les Crustacés porteur's d'Epicarides, comme l'ont signalé les premiers Giard et Bonnier. J'ai eu moi-même (3 2 g) l'occasion d'enobserver un exemple très significàtif' sur des $\mathrm{Pel}$ toguster curoatus fixés sur des Pagures et parasités par un Cryptoniscien, Liriopsis pygmaea. Pendantla croissance, ce parasite se nourrit aux dépens de son hôte par succion; à l'état adulte il ne se nourrit plus. Or, chez les Peltogaster porteur d'un Liriopsis, 
les oocytes, dans l'ovaire, sont toujours en voie de dégénérescence et comme vidés. La cause en est évidemment dans ce que l'Epicaride détourne vers lui les substances dont s'édifierait l'ovaire du Rhizocéphale: mais cet état cesse quand le parasite cesse lui-même de se nourrir. On trouve assez aisément des Peltogaster qui ont porté précédemment un Liriopsis, ce qu'on reconnaît à l'orifice qui persiste ensuite dans le manteau. Or, chez ces individus, l'ovaire est régénéré et mûrit régulièrement ses oocytes. Leur degénérescence était donc bien due à la déviation de la nutrition provoquée par l'Epicaride.

La castration parasitaire se retrouve chez les Végétaux : soit la castration directe par développement de champignons dans les organes floraux; soit, ce qui est plus intéressant, la castration indirecte, par action, à distance, de parasites divers. Ces parasites déterminent des troubles de nutrition qui agissent sur l'ensemble de la plante et amènent la virescence des pièces florales ou la transformation des étamines et du pistil en pétales. Molliard $(209)$ a signalé un certain nombre de cas de ce genre : Knautia aroensis attaquée par Peronospora violacea; Matricaria inodora attaquée par Peronosporaradii; Viola s rlvatica sous l'influence de Puccinia viola ; diverses Ombellifères et Crucifères, sous l'influence d'Acariens. Chez Primula officinalis, le pistil et les étamines deviennent pétaloïdes, sous l'action des Dématiées envahissant les radicules. De même, Scabiosa columbaria, sur des pieds dont les racines portent des galles de Nématodes (Helerodera). Molliard 
émet l'hypothèse que la plupart des fleurs doubles, sinon toutes, seraient la conséquence d'associations parasitaires. Or c'est là une castration typique.

Il ramène à la même interprétation une transformation de l'inflorescence que GIARD $I \supset 4$ a vait signalée chez une Composée, Pulicariadrsenterica et au sujet delaquelle il avait émis un certain nombre de suggestions très ingénieuses. En certaines stations et pendant une série d'années, on voit des pieds chez lesquelles les fleur's périphériques des capitules ont perdu la forme ligulée et sont tubuleuses comme celles du centre; elles présentent en outre diverses anoraalies: en particulier les fleurs de ces plantes ont une forte tendance à l'unisexualité. Or, Moldiard 2 I $O$ a constaté que, chez les Pulicaires présentantces anomalies, les racines étaient attaquées par un Charançon (Baris analis), et c'est à l'action exercée par ce parasite qu'il faut attribuer les modifications des inflorescences. En effet,les pieds ainsi modifiés et que l'on a débarrassés de leurs Charançons produisent ultérieurement des inflorescences normales. Moldiard a, du reste, eu l'occasion de trouver des modifications analogues, toujours liées à la présence de parasites: un Sinapis arvensis, à fleurs virescentes, présentait des larves de Curculionides dans la région du collet; des Trifolium repens, également virescents, présentaient des larves de Curculionides (Hrlastinus obscurus) dans les tiges, où ces larves creusaient de longues galeries; on n'en trouve pas dans les pieds normaux. Des Primula officinalis et des Séneçons ont fourni des faits de même ordre. En particulier des Senecio jacobœa, dont l'allure générale était complè-

II. Caullerr. - Le Parasitisme 
tement modifiée et dont les inflorescences étaient transformées en boules compactes, sans ligules périphériques, avaient la souche minée par des larves de Lixus.

Voyons maintenant les altérations des caractères sexuels secondaires, corrélatives de la castration parasitaire. Le premier de ces faits a été signalé par J. PÉrez (I 82), sur des Hyménoptères du genre Andrena parasités par des Stylops. Chacun des deux sexes perd plus ou moins ses caractères distinctif́s et tend à acquérir ceux du sexe opposé. En même temps, chez la femelle, il y a atrophie des ovaires, dont les oocytes n'arrivent plus à maturité. Chez le mâle, e'est seulement le testịcule situé du côté où siège le parasite qui est altéré ; l'autre reste fonctionnel. Il est à noter que ces modifications n'ont pas été retrouvées en Amérique sur les mêmes associations parasitaires.

Le cas le plus frappant, découvert par Giard (4I5) el réétudié soigneusement par G. Sмгтн (I 8 J), est celui des crabes parasités par des sacculines. La femelle ne subit guère de modifications, tandis que le mâle se rapproche du type femelle. Le degré de ces modifications est très variable : il peut aller jusqu'à un point où le diagnostic du sexe devient très difficile. Elles portent sur la forme de l'abdomen, sur l'indépendance de ses segments, sur les appendices abdominaux et aussi parfois sur les pinces.

Prenons-en deux exemples: Carcinus manas, et Inachus scorpio (mauritanicus).

Chez Carcinus manas (le Crabe enragé de nos plages), l'abdomen de la femelle est large etarrondi 
et tous les segments sont bien distincts ; l'abdomen du mâle est pointu et de forme triangulaire; de plus les segments III, IV et V sont soudés en un seul. Or, chez les màles sacculinés, ces segments redeviennent indépendants en même temps que l'abdomen s'élargit et s'arrondit (fig. 42).
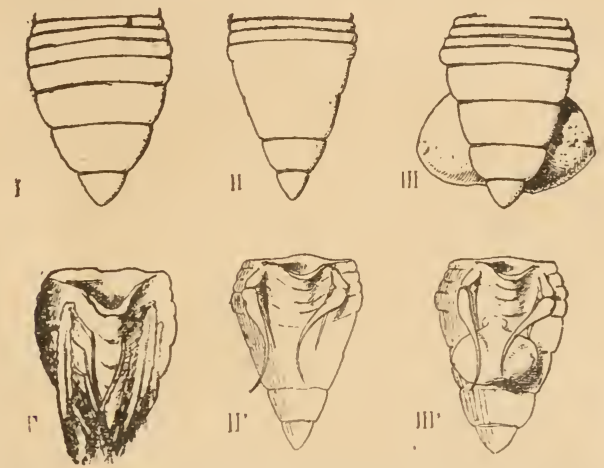

Fig. 42. - Modifications de l'abdomen des Carcinus monas (face dorsale et ventrale) sous l'influence de la sacculine (d'après Giard): I-I'; L'abdomen de la femelle normale, II-II' Id. mâle normal; III-III' Id., mâle sacculiné.

Chez Inachus scorpio, que G. Smith a spéciale-ment étudié, sur des matériaux considérables récoltés à Naples, les faits sont encore plus frappants. La différence de forme de l'abdomen daus les deux sexes est très considérable, comme c'est lá règle chez les Oxyrhynques. Celui du mâle est rectangulaire et très étroit, celui de la femelle large et arrondi. Or, on trouve des mâles sacculinés dont l'abdomen a pris la forme temelle. Mais ici les modifications portent aussi sur les appendices abdomi- 
naux. La femelle possède, à chaque seginent, une paire d'appendices pennés, auxquels s'accrochent les paquets d'œufs; le mâle, au contraire, n'a qu'une paire de stylets copulateurs à la partie antérieure de l'abdomen. Or, on trouve, parmi les mâles sacculinés, tous les degrés de dèveloppement_des appendices de la femelle, comme le montre la figure 43 I ${ }^{\text {re }}$ ligne. Certains mâles ont les appendices au complet, et leur sexe véritable ne se reconnaît plus extérieurement qu'à des vesiiges plus ou moins visibles de stylets copulateurs. Pour certains d'entre eux, la dissection est nécessaire et les renseignements qu'elle fournit sont parfois douteux, en raison de l'atrophie des testicules et des canaux déférents. Enfin, dans le genre Inachus, l'altération des caractères porte aussi sur les pinces; celles du mâle sont normalement beaucoup plus fortes que celles de la femelle et, chez un certain nombre de mâles sacculinés, les pinces sont faibles et du type temelle

En examinant des crabes qui ont porté antérieurement une sacculine et que l'on reconnaît à une cicatrice annulaire à son ancien point d'insertion, Sмiтн en a trouvé qui avaient été originairement des mâles et chez qui les glandes génitales, après la chute de la sacculine, étaient en voie de reconstitution, mais présentaient de jeunes oocytes, c'est-àdire que la glande maintenant avait une orientation vers le sexe femelle.

Si nous rapprochons l'ensemble des faits précédents de ce que nous avons dit plus haut du métabolisme du crabe, sous l'influence de la sacculine, nous royons que, chez lc màle, parallèlemest à la 
déviation du métabolisme, les caractères sexuels secondaires sont modifiés dans le sens du sexe temelle et que le retentissement peut même aller jusqu'à une modification de la polarité de la glande génitale elle-même $\mathbf{I}$.
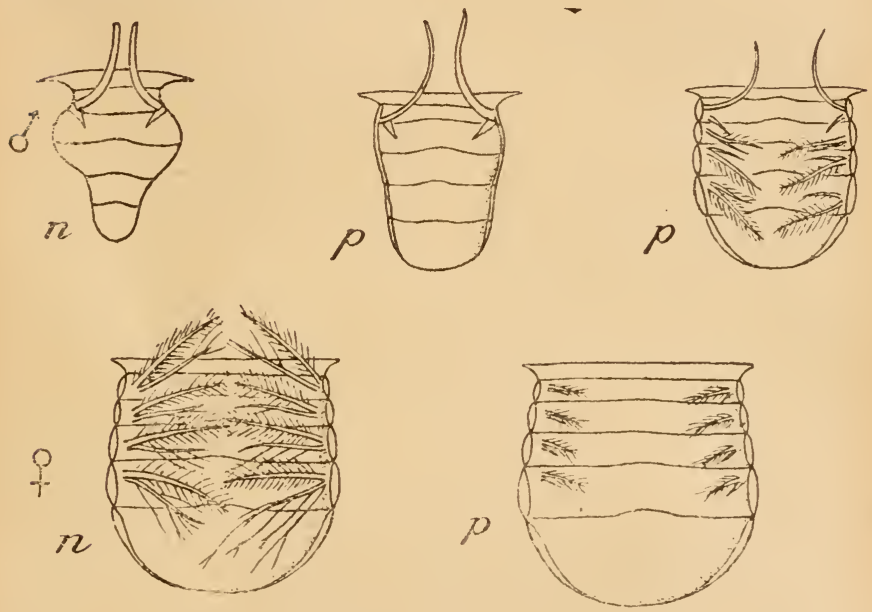

Fig. 43. - Modification de l'abdomen d'Inachus mauritanicus sacculiné (face ventrale) d'après G. Surtr : $n$ individus normaux: $p$ ind. parasités (mâles sur la première rangée, femelle sur la seconde).

Chez les Pagures porteurs de Peltogaster, F.-A. Potrs a constaté aussi que les mâles prennent

I. On peut aujourd'hui ranger les modifications précédentes dans la catégorie des faits d'intersexualité, tels qu'ils sont définis par Goldschmot $\left(f_{1} 6\right)$ et par F.-R. Lillie. Le premier, sur des Liparis dispar (ce Bombycien, comme son nom spécifique l'indique, offre un dimorphisme sexuel très net), a montré que,par des croisements appropriés de races, 
plus ou moins les caractères de la femelle, sanś que l'inverse se produise. Grard avait noté auparavant que,chez les Pagures mâles parasités parun Epicaride (Phr)xus paguri, les appendices abdominaux prenaient souvent le type femelle. Rathke, un demisiècle plus tôt, avait cru que seules les femelles de Crevettes (Palcemon) étaient parasitées par les Bopyres. Or, en réalité, les mâles le sont aussi souvent, mais, sous l'influence du parasite, ils prennent les caractères sexuels secondaires femelles, ce qui avait trompé Ratнке.

Chez des Hémiptères homoptères du genre $T y$ -

on obtient à volonté des individus offrant une mosaïque de caractères mâles et femelles, c'est-à-dire des gynandromorphes, et que ces individus, au point de vue des instincts sexuels, sont intermédiaires entre les màles et les femelles. Il a pu étalonner les diverses races et, à l'aide de ces données, en croisant deux races convenablement choisies, obtenir tel ou tel degré d'intersexualité prévu d'avance, jusqu'au renversement complet du sexe chez une portion des individus. Ce sont évidemment des états de ce genre qui sont réalisés dans les Inachus, sous l'influence de la sacculine. Les transformations des crabes sont comparables aussi aux anomalies présentées par les Free-Martin et expliqués par F.-R. Lillie $(\{I \&)$. Ces individus sont des génisses jumelles d'un veau mâle, que l'on sait, depuis l'antiquité, ètre stériles et qui, anatomiquement, sont des intersexućs, offrant, dans le système des voies génitales, un mélange varié de caractères mâles ou femelles, avec déviation plus ou moins forte vers lesexe màle. LiLlie a montré que ces anomalies étaient la conséquence d'une anastomose précoce qui, dans les cas de grossesse gémellaire, exceptionnels chez la vache, s'établit entre les vaisseaux des annexes fotales. L'embryon femelle subit ainsi, dès un stade très précoce, l'action du sang mâle et des hormones qu'il renferme. Sous l'influence de ces hormones, il y a inhibition des caractères femelles et développement de caractères mâles. 
phlocyba $(\boldsymbol{T}$. hippocastani et $T$. douglasi $)$, parasités par un Hyménoptère (A phelopus melaleucus) et par un Diptère (Atelenevra spuria), GIARd $(4 I 5)$ a constaté une atrophie très marquée de la tarière des femelles dans les deux espèces. Chez les mâles parasités de T. hippocastani, le pénis est également réduit.

Chez les végétaux, on peut citer le cas d'une Caryophyllée, Lrchnis dioica: sur les pieds femelles de cette plante dioïque parasités par $U^{\prime}$ stilago antheraruin, la présence du parasite a pour effet de provoquer la réapparition des anthères qui, d'ailleurs, sont envahies par le champignon.

Les nombreux exemples d'action morphogène produite par les glandes génitales au moyen d'un mécanisme hormonique éclairent les faits constatés dans le cas de la castration parasitaire.

Il y a toutefois dans les faits relatifs aux Crabes et aux Insectes un paradoxe apparent. Car, chez les Arthropodes, la castration expérimentale s'est montrée sans effet sur les caractères sexuels secondaires, même pratiquée très tôt. Mais, entre le mécanisme des deux actions, il y a évidemment des différences considérables dans les conditions.

$$
\text { ** } *
$$

Nous avons vu au début du chapitre que les parasites, au moins à l'état d'activité, ne provoquaient pas en général d'action phagocytaire ; ce n'est pas à dire qu'il n'y aitjamais de réactions cellulaires à leur 
présence. On pourrait citer divers exemples de ces dernières.

Autour de l'ouf des Hyménoptères entomophages. il seproduit une enveloppe de cellules de l'hôte, formant un feuillet épithélial,qui joue très certainement un rôle important dans les échanges entre le parasite et I'hôte.

Le ver du Cayor (larve de Cordylobia anthropophaga) détermine la formation d'une tumeur cutanée ouverte (myiase furonculeuse), consistant en une prolifération néoplasique du tissu dermique, autour de la larve. Ces cellules fondent en une sorte de purée cellulaire, dont elle se nourrit et qu'il ne faut pas confondre avec une suppuration; il n'y a suppuration en eflet que si la larve est malade ou meurt et si l'orifice de la tumeur se ferme (RouBAUD, 390$)$.

Il se produit, chez les Poissons, une réaction de même ordre autour des larves Glochidium d'Unionida. En quelques heures, elles sont englobées dans un kyste épais et vascularisé, dont les éléments sont phagocytés par les cellules palléales du jeune mollusque. F.-H. Reuling (4o8) a constaté récemment le fait intéressant que cette réaction de l'hôte ne se produit pas indéfiniment. Après deux ou trois infestations successives du Lepidostée par des Glochidiuın de Lampsilis anodontoides, il n'y a plus de réaction et on ne peut plus obtenir le développement. De même l'auteur a pu obtenir, sur Micropterus salmonoides, deux infestations massives par les Glochidium de Lampsilis luteoln, mais une troisième a été abortive, dounant des kystes anormaux, d'où le parasite at été 
expulsé après quarante-huit heures, alors que l'infestation réunissait parfaitement avec des Glochidium de la même ponte sur de témoins neufs. Il y aurait donc rapidement immunité acquise par le poisson, dont le sérum détruit alors, in vitro. les tissus de Glochidium, tandis que le sérum des témoins neufs est sans action.

Avec certains Protozoaires, nous voyons des réactions cellulaires localisées. Diverses Coccidies et Grégarines déterminent l'hypertrophie d'une cellule ou d'un groupe de cellules. Ainsi Caryotropha mesnili, Coccidie parasite des spermatogonies d'une Annélide (Polymnia nebulosa), étudièe par SiedLECKI ( $2 \tilde{o} o$ ), amènel'hypertrophie de la cellule où elle sedéveloppe, ainsi que de son noyau. Quelques spermatogonies voisines peuvent subir des modifications analogues et se fusionner avec la première en une cellule géante plurinucléée; le reste du bouquet de spermatogonies n'évolue pas normalement en spermatozoïdes, mais reste à l'état de cellules épithéliales, formant autour du parasite une enveloppe compacte. Il y a donc ici castration partielle directe.

Des faits analogues ont été signalés pour diverses Grégarines: Pyxinia frenzeli, parasite de l'épithélium intestinal des larves d'Attagenus pellio, produit une hypertrophie de la cellule hôte, suivie d'atrophie (Laveran et Mesnil). Clepsidrina davini détermine la fusion en un syncytium des cellules des cryptes épithéliales intestinales des Gry llomorpha, auxquelles elles sont fixées (LÉGER et DUBoscQ 233). Hesse (225) a signalé des faits de même genre pour des Grégarines d'Oligochètes : Mono- 
cystis agilis, Rhynchocrstis pilosa, agissent sur les spermatogonies comme Caryotropha mesnili. Nematocystis magna hypertrophie la cellule épithéliale qui la supporte. Ces hypertrophies ont parfois amené des méprises. Les Myxocystis, décrits comme

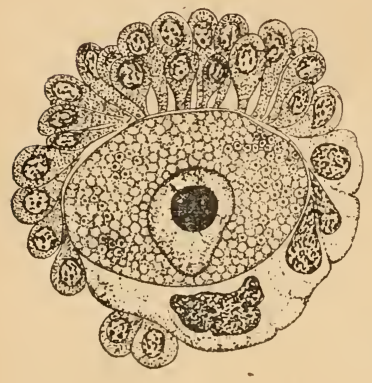

A

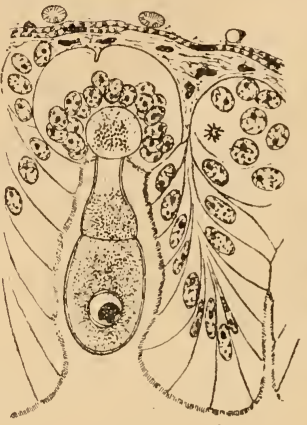

$B$

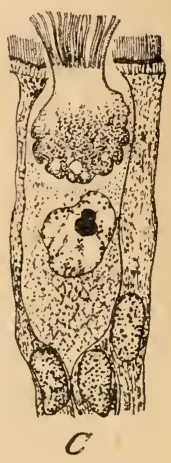

Fig. 4'. - Réactions cellulaires de l'hôte à des coccidies et des grègarines: A Garyotropha mesnili(d'après S1EDLEGKI), B Clepsidrina davini (d'après LÉGer et Dubosç), C Hypertrophie d'une cellule épithéliale intestinale de Blaps parasitée par Stylorhynchus longicollis (dont on ne voit que l'épimérite) d'après Léger et DuboscQ.

des Sporozoaires spéciaux parasites des Limnodrilus, ont été reconnus pour n'être qu'une Microsporidie parasite des lymphocytes ou des spermatogonies du ver, déterminant l'hypertrophie de la cellule parasitée et de son noyau et la fusion de plusieurs cellules en une cellule géante. Diverses Microsporidies, comme Nosema anomalum chez l'Epinoche (Stempell), une Glngea de Balanus amaryllis (Ch. PÉrez) et une espèce que j'ai moi-mème étudiẹe 
dans le foie du lançon (Ammodytes lanceolatus), produisent, à la périphérie des plages envahies, des noyaux géants et polymorphes. Stempell (252) les avait considérés comme appartenant en propre au parasite et ayant la signification de noyaux végétatifs. Il est plus probable que ce sont des éléments de l'hôte, hypertrophiés et fusionnés en cellules géantes. Il en est probablement de même pour la cellule à grand noyau et bordure en brosse qui enveloppe les kystes de Gilruth de l'estomac du mouton, étudiés par Chatton ( 2 I g). Un Sporozoaire d'affinités encore obscures, Selysina perforans, parasite d'une Ascidie (Stolonica socialis) et étudié par DuboscQ (222) détermine aussi la formation de cellules géantes plurinuclées, par fusion de cellules plus ou moins nombreuses.

Dans les segments de Potamilla torelli, envahis par Haplosporidium potamillce (fréquemment accompagnée d'une levure à asques aciculaires, voisine des Monospora des Daphnies), on assiste à une prolifération de l'endothélium péritonéal en une sorte de papillome (Caullery et Mesnil I J I).

On pourraitallonger encore cette série d'exemples, où il s'agit certainement de l'action de substances sécrétées d'une façon continue par les parasites.

$$
*^{*} *
$$

Ces actions cellulaires très localisées nous conduisent naturellement à un type de modifications dues aux parasites et très répandues chez les Végétaux, je veux parler des Galles ou Gécidies. On peut citer 
quelques formations analogues chez les animaux et que nous examinerons d'abord. Giard (4 I 5) a proposé de leur donner le nom de thylacies ( $\theta 0 \lambda \alpha \times$ เov bourse). Suivant que le parasite est animal ou végétal, on dira qu'il s'agit de Zoocécidies ou de Phytocécidies, de Zoothrlacies ou de Phylothrlacies.

Un certain nombre de Myzostomes stationnaires déterminent, sur les pinnules des Crinoïdes, la formation de loges à paroi calcaire épaisse, à l'intérieur desquelles ils se blotissent, communiquant avec l'extérieur par un étroit orifice. De même un Copépode, Pionodesmotes phormosomce, étudié par J. Bonnier (324), forme aussi une véritable galle sur un oursin abyssal, à test mou, Phormosomı uranus : ̀̀ son contact, le test se calcifie fortement en une sphère saillante dans le colome (fig. 45) et contrastant avec la minceur génerale de la paroi de l'oursin. Ces galles offrent un orifice étroit, par où la femelle du Copépode hypertrophié ne peut pas passer; le mâle, beaucoup plus petit, doit pouvoir encore sortir. Récemment Stephensen (348)a signalé aussi la formation d'une galle aux dépens d'une Ophiure (Astrocharis gracilis), par un Copépode (Astrochordcuma appendiculatum).

Un crabe, Hapalocarcinus marsupialis détermine, par sa présence, à l'extrémité des branches d'un Madréporaire, Pocillopora caspitosa, dont il modifie la croissance, des loges où il reste blotti. Ce cas, signalé par Semper a été récemment bien étudié par F. A. Poтrs (35o), qui a suivi la réalisation progressive de la loge où vit le Crabe ; il y persiste une série de fenêtres alignées, assurant la 
circulation de l'eau. Les Hapalacarcinus modifien de même d'autres coraux (Seriatopora hrstrixi,

A
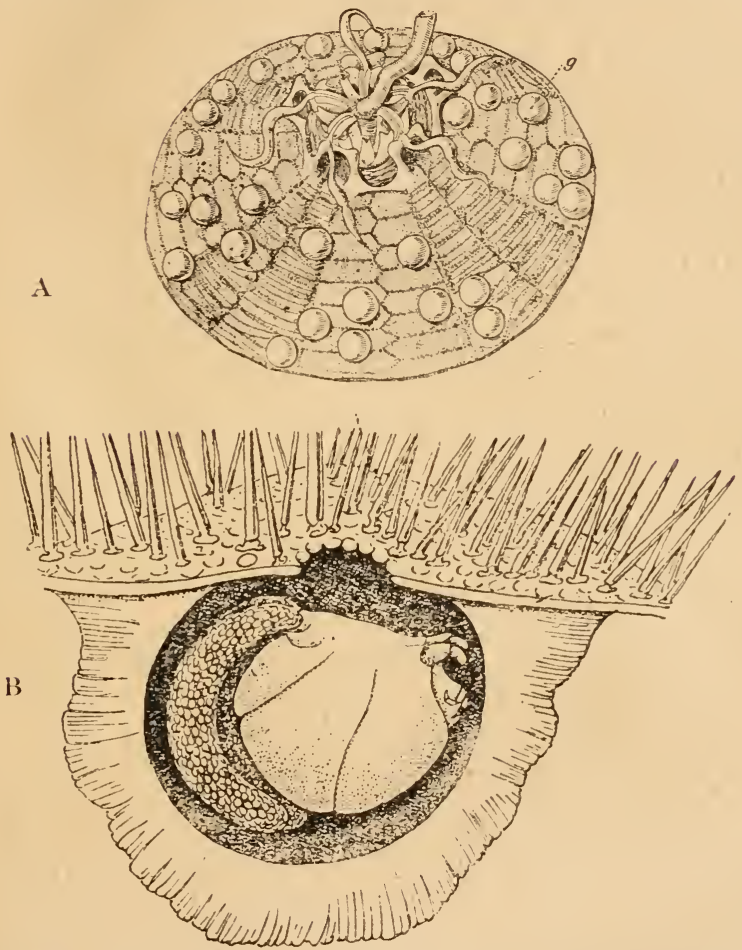

Fig. 45. - A, Fragment du test (face interne) du Phormosoma uranus, avec nombreuses galles sphériques en saillie $g$ de Pionodesmotes phormosomœ. B vue intérieure d'une des galles; avec son orifice externe et le parasite(\$) (d'après J Boxwier).

Sideropora). D'autres Crabes, les Gryptochirus, habitent de mème des cavités dans des polypiers 
massifs (Leptoria), où ils vivent par couples, le mâle étant plus petit que la femelle. Giard $(415)$ avait créé le terme de thylacie, pour les Typhlocyba parasitées par Aphelopus melaleucus; l'Hyménoptère est porté en effet dans une poche volumineuse, placée latéralement sur l'abdomen.

On peut considérer aussi comme une galle la poche dans laquelle Xenocceloma est logé sur son hôte(Polycirrus arenivorus); les tissus de l'Annélide subissent, par la présence du parasite, une prolifération et une différenciation spéciales (v. p. I3o).

Enfin, on peut assimiler à des galles temporaires la formation du kyste vascularisé, où évoluent les Glochidium sur les Poissons, ainsi que les tumeurs de la myiase furonculeuse produites par le ver du Cayor.

Mais ce type de réaction reste exceptionnel et peu développé chez les animaux.

$$
*^{*} *
$$

$\mathrm{Au}$ contraire, les cécidies ont une importance capitale chez les Végétaux et sont également intéressants au point de vue physiologique comme au point de vue morphologique. Je me bornerai ici toutefois à quelques remarques d'ordre général à leur sujet, leur étude spéciale ayant sa place dans une autre partie de l'Encyclopédie.

Les animaux producteurs de galles, ou cécidozoaires, appartiennent à des groupes très variés. Les plus importants sont les Nématodes (Helminthocécidies), en particulier les Heterodera; les Acariens, 
surtout les Eryophyes et Phytoptus (Phytoptocécidies,; mais avant tout les Insectes. Presque tous les ordres renferment des types cécidogènes; mais ceux qui jouent le plus grand rôle sont les Pucerons, les Diptères (Cécidomyies) et les Hyménoptères. Parmi ces derniers, les Cynipides constituent une raste famille, s'attaquant de préférence aux Quercinées et y présentant pour le biologiste des faits d'un grand intérêt (parthénogenèse, polymorphisme, etc.); les Tenthrédinides et les Chalcidiens ont aussi une très grande importance comme cécidozoaires ( $\mathrm{I}$ ).

Les galles se forment aux dépens de toutes les parties des plantes, racine, tige, feuilles, tleurs, bourgeons; chaque cécidozoaire produit, d'une façon générale, une galle déterminée sur une partie fixe d'une plante donnéc. Il y a, en général, une spécificité très stricte entre cécidozoaires et plantes, spécificité soumise toutefois aux mêmes vicissitudes que le parasitisme en général. Beaucoup de cécidozoaires ne s'attaquent qu'à une plante et sont monophages; d'autres sont plus ou moins pléophages. C'est le cas d'Heterodera radicicola et celui d'une Chrytridinée, Pycnochytrium aureum, qu'on connaît sur une centaine de plantes différentes. Par contre, parfois, sur des espèces très voisines, des Cécidozoaires, sans être distinguables morphologiquement, consti-

I. Il ne faut naturellement pas confondre les véritables cécidozoaires, produisant les galles, avec les commensaux et inquilines qui y vivent parfois en grand nombre. Dans la galle produite par Biorhiza aptera (Cynipide), on a dénombré 59 espèces parasites et I commensaux. 
tuent des races physiologiques bien individualisées. On peut citer ainsi l'Isosoma graminicola, qui est représenté par deux races distinctes sur Triticum repens et sur Triticum junceum.

La morphologie, la structure, les dimensions, la couleur des galles sont aussi étroitement définies que pour les organes normaux. Il y a une morphologie précise des galles; elles résultent, d'une façon générale, de deux processus : une multiplication cellulaire ou hyperplasie et une hypertrophie des cellules et des noyaux. Nous aurons un exemple très frappant de l'hypertrophie des cellules dans le renflement des racines de melon, produit par Heterodera radicicola, où le Nématode détermine la formation de cellules géantes, renfermant parfois jusqu'à 200 noyaux.

En général, surtout dans les parenchymes, les tissus ont un caractère nettement embryonnaire ; les cellules et les noyaux sont plus grands que dans les tissus normaux; l'appareil chlorophyllien est réduit; il y a fréquemment production d'anthocyanine. Au point de vue chimique, les tissus des cécidies sont plus riches en eau que les tissus normaux et plus riches aussi en composés azotés solubles, en amidon et en tanin.

Le point qui doit nous intéresser le plus ici est le mécanisme de la production des galles. Il faut remarquer tout d'abord qu'elles ne se forment que sur les organes de la plante qui sont en voie de développement, et que les cécidozoaires ne peuvent produire de galles qu'à l'état d'œufs ou de larves. L'hypothèse la plus naturelle - elle s'était déjà 
présentée au Xvir ${ }^{e}$ siècle à MALPIGHI et elle est généralement admise aujourd'hui - est que ces formations sont dues à l'action sur la plante de substances

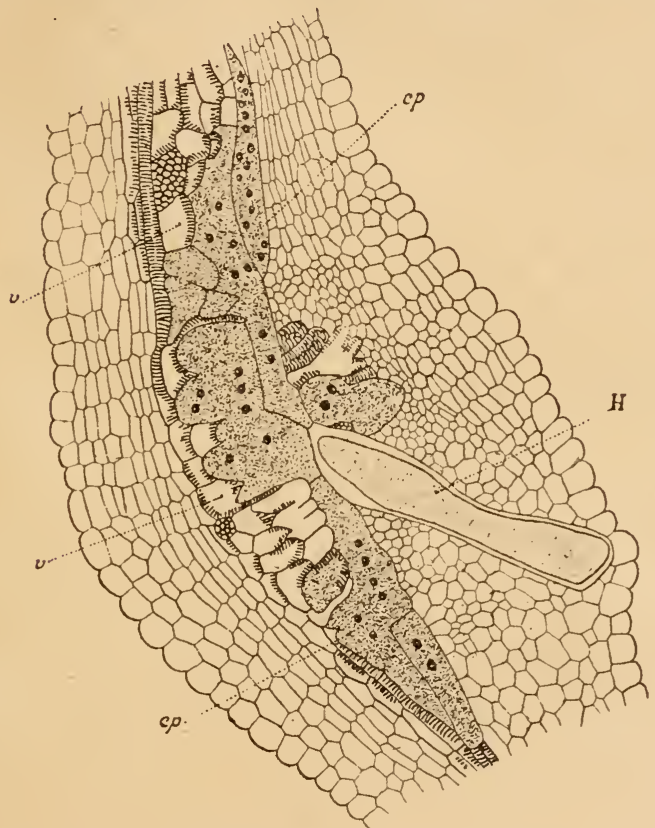

Fig. 46. - Coupe longitudinale d'une racine de melon attaquée par un Heterodera radicicola $(H) ; c p$ cellules plurinucléées (d'après Molliard).

irritantes, déposées dans les tissus par l'animal cécidogène, soit au moment de la ponte, soit au cours de la croissance de la larve. Ces substances doivent amener une déviation dans la nutrition des tissus. On remarque d'ailleurs un parallélisme géné- 
ral entre les différenciations histologiques et morphologiques réalisées dans beaucoup de galles et celles qui résultent de déviations de la nutrition de la plante dues à d'autres causes et qui se traduisent, par exemple, par de la fasciation ou par la virescence des fleurs. Il y aussi beaucoup d'analogie, comme l'a remarqué Molliard (206), entre les galles et les, fruits et elles doivent reposer sur la similitude des conditions de nutrition dans la formation des unes et des autres, Les galles seraient donc, en définitive, une réaction de la plante à des substances inoculées par le parasite cécidogène et suivant une morphologie déterminée par la constitution propre à la plante. Il n'y à production de galle que si l'action s'exerce sur un tissu de nature embryonnaire. Dès lors, toutes les corrélations qui règlent le développement de la plante elle-même et qui interviennent dans la formation des parties nouvelles pour en déterminer la symétrie, entrent en jeu, mais dans des conditions modifiées. Ainsi se réalise un véritable organe nouveau, dont le plan et l'évolution dépendent des propriétés intrinsèques de la plante et, celles-ci étant données, sont déterminées d'avance.

Malgré les apparences d'adaptation des galles aux circonstances du développement des larves cécidogènes et de leur éclosion, il faut considérer les cécidies comme une réaction propre de la plante, indépendamment de toute finalité concernant le parasite. S'il y a eu évolution et adaptation de l'un à l'autre, on ne peut guèrele concevoir que comme une modification dans l'action irritante du parasite, par 
exemple comme une variation dans les substances par lesquelles il agit sur la plante ou dans les conditions d'action de ces substances.

Ce n'est que dans ces dernières années que quelques résultats expérimentaux ont pu être obtenus à l'appui de l'hypothèse précédente. Les conditions de production des galles comportent certainement un déterminisme très précis, auquel ne peuvent équivaloir des expériences brutales.

Des observations et expériences très suggestives à ce sujet ont été faites il y a déjà près de quarante ans par BeiJerinck ( $I$ g 8 ) sur les galles d'Hyménoptères (Cynipides, Tenthrédinides). Elles ont été reprises récemment par W. MagNus, qui, en confirmant sur certains points les conclusions de BEIJERINCK, s'en écarte cependant sur d'autres.

Beijerinck a étudié, en particulier, les galles produites sur les feuilles de saule, par les Nematus (Pontania, Tenthredinidae). Il remarque qu'en même temps que son œuf, la tenthrède dépose, dans la blessure qu'elle fait à la plante, une gouttelette de liquide, sécrétion des glandes abdominales à venin. C'est, d'après lui, ce liquide qui détermine la formation de la galle, car celle-ci se produit même si, - comme cela a lieu quelquefois, - l'ouf n'est pas pondu et aussi quand, à l'airle d'une aiguille, on tue l'œuf. Les galles, dans ces conditions, n'atteignent pas la taille définitive normale, mais on voit qu'elles s'ébauchent en dehors de l'action de l'œuf et de la larve. Ces expériences ont été refaites et vérifiées par Magnus (204) sur diverses Pontania, en particulier P. proxima (du Salix amygdalina). Magnus 
les a même perfectionnées, en se bornant à enlever l'œuf de la plante, presque immédiatement après la ponte et sans la blesser. Il a pu comparer toute la marche de la pro duction de la galle dans les plantes ainsi opérées et dans d'autres servant de témoins, où l'œuf avait été laissé. Or, dans celles d'où l'œuf avait été extrait, la galle se forme bien, mais plus lentement et elle reste plus petite. Elle est donc réalisée sans l'intervention de l'ueuf lui-même, ni de la larve. Il n'en est pas ainsi de toutes les galles. D'après les expériences de Maśnus, dans celles des Cynipides (Rhodites, Biorhiza), la présence de l'œuf et de la larve est nécessaire.

Beijerinck a conclu de ses expériences sur les Pontania que le facteur déterminant est la sécrétion déposée par la tenthrède dans la blessure de la plante. Mais ni lui, ni Magnus n'ont réussi, en inoculant le produit en question directement dans les feuilles de saule, à provoquer une réaction de la plante, ni surtout une réaction bien définie comme l'est la galle naturelle. Cela doit tenir aux conditions de l'inoculation. La blessure faite à la plante par la tarière de l'insecte comporte une précision très grande quant aux tissus déchirés et par conséquent aux cellules qui réagiront. MAGNus ne considère donc pas comme absolument établi que la galle soit rẻellement le résultat direct de l'action d'une substance chimique déterminée sur les cellules de la plante. La blessure elle-mème est pour lui un facteur décisif.

11 distingue d'ailleurs deux phases dans l'évolution des galles : une phase initiale, où se forment, par multiplication cellulaire, des tissus indifféren- 
ciés, et une seconde phase où les tissus formés se différencient. Celle-ci, dans toutes les galles, serait sous la dépendance constante de la larve vivante et en voie de développement, agissant par ses produits de sécrétion. Une injection, une fois faite, d'une substance chimique, ne pourrait donc pas suffire à la réalisation complète d'une galle.

Si les sécrétions introduites par le parasite sont bien la cause efficiente de la formation de la galle, reste à savoir quelle est en elles la substance agissante. Il est indiqué de songer à des enzýmes et on a vérifié, sur diver's oufs ou larves de Cécidozoaires, qu'ils ćtaient effectivement riches en enzymes protéolytiques; cela cadrerait avec le fait que les galles renferment les composés azotés surtout sous des formes solubles et non sous forme protéique. En discutant ces prublèmes, MAGNus arrive à une hypothèse d'ordre grénéral, que je relate ici, en raison de l'analogie qu'elle comporte avec les conditions du parasitisme chez les animaux. La production des galles serrit le résultat, non de l'action directe d'enzymes, mais de celle de substances secrétées par les Cécidozoaires et qui empêcheraient ou suspendraient l'action des enzymes propres de la plante. Ce seraient, en d'autres termes, des anti-corps produits par le parasite et introduits par lui dans la plante qui modifieraient les conditions du métabolisme cellulaire. La spécificitś des anti-corps conditionnerait la spécificité des galles différentes produites. sur une mème plante par des parasites distincts. Cette hypothèse reste pour le moment à étayer sur des faits. 
Quel que soit le mode précis d'action des subs. tances inoculées par le parasite, dans la production et la différenciation des galles, il est intéressant de signaler quelques résultats positifs obtenus récemment, en dehors de l'intervention de l'organisme cécidogène, par l'introduction dans la plante des substances fabriquées par celui-ci. Ces résultats sont dus à Molriard et à E. F. Smith.

Les expériences de Molliard (2o5) ont porté d'abord sur le Rhizobium radicicola des racines de Légumineuses, isolé des racines de la fève, en culture pure. Le liquide de culture, filtré sur bougie de porcelaine, a servi ensuite de milieu de développement pour des graines de pois, mises au préalable à germer aseptiquement sur de l'ouate humide. Des témoins poussaient dans les mêmes conditions, mais sur de l'eau de source. Sous l'action du liquide de culture du Rhizobium, les racines de pois ont montré une hyperplasie du péricycle et une hypertrophie des cellules corticales; mais il ne s'agit pas d'une action spécifique ni de transformations considérables.

Plus récemment, Molliard (207) a réussi à reproduire, au moins partiellement, la galle que développe dans le pistil de certains pavots (Papaver dubium, $P$. rhoeas) un Cynipide (Aulax papaveris). Ce cécidozoaire est grégaire. Il y a jusqu'à 5o larves dans une seule galle. Moldiard broie un lot de ces larves et, à l'aide d'une seringue garnie d'un filtre d'amiante pour obtenir un liquide limpide, il injecte le produit de broyage au centre du plateau stigmatique d'un bourgeon floral des pavots sur l'axe 
du pistil. La plante est ensuite protégée contre tout accès de l'IIyménoptère. Au bout de quelques jours, les fleurs ainsi opérées montrent des placentas hypertrophiés, offrant une similitude d'aspect très remarquable a vec la galle naturelle. Mais on n'obtient pas les transformations subséquentes de cette ébauche, faute de l'action répétée de nouvelles doses de la substance irritante, répétition qui, dans les conditions naturelles, doit être d'autant mieux assurée et ménagée que les larres sont plus nombreuses.

E. F. Smith $(2 I I)$, aux Etats-Unis, a fait une série de recherches parallèles aux précédentes, sur les galles en couronne (crowngalls), produites par une bactérie(Bacterium tumefaciens), en faisant agir sur la plante les substances élaborées par cette bactérie. Il cultive celle-ci sur des milieux très simples ( $\mathbf{r}$ ). Dans ce milieu, après culture, on trouve de l'aldéhyde formique, de l'ammoniaque, des amines, de l'alcool, de l'acétone, des acides formique et acétique. Smith observe que beaucoup de ces substances sont parmi celles qui se sont montrées les stimulants les plus efficaces de la parthénogénèse expérimentale, dans les recherches de J. Lовв. Il badigeonne les bourgeons de la jeune plante avec ces substances ou en fait des injections. Les plantes utilisées ont été le chou-fleur, le ricin et la tomate. Mais, ici encore, l'action n'a pu être répétée d'une façon continue, comme elle a lieu dans les conditions

I. Eau distillée, additionnée de I o/o de dextrose et I o/o de peptone, plus du carbonate de chaux pour neutraliser les acides formés, qui s'opposeraient au développement de la bactérie. 
naturelles. Sмiтн a obtenu des tumeurs qui restent petites et présentent de l'hyperplasie a vec vaisseaux et de l'hypertrophie cellulaire. Les cellules sont plus compactes que dans les tissus normaux : elles sont dépourvues de chlorophylle. Leur volume atteint jusqu'au centuple de celui des cellules normales. Les transformations réalisées sont donc bien de l'ordre de celles qui sont caractéristiques de la galle naturelle.

En somme ces résultats, sans constituer la réalisation complète des galles, sont cependant suffisants pour justifier l'hypothèse d'où sont partis les expérimentateurs, surtout si l'on tient compte de la différence existant entre les conditions expérimentales el les conditions naturelles.

Les galles peuvent donc être considérées comme la réaction spécifique des tissus jeunes des plantes à des substances chimiques intrcduites dans ces tissus par les organismes cécidogènes.

La fréquence des galles chez les plantes et leur haute différenciation, opposées à la rareté des formations analogues chez les animaux, $\mathrm{n}^{2}$ est sans doute que l'expression de la prédominance, chez les végétaux, des réactions locales sur les réactions générales. Cela se conçoit, si l'on songe à la constitution des uns ét des autres et à la différence des rapports physiologiques entre les parties dans les deux cas, si, en particulier, on envisage le rôle de l'appareil circulatoire chez les animaux. 


\section{CHAPITRE XI}

\section{LA SYMBIOSE CHEZ LES ANIMAUX}

Sommaire. - Définition. - Zoochlorelles et Zooxanthelles : leur extension, leur nature, leurs rapports physiologiques avec les animaux qui les renferment. - Pénétration et transmission. - Champignon (Nephromyces) du rein des Molgulitee. - Les levures intra-cellulaires des Insectes et la symbiose héréditaire. - Historique. - Etude du cas d'lcerya purchasi - Transmission par l'œuf. - Cultures in vitro. - Mycétocytes. - Le mycétome et ses diverses catégories; son ròle physiologique.

Les Bactéroïdes chez divers animaux : blatte, cyclostome etc. - La symbiose chez les Diptères hématophages stricts (Glossines, Pupipares).

Recherches de Pinraxtoni sur les organes lumineux. - La luminosité animale est-elle due à des bactéries symbiotiques?

Les derniers chapitres de ce livre seront consacrés à l'étude de la syrmbiose. Le mot a été créé par le botaniste Ant. de BARY (85) pour désigner l'association intime et constante de deux organismes dans des conditions qui peuvent être considérées comme leur assurant des bénéfices réciproques. Liexemple type de ces associations était les Lichens, dont la nature venait d'être établie par SGr wendener. O. Her- 
TwIG ( $t \circ 9)$, étendant cette conception à certaines associations entreanimaux et végétaux, ou entre animaux, définissait la symbiose : " la vie en commun, d'une façon permanente, d'organismes spécifiquement distincts et ayant des fonctions et des besoins vitaux complémentaires ». La délimitation de la symbiose, et du commensalisme, ou mème du parasitisme, n'est pas aisée. On y fait rentrer souvent des associations comme celles d'Eupagurus priedauxi et Adamsia palliata; d'autres fois, on groupe les associations de cegenre sous le nom de mutualisme, en restreignant la symbiose aux cas où l'union des deux organismes est particulièrement intime. L'analyse des exemples de symbiose ainsi comprise montreraqu'elle n'est pas toujours purement mutualiste, et que l'un des deux organismes est, en réalité, plus ou moins parasite sur l'autre. Enfin, il est des associations constantes, commecelles des Dicyémides et des Céphalopodes, des Trichonymphides et des Termites, des Ophrroscolex et des Ruminants, qui sont aussi difficiles à classer. La précision de la notion de sym. biose résultera surtout de l'examen des divers cas.

$$
*^{*} *
$$

Le premier exemple que nous étudierons est celui des zoochlorelles et zooxanthelles, algues unicellulaires qui vivent dans le cytoplasme de Protozoaires et dans les tissus de divers Invertébrés.

L'existence de corps verts ou jaunes dans les tissus d'Invertébrés a été signalée dès 1850 ; leur interpré- 
lation comme algues intracellulaires a été proposée en I8ji par Cienkowski (92), puis par Gesa Entz (99) et K. Brandt $(90)$; elle a été particulièrement confirmée en r 89o, par BeiJerinck $(86)$ et par DaNGEARD (95). Néanmoins, cette opinion fut contestée pendant assez longtemps, notamment par E. Ray LANkester. On trouve un excellent résumé de ces discussions dans une sythèse de la question due à Botivier (89).

Les corpsjaunes(zooxanthelles) se rencontrent chez les animaux marins, les corps verts (zoochlorelles) surtout chez les animaux d'eau douce. Voici quelques exemples d'animaux qui en présentent:

Protozonines. - Diverses amibes nues ( $A$. viridis) ou testacées (Difflugia piriformis, D. nodosa); des Foraminifères (Trichosphcerium sieboldi, Peneroplis pertusus, etc.). Un grand nombre de Radiolaires, notamment les Sphérozoaires (Collozoum, Sphcerozoum), des Héliozoaires (Acanthocystis, Aclinospharium, Heliophrys, etc.); des Flagellés (Anisonema viridis, Noctiluca, Leptodiscus); de trèsnombreux Infusoires (Paramcecium bursaria, Fronto. nia leucas, Ophrydium versatile, Stentor polymor. phus, Trichodina patellce etc.).

EPonges. - Spongilla viridis.

Cólentérés. - Hydra viridis, Halecium ophiodes, des Méduses (Cotylorhiza, Sarsia, Rhizostoma), des Siphonophores (Velelles, Porpites), de nombreuses Actinies, des Hexacoralliaires et des Hydrocoralliaires (Millepora), des Grorgones, des Alcyonaires, etc...

C'TÉNOPHORES : Euchlora. 
Turbellaniés: Conooluta, Vortex viridis, etc.

Rotifìres : Ascomorpha helvetica.

AnNélides : Eunice gigantea.

BryozoAIres : Zoobothrium.

Mollusques : Tridachna, Elysia viridis.

La nature végétale de ces corps jaunes ou verts, en général sphériques et mesurant de 3 à ro $\mu$ de diamètre, résulte des caractères suivants:

$\beth^{\circ}$ Ils ont la structure d'une algue unicellulaire : on y reconnait, en effet, une membrane cellulosique, un chromatophore qui remplit à peu près le cytoplasme, un pyrénoïdc, un noyau (qu'on décèle par coloration). On y trouve en outre des grains d'amidon et des corpuscules métachromatiques.

$2^{\circ}$ Leur présence n'est pas absolument constante dans la plupart des types cités ci-dessus. S'il y a, en effet, des espèces que l'on troure toujours infectées comme Hydra viridis, les Consoluta et quelques autres formes, d'autres presque toujours (Paramcecium bursaria, (Ophrydium versatile), il en est qui ne le sont que d'une façon accidentelle ou dans certaines localités. Les Noctiluques, par exemple, ont des zooxanthelles dans l'Océan Indien, mais non dans nos mers. Trichodina patella abondamment infectée sur la côte normande (cap de la Hague), ne l'est jamais à Wimereux. On ne peut done dire que ces corps soient des organites indispensables aux espèces où on les trouve.

$3^{\circ}$ On a pu observer la contamination des espèces qui les présentent. C'est ce qu'a réalisé notamment F. Le Danteg ( I I g) pour Paramcecium bursaria, en s'entourant des précautions nécessaires. Il écrase, 
après passage dans diverses eaux filtrées, un individu vert, de façon à mettre en liberté les zoochlorelles et transporte dans la goutte qui les renferme un individu provenant d'une culture incolore. Au microscope, il constate l'ingestion de zoochlorelles par cet Infusoire. Elles n'y sont pas digérées et on les voit se multiplier ensuite par quadripartition. Au bout de quelques jours, la paramécie, primitivement inco. lore, a verıli. Schewiakoff a fait une observation analogue avec Frontonia lencas, mais Famisrzin ( $I$ O I ) conteste qu elle soit probante. Doflein ( $2 I 5$ ) a infesté Amœba vespertitio avec les chlorelles de Frontonia. A werintzefr, de même, a infesté des Dileptus anser avec celles de Stentor siridis.

$4^{\circ}$ Elles peuvent subsister longtemps en dehors de l'espèce qui les héberge, comme l'ont constaté notamment Gienkowsix, Brandt, Schewiakoff.

$5^{\circ}$ Leur division, très facile à voir aujourd'hui sur matériaux colorés, a été vue in vivo, par àe nombreux observateurs, notamment par BEIJERINCK et FAMINTzrn. Famintzin a essayé d'obtenir lear multiplication hors des Infusoires. Il n'a réussi qu'avec beaucoup de difficultés. Il écrase pour cela. entre lame et lamelle, une paramécie verte. Les zoochlorelles restent plus ou moins adhérentes à la lamelle, sous laquelle il fait passer une goutte de solution saline (renfermant $\mathrm{I} /$ rooo de phosphate acide de potassium et $1 /$ rooo de sulfate d'ammoniaque). Dans ce milieu, il a observé deux quadripartitions successives, avec période de croissance intercalaire.

$6^{\circ}$ On peut débarrasser les animaux de leurs algues, les blanchir, soit en les maintenant longtemps 
à l'obscurité où ils les rejettent, soit par un procédé décrit par Whitney (145), pour Hydra viridis, et consistant à ajouter à l'eau de 0,5 à I, 5 o/o de glycérine. L'Hydre décolorée par ce procédé vit bien et bourgeonne; il est intéressant de noter qu'elle ne se réinfeste pas quand on la met dans un aquarium renfermant d'autres hydres vertes.

Ce sont donc incontestablement des algues autonomes. BeiJERinck identifie les zoochlorelles à une algue existant à l'état de liberté, Chlorella oulgaris, dont il a pu faire la culture dans de l'eau additionnée de 8 o/o de gélatine, o,8 o/o de peptone, 0,2 o/o d'asparagine et $\mathrm{I}$ o/o de sucre de canne; c'est une Protococcacée. Il a réussi une fois à cultiver des zoochlorelles extraites d'Infusoires; la culture commencée s'est ensuite continuée sans difficulté et s'est montrée identique à celle des chlorelles libres. Famintzin a vérifié ces résultats pour les chlorelles libres qu'il a cultivées dans des solutions salines, ainsi que pour la zoochlorelle de Par̈amacium bursaria. Les zoochlorelles des divers animaux ne sont d'ailleurs pas nécessairement toutes d'une même espèce.

Les zooxanthelles seraient des Cryptomonadinées. Schaudinn rapporte au genre Cryptomonas celles des Foraminitères (Gryptomonas brandti Sch. chez Trichosphorium sieboldi, G. schaudinni Winter chez Peneroplis pertusus). Keeble ( I I I ) attribue les corps verts de Conooluta oiridis aux Chlamydomonas, caractérisées à l'état de flagellispores par quatre flagelles et un stigma.

La contamination naturelle se fait souvent dès l'œuf, chez les Métazoaires, ainsi que Hamann l'a 
constaté pour $\mathrm{Hrdra}$ viridis, dès 1882 . C'est donc une infection héréditaire. Hadzi $(I O 8)$ a constaté cette mème transmission par l'œuf chez un autre Hydraire, Halecium ophiodes; les zooxanthelles, qui teintent en brun les cellules endodermiques, passent dans l'oocyte en voie de croissance.De même, l'œuf est régulièrement contaminé chez les Millépores, d'après les observations de Mangan ( 123 ).

Mais, chez Convoluta viridis, où la présence des algues est constante, il en va autrement, d'après les recherches de Kreble et Gamble ( $\begin{array}{lll}\text { I } & 2\end{array}$ ). Les jeunes Convoluta, au sortir du cocon, sont incolores; mais les corps verts existent à la surface ou dans l'intérieur des cocons. Il est à remarquer d'ailleurs que les auteurs, qui ont étudié le développement embryonnaire des Convoluta (Georgeritch, Sekera, von Graff), n'ont pas constaté de corps verts jendant le développement embryonnaire. En élevant les jeunes Conooluta, dès l'éclosion, dans de l'eau de mer rigoureusement filtrée, KeEBLe a pu les conserver incolores pendant un mois; tandis que celles qui étaient maintenues dans l'eau de mer ordinaire verdissaient. En ajoutant des Conooluta vertes à une culture restée incolore, on voit cette dernière verdir en un à trois jours. Les cocons vides, après l'éclosion des embryons, se montrent au bout de trois semaines remplies de petits corps verts quadriflagellés (Carteria, sous genre de Chlamydomonas). L'infection des Convoluta, d'après cela, se fait, non par des corps verts ayant la structure de ceux de l'adulte, mais à un état flagellé beaucoup plus petit et très difficile à voir. 
D'après les observations de Brandt et de Famintzin, les jeunes Collozoum n'ont pas de xanthelles et la contamination doit se faire par des flagellispores très petites, qui ne semblent pas avoir encore été vues: mais une fois à l'état de corps jaunes dans l'Infusoire et dans le Radiolaire, la multiplication a lieu, sous cette forme, par bipartition ou quadripartition. Il semble en être de mème chez Trichodina.

Arrivons à la nature des rapports entre les zoochlorelles ou zooxanthelles et leurs hôtes. On y a vu en général une symbiose profitable à l'un et l'autre. Brandt $(9 o)$ a développé particulièrement cette conception. L'algue trouverait dans l'animal une protection efficace et s'y logerait de façon à recevoir encore la lumière. Les zooxanthelles sont particulièrement fréquentes chez les animaux pélagiques à surface transparente (Radiolaires, Méduses, Cténophores, etc.) ; elles trouveraient dans la cellule animale l'acide carbonique rare dans les couches superficielles de la mer. Par contre, elles dégagent de l'oxygène, aidant les tissus animaux à respirer. Elles produisent de l'amidon, qui serait utilisé par l'animal ; ou même, a vant que cette réserve ne soit formée à l'état insoluble, les produits solubles et assimilables qui y conduisent seraient directement utilisés. Les animaux qui renferment normalement des corps jaunes ou verts (Radiolaires, Conooluta) ne se nourriraient plus directement, mais par l'intermédiaire des produits de synthèse que réalisent leurs algues symbiotes et celles-ci, d'autre part, ne pourraient plus que diflicilement vivre isolees en 
liberté. Il se constitue ainsi une unité biologique nouvelle, le phytozoaire.

Dès i889, Famintzin s'est élevé contre beaucoup des conclusions de Brandt. D'après ses observations, contrairement à ce que dit Brandr, les Sphérozoaires (Collozoum, etc.), ingèrent directement des proies solides, à l'aide de leurs pseudopodes (mème des Copépodes), non seulement à l'état jeune où ils sont dépourvus de xanthelles, mais même à l'état adulte. Et, en cas de famine, les Radiolaires à xanthelles résistent longtemps, en digérant leurs xanthelles elles-mêmes. L'amidon, signalé parfois dans les Radiolaires, provient de xanthelles résorbées. Il en est de mème pour les Actinies, d'après Famintzin. La plupart des animaux à chlorelles ou xanthelles se décolorent au bout d'un certain temps, s'ils sont mis à l'obscurité (on a pu décolorer ainsi des infusoires, des hrdres, des actinies), en rejetant leurs algues à un état brunàtre et en partie digérées.

Ce sont des conclusions du mème ordre auxquelles Keeble et Gambe arrivent avec Conoolutı. Ces auteurs ont constaté d'abord que, contrairement à l'opinion reçue, elle ingère des corps solides (diato. mées, algues, spores, bactéries), au moins quand elle est jeune, par une bouche située ventrablement, dans la région postérieure et qui mène dans le parenchyme. Elle se nourrit par elle-même et non par ses corps verts. Il y a évidemment une adaptation profonde des corps verts à la Convoluta. D'après KeEBLE, les cellules vertes finissent par être incapables de vivre librement, leur membrane s'atrophie et leur noyau dégénère. Dans les conditions normales, elles 
vivent ainsi, mais, en cas de famine, elles sont digérées par la Convoluta. "Les rapports entre l'animal et ses cellules vertes sont complexes, disent les auteurs anglais, et ne peuvent être décrits comme une symbiose. " Elles servent à la Convoluta, dit Keeble, d'une sorte de système excréteur. "Les rapports entre les cellules vertes et l'animal changent au cours du développement. Elles passent d'une symbiose initiale à un état dans lequel l'animal est parasite de ses algues, quand il cesse de se nourrir. ")

Il résulte de cet ensemble de données que l'association des algues et des animaux n'est pas, à tout le moins, une parfaite symbiose et que, dans certaines circonstances, l'animal vit en parasite sur les algues.

Il semble qu'il faille voir aussi une symbiose dans la présence absolument constante de champignons rapportés aux Chytridinées, à la surface et à l'intérieur de la concrétion rénale d'un certain nombre d'Ascidies du groupe des Molgulides. Giard (4I5) les a appelés Nephromyces molgularum ; mais jusqu'ici, on n'a pas réussi à les cultiver, ni à ramener à un cycle défini les diverses différenciations qu'ils présentent. Ils végètent aux dépens de la concrétion et l'empêchent probablement de croître indéfiniment:

Une très importante catégorie de faits, parallèle à celle offerte par les xanthelles et chlorelles, a été mise au jour récémment. Il s'agit cette fois de cham. 
nignons inférieurs, et surtout de levures, qui existent d'une façon constante chez de nombreux Insectes et sous des formes précises.

Ces formations ont été observées depuis de nombreuses années, mais n'ont été définitivement interprétées qu'en rgro. Chez les $\mathrm{Pu}$ cerons, dès I858, Huxtey décrivait un organe assez ra. riable situé dans l'abdomen, à côté des ovaires(fig. $47, \mathrm{~m}$ ), et dont les cellules étaient bourrées d'inclusions généralement sphériques, ressemblant à du vitellus; d'où le nom de pseudovitellus, donné à cette formation. BALBIANI (84) l'étudia un peu plus tard et lui donna le nom de $p$ selldova, ou corps pert, à cause de sa pigmentation. Il vit en outre qu'il dérivait d'un amas particulier et constant, situé au pôle postérieur de l'ouf et appelé par lui masse polaire. MetchnikofF ( 126 ) en suivit toute l'évolution, au cours du

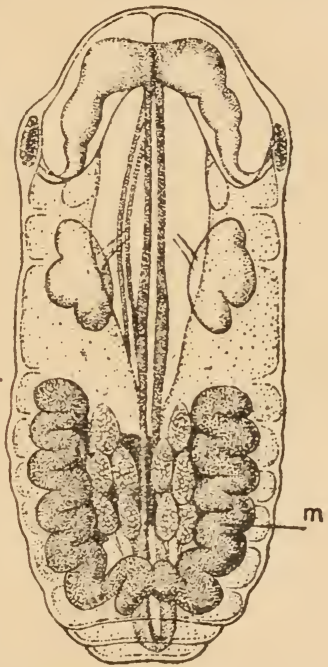

Fig. 47. - Larve de puceron (Drepanosiphon platanoides) montrant le corps vert ou mycétome $m$ (d'après BALbrani, tiré de HenneGUY). développement et l'appela vitellus secondaire. Ce corps, vu par de nombreux observateurs, a donné lieu aux hypothèses les plus diverses, jusqu'à ce que sa véritable nature fût indiquée,en rgro,d'une façon indépendante el à peu près simultanée, par PIERAN- 
Toni ( 132 ), et Sulc ( 144 ). Dans les inclusions des corps verts, ces auteurs reconnurent des levures, ou blastomycètes Schizosaccharomyces aphidis Pier.), qui apparaissent ainsi comme existant d'une façon constante et dans des rapports fixes chez les Pucerons.

Des formations analogues étaient déjà connues chez les Coccides, où même leur interprétation exacte est plus ancienne. Signalées en effet, vers I85̌o, par Leydig ( I $2 I$ ), étudiées en I866 par METCINIKOFF, puis par divers auteurs, elles furent reconnues pour contenir des éléments végétaux, en 1877 , par Putnam et, en i 887, par Moniez ( I 28 ). Lindner, en 1895 , y reconnut formellement des levures, chez Aspidiotus nerii. Vejdovsky (1906), Conte et FaUCHERon (94) en donnèrent indépendamment la même interprétation, qu'a confirmée Pierantoni, en les rattachant aux formations analogues des Aphides.

En dehors de ces deux groupes, et sous diverses formes, on retrouve les mêmes productions chez les Aleurodides (où Signoret les a vait aperçues en I867), les Psyllides (où elles ont été signalées par MetchniкоFF), les Cigales et les Cicadelles.

Prenons une première vue des faits, en les étudiant sur un Coccide, Icerya purchasi, d'après PieranToNi, et en suivant le développement de l'insecte. Au pôle postérieur des oocytes en voie de croissance dans l'ovaire, on constate régulièrement la présence d'une centaine de corpuscules sphériques (fig. $48 \mathrm{~A}, c o$ ) très colorables, qui se retrouvent aussi dans la cavité générale et, - plus nombreux qu'ailleurs -, dans le cytoplasme de grosses cellules constituant 
des organes jaunàtres, placés de part et d'autre de l'intestin et limités par un épithélium aplati. Dans ces organes, les corpuscules en question sont en roie de multiplication. Ils forment ainsi, au pôle postérieur de tous les oufs pondus, une masse constante, ou masse polaire, vue par Metchnikoff. Au début du développement embryonnaire, cette masse polaire est enveloppée par des cellules spéciales, appelées mycétocytes par Sulc; elle reste d'abord adhérente au blastoderme, puis elle tombe dans le vitellus. Elle s'accolle ensuite à la bandelette germinative (fig. 48, B); finalement elle se trouve logée dorsalement, dans la région postérieure de l'embryon et se divise en deux masses, placées sur les côtés du proctodœum et qui deviennent les corps jaunes, signalés au début de cette description. Au cours de ce développement, les blastomycètes se sont activement multipliés; les mycétocytes deviennent énormes; leurs noyaux comprimés ont des formes irrrégulières. Malgré qu'ils soient bourrés de ces champignons, les mycétocytes restent bien vivants et continuent à se diriser caryocinétiquement. Liensemble des cellules à blastomycètes constitue le mycétome.

En extrayant le mycétome de l'animal, le dissociant et plaçant des fragments dans une solution de gélatine à 8 o/o additionnée de $20 \%$ de sucre de betterave, Pierantoni a obtenu, sur ce milieu, au bout de quatre jours, à la température de $15^{\circ} \mathrm{C}$, des colonies de Saccharomycètes, - qu'il considère comme dérivant des corpuscules intracellulaires bourgeonnant suivant le type caractéristique des 
levures, alors que dans les mycétocytes les éléments se multipliaient par division égale. Ces levures sont aérobies et d'ailleurs les corps jaunes sont abondamment pourvus de trachées.

La forme des blastomycètes dans les cellules n'est pas toujours sphérique; ainsi, chez Dactylopius citri, ils se présentent, dans chaque mycétocyte, sous forme de croissants (fig. $48 \mathrm{C} ; c o$ ) réunis par groupes dans des sphères intracellulaires.

Les blastomycètes existent dans les œufs mâles comme dans les oufs femelles, mais, chez le mâle, le mycétome va en se réduisant graduellement.

Buchner $(g I)$ a complété les données précédentes en'étudiant directement le mycétome dans les divers groupes d'Insectes cités ci-dessus et ses constatations coïncident avec celles de Pierantoni. Il a étudié des Aphides (Drepanosiphum), des Coccides (Lecanium corni), des Aleurodides (Aleurodes de l'érable), des Psyllides (larve de Psyllide du saule), des Cicadides (Cicada orni, cigales du Japon et de Liberia), et Cicadelles (Aphrophora salicis). Il en a tiré des blastomycètes variés, dont on trouvera dans son mémoire la description taxonomique (genres Saccharomyces, Oospora, Kermincola, Coccidomyces, etc...), avec l'indication des cultures qui en ont été faites.

Le mycétome présente des dispositions diverses, que Buchner classe comme suit :

$I^{\circ}$ Le moins différencié est celui de certaines Coccides, Jassides et Fulgorides, où les blastomycètes siègent dans des cellules dispersées du corps graisseux, sans différenciation d'un mycétome localisé 
(Lécaniides, Diaspides). La présence des blastomycètes n'en est pas moins constante, quelle que soit la localité d'où proviennent les individus ;

$2^{\circ}$ Le second stade est celui où il y a un mycétome différencié (Aphides, Aleurodides, Coccides : Icerya purchasi, Dactylopius citri), renfermant une seule

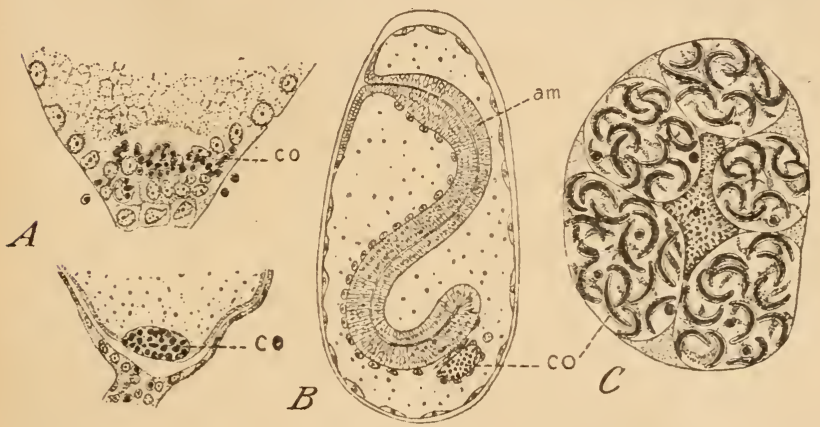

Fig. 48. - Levures symbiotiques et mycétocytes d'Homoptères (d'après Pieraxtoni) : A, deux coupes montrant la pénétration des corpuscules de levure co dans l'oocyte en voie de développement d'Icerya purchasi; $\mathrm{B}$, embryon d'Icerya purchasi avec son amas co de corpuscules embryonnaires; C, un mycétocyte de Dactylopius citri, avec corpuscules co en forme de croissants.

forme de blastomycètes (espèces monosymbiontes); $3^{\circ}$ Certaines espèces sont disj'mbiontes, hébergeant simultanément deux types de blastomycètes, l'un dans des mycétocytes épars, l'autre dans un mycétome différencié (Cicada orni), dont toutes les cellules sont fusionnées en un énorme syncytium plurinucléé, dans les mailles duquel sont logés les blastomycètes;

$4^{\circ}$ Les deux formes des blastomycètes d'une espèce 
disymbionte siégent dans deux mycétomes distincts superposés (Cicadelles, Ptyelus lineatus);

$5^{\circ}$ Les deux mycétomes du cas précédent se fu. sionnent en un seul (Cigale de Libéria, Psyllides);

$6^{\circ}$ Enfin, il peut y a voir simultanément trois espèces de blastomycètes, dont deux dans un mycétome, le troisième dans des mycétocytes dispersés (Psyllides) ou dans un mème mycétome (Aphalara caltha).

Quelles que soient ces diverses complications topographiques, le caractère général commun à tous les cas est que l'infection est absolument constante dans toutes les localités; qu'elle est transmise d'une génération à l'autre au cours de l'oogenèse; qu elle se localise pendant le développement dans des cellules déterminées, qui viennent ensuite constituer un organe spécial, le mycétome, à structure et à position définies.

Quels sont maintenant les rapports physiologiques des blastomycètes et de leurs hôtes? Les premiers n'exercent, de toute évidence, aucune influence nocive sur les seconds ; ils n'ont aucunement la signification de microbes pathogènes. Il est non moins évident, d'autre part, qu'ils trouvent dans les mycétocytes un milieu de culture favorable, ainsi que des conditions excellentes de dissémination par la reproduction de leurs hôtes.

Sulc a émis l'hypothèse que les blastomycètes joueraient un rôle dans la décomposition des urates. Pierantoni a des vues différentes. La constance et la localisation précise des blastomycètes, dans des groupes entiers d'Insectes, sont pour lui l'indication 
qu'ils remplissent une fonction physiologique importante dans le corps de leurs hôtes. Or, tous les Insectes où on les constate, et en premier lieu les Pucerons, se nourrissent sur des Végétaux, d'où ils extraient des quantités considérables de substances sucrées et d'amidon. Les P'ucerons ne peuvent même utiliser tout le sucre qu'ils ingèrent et en rejettent de grandes quantités sous forme de miellée; nous avons vu les rapports qui s'établissent de ce chef entre les Pucerons et les Fourmis. D'après PieranToNi, les blastomycètes produiraient des enzymes aidant à la digestion du sucre et trouveraient naturellement eux-mèmes dexcellentes conditions de nutrition par la présence de ce sucre dans les tissus. Les trachées du mycétome serviraient à la fois à l'accès de l'oxygène pour' ces aćrobies et à l'émission de l'acide carbonique. L'association constante des blastomycètes et de ces Insectes, le caractère des rapports précédents, leur transmission régulière dans l'oogenèse, constituent pour Pierantonr les caractéristiques d'une sy'mbiose physiologique héréditaire.

D'autres cas de symbiose ont été décrits chez les Insectes, mais qui ne présentent pas tous actuellement un caractère également évident. Il faut, en effet, se méfier de prendre pour des microbes indépendants des formations intracellulaires, ressemblant à première vue à des champignons ou à des Bactéries. Les critériums distinctifs sont les strue- 
tures et surtout les cultures, en évitant pour celles-ci toute cause de contamination extérieure.

Ainsi, un cas douteux nous est fourni par les bactérö̈des dont sont bourrées, chez les Blattida, d'une façon constante, certaines cellules du corps graisseux. Signalées d'alıord par Blochmann ( 87 ), ces formations ont été considérées par divers auteurs (Cú́NoT, Henneguy, Prenant) comme des sortes de cristalloïdes, a uxquels ils ont donné le nom de bactéroïdes, à cause de leur ressemblance purement extérieure a vec des bactéries. Mercier ( I 24 ), au contraire, les a regardées comme de véritables bactéries symbiotiques, qu'il a appelées Bacillus cuenoti et qu'il retrouve dèsl'embryon. Enles prélevant, avec des précautions d'asepsie, sur des embryons encore renfermés dans les oothèques, il a obtenu des cultures. Mais on ne peut être sûr que la bactérie cultivée soit bien l'élé-

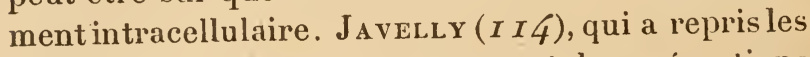
expériences de MERCIER, en prenant des précautions d'asepsie minutieuses, n'a obtenu aucune culture et, d'après lui, Mercier a dû cultiver une impureté se trouvant sur les oothèques, probablement le Bacillus subtilis.

Dans un autre groupe, chez un Mollusque Prosobranche, Cyclostoma elegans, CLAPAnÈDE a décrit, en 1858, une glande à concrétions, dans laquelle, en 1887, Garnault a signalé de grandes cellules renfermant, outre les concrétions, de nombreuses formations bactéroïdes; ce sont là aussi des formations constantes. Mrrcier ( $I$ I 5 ) en a repris l'étude et accepte l'interprétation de Garnault, qui considère les bactéroïdes comme des bacilles. Il a tiré de la 
glande à concrétions du Cyclostome une culture, montrant des éléments bactériformes semblables à ceux de la glande; mais il n'affirme pas qu'ils lui soient identiques.

Blochmann $(8 ;)$ a signalé encore, chez les Fourmis, des bactéroïdes qui devraient ètre réétudiés. Korschelt en a décrit dans les corps adipeux et les glandes salivaires de Pieris brassica. KaraWAIEW ( $\begin{aligned} & \boldsymbol{I} \\ & \text { I) }\end{aligned}$ ), dans une région bien déterminée de l'épithélium intestinal d'un Coléoptère (Anobium paniceum), a vu des organismes qu'il considérait comme des Flagellés et en qui Escherich a reconnu des levures, qu'il a cultivées sur milieux sucrés; d'après ce dernier auteur, il y a un rapport régulier entre l'activité alimentaire de l'Anobium et l'abondance des levures, et ici il semble bien s'agir d'un vrai organisme symbiotique.

Une étude très intéressante a été récemment faite par Roubaud ( $I$ \& I ), sur des levures symbiotiques des Glossines, signalées antérieurement par STUHLMANN. Chez la tsétsé adulte, dans l'intestin moyen, se trouve une zone d'épithélium épaissi, présentant macroscopiquement des taches ou des bandes grisblanches. Les coupes faites à ces niveaux montrent des cellules trois à cinq fois plus hautes qu'au voisinage, formant ainsi de volumineuses papilles et bourrées de formations bacillaires de 3 à $5 \mu$ de longueur. Ces éléments, libérés par la désagrégation des cellules, tombent dans la lumière intestinale. Des frottis montrent qu'elles se multiplient par bourgeonnement typique de levures et RocBaud les rapproche des Gicadomyces de Sulc. Les cellules qui 
les renferment sont donc pour lui de véritables mycétocytes et la constance de ces formations est absolue chez toutes les Glossines étudiées par Stuhlmann et jar Roubaud. Celui-ci les a retrouvées chez la larve et a suivi leur sort dans la nymphose. Chez la larve (qui vit dans l'utérus maternel), les mycétocytes sont localisés au niveau du proventricule. Roubaud admet (sans pouvoir l’établir irréfutablement) que la levure est transmise héréditairement, soit par l'œuf comme chez les Hémiptères, soit plutôt par la sécrétion lactée materneile, car il n'a pu en trouver trace dans les oocytes. Ces éléments sont peu abondants chez les larves, qui sont nourries d'un lait directement assimilable ; ils se développent chez l'adulte, quand la digestion devient active. RouBAuD rattache leur présence au régime hématophage strict des Glossines. A l'appui de cette thèse, il fait observer qu'on ne trouve ni levures, ni mycétocytes chez les Stomoxydes, auxquels se ratiachent phylogénétiquement les Glossines, ni chez les Tabanides, les Culicides, les larves d'Auchméromyies, les Lyperosia, toutes formes qui ne sont pas strictement hémophages. Par contre, chez les Pupipares, groupe d'une origine tout à fait distincte de celle des Glossines, mais adapté à la mème hémophagie stricte qu'elles et présentant le même mode de développement, on retrouve, par une remarquable convergence, les mycétocytes et les levures. Cela résulte des recherches de Sizora sur les Mélophages et de celles de Roubaud sur les Liptotena et les Hippobosques. Il y aurait done, suivant RouBAud, une corrélation étroite entre l'bémophagie stricte et 
l'existence des symbiotes intestinaux; les diastases des levures faciliteraient la digestion des albumines et des éléments figurés du sang. Il y a là, en tout cas, une suggestion intéressante.

$$
\text { ** } *
$$

Pierantoni a été conduit par ses travaux sur le mycétome à des recherches encore en cours et qui, si les résultats en sont définitivement confirmés, étendraient le domaine de la symbiose physiologique héréditaire à une autre catégorie importante de phénomènes, ceux de la luminosité animale. Il y a donc là une question posée d'un intérêt considérable, mais qui exige une très grande rigueur expérimentale.

Il a été frappé tout d'abord ( 35 par le parallélisme entre la structure des corps lumineux des lampyres (vers luisants)et celle de certains mycétomes (Aphrophora). Les organes lumineux sont constitués par un parenchyme, dont les cellules sont bourrées de petits corpuscules faisant-songer aux bactéries et en ayant les réactions colorantes. D'autre part, l'œuf du lampyre, qui est lumineux, renferme les mèmes corpuscules. Pierantoni dit aroir obtenu, sur agar peptoné, à partir des organes lumineux des lampires, des cultures de deux bactéries différentes; il ne dit pas si elles sont lumineuses. Il reste toujours extrêmement difficile d'affirmer que les organismes cultivés sont bien les corpuscules intracellulaires observés. Les documents et expériences publiés sont encore très sommaires. 
Mais c'est surtout sur les Céphalopodes lumineux que l'auteur italien ( $I 3 I$ ) a fait ses recherches Au point de vue morphologique, il a montré tout d'abord qu'il y a un lien intime entre les organes connus jusqu'ici sous le nom de glandes nidamentaires accessoires et les organes lumineux voisins de l'anus et de la poche du noir. Ces glandes n'ont aucun rapport avec la confection de la coque de l'œuf et n'émettent pas de sécrétion proprement dite. En général elles n'existent que chez la femelle, où elles sont adjacentes aux glandes nidamentaires proprement dites; mais on les trouve chez le mâle de certaines espèces (Loligo forbesi). Sous leur forme la plus simple (Loligo), ce sont des amas de tubes épithéliaux, plongés dans du tissu conjonctif, et, dans ces tubes, il y a toujours des amas de granulations, qui, d'après Pifrantoni, seraient des bactéries d'origine extérieure, dont il a obtenu des cultures. La glande serait donc un organe de symbiose. Chez les Seiches, la structure de la glande nidamentaire accessoire est complexe; elle comprend des tubes de trois couleurs (blanc, jaune et rouge-orangé), bourrés aussi de bactéries d'aspects différents dans les trois cas (cocco-bacilles, bacilles et cocci). Il y aurait aussi de nombreuses bactéries dans les cellules épithéliales et le tissu conjonctif. Elles seraient ensemencées lors de la ponte, à la surface de l'œuf et entre les feuillets de la coque. Elles seraient donc transmises héréditairement, se localiseraient et se multiplieraient dans la glande nidamentaire accessoire qui serait pour elles un récepteur spécifique. Il a été obtenu (l'étude bactériologique a été faite par ZIR- 
Polo) des cultures de'ces divers bacilles: celles qui proviennent des tubes jaunes sont luminescentes. Or Pierantonr a constaté, sur les Seiches femelles, à la saison des amours, une luminescence de la face ventrale, qui n'avait pas été signalée jusqu'ici.

Arrivons aux Céphalopodes pourvus d'organes lumineux ventraux. Pierantosi a pu les étudier sur le vivant, dans de bonnes conditions, sur les Sépiolides où ces organes ont été assez récemment découverts (Rondeletia, Sepiola). La glande nidamentaire accessoire (présente seulement chez les femelles) n'a plus que deux catégories de tubes (blancs et rouges). Les organes lumineux qui, chez la femelle, occupent la partie centrale de la glande, sont formés de tubes jaunes; il paraît extrêmement probable que les organes lumineux sont une partie spécialisée de cette glande, où se sont concentrés les tubes jaunes. Il s'est formé, en outre, en profondeur, un réflecteur, aux dépens du tissu musculaire, et, superficiellement, une lentille, aux dépens du tissu conjonctif. Ces tubes de l'organe lumineux, fortement dilatés (fig. 49), sont remplis d'une masse finement granuleuse, constituée, d'après Pierantoni, par des bactéries et qui est la substance lumineuse ellemême En prenant de minutieuses précautions d'asepsie, Pierantoni et Zirpolo ont obtenu des cultures qu'ils considèrent comme prorenant de ces corpuscules. Sur bouillon de seiche, elles donnent un voile blanc, magnifiquement luminescent en vert émeraude, qui illumine tout le liquide quand on agite.

Pieranton insiste sur les précautions d'asep- 
sie employées et sur les différences d'aspect entre les bactéries cultivées et les bactéries lumineuses, qui se rencontrent d'une façon banale sur la peau ou les muscles des seiches et des poissons morts. Il conclut done que la luminescence des Sépiolides serait due à des bactéries sy mbiotiques ( $\mathrm{I}$ ), localisées dans l'organe lumineux, qui est une différenciation de la glande nidamentaire accessoire des Seiches et des Calmars. Il a vérifié que cet organe lumineux fonctionne de deux façons: par illumination intérieure de sa substance (bactéries symbiotiques), et par émission du contenu de ses tubes dans l'eau ambiante, qui devient alors une nappe lumineuse. Les bactéries photogènes s'ensemenceraient de génération en génération, lors de la ponte des œufs. Il y aurait donc là une symbiose physiologique héréditaire, ayant probablement une grande généralité : aussi l'auteur italien se propose-t-il de reprendre l'étude des divers organes lumineux des Céphalopodes abyssaux, malheureusement très difficiles à obtenir en bon état, et il a déjà fait quelques observations sur une espèce recueillie à Messine (Cha-

I. Zirpolo (1 $48-149)$ a caractérisé deux types de bactéries :

a) Bacillus pierantonii (extrait de l'organe lumineux de Sepiola intermedia): bacille mobile de $\mathbf{I} \mu, 5 \times 0 \mu 5$; ni cils, ni spores; ne résiste pas a:ı Gram, ne prend pas le Ziehl. Colonies sphéroüdales translucides, blanc jaunâtre sur agar: trouble le bouillon; luminescence vert émeraude (très vive dans le bouillon additionné de phosphate di- ou trisodique).

b) Micrococcus pierantonii (ex trait de l'organe lumineux de Rondeletia minor).Diam. I $\mu 2-$ I $\mu$ 8. Mèmes caractères que le précédent, colonies sphériques: se développe très rapidement et est très lumineux sur les muscles de seiche. 
rybditeathis). Le noyau luminescent des organes photogènes serait « toujour's constitué par des cellules remplies de microorganismes, transformés par adaptation à la vie intracellulaire ». Mais cela n'est basé que sur l'étude de pièces fixées et colorées. Il n'a pu être fait de culture et la situation intracellulaire des corpuscules considérés comme des bacté-
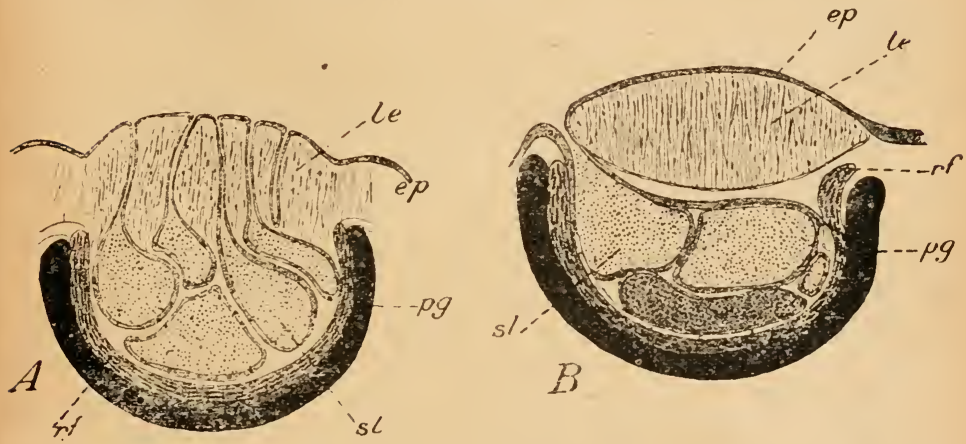

Fig. 49. - Coupe de l'organe lumineux de Rondeletia minor (A) et de Sepiola intermedia (B) : ep épiderme, le lentille, $p g$ couche pigmentaire, $r f$ réflecteur, $s l$ substance lumineuse (d'après Pierantoni).

ries pose des problèmes graves qui seront examinés plus loin.

Pierantoni ( I 3 J) a été entraîné à des généralisations plus étendues encore; il a appliqué les conceptions précédentes à tous les animaux lumineux, à la fonction chromogène (par exemple chez la pourpre) et d'une façon générale à toutes les actions diastasiques. Mais ici nous sommes encore entièrement sur un terrain spéculatif et nous aurons l'occasion de 
discuter ces idées dans le dernier chapitre. Restant sur le terrain de l'observation proprement dite, qui pour l'instant est constitué par les organes lumineux ouverts des Céphalopodes, nous exprimerons le désir de voir encore reprendre par des méthodes aussi rigoureuses que possible la démonstration de la nature bactérienne des grains lumineux. La fréquence de bactéries lumineuses banales dans la mer est une cause d'erreur très difficile à éliminer. Il faudrait imaginer des expériences témoins simples et irréfutables pour prouver que les bactéries lumineuses cultivées sont bien extraites de l'organe. Les méthodes zoologiques sont insuffisantes ici. L'intérêt très grand des résultats annoncés par Pierantoni rend cette vérification d'autant plus désirable. 


\section{CHAPITRE XII}

\section{LA SYMBIOSE ENTRE VÉGÉTAUX}

Sommaire. - Les Lichens. - Historique. - Nature des rapports de l'algue et du champignon. - Théories diverses. - Etude expérimentale de l'algue en culture pure. Recherches de ChоDat. - Les bactéroïdes des Légumineuses. - Les mycorhizes endotrophes et ectotrophes. Les mycorhizes des Orchidées. Historique. - Recherches de Noël Bernard. - La germination naturelle de Neottia nidus avis. - Germination des graines d'Orchidées en tubes stériles par ensemencement de Rhizoctonia. - Spéciticité de ces Rhizoctonia. - Leurs rapports avec l'Orchidée. - Conditions d'infestation. - Variations de virulence. - Exaltation par passages. - Phagocytose et immunité. - La symbiose et l'évolution des végétaux. - La symbiose, frontière de la maladie. - Symbiose, mutualisme et parasitisme.

Nous arrivons maintenant aux symbioses entre végétaux. La plus classique est celle des Lichens. Elle est si complète qu'elle a produit des plantes ayant un faciès propre, bien défini, dont on a pu faire une classification cohérente et étudier la structure, sans qu'on soupçonnât le dualisme de leur nature, si bien que cette dernière notion s'est heurtée à une longue et vive opposition.

Tout lichen résulte de l'association d'un champi- 
gnon et d'une algue. Le mycélium du premier (h)phes) forme la partie incolore; c'est généralement un Ascomycète, rarement un Basidiomycète. L'origine exacte de ces champignons est le plus souvent encore inconnue : pour un certain nombre, on a pu reconnaître la famille à laquelle ils appartiennent (Xylariacées, Hysteriacées, Patellariacées). Les algues, ou gonidies, sont le plus souvent des Protococcacées, quelquefois des Chroolépidacées; souvent il s'y associe des Cyanophycées. Sur l'appareil végétatif, se différencient des appareils reproducteurs, qui sont, soit de pures fructifications de Discomycètes et Pyrénomycètes, soit de ces fructifications où l'algue a pénétré et qu'on nomme alors apothécies. Les spores du champignon peuvent commencer à germer seules, mais le développement du jeune thalle s'arrête très vite s'il ne rencontre pas l'algue qui lui convient.

En outre, beaucoup de lichens se propagent par des organes spéciaux, appelés sorédies. Ce sont de petites masses sphériques, constituées par l'algue entourée de quelques hyphes. Ainsi l'association est réalisée d'emblée. Les sorédies se forment dans des organes spéciaux.

Les associations lichéniques se présentent, comme toutes les précédentes, au point de vue de la spécificité. Celle-ci est généralement rigoureuse. Il arrive cependant que le même champignon peut s'accommoder de plusieurs algues très différentes. Il donne alors avec chacune un lichen distinct. Ainsi Möller ( $6 I$ ) a montré qu'un champignon du groupe des Basidiomycètes donne un lichen du 
genre Cora avec une algue du genre Chruococcus et un Dictyonerna avec une algue du genre Scytonema. Les deux lichens peuvent mème ètre réalisés côte à côte, sur le mème thalle, en parabiose. Inversement, la mème algue peut aussi former des lichens différents avec des champignons variés; un lichen peut même se transformer en un autre par substitution progressive de champignon, processus qui a reçu le nom d'allélositisme. Des associations hétérogènes peuvent être localisées en des points limités d'un même lichen; elles forment alor's ce qu'on appelle des céphalodies. Ainsi, à la face inférieure des Solorina saccata, lichen dont les gonidies sont vertes, on observe des productions arrondies, visibles à l'œil nu, qui sont des associations des hyphes avec des Cyanophycées.

Le dualisme des lichens a été découvert en $x 86 \mathrm{~J}$ par Schwendener i i 66 ). Bornet ( I 5 4) a précisé les rapports anatomiques des gonidies et des hyphes. Restait à faire la synthèse d'un lichen, en cultivant séparément les deux constituants, puis les unissant. Mais les cultures isolées de l'algue ou du champignon sont très difficiles à obteuir et les méthodes de culture étaient alors insullisantes. Rees, Staht, Mör.LER ont apporté des contributions à cette synthèse, qui a été réalisée en I 889 par G. Bonsıer, à partir decultures pures des deux éléments; des fructifications ont été obtenues sur le lichen résultant. Il y aurait intérèt d'ailleurs à reprendre cette démonstration aujourd'hui, avec la púreté qu'on sait maintenant apporter dans les cultures.

Aujourd'hui le dualisme des lichens est universelle- 
ment admis. Cependant, en Igr 3 encore, le botaniste finlandais Elfring ( 58 ) a cherché à montrer que les hyphes sont capables de produire par elles-mêmes des gonidies et que celles-ci, une fois formées, peuvent. vivre isolément à l'état d'algues. Mais si le dualisme n'est plus vraiment en question, les rapports entre les deux composants sont encore sujets à discussion. Le fait global est qu'il y a union permanente entre eux et qu'il en résulte un organisme individualisé, avec sa morphologie et.sa physiologie propres et bien définies, et que les deux composants vivent très difficilement isolés. Il y a donc là un ensemble de données correspondant bien à la notion de symbiose.

Mais faut-il y voir une symbiose parfaitement mutualiste, comme on le croit généralement, chacun des composants étant pour l'autre la source d'avantages réciproques équilibrés? Il faudrait pour l'affirmer connaître à fond la nutrition des deux plantes à l'état isolé et dans la vie commune. Or cette connaissance est encore très insuffisante et l'association a été considérée jusqu'ici de façons très divergentes qui se résument aux trois suivantes:

$\mathrm{I}^{\circ}$ Le champignon vit en parasite aux dépens de l'algue;

$2^{\circ}$ L'algue est parasite du champignon;

$3^{\circ}$ L'association est une symbiose mutualiste.

$\mathrm{I}^{\circ}$ Schwendener était partisan de la première théorie qu'il développe en un style imagé : Le champignon est le maître, les algues vertes sont les esclaves : « il les entoure, dit-il, comme une " araignée entoure sa proie d'un étroit réseau de 
"fils, qui se transforme peu à peu en une enve" loppe impénétrable. Mais, tandis que l'araignée " suce le sang de sa victime et ne l'abandonne que ( morte, le champignon excite les algues prises dans ( son réseau à une plus grande activité et même (c à une multiplication plus intense; il rend possible ( ainsi une croissance plus vigoureuse et un bon (" développement de toute la colonie. ) Les algues (c maintenues en esclavage sont transformées, en (c peu de générations, à tel point qu'on ne peut plus " les reconnaître. ) Ces opinions ne sont pas, à vrai dire, justifiées par des études physiologiques précises faites sur les composants isolément. Dans la pensée de Scutwexdener, l'algue opère les synthèses à partir de l'anhydride carbonique de l'air, le champignon lui transmet l'eau et les sels minéraux du sol.

Beaucoup d'auteurs ont partagé les vues de ScHwendener, par exemple Bornet, G. Bonnier, WarMiNG. Ce dernier considère que l'algue peut vivre seule, tandis que le champignon a besoin de l'algue et celle-ci est empêchée par le champignon de se reproduire à l'état de zoospores. L'algue est donc parasitée et Warmısg donne le nom d'hélotisme à ce mode spécial de parasitisme, où le parasite (le champignon) fournit à l'hòte (l'algue) une partie de sa nourriture.

Un auteur russe récent, DANiloff, va jusqu'à admettre que le champignon tue les gonidies à l'aide d'un réseau d'hyphes suceurs qui y pénètrent et qu'il rapproche d'un mycoplasma d'ErIcksos.

$2^{\circ}$ La théorie inverse - parasitisme de l'algue sur 
le champignon - a été formulée par Beijerinck (189o). Cet auteur n'a pu réussir à cultiver l'algue (Cystococcus) du Physcia parietina en lui fournissant de l'azote nitrique ou ammoniacal additionné de sucre; mais il en a obtenu la culture avec de l'azote peptique et voici, d'après lui, les rapports de l'algue et du champignon : le champignon se nourrirait d'azote ammoniacal et de sucre; des peptones produites par lui diffuseraient de son cytoplasme et assureraient l'assimilation du Cystococcus. Ainsi l'algue se nourrirait en réalité aux dépens du champignon, au moins en ce qui concerne les substances azotées. Cette opinion a trouvé une confirmation dans les travaux d'Artari. Suivant ToBLER, l'algue recevrait également une partie de son carbone du champignon, qui est saprophyte et elle suppléerait ainsi au déficit de son assimilation chlorophyllienne, entravée par sa situation défectueuse dans le thalle du champignon,

$3^{\circ}$ Entre ces deux conceptions se place l'idée de la symbiose mutualiste, qui a eu pour principaux représentants de Bary, Reinie et Van Tieghem. Selon Reinke ( I 64), ces rapports de l'algue et du champignon sont ceux des feuilles et des racines d'une plante verte. L'algue (autotrophe) fait la synthèse des hydrates de carbone et emprunte au champignon (hétérotrophe) les matières azotées et albuminoïdes que celui-ci fabrique à l'aide des hydrates de carbone fournis par l'algue ; lui-même, en outre, draine l'eau et les substances minérales.

La symbiose apparaît sous un jour encore différent dans les recherches de M. et Mme F. Moreau 
( 162 ). Elle se présente comme une srmbiose antagoniste, reflétant les conceptions de Noël Bernard, à propos des Orchidées, que nous allons étudier plus bas et se rattachant, d'autre part, à l'idée de parasitisme de l'algue sur le champignon. Le thalle aérien d'une Peltigéracée - groupe spécialement étudié par ces auteurs - est, suivant eux, l'équivalent d'un organe déformé par un parasite, comme une galle ou cécidie. Cette notion doit ètre étendue à l'ensemble des lichens dont les thalles ont la valeur d'algocécidies. Les lichens seraient des champignons malades, atteints diune affection chronique, spécifique, qui a acquis pour l'espèce un caractère de géneralité et de nécessitẻ, l'agent infectieux étant une algue.

En se débarrassant des fantômes verbaux, il s'agit en réalité d'analyser, par des expériences précises, les rapports de l'algue et du champignon, en comparant minutieusement leur comportement à l'ètat isolé et en association.

En ce qui concerne le champignon, ces études sont encore peu avancées. On a rarement réussi à le cultiver à l 'état de pureté. Mölcer a obtenu des mycéliums sans gonidies, mais qui n'ont pas produit de corps reproducteurs. La spore qui germe doit rencontrer rapidement la gonidie convenable. Au contact de celle-ci, comme en vertu d'un tropisme et d'un tactisine spéciaux, le mycélium forme des renflements qui fixent les gonidies, les entourent et les incorpor'ent. Les gonidies semblent être, au moins dans les conditions normales, la condition nécessaire de l'évolution du mycélium. Les champignons des 
lichens ont certainement subi une adaptation étroite - aux gonidies et ont plus ou moins complètement perdu la faculté de vivre isolément.

Quant à l'algue, elle vit plus aisément seule et son étude à l'état isolé a reçu dans ces derniëres années une impulsion vigoureuse, grâce aux belles recherches de R. Chodat ( 56 ), sur les méthodes de culturepure de ces organismes (I). Mais ces recherches mèmes ont souligné la difficulté de tirer des conclusions nettes en ce qui concerne les Lichens. Chonat, en effet, a constaté que la plupart des algues inférieures qu'il a cultivées, et non pas seulement les gonidies extraites des lichens, sont plus vigoureuses si on leur fournit une nourriture organique et non pas seulement de l'azote nitrique ou ammoniacal. La préférence des gonidies pour l'azote peptique n'est done pas un signe certain du parasitisme de l'algue.

On trouvera une contribution intéressante (à laquelle j'ai fait ici divers emprunts) à cè problème

I. Voici le principe de ces méthodes : on vroie le lichen dans un mortier flambé et contenant de l'eau stérilisée. On observe au microscope une gontte du liquide, de façon à y compter les gonidies. On fait des dilutions en conséquence et on ensemence des gouttes de ces dilutions dans des milieux appropriés, tel que, par exemple, le milieu de DrTMER :

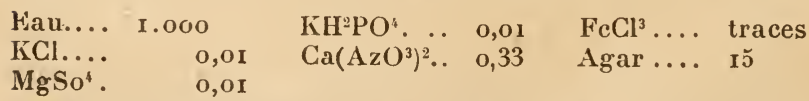

Sur ce milieu, poussent divers organismes, dont les gonidies et on peut admettre que chaque colonie provient d'une cellule unique. On isole alors les colonies par repiquage. La mise en culture définitive d'une gonidie par ce procédé exigre au moins deux mois. 
dans un travail récent d'un élève de Chodat, A. Letellier ( 160 ), ct j'en résumerai brièvement les résultats essentiels à titre d'exemple. Il a étudié en culture pure la nutrition d'un Nostoc (Nostos peltigera), extrait d'un Peltigera, celle d'un Cystococcus (I) extrait de Xanthoria parietina, celles de divers Stichncoccus (les uns libres et un autre provenant de Coniocybe furfuracea), celles de Coccomyxa (libres ou provenant d'un Solorina). Leteller a constaté ainsi que Nostoc peltiger $\not e$ se distingue des Cyanophycées libres, précédemment étudiées, par son pouvoir élevé d'assimiler différents sucres et par ses ferments protéolytiques. Parmi les $C$ ystococcus, les gonidies assimilen de préférence la nourriture organique. Des Cystococeus libres, les uns se comportent de mème, les autres préfèrent une nourriture azotée inorganique. Les Stichococcus gonidies semblent, au point de vue de leur nutrition azotée, a voir des caractéristiques moins parasites que celles de certains Stichococcus libres. Dans le groupe des Coccomyxa, les gonidies préfèrent une nourriture inorganique, tant en azote qu'en carbone.

Il n'y a donc pas de distinction générale et uni. forme entre les gonidies et les algues congénères

I. Chodat lui-même avait déjà étudié des Ćystococcus provenant de divers Cladonia et constaté des différences minimes dans la morphologie et la physiologie de ces algues, suivant leur provenance; il les considère comme des races distinctes. Les colonies de C. xanthoriœ-parietina diffèrent beaucoup de celles de Cladonia (étant, bien entendu, cultivées sur les mêmes milieux). Ces résultats montrent l'adaptation réciproque de l'algue et du champignon dans le lichen et la spécificité acquise de leur association. 
vivant en liberté. Tantôt les unes, tantôt les autres s'accommodent mieux d'une nourriture organique. Les rapports de nutrition entre les algues et les champignons dans les lichens doivent donc ètre très variés.

Ces quelques résultats indiquent la complexité du problème et montrent qu'il exigera des études particulières, nombreuses et extrêmement précises.

En réalité, les lichens actuels résultent d'une longue adaptation réciproque des champignons et des gonidies. Les deux organismes se sont modifiés dans cette association et n'ont plus leur propriétés initiales.

$$
* * *
$$

Un autre exemple de symbiose dans le règne végétal, également classique aujourd'hui et que je me bornerai à rappeler, est celui des nodosités des racines de Légumineuses; les bactéries du sol, qui assimilent l'azote de l'atmosphère, sont incorporées aux radicelles, dans les nodosités et modifiées morphologiquement en bactéroïdes, dont la substance est finalement assimilée par la plante. L'influence favorable des Légumineuses sur le sol est connue depuis des temps reculés et Liebig montra qu elle reposait sur un eṇichissement en azote. Hellriegre et WillFAHRT en 1888 établirent que celui-ci est dù à la symbiose de la plante avec des bactéries du sol, qui tirent l'azote de l'atmosphère, comme le prouvèrent Schlosing el Laurent. Les bactéries furent isolées par Beiseninck (Bacterium radicicola) et 
les nodosités ont pu être produites par voie synthétique, en cultivant, d'une part, les bactéries, d'autre part la plante, dans un sol stérilisé, puis ensemençant les premières dans ce sol (I).

Une symbiose analogue existe pour l'aulne dont les racines offrent aussi des nodosités produites par des Streptotrichées et pour diverses Eléagnées (Eleagnus, Hippopha).

On a constaté aussi des nodosités produites par des bactéries symbiotiques sur les feuilles des Rubiacées et des Myrsinacées tropicales, dans des conditions qui sont semblables à ce que montrent les Légumineuses. Toutes ces lormations se rapprochent au fond beaucoup des galles et pourraient être considérées comme des bactériocécidies.

$$
\text { ** }
$$

Je m'étendrai davantage sur des associations extrêmement répandues entre des champignons dits mycorhizes et les racines des plantes arborescentes ou herbacées.

Dès le milieu du $\mathbf{x I x}^{e}$ siècle, on en a signalé et on en connaît aujourd'hui un grand nombre de cas : dans le prothalle de certaines Hépatiques, chez des Muscinées, dans les divers groupes de Cryptogames vas-

I. D'après Proy (C. R. Acad. Sci., t. I5j, 1913, p. 77) les bactéroïdes des Légumineuses sont des Myxobactéries. Or, il a reconnu que la condition sine qua non de la culture des Myxobactéries (en particulier Cihondromyces crocatus) est leur association avec un Micrococcus (voisin des Micrococcus latens). Les Myxobactéries, au moins à l'état isolé, seraient donc elles-mèmes un exemple de symbiose. 
culaires (prothalle et sporophyte des Lycopodiacées. - Lycopodium, Psilotum, Phylloglossum, - chez des Fougères-Ophioglossées), dans la plupart des plantes vivaces et arborescentes. En r88I , KAMIENSK I émit l'hypothèse d'une symbiose entre le champignon et son hôte. Cette idée fut développée surtout à partir de I 885 par FraNK ( I O 2), qui montra en même temps la grande extension et la constance des mycorhizes. Il distingue les mycorhizes ectotrophes, qui restent extérieurs aux racines, autour desquelles ils forment un manchon mycélien et se rencontrent surtout sur les arbres forestiers (Conifères, Amentacées) et les mycorhizes endotrophes, qui pénètrent dans les cellules de la racine.

Daprès Frank, il y a symbiose mutualiste entre les mycorhizes ectotrophes et les plantes qui les portent. Le champignon se substituerait fonctionnellement aux poils radicaux : il puiserait dans le sol, pour les amener à la plante, les sels minéraux et les aliments organiques azotés de l'humus; la plante, de son côté, céderait au champignon des hydrates de carbone fabriqués par elle. Les endotrophes contribueraient en outre finalement à la nutrition de la plante, en étant digérés par elle et lui fournissant ainsi des matériaux azotés.

La conception primitive de Frank a été notablement modifiée depuis. C'est chez les Orchidées que ces recherches ont pris le caractère le plus précis et nous les examinerons à part. En ce qui concerne les arbres des forêts, le rôle des mycorhizes n'apparaît pas commeune symbiose aussi précise que l'indique Frank. Les poils radicaux ne sont nullement sup- 
primés et restent fonctionnels. Le champignen parait être un parasite, peu nocif et toléré. On trouvera un historique de l'ensemble des recherches sur les endotrophes, jusqu'en rgo4, dans la thèse de GALLAUD ( 59 ), qui contient une étude morphologique et physiologique approfondie de ces champignons dans les plantes de nos pays.

Les mycorhizes endotrophes (abstraction faite de ceux des Orchidées) semblent constituer, d'après les caractères de leur appareil végétatif, un groupe assez naturel, mais dont les affinités restent obscures Leur mycélium présente, à l'extrémité de leurs filaments, de fréquentes vésicules extra- ou intracellulaires et surtout des arbuscules fortement ramifiés, soit intra - soit extra cellulaires, qui leur sont spéciaux et ont été bien mis en évidence par GALI.AUD (fig. 53). Ces arbuscules subissent un mode de dége̋nérescence caractéristique, dans lequel l'extrémité des rameaux principaux se termine par des sortes de boules ou sporangioles. Arbuscules et sporangioles se retrouvent lans les mycorhizes des plantes les plus variées et on ne les connaît pas ailleurs. Il n'a pas été possible jusqu'ici d'isoler ces mycorhizes et de les cultiver; on ne connait donc pas leur position systématique. Ils ont été certainement très modifiés par leur adaptation à la vie associée avec les tissus des racines.

Quant à l'action réciproque de la plante et du champignon, les cellules renfermant les arbuscules, ou celles situées au voisinage, ne contiennent pas de grains d'amidon. Il semble que le champignon consomme les sucres aux dépens desquels cet amidon se for- 
merait. Dans les cellules à arbuscules, le noyau se gonfle, prend des contours a moboïdes, offre un excès de chromatine et se divise parfois par amitose. En général, la cellule finit par digérer le champignon. Les mycorhizes endotrophes prennent en somme à leur hôte des hydrates de carbone. Leurs communications avec le dehor's sont, d'autre part, bien insuffisantes pour qu'on puisse admettre qu'ils tirent du

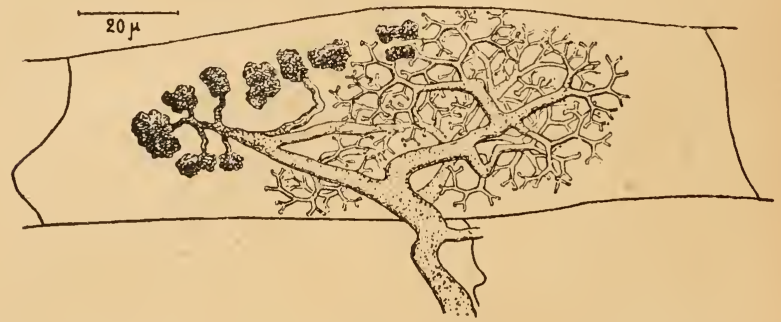

Fig. 5o. - Terminaison intracellulaire (arbuscule et. sporangioles) d'un mycorhize endotrophe dans Allium spharocephalum (d'après GaLLAUd).

sol et apportent à la plante des matériaux appréciables. Ils se nourrissent donc aux dépens de la plante et se comportent comme des parasites. Mais leur action ne parait s'exercer que sur des substances organiques inertes élaborées par la plante et non sur la substance vivante de celle-ci, comme c'est le cas des champignons vraiment parasites (Urédinées, Péronosporées, etc.). Ils finissent par être phagocytés. Gallaud considère que les mycorhizes endotrophes sont, en général, des saprophytes, qui végètent dans les tissus des plantes, sans y causer de dégâts notables, mais sans aider non 
plus leurs hòtes à assimiler. Il ne semble donc pas, au moins en l'état de nos connaissances, que nous devions voir dans les associations entre plantes et mycorhizes une symbiose effective.

Toutefois ces conclusions ne sont vraisemblablement pas valables pour tous les mycorhizes, comme on est amené à le penser d'après les faits relatifs à ceux des Orchidées et probablement aussi des Lycopodes et des Ophioglossées.

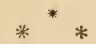

L'existence de mycorhizes endotrophes est générale chez les Orchidées et ils y ont été signalés dès le milieu du $\mathbf{x I x}^{\mathrm{e}}$ siècle. En 1846 , Reisser vit le mycélium et en tenta la culture. Au cour's des vingt. cinq années suivantes, une série d'observateur's, tels qu'Irmisgh, Schacht, Prillieux, Fabre, Drude, etc., les virent, sans toujours en reconnaitre la nature, et ce fut Kamienski, qui, en I88 r, interpréta leur présence comme une symbiose avec l'Orchidée. WAHRLICH, en I889, en montra la généralité en les trouvant dans les racines de toutes les Orchidées qu'il examina, soit environ ว̌oo espèces. Mais c'est Noël Bernard ( 5 I ) qui montra leur importance et leur rôle précis dans la vie de la plante.

Il prouva, en effet, que c'est la présence du champignon qui rend possible le développement de la graine des Orchidćes. On sait que ces plantes, dont la fleur est si spéciale, produisent, en nombres énormes (plus d'un million par capsule, dans certaines Orchidées exotiques), des graines très petites

iI. Caullert. - Le Parasitisme 
et d'une structure rudimentaire. Elles n'ont pas d'albumen et l'embryon y est indifférencié, réduit à un massif de cellules avec un suspenseur. La germination des Orchidćes n'avait été réussie, pendant le $\mathrm{x}_{\mathrm{x}}{ }^{\mathrm{e}}$ siècle, que d'une façon irrégulière, empirique et par des procédés tenus secrets. BERnard, qui avait vainement essayé de faire germer des graines de Neottia nidus-asis, Orchidée indigène dépourvue de chlorophylle, résolut entièrement le problème, en découvrant une Neottia, dont la hampe florale s'était recourbée vers le sol et dont les graines avaient spontanément germé au contact de la terre, dans la capsule même du fruit. En observant les jeunes plantules au microscope, il constata qu'elles étaient envahies par le mycélium de champignons et que cette infection, extrèmement précoce, se faisait par le point d'attache du suspenseur. La pénétration du champignon se présentait donc comme le premier phénomène de la germination; il y vit la cause déterminante de celle-ci et cette hypothèse fut pleinement vérifiée.

Ainsi s'expliquaient aisement les réussites empiriques et les insuccès des praticiens. On savait, en effet, que pour faire germer les graines, il fallait les semer sur la terre du pot où avait poussé la plante mère, c'est-à-dire sur un sol contenant le champignon. Avec le temps, la germination des Orchidées dans les serres était devenue graduellement plus facile, parce que la terre des serres était devenue yeu à peu plus riche en champignons à la suite d'une longue culture. Dans la nature, le nombre immense des graines compense, pour la perpétuation 
de l'espèce, la perte des nombreux embryons qui ne rencontrent pas le champignon nécessaire à leur développement. Il y a là un mécanisme parallèle à celui qu'offrent les animaux parasites et qui a les mêmes conséquences.

Bernard vit aussi l'influence que le champignon exerce sur la tubérisation et crut même que, d'une manière générale, celle-ci était la conséquence de l'infestation d'un organe souterrain par des champignons symbiotiques; il a montré la coexistence des deux faits chez nombre de plantes. On peut, il est vrai, réaliser la tubérisation en dehors de la présence des champignons. Molliard, par exemple, l'a obtenue pour des radis, en les cultivant sur une solution de glucose en milieu aseptique, mais cela n'est pas incompatible avec l'explication de N. Bernard.

En ce qui concerne le rôle des champignons dans la germination, BERNARD ( 152 ) l'a prouvé expérimentalement, de façon rigoureuse. Il a réussi à isoler et à cultiver, in vitro, le champignon, ce à quoi on n'est pas encore parvenu pour les autres mycorhizes.

Voici, en quelques mots, sa méthode. Il dissèque une racine ou une plantule infestée et cultivée en tube stérile, sous le microscope binoculaire, dans des conditions de rigoureuse asepsie et il isole des pelotons mycéliens intracellulaires du champignon, qui en constituent une des caractéristiques essentielles. Il est ainsi à l'abri de toutes les moisissures ou bactéries banales, qui, dans des conditions ordinaires, étouffent le mycorhize sur le milieu de culture. Ces pelotons sont alors ensemencés, un à un, à 
l'aide d'une anse de platine stérile, sur un milieu de culture, où ils donnent un voile, dont nous verrons plus loin les particularités.

Les graines, recueillies aseptiquement - en flambant les capsules et les plongeant rapidement dans l'alcool, avant de les ouvirir, - sont semées dans des tubes de culture stériles, de la forme usitée en bactériologie, sur agar ou coton hydrophile additionné d'une décoction de salep (I). Dans ces conditions. elles restent, pendant des mois entiers, sans subir de modifications; ou bien elles verdissent et acquièrent un début de différenciation, variable suivant les espèces, mais qui reste toujours rudimentaire. Elles ne germent pas.

Mais si, dans les tubes où elles sont ainsi restées inertes, on ensemence le mycélium du champignon cultivé d'autre part, en peu de temps, on voit ces graines évoluer. Elles prennent généralement tout d'abord l'aspect d'un petit tubercule, en forme de toupie, ne produisant que tardivement des feuilles et des racines et semblable à ce que Treub a observé chez les Jycopodes (qui présentent aussi des mycorhizes et a appelé protocorme.

Le protocorme donne alors graduellement la plante feuillée. Bernard a obtenu régulièrement de la sorte

1. Le salep est une poudre obtenue en broyant des tubercules d'Orchidées (Ophrydées) desséchés. La décoction se fabrique par macération de 60 grammes de salep dans deux litres d'eau pendant vingt-quatre heures, puis chauffage pendant une heure à 120 degrés à l'autoclave. Bkrnarna employé des dilutions variées de ces décoctions graduées, en mesurant l'abaissement de leur point de congélation (voir 759, note $\mathrm{J}, \mathrm{p}, 180$ ). 
la germination de très nombreuses Orchidées en tubes de culture. La figure ̌r montre une Phalcenopsis - Orchidée épiphyte dont la germination était particulièrement difficile à réaliser, - qui a poussé dans ces conditions et qui, ayant été confièe à un praticien et ayant été cutivée ensuite en terre par les procédés ordinaires, a fleuri normalement ( $\mathrm{u}$ ). Les figures 52 , montrent des semis $\mathrm{C}_{1}$ - $\mathrm{C}^{\prime}$, analogues de Cattléyées et de nombreuses jeunes plantes en voie de différenciation.

Revenons aux champignons eux-mêmes. Leur végétation dans la plante est caractérisée par la formation, dans les cellules, de pelotons serrés de filaments. Ces formations, réapparaissent, quoique assez rares, dans les cultures in vitro. Ce n'est pas la compression mécanique qui détermine leur formation dans la cellule. Ils n'en sont pas moins le mode de régétation intra-cellulaire caractéristique

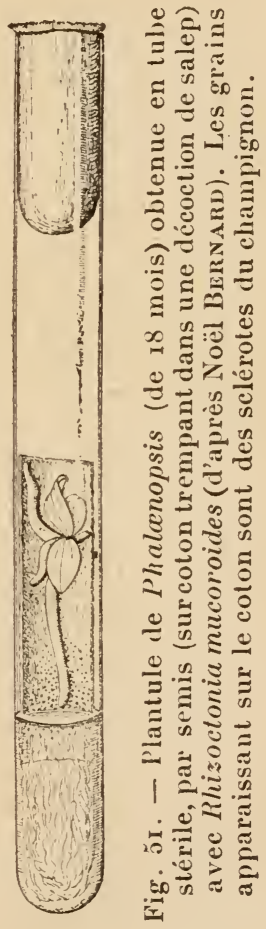
du mycorhize et BERNARD considère qu'il est déterminé par une action humorale; il compare celle-ci à l'agglutination d'une bactérie par le sérum d'un ani-

1. Vers le bas de la tigure, les points que l'on voit à la surface de l'agar sont des sclérotes du champignon. 
mal vacciné. On n'a pas réussi à obtenir la forme parfaile du mycorhize, mais seulement des états mycéliens. Bernard pense que tous les mycorhizes des Orchidées appartiennent à un même groupe naturel, qui s'est adapté à ces plantes et qu'il range dans le genre Rhizoctonia. Une espèce de ce genre, R.solani, est commune sur la pomme de terre et y forme- des sclérotes verdàtres. Elle est considérée comme identique au $R$. violacea de Tulasne, trouvée sur les racines de luzerne et de safran. Ce champignon forme des pelotons intracellulaires, comme les endophytes des Orchidées.

Les nombreux champignons, extraits par BERNARD des Orchidées, ont été considérés par lui comme constituant trois espèces :

I. Rhizoctonia repens, le plus répandu, tiré de très nombreux genres et espèces et qui serait la forme la plus primitive.

2. R. mucoroides, extrait uniquement des racines de Phalanopsis et de Vanda, mais retrouvé toujours dans les plantes de ces genres quelle qu'en fut la provenance (I).

3. R. lanuginosa, obtenu seulement d'Odontoglosum grande.

BURGEFF (I55), qui a repris les recherches de Bernard et en a vérifié et confirmé tous les principaux résultats, admet une variété spécifique des champignons beaucoup plus considérable. Il fait de ces champignons un groupe nouveau, les Orchéo-

I. Bernard a obtenu le même Champignon des racines d'Ophioglossum, mais il était sans action sur les Orchidées. 
mycètes et en décrit r5 espèces. En principe, il considère que chaque espèce d'Orchidées a son endophyte propre (I).

L'œuvre de Bernard nè s'est pas bornée à ces résultats d'importance théorique et pratique considérable. En possession des Rhizoctonia, il a pu analyser d'une façon pénétrante la symbiose et établir des faits ou émettre des suggestions d'intérêt capital.

Les rapports des Orchidées avec leurs mycorhizes sont loin deetre constants et uniformes. Il est bien évident que la structure rudimentaire des graines est un état secondaire, résultant d'une évolution qui a rendu peu à peu la symbiose nécessaire et qui doit être représentée par différentes étapes.

Et en effet, parmi les Orchidées étudiées par BERNARD, chez une espèce d'Extrème-Orient, Bletilla hyacinthina, que les spécialistes Pfitzer) considèrent comme primitive, d'après l'ensemble de ses caractères, la symbiose avec le champignon n'est pas indispensable à la germination de la graine. Bernaro a pu faire évoluer aseptiquement des plantules; mais alors elles germent différemment, sans

1. BurgefF a fait une étude étendue des propriétés de ces champignons en culture.

Ils transforment les sucres (à l'aide d'invertine et de maltase), dédoublent les glucosides (par l'émulsine), produisent de la tyrosinase, n'assimilent pas l'azote libre, mais bien l'azote organique (du salep), produisent des diastases protéolytiques, etc...

Bernard a reconnu que les Rhiroctonia digèrent la cellulose. Ils désagrègent en effet le coton hydrophile sur lesquels on les a souvent cultivés. 
développer de protocorme et la comparaison des deux modes sur une même plante permet de voir quelle est l'influence propre des champignons sur la forme de la végétation. Dans la plante développée, la symbiose est très intermiltente. Le rhizome auquel la plante se réduit périodiquement est indemne de mycorhizes; chaque année, se fait une poussée de racines qui s'intestent à nouveau. Les mycorhizes se présentent donc comme une maladie intermittente et habituelle.

Mais Bletilla constitue une exception et, chez la gr'ande généralité des Orchidées terrestres ou épiphytes, l'embryon ne se développe que sous l'influence du champignon. En son absence, il ne se produit qu'une ébauche de germination; en sa présence, celle-ci se déclanche sans tarder. Chez la plupart des formes (Cattleyées, Cypripédiées, Ophrydées, etc.), à l'état adulte, la symbiose reste intermittente; elle se reproduit chaque année, à la pousse des racines, et disparait avec celles-ci.

Chez les Sarcanthinées (Phalcenopsis, Vanda), épiphytes, que Pficzer considère comme les plus évoluées des Orchidées, la germination exige aussi un Rhizoctone ( $R$. mucoroides) et la symbiose devient continue, les racines ici étant persistantes. Ce caractère atteint son extrême chez Taniophyllum.

Les Or'chidées terrestres montrent les mêmes degrés de symbiose que les épiphytes et c'est chez Neoltia nidus-avis que ce 'mode de végétation est porté à son maximum d'extension. Ici, en effet, la s) mbiose est absolument continue, pendant toute la 
vie du végétal et, au lieu de se limiter aux racines, comme dans les cas précédents, elle gagne le rhizome. De plus, elle se transmet directement d'une génération à l'autre. Quand - et le cas est fréquent - la Neottia fleurit et fructifie souterrainement, les champignons du rhizome se propagent directement jusqu'au fruit et vont infester les graines qui germent sur place. A ce degré, comme le fait remarquer Bernard, Champignon et Orchidèe réalisent pratiquement une individualité nouvelle et permanente, comparable à celle d'un lichen.

Ainsi se marquent, chez les Orchidées, quelques étapes d'une évolution dans la symbiose, accomplie par plusieurs séries de formes indépendantes les unes des autres et BERnard aperçoit cette mème évolution comme très probable dans d'autres groupes, où la symbiose se présente avec des caractères similaires, mais où elle n'a pas encore été étudiée comme chez les Orchidées, notamment chez les Ophioglossées et les Lycopodes.

On retrouve, en effet, chez ces plantes, soit dans le gamétophyte (prothalle), soit dans le sporophyte, la même étrangeté de faciès de l'appareil végétatif (tubérisation du prothalle, forme en toupie des plantules, localisation analogue des champignons) que chez les Orchidées. La symbiose a donc dù être un important facteur d’évolution dans des groupes tout à fait indépendants et éloignés les uns des autres. Il serait évidemment des plus intéressants de vérifier les idées de Brrnard sur les Ophioglossées et les I,ycopodinées (I).

r. Bervard en arrive mème à se demander si la sym- 
Un des aspects les plus intéressants des recherches de Bernard, au point de vue qui nous occupe ici, est lanalyse physiologique des rapports des Rhizoctonia et des Orchidées. Dans les conditions où il a cultivé les champignons, il est arrivé, en effet, d'une façon tout à fait générale, qu'après une longue période de culture in vitro, les Rhizoclonia se sont montrés peu à peu incapables de faire germer les graines. Ils sont devenus inactifs. Cette inactivité est complète après deux ou trois ans de culture en tubes. Mais on leur rend leur activité en les faisant repasser dans des plantules ou des racines. Il y a là un phénomène que BERnard compare dune façon très suggestive et, semble-t-il, très juste, aux variations de virulence (atténuation et exaltation), des virus bactériens.

Cela l'a amené à étudier comment le Champignon végète et se propage dans l'Orchidée et à faire cette étude, soit avec le champignon normal de l'espèce, soit en réalisant des associations anormales, par exemple en inoculant $R h$. mucoroides ou $R$. lanuginosa à des espèces qui hébergent $R$. repens, ou inversement.

biose n'a pas été un des facteurs capitaux de l'évolution des plantes, celui à qui est due l'apparition, aux dépens des Muscinées primitives, des plantes à sporophytes vivaces et arborescents, presque toutes infestées de mycorhizes. Les plantes annuelles seraient revenues à cet état en éliminant leurs champignons symbiotiques. Cette évolution aurait pu se reproduire plusieurs fois. Les Orchidées représenteraient une de ces évolutions secondaires. Ce ne sont là pour le moment que des conceptions purement spéculatives. 
La pénétration du champignon se fait par des portes d'entrée déterminées, le point d'attache du suspenseur. par exemple, ou la base des poils absorbants des racines. Ces points sont ceux oì la plante présente le maximum de perméabilité et qui jouent le rôle principal dans les échanges avec le milieu. Il faut supposer que ces zones excrètent des substances solubles qui, dans la culture, attirent le champignon (I) et qu'elles offrent le minimum de résistance à sa pénétration. J es Rhizoctonia digèrent la cellulose pure. Ils ne font que traverser les cellules épidermiques sans s'y pelotonner. Chaque région de pénétration, une fois celle-ci effectuée, acquiert une immunité qui s'oppose à toute infestation nouvelle. Ainsi le suspenseur n'est envahi qu'une fois. Les infections successives doivent se faire par des portes d'entrée distinctes.

L'allure du Rhizoctonia dans les tissus dépend de son degré d'activité et c'est seulement pour un degré convenable que s'établit la symbiose. Aussi, soit dans la nature, soit dans les cultures, toutes les graines sont-elles loin de germer, mème si elles rencontrent le champignon, comme le montrent les semis en tube (fig. 52). La symbiose, suivant l'expression de Bernard, est à la frontière de la maladie.

Le Rhizoctone ne fait que traverser l'épiderme comme il a été dit et c'est dans le parenchyme sousjacent qu'il végète, sous la forme très caractéristique de pelotons filamenteux dans les cellules. Mais, dans

I. Cette attraction ne se produit qu'धvec les Rhizoctonia d'Orchidées. Elle n'a pas lieu avec le $R$. violacea de la luzerne. 
le cas où la graine germe heureusement, son envahissement reste limité. Il y a toujours comme une barrière qui empêche la propagation du mycélium au sommet végétatif et qui recule au fur et à mesure de la croissance. Au point où l'invasion s'arrête,
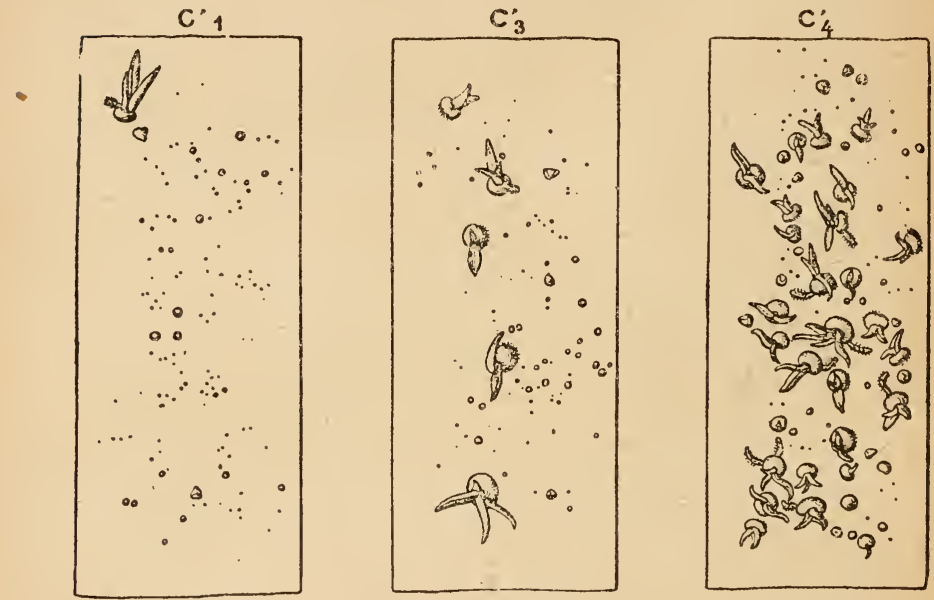

Fig. 52. - Semis de Lelio-Cattleya en tubes stériles, inoculés avec des Rhizoctoria d'activités croissantes $\mathrm{C}_{1}, \mathrm{C}_{3} \mathrm{C}_{4}$ (d'après Noël Bernard).

une partie des cellules du parenchyme de l'orchidée joue le rôle de phagocytes (fig. 53); leur noyau devient plus volumineux (il atteint jusqu'à 60 fois son volume primitif suivant BURGEFF) et lobé et les pelotons mycéliens contenus dans ces cellules sont digérés, laissant un résidu (I); le fait avait d'ailleurs

I. La formation des sporangioles aux dépens, des arbuscules des mycorhizes endotrophes étudiés par GaLlaud, est un phénomène de même ordre. 
été vu par les premiers observateurs des mycorhizes, comme Prillieux en 18556 , mais n'avait pas

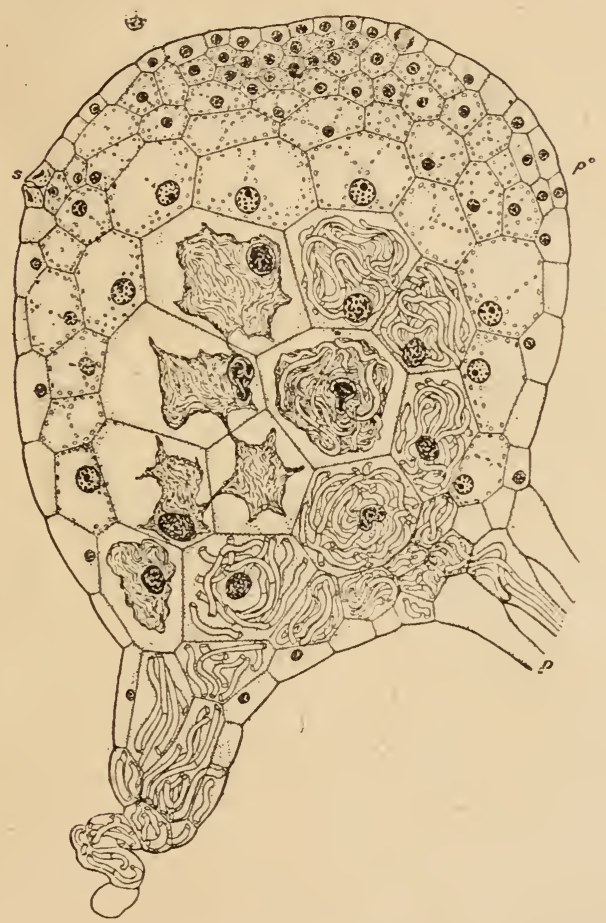

Fig. 53. - Coupe d'une germination d'Odontoglossum, montrant la pénétration, par le suspenseur, après un mois, et le pelotonnement intracellulaire de Rhizoctonia ianuginos $a$, ainsi que sa destruction par phagocytose : $s$ stomate $p$ poils absorbants (d'après Noël Bernard).

été interpiété. Magnus, en rgoo, et Shibata, en I902, ont décrit cette digestion. Elle est, dit Bernard, une 
véritaḅle phagocytose, qui règle, dans la symbiose, l'extension de l'infection. La différenciation du noyau des phagocytes précède même la pénétration du champignon à leur intérieur, et doit être l'effet d'une action à distance, causée par des produits solubles ou une diastase du mycorhize.

La plupart des auteurs qui ont constaté cette digestion avant BERNARD, et en particulier FrANK, l'avaient considérée comme un acte de nutrition essentiel pour la vie des plantes à mycorhizes endotrophes. Les plantes, d'après eux, étaient fungioores, comme il y a des plantes insectivores, et cette digestion était une preuve de la symbiose mutualiste, la compensation à la consommation d'hydrates de carbone consommés aux dépens de l'hôte par le champignon. Mais Bernaru a constaté nettement qu'elle n'a aucun rapport avec le développement de la plante. Les Rhizoctones ne jouent pas de rôle direct dans la nutrition des Orchidées.

La phagocytose est une réaction de défense de l'organisme. En infestant les Orchidées avec des Rhizoctones anormaux, comme il a été dit, ou avec des Rhizoctones inactif's, - ou bien l'infection est arrêtée rapidement par les phagocytes, la symbiose ne s'établit pas et la graine avorte - ou bien la plante périt par un envahissement généralisé de ses tissus et de son sommet végétatif, sans que l'on constate de réaction phagocy taire, ou tout au moins celle-ci ne joue qu'un rôle très effacé. Entre l'infestation bénigne, rapidement enrayée par une phagocytose presque immédiate, et l'infestation rapidement mortelle avec phagocy tose insignifiante ou nulle, se 
trouve le cas intermédiaire de la symbiose, oì la phagocytose s'exerce, sans cependant arrêter la propagation du champignon. et où cependant la plante ne succombe pas. Cette symbiose peut durer toute la vie, comme chez Neottia nidus-avis, où être intermittente.

Le champignon n'atteignant jamais le sommet végétatif, la plante réalise une certaine immunité, qui est la condition de son développement. Le pelotonnement intracellulaire des Rhizoctones doit être un phénomène en rapport avec cette immunité; car, dans les cas d'infestation mortelle, étudiés par Bernard, le champignon abandonne ce mode de végétation et, dès lors, les filaments mycéliens courent en droite ligne, envahissant tous les tissus. La propriété humorale à laquelle il a été fait déjà allusion fait défaut.

Bernard a cherché enfin à comprendre le mode d'action des mycorhizes, sans s'arrêter au mot, ni à l'idée mystique de symbiose. Il s'est demandé si le rôle efficace des mycorhizes n'était pas dû à une modification favorable qu'ils produiraient dans le milieu intracellulaire. Or, il a réussià obtenir la germination de certaines Orchidées sans champignon, en semant les graines sur des solutions concentrées (gélose ou coton hydrophile imbibé d'une décoction de salep forte et souvent additionnée de saccharose). Il a noté d'autre part que les Rhizoctones cultivés sur salep-saccharose, déterminent une augmentation de la concentration moléculaire de la solution employée (ce que l'on constate par la variation de son point de congélation). Il est possible que leurs 
diastases disloquent les molécules complexes en un nombre plus grand de molécules simples. On peut donc imaginer qu'ils agissent de même dans leur végétation intracellulaire et qu'ils augmentent le degré de concentration moléculaire de la sève des plantules où ils ont pénétré : cette condition permettrait la germination. Bernard rupproche cette suggestion de la réalisation de la parthénogénèse expérimentale chez les animaux par l'emploi de solutions hypertoniques. Quoi qu'il an soit de l'hypothèse, il reste le fait que la concentration plus forte des solutions permet de se passer du champignon pour obtenir la germination d'un certain nombre d'espèces d'Orchidées.

La symbiose entre l'Orchidée et ses mycorhizes n'est nullement une entité fixe, ni une association mutualiste pour l'entr'aide. Elle est un phénomène de parasitisme, une infection, une maladie constante et devenue nécessaire, mais qui, suivant son degré ou son allure, assure le développement de la plante ou l'arrête, ou même tue la plante. Elle est, dans la biologie générale, un chapitre de pathologie, parallèle à celui des infections bactériennes et ne se distinguant pas du parasitisme.

Il y aurait évidemment lieu d'étudier avec le même esprit les plantes qui ont une allure analogue, Hépatiques (Fegatella), Lycopodiacées (Lrcopodium, Psitotum, Phylloglossum), Ophioglossées.

Nous avons ainsi achevė de passer en revue les 
principaux groupes de faits qui se rattachent à l'idée de symbiose. Il s'en dégage la conclusion qu'ils ne constituent pas une catégorie franchement distincte, mais se rattachent au parasitisme et au commensalisme par une série d'intermédiaires, sans offrir avec l'un ou l'autre une opposition caractérisée.

Dans les exemples classiques comme celui des lichens, il faut abandonner l'idée d'une association purement mutualiste à bénéfices réciproques équivalents. C'est un conflit entre l'algue et le champignon associés d'une façon intime et constante, où les deux organismes ont réagi l'un sur l'autre. C'est d'ailleurs la conclusion formulée en r 906 par le botaniste russe Erenkine : " La conception mutualiste de la symbiose, dit-il, doit ètre remplacée jar celle d'un état d'équilibre instable: les deux organismes associés réagissent différemment aux conditions $\mathrm{du}$ milieu extérieur et à leurs variations. Celles-ci sont inégalement fa rorables à l'un et à l'autre ; suivant les cas, ce sera l'un qui dominera l'autre ou inversement. Ces variations doivent rester dans les limites où l'un des deux organismes ne succombe pas. " Conception qui équivaut à celle de N. Bernard : "La symbiose est à la frontière de la maladie. ")

Dans cette association, les deux organismes réagissent l'un sur l'autre; il y a évolution dans la s)mbiose, évolution à la fois morphologique et fonctionnelle, aboutissant, par suite, à des nécessités nouvelles comme dans la germination des Orchidées, ou à des fonctions absolument nouvelles, comme dans le cas des levures des Insectes ou des bactéries lumineuses des Céphalopodes. Ces derniers cas, que 
Pierantoni appelle symbiose physiologique héréditaire, ne paraissent pas, au premier abord, cadrer avec la notion de conflit, ou d'instabilité. Il n'y a cependant aucun doute qu'ils ne représentent originairement des infections des Insectes ou des Céphalopodes par des organismes étrangers; mais le conflit s'est terminé par la domination de l'un des organismes sur l'autre et un équilibre stable, correspondant précisément à une fonction nouvelle. Ce sont ces cas qui, dans l'état actuel de nos connaissances, représentent l'évolution la plus complète. 


\section{CHAPITRE XIII}

\section{LA SYMBIOSE EST-ELLE UNE CARACTÉRISTIQUE PRIMORDIALE DE LA VIE CELLULAIRE?}

Sommairi. - Les théories particulaires de l'hérédité. - Les granules d'Altmaxn et les mitochondries. - Généralisations de Pierantoxi à partir des faits de symbiose héréditaire chez les Insectes et les Céphalopodes. - Passage des bactéries intracellulaires à la forme granulaire? Réalisation de diverses fonctions de la cellule par des bactéries symbiotiques.

La théorie des symbiotes de Portier: Dualisme de la cellule; les mitochondries seraient des bactéries symbio. tiques. - Critique de la conception symbiotique des $1 s a$ ria chez les Insectes. - Possibilité de la vie aseptique; sa réalisation rigoureuse à grande échelle chez les Drosophiles (GuyéNot). - Les bactéries cultivées par Portier, à partir de divers organes de Vertébrés, ne peuvent être des mitochondries, de par leurs propriétés.

Aucun fait ne vient présentement à l'encontre de l'unité fondamentale de la cellule. La symbiose intracellulaire reste un fait exceptionnel quoiqu'assez répandu.

Conclusions générales.

Les faits de symbiose, tels que nous venons de les examiner, forment une série continue et ont une extension assez considérable dans la nature. Il suffit de songer aux zooxanthelles et zoochlo- 
relles, aux lichens, aux mycorhizes, aux bactéroïdes des nodosités radiculaires, aux levures des Insectes et aux bactéries lumineuses, si le rôle de ces dernières est définitivement reconnu. Néanmoins ils restent des exceptions dans l'ensemble de la vie organique. La vie normale ne suppose pas ces associations internes comme une nécessité générale. Elles sont une déviation de la nor'male.

Or, en ces dernières années, s'est manifestée, chez un certain nombre de biologistes, une tendance à en faire au contraire la forme fondamentale du fonctionnement vital. Les cas rappelés ci-dessus ne seraient que des exemples grossiers et macroscopiques, en quelque sorte, de ce qu'est la vie cellulaire; celle-ci serait toujours une symbiose. La cellule, en effet, telle qu'elle a été décrite jusqu'ici, serait bourrée de microorganismes symbiotiques, auxquels appartiendraient les pouvoirs métaboliques essentiels.

L'idée n'est pas neuve. Il s'est succédé déjà une longue série de théories, où l'on s'efforçait d'expliquer l'hérédité et la vie par la conception de particules douées de propriétés spéciales. On trouvera une énumération méthodique de ces conceptions dans le livre de Y. Delage ( 96$)$ sur l'hérédité: La plupart étaient purement spéculatives ; d'autres'tendaient plus ou moins à acquérir une réalité objective. Certaines d'entre elles, comme les micelles deN AEGELI, les pangènes de Df. Vries, les biophores de Weis. MANN, auxquelles se rattachent, en somme, les gènes de Johannsen, ont joué un rôle important dans la biologie contemporaine, parce qu'elles ont été con- 
çues à l'image de la structure cellulaire, telle que la révélait le microscope. Elles fournissent en ce moment encore une représentation matérielle aux études d'hérédité mendélienne. D'autres, au contraire, ont été conçues d'une façon toute spéculatire, comme les microzymas de BÉchàp. D’autres enfin ont eu un point de départ purement d'observation, comme les granules d'Altwann (83), devenus ultérieurement les mitochondries; celles-ci tiennent aujourd'hui une place de premier plan dans les recherches cytologiques et aussi, malgré les préventions excessives des physiologistes, dans le domaine de la physiologie. A la conception de la cellule comme unité morphologique ultime, Artmans a voulu substituer celle du granule. Le granule est une individualité qui se continue et se reproduit. L'aphorisme omnis cellula e cellula fait place à omne granulum e granulo. Pour Altuans cependant, les granules sont des éléments intrinsèques de l'organisme. La tendance qui se fait jour actuellement est, au contraire, de les considérer primitivement comme extrinsèques, comme des organismes symbiotiques, adaptés à la vie intracellulaire et en qui réside, en somme, le substratum des principales fonctions cellulaires.

Des conceptions de ce genre se sont offertes incidemment à certains biologistes. Raphaël Dubors, dans ses travaux sur la lumière animale ou sur les organes chromogènes, place le siège de ces fonctions dans des corpuscules intracellulaires, les vacuolides, uuxquels il accorde une grande autonomie ; il a revendiqué, à diver'ses reprises, la pater- 
nité de notions auxquelles avaient conduit des études systématiques sur la structure cellulaire et qui se rapprochaient des siennes propres. Il est aujourd'hui de ceux qui aboutissent à une conception comme celle qui va nous occuper et qui s'efforcent de lui donner une base expérimentale.

Dans ces dernières années, cette conception a été formulée d'une façon plus particulièrement précise et comme aboutissement d'observations et d'expériences méthodiques par Pierantoni et par PoliTIER (I). Il importe de distinguer exactement ce qui, dans les théories formulées, est acquis et ce qui reste discutable ou même mal fondé.

Examinons d'abord les idées de Pierantoni qui, aussi bien, a précédé légèrement Portier. Ce sont ses recherches sur les levures symbiotiques des Insectes, dont les résultats sont indiscutables, qui l'ont conduit à étudier les organes lumineux des Céphalopodes. La première de ses conclusions est que la luminosité, dans le cas des Rondeletia et des Sepiola, est due à des bactéries symbiotiques, pullulant dans la lumière des tubes glandulaires de l'organe lumineux, se déversant occasionnellement au dehors, et sünoculant régulièrement, de génération en génération, par l'œuf. Il est évidemment très

I. Galippe ( 103 , a abouti aux mêmes conclusions, par sa conception du parasitisme normal. Ce sont, d'après lui, des infiniment petits qui régissent normalement et nécessairement l'activité cellulaire. Ils caractérisent le fonctionnement de la cellule et sorit en quelque sorte la rcprésentation la pius simple de la vie chez les êtres organisés.

GaLipPe souligne lui-même les aftinités de ces idées avec les microzymas de Béchamp. 
tentant de chercher à ramener à une explication de cette nature la production de la lumière chez les autres Céphalopodes et chez les animaux en général; c'est à quoi Pierantoni est présentement occupé. Chez les Céphalopodes abyssaux, les organes lúmineux sont clos; la partie photogène est un complexe cellulaire, de nature plus ou moins syncytiale, dans lequel pullulent des granulations qui sont le siège des phénomènes lumineux. D'après Pierantoni ( I 3 z), ces granules sont des bactéries adaptées à la vie intracellulaire. Dans ses recherches en cours, sur Char)bditeuthis, il dit avoir constaté, "à la partie la plus externe de la masse de l'organe lumineux anal (qui est clos), une couche, « où, avec des cor" puscules extrèmement petits, se trouvent aussi " des formes bacillaires (de vraies bactéries) en " voie de fragmentation en grains minuscules; des "bactéries qui, en somme, éooluent de la forme " bucillaire à la forme granulaire ". Mais on aperçoit combien une affirmation de ce genre est dificile à prouver d'une façon irréfutable, ce qui cependant est nécessaire. Dans l'esprit de PikraxToNi, les granulations intracellulaires qui semblent bien être le siège de la luminosité chez tous les animaux lumineux et qui correspondent aux vacuolides de.Dubors, seraient donc des bactéries devenues intracellulaires et passés à la forme de simples granules. De même, d'après les recherches de Dubors sur la formation de la pourpre chez Murex trunculus, celle-ci se forme par des " corpuscules très petits, que Duвors appelle vacuolides zymasiques, ou sphérules élémentaires, et « comment ne pas penser, 
- sur la base de ce qui a été exposé de la transformation et de l'adaptation des bactéries photogènes à la constitution de la substance photogène des organes lumineux, - à une adaptation analogue pos̊sible de bactéries chromogènes à la fonction de la production des couleurs ? "Pierantoni a entrepris des recherches expérimentales pour prouver, par voie de cultures, que les granulations pigmentaires sont aussi des bactéries symbiotiques. Tout cela " place sous un nouveau jour l'activité des " plasmes cellulaires et assignerait aux inclusions " cytoplasmiques et peut-être à beaucoup des cons" tituants du protoplasme une vie autonome et une « activité spécifique, au bénéfice des organismes " dans lesquels ils vivent. »

Telles sont les conceptions de Pinrantoni qui tendent, on le voit, à reporter sur des organismes symbiotiques, adaptés à la vie intracellulaire, un grand nombre des fonctions spéciales que l'on rencontre chez les animaux : fonction lumineuse, chromogène, pigmentaire, etc... Cela reste une idée purement théorique, tant qu'il n'a pas été donné une preuve irréfutable de la culture autonome des granulations en question. Or elle n'est nullement fournie à l'heure actuelle.

Portier a été conduit à des vues analogues par des recherches sur les Insectes xylophages et il les a formulées d'une façon beaucoup plus générale et plus rigide, en 1918 , dans son livre sur Les Symbiotes.

Pour Portier, la cellule n'est nullement l'unité fondamentale dans les organismes. Eille est essen- 
tiellement un complexe symbiotique. Elle est toujours bourrée de symbiotes, indispensables pour effectuer les synthèses organiques et qui ne sont autres que les mitochondries ; celles-ci seraient des bactéries adaptées à la vie intracellulaire symbiotique. Les bactéries seules seraient autotrophes, c'est-à-dire capables de se nourrir par elles-mèmes . Toute cellule, et par suite tous les animaux et les végétaux à constitution cellulaire, seraient hétérotrophes et n'assimileraient que par l'intermédiaire de bactéries symbiotes (I). Il n'y a évidemment aucune impossibilité a priori à une semblable conception; mais, comme elle remettrail en question toutes les notions fondamentales de la Biologie, elle doit être basée sur des preures inattaquables. Or, on peut affirmer sans crainte que ce n'est nulle-

I. Voici l'énoncé textuel de la théorie : «Tous les êtres " vivants, tous les animaux, depuis l'Amibe jusqu'à " l'Homme, toutes les plantes, depuis les Cryptogames jus" qu'aux Dicotylédones, sont constitués par l'association, "l'emboitement de deux ètres différents.

"Chaque cellule vivante renferme dans son protoplasme " des formations que les histologistes désignent sous le " nom de mitochondries. Ces organites ne seraient pour " moi autre chose que des bactéries symbiotiques, ce que " je nomme des symbiotes.

"Le symbiote est un microorganisme qui possède deuxi " propriétés remarquables : une extrême plasticité, qui lu " permet une adaptation aux conditions les plus variées et " un pouvoir de synthèse très étendu, variable d'ailleurs " avec les conditions dans lesquelles il est placé.

« La bactérie symbiotique vient du milieu extérieur : elle " peut, dans c rtains cas, y retourner et vivre d'une vie “ indépendante. Les bactéries seraient donc les seuls ètres " simples, tous les autres seraient doubles »(Pontrir, Les (Symbiotes : préface, p. viI-viıI). 
ment le cas, et saisir même, dans l'argumentation de l'auteur, des confusions aux points essentiels .

Le point de départ des idées de Portier se trouve dans ses "Recherches phrsiologiques sur les champignons entomophy,tes ) ( I 38 ). Il a cru constater une symbiose constante et générale entre les Insectes xylophages et les champignons de genre Isaria. Cette symbiose se manifesterait même après la mort, avec une netteté particulière, chez les Lépidoptères, qui, très fréquemment, selon l'expression des entomologistes, tournent au gras. Cela est dû à l'envahissement de leur cadavre par le mycélium d'Isaria, dont les conidies étaient présentes antérieurement à l'état de symbiotes. L'infestation très fréquente d'Insectes par les Isaria est bien connue, mais elle est considérée généralement comme un phénomène

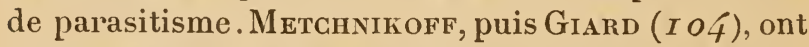
même essayé de se servir de ces parasites pour produire, chez les larves d'Insectes nuisibles, de grandes épizooties, notamment sur le charançon de la betterave et le ver blanc du hanneton.

Portier a acquis l'idée d'une symbiose constante de ces champignons, en étudiant l'évolution d'une chenille, Nonagria typhoe. C'est là son point de départ. Il trouve des conidies d'Isaria dans le tube digestif de cette chenille, les retrouve et les figure dans l'épithélium intestinal et dans tous les tissus de l'adulte, y compris les œufs, par lesquels elles seraient transmises à la génération suivante. Mais l'assimilation des productions figurées aux conidies d'Isaria reste des plus contestables. Il n'en est pas donné de preuve positive et l'on ne peut se défendre 
de penser que les corp̣s figurés, surtout par la façon dont ils se colorent (cf. fig. 9, p. 3o; les $S$ rm. biotes, fig. $26, \mathrm{p} . \mathrm{I} 76$ ) ressemblent beaucoup à des spores de Microsporidies, dont la présence dans les divers tissus s'expliquerait très aisément; tous les faits produits relativement à la chenille de Nonagria t)phae, semblent n'être que le résultat d'un infestation par une Nosema, comme celle du ver à soie par la Pébrine, et l'on sait assez que cette dernière n'a rien d'une symbiose( $\mathrm{I}$ ). La présence des corpuscules dans les oocytes serait très naturelle, si ce sont des sposes de la microsporidie; on retombe sur l'observation qui a fourni à Pasteur, pour la pébrine, la base de sa méthode de grainage. Il serait très désirable que l'on vérifiât sur les Nonagria trphœ, prises dans les stations où Portier les a étudiées, si cette explication des faits qu'il signale n'est pas celle qui convient réellement.

Quant aux autres faits empruntés aux insectes xylophages, ils ne me paraissent pas avoir de portée pour fonder la conception de la symbiose intracellulaire. Les seuls qui peuvent l'appuyer, chez les Insectes, sont ceux relatifs aux levures du mycétome des Hémiptères (Pucerons, Coccides, etc...) : ceux-là sont indiscutables, mais leur portée est strictement limitée.

1. La constance de la présence d'un organisme à l'intérieur d'un autre n'est pas un critérium suffisant pour considérer que l'on a affaire à une symbiose. Il y a des parasites indiscutables qui sont absolument constants. Telle est, entre autres exemples la grégarine Lithouystis schneideri chez Echinocardium cordatum, dont il a été question plus haut p. 248). 
Une autre base de la théorie de Portier, - celle-là indirecté, - serait l'impossibilité de la vie aseptique et la nécessité de symbiotes, en cas d'asepsie au sens ordinaire du mot. L'intestin des animaux renferme ordinairement une flore abondante et variée, tantôt utile, tantôt nuisible, et PAsteur considéraitcomme possible que l'existence d'une semblable flore fût absolument nécessaire. Il est vraisembable, ainsi qu'on l'a vu précédemment, que, chez la plupart des animaux, la flore ou la faune intestinale contribue à la transformation des aliments et il est même possible qu'elle joue un rôle régulier et important. Nous avons mentionné cette possibilité pour les Infusoires de la panse des Ruminants et les Trichonymphides des Termites. Mais la possibilité de la vie aseptique est aujourd'hui pleinement établie. Elle a été réalisée rigoureusement chez les mammifères, malgré les difficultés techniques d'un élevage aseptique

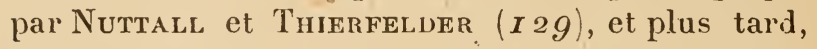
dans le laboratoire de Metchnizoff, par Cohendy (93). L'expérience est pratiquement très compliquée et on conçoit que des raisons d'ordre tout à fait secondaire la rendent précaire. Mme Metchnikoff ( I 2 7) a élevé aussi aseptiquement des têtards de grenouilles, Wolzman ( I 46 ) des Mouches(Calliphora). Portier ( 138 ), enfin, a constaté que les chenilles mineuses - notamment celles de Nepticula flosizlalella, sur le noisetier, - sont naturellement aseptiques, tant qu'elles restent sous l'épiderme de la teuille. Mais surtout, le problème de la vie aseptique a été résolu pratiquement et à grande échelle par Delcount et Guxḱnot (97) sur les Drosophiles 
et leurs résultats ont été confirmés par des auteurs tels que J. Lоeb. Délcourt et Guyénot ont réalisé pour cela une technique précise, grâce à laquelle l'élevage se fait régulièrement - comme la culture pure d'une espèce bactérienne - et infiniment mieux que dans les conditions ordinaires. GuÝ́xot ( $~ \circ \nearrow$ ) a poursuivi cet élevage aseptiquement pendant près de 5o générations successives, chacune comprenant des milliers d'individus, sans que jamais il y eut de symptômes défavorables.

L'intérèt de ces recherches n'est d'ailleurs pas seulement dans la démonstration de la possibilité de la vie aseptique. Cette méthode, comme l'a montré Gư⿱⺈́not, met l'expérimentateur en possession de conditions de milieu absolument constantes pour l'étude précise des problèmes fondamentaux de la nutrition. Or, dans les mouches ainsi élerées, on ne trouve aucun des symbiotes que Portier considère comme essentiels.

Mais, en réalité, tout ce qui précède n'a trait qu'à des côtés secondaires de la théorie des symbiotes, telle qu'elle est formulée par Portier. Le point essentiel,en effet, est le dualisme de constitution de la cellule, l'existence - absolument générale -.. à son intérieur, d'organismes autonomes qui seraient les mitochondries. Il faut donc apporter la preuve que les mitochondries sont bien des organismes a utonomes, des bactéries adaptées à la vie intracellulaire, en les extrayant de la cellule et les cultivant. Cette preuve, Portier déclare l'avoir réalisée, à partir de divers organes glandulaires des Mammifères, principalement des testicules, oì l'appareil mitochondrial a été 
très étudié par les cytologistes, dans la lignće séminale. Mais, en réalité, les opérations de Portier se rapportent surtout au tissu adipeux péri-testiculaire; il a obtenu aux dépens de ce tissu, - en s'efforçant d'opérer d'une façon rigoureusement aseptique - des cultures qui seraient celles de symbiotes intra-cellulaires, et il a étudié les propriétés physiques et chimiques de ces organismes.

A vrai dire, il n'obtient pas ces cultures de façon constante et les conditions où elles se produisent ne sont pas précisées. Mais une première objection à son interprétation résulte de ce que les organismes cultivés ont des propriétés qui sont inconciliables avec l'lıypothèse que ce seraient des mitochondries.

Ils se cultivent d'abord avec une facilité paradoxale, sur du bouillon ordinaire de ba'ctériologie, additionné de 5 o/o de glycérine et de i o/o de nitrate de potassium. Or, on sait combienil est difficile, en général, de trouver un milieu convenantà des bactéries adaptées à des conditions aussi spéciales que la vie intracellulaire. On n'a pas encore pu réussir à cultiver le bacille de la lèpre, dont l'authenticité n'est pas douteuse. Dans d'autres cas où on avait cru cultiver des formations bactéroïdes intracellulaires, comme celles de la Blatte (Bacillus cuenoti de MERCIER), il est aujourd'hui plus que probable que l'organisme cultivé était une impureté (JAVELLY, I I 4). Il serait donc au moins surprenant que les mitochondries, formes extrêmement nodifiées, à supposer que ce fussent des bactéries, se laissassent cultiver aussi aisément dans un milieu banal.

Les propriétés de la culture ne sont pas moins 
bizarres. Les bactéries sont extrêmement poly. morphes. Elles résistent étonnamment à la chaleur, à I 5 degrés en milieu humide, à I 45 -r 50 degrés en milieu sec. Le voile immergé dans l'alcool absolu et le chloroforme résiste des mois entiers ; deshydraté, il peut ètre porté à l'ébullition dans ces deux liquides, ou chaufté à I 20 degrés en tube scellé dans l'acétone. Enfin ces bactéries sont mobiles el aérobies strictes.

Or, par contre, des observations précises de divers auteurs notamment de Regaud $(I 40)$ et de Guilliermond ( 106$)$, nous ont appris que, dansles cellules, les mitochondries observables sur le vivant, sans l'action d'aucun réactif, sont des formations extrèmement fragiles; une faible variation de tension osmotique les fait se gonfler et disparaître; elles ne résistent pas à une température supérieure à 40 degrés. Elles sont détruites aussi par l'alcool et par les acides, même étendus. Pour les conserver, il faut des fixateurs spéciaux, comme le formol. Ce sont des formations homogènes, des corps semiliquides, malléables, sans structure, alors que les bactéries ont une forme rigide et une structure précise et qu'elles résistent aux réactifs les plus divers. Convenablement fixées et colorées, elles ont, il est vrai, dans les préparations, une silhouette qui rappelle les bactéries, mais c'est là une ressemblance contingente et tout à fait superficielle.

En se basant sur ces considérations, les histologistes, et parmi eux Regaud, Guilliermond, LAGUESSF, considèrent l'identification faite par Portier comme absolument impossible. Les mitochondies 
sont des corpuscules intracellulaires, dérivant peutêtre toujours les uns des autres par division, jouant certainement un rôle considérable dans les différenciations et les synthèses intracellulaires, mais dont les propriétés authentiques sont inconciliables avec celles des bactéries cultivées par Portikr et désignées par lui sous le nom de symbiotes.

Ces propriétés, comme Portier le reconnaît, rappellent aux bactériologistes, soit celles du Bacillus subtilis qui aurait été introduit au cours des manipulations (les prélèvements aseptiques de certains organes sont extrêmement difficiles à réaliser), soit celle de saprophytes banaux, pourvus de spores, qui peuvent occasionnellement franchir la barrière extérieure ou intestinale de l'organisme et s'immobiliser à l'état de spores dans des organes ou des tissus. Des expériences de contrôle, faites contradic. toirement, à la demande de la Société de Biologie, par MM. Portier et Bierry d'une part, L. Martin et Marchoux de l'autre, ont conduit les quatre expérimentateurs aux conclusions suivantes :

“ I. Le transport de morceaux d'organes d'un ani" mal dans des milieux de culture est toujours difficile à " réaliser avec une asepsie constante. C'est une des " opérations les plus délicates de la bactériologie ;

« $2^{\circ}$ On n'obtient généralement pas de culture en par" tant d'organes sains quand, pour ensemencer les " milieux, on se sert de pulpe de testicule, recueillie au “ moyen d'un tube effilé de Pasteur.

« $3^{\circ} \mathrm{On}$ peut rencontrer, dans des conditions et des pro" portions qui, pour être fixées, exigeraient un nombre “ considérable d'expériences, des microbes dans les tes- 
" ticules, quand on opère avec des.organes entiers ou “ des fragments volumineux. La présence de ces mi" crobes dans les testicules n'est pas un fait constant, il " est impossible dès lors d'affirmer leur existence à "l'état normal” ( $C$. R. Soc. Biologie, t. 83, p. 654, 8 mai 1920$)$.

Par conséquent, il ne peut ètre considéré comme acquis que l'on a cultivé des mirrobes normaux intracellulaires, encore moins les mitochondries.

On n'est pas davantage fondé à dire a vec Portier (Les Symbiotes, p. 79), que des mitochondries ont été antérieurement cultivées in vitro, en en donnant pour preuve les bactéroïdes des Légumineuses. Celles-ci ont bien été cultivées et sont des organismes autonomes. Mais elles n'ont en commun avec les mitochondries que d'être intracellulaires.

La thèse de la symbiose intracellulaire normale et primordiale, telle que la pose Portier, ne repose donc pas sur des faits authentiques établis expérimentalement et la théorie cellulaire classique subsiste actuellement tout entière. Cela n'écarte pas toute possibilité de réalité pour les idées de dualisme cellulaire et l'existence d'organismes intracellulaires autonomes. Mais la démonstration en reste entièrement à faire (I), et d'autre part, il est, tout aussi naturel, sinon beaucoup plus, d'attribuer à la

I. Poktrkn, dans son livre, a été conduit à réviser toute la Biologie générale, pour la placer sur la base de sa théorie symbiotique. Les faits fondamentaux étant caducs, ces vues bypothétiques n'ont qu'un intérêt spéculatif. Les problèmes de la careuce et des vitamines notamment, sont susceptiblse de solutions indépendantes des symbiotes,mais qu'il n'y a pas 
cellule elle-même la faculté de réaliser les fonctions essentielles de la vie, que de l'imaginer impuissante et ne pouvant assimiler que par l'intermédiaire de bactéries.

La symbiose reste donc, pour le moment, dans les organismes pluricellulaires, ou dans la cellule considérée isolément, un phénomène exceptionnel; on en connait des exemples ayant une grande extension, et on lui trouvera ultérieurement une extension plus considérable encore. En l'état actuel de nos connaissances, elle ne représente aucunement la forme fondamentale de la vie cellulaire.

Si l'on cherche à dégager une conclusion d'ensemble des faits analysés dans ce volume, on arrive à la notion qu'il n'existe entre eux aucune distinction de nature. Commensalisme, jarasitisme, symbiose ne sont que des catégories créées par nous et, dès que l'analyse y pénètre, il devient impossible de les délimiter.

Sous des aspects variés, ils ne sont que des manifestations de la concurrence vitale, caractérisées par une spécialisation dans la façon dont elle s'exerce, mais dépourvues de toute finalité ou harmonie préétablie. Ont persisté les associations qui se soldaient

lieu d'envisager ici, mon seul objel étant d'examiner les fondements de la théorie symbiotique. Ontrouvera, au sur plus, une discussion de beaucoup des questions qui s'y rattachent dans le livre de $\mathrm{A}$. Lumxère: Le mythe des symbiotes. 
par un bilan compatible avec l'existence et la perpétuation des associés; beaucoup d'autres ont dù se réaliser occasionnellement, mais n'ont pas subsisté faute de satisfaire à cette nécessité.

En passant des conditions normales d'existence des formes libres à celles où ils sont associés, les organismes ont subi des déformations multiples et parfois énormes, qni sont l'illustration la plus frappante peut-être de la réalité de l'Evolution, et surtout de l'influence du milieu sur les organismes, mais la diversité capricieuse de ces déformations indique que les transformations évolutives sont conditionnées surtout par les propriétés intrinséques des formes vivantes. 



\section{BIBLIOGRAPHIE}

Il ne peut être question de donner ici une bibliographie étendue du parasitisme et de la symbiose. Pour certains groupes entièrement parasites, ce serait tous les travaux publiés sur eux qui devraient être énumérés. Le présent index comprend les mémoires cités dans ce volume et quelques livres ou travaux permettant de s'orienter rapidement dans un groupe de parasites donné ou dans une question particulière. Les mémoires ou livres contenant une documentation bibliographique importante sont indiqués par une ou deux astérisques $\left({ }^{*},{ }^{* *}\right)$.

Précis, Traités, Périodiques spéciaux consacrés au parasitisme

1. Brumpt (E.). - Précis de Parasitologie. Paris, $2^{e}$ éd., 1913.

2. Guiart (J.). - Précis de Parasitologie. Paris, 1910.

3. Leuckart (R.). - Die Parasiten des Menschen und die von ihnen herrührenden Krankheiten, $2^{\mathrm{e}}$ édit., 1889 .

4. Linstow (O.von). - Compendium der Helminthologie.

3. Neveu-Lemalre (M.). - Précis de Parasitologie humaine. Paris, 1908. 
6. - Parasitologie des animaux domestiques. Paris, I9II (1255 p.).

7. Ralllikt (A.). - Traité de Zoologie médicale'et agricole. Paris, I895.

8. Centralblatt für Bacteriologie und Parasitenkunde, Iéna (depuis r88 $\mathrm{\jmath}$ ).

9. Archives de Parasitologie. Paris (1898-1914).

10. The Journal of Parasitologr, Urbana Ill. (depuis I914).

11. Parasitology, Cambridge (depuis 1907).

12. ** Bulletin de l'Institut Pasteur. Paris (Analyses), depuis Igo3.

13. Bulletin de la Société de Pathologie exotique. Paris (depuis 1908).

\section{Commensalisme}

14. Alcoce (A.). - A case of commensalism between a Gymnoblastic Anthomedusoid (Stylactis minoi) and a Scorpenoid Fish (Minous inermis) Ann. Mag. Nat. History (Sér. 6), t. 10, 1892.

I5. Aurivilurus (C.). - Die Maskierung der Oxyrihynchen. Svensk. Vetensk. Akad. Handl., t. 23, I889.

i6. Bonnier (J.) et Pírez (Ch.). - Sur un Crustacé commensal des Pagures (Gnathomysis gerlachei, C. R. Acad. Sciences,.t. 132, Igo2.

17. Bouvier (E.-L.). - Sur le Commensalisme d'un Crabe portunien le Lissocarcinus orbicularis, Bul. Muséum, Paris, r9o7.

18. - Le Commensalisme chez certains polypes madréporaires. Ann. Sc. Nat. Zoologie (sér. 7), t. 20, 18gã.

r9. Bouvier (E.-L.) et Seurat. - Eumedon convictor, Crabe commensal d'un Oursin. C. R. Acad. Sciences, t. I40, 1905 .

20. Bhunelu (G.). - Richerche etologiche, osservazioni ed exper. sulla symbiose dei Paguri e delle Attinie Zool. Jahrbücher (Abth. $f$. allg. Zool.), t. 34, I913. 2I. Bürger (O.). - Ueber das Zusammenleben von Antho- 
loba reticulata und Hepatus chilensis.Biol.Centralbl., t. 23, 1903 .

22. Chevreux (E.). - Sur les commensaux du Bernard l'ermite. Bul. Muséum, Paris', rgo8.

23. Collin (B.). - Etude monographique sur les Acinétiens. Arch. Zool. expér., t. 51, 1912, (v. p. 297-305). 24. Cowles. - Transplanting of sea-anemones by hermit-crabs. Proc. Nation. Acad. of Sciences, t. 6, 1920.

25. Couprx (II.).-Sur l'alimentation de deux commensaux (Nereilepas et Pinnotheres). G. R. Acad. Sciences, t. 119,1894 .

26. Coutrìre (H.). - Notes sur la faune des récifs madréporiques de Djibouti, Bul. Muséum, 1898 .

27. - Observations sur quelques animaux des récifs madréporiques de Djibouti.Ibid., 1898.

28. - Sur le commensalisme de l'Arete dorsalis, var. pacificus, etc. (avec IIeterocentrotus mamillatus), Hoid., 1904 .

29. Duerdex. - On the habits and reactions of Crabs bearing Actinians in their claws. Proc. Zool. Soc. London, rgo5, vol. 2 .

3o. Emery (C.). - Fierasfer. Fauna und Flora des Golfes von Neapel., Monogr., II, r88o.

3r. Euders (H.-E.). - Notes on the commensals found in the tubes of Chcetopterus pergamentaceus. American Naturalist, t. 39, I905.

32. Fauré-Frínet (E.). - Le commensalisme spécifique chez les Vorticelles d'ean douce. C. R. Soc. Biol., t. 61 , 1906 (p. $456-458$ ).

33. - Le commensalisme des Opercularia,Ibid., (p. 5ı द-5 I5 et 583-5ั85̌).

34. Faurot (L.). - Etude sur les Actinies. Arch. Zool. expér. (sér. 3), t. 3, 1895 .

35. - Etude sur les associations entre Pagures et Actinies. Ibid. (sér. 5), t. 5̆, I910.

36. Giard (A.). - Sur un type synthétique d'Annélides (Anoplonereis herrmanni) commensal du Balanoglossus. C. R. Acad. Sciences, t. 115, 1882

37. Gravıer (Ch.). - Lepidasthenia digueti, Polynoë com- 
mensale d'un Balanoglossus du golfe de Californie. C. R. Acad. Sciences, t. 140, 1905 .

38. Heath (H.). - The association of a Fish with a $\mathbf{H y}$ droid. Biol. Bull. Wood's Hole, t. I9, 1910.

39. Jungersen (H.). - On a new Gymnoblastic Hydroid (Ichthrocodium sarcotretis), epizoic on a new parasitic Copepod (Sarcotretes scopeli), infesting Scopelus glacialis Rhdt. Vid. medd. fra den naturh. Foren., t. 64, 1911 .

40. Lunel (G.). - Sur un cas de commensalisme d'un Caranx et d'une Crambessa. Recueil Zool. suisse,t. I, 1884 .

41. Malaquin (Ch.). - Quelques commensaux du Bernard l'ermite. Rev. Biol. Nord, t. 2, I89o.

42. Minckiewicz (R.). - Mémoire sur la biologie du Tonnelier de mer (Phronima sedentaria). Bul. Inst. océanog. Monaco, 1909.

43. - L'instinct du déguisement et le choix des couleurs chez les Crustacés. Rev. génér. Sciences pures et appl., t. 20, 1909.

44. Pellegrin (J.). - Commensalisme de jeunes Caranx et de Rhizostomida. Ass. franc. Avanc. Sciences (Congr .Cherbourg), r9o5.

45. Pérez (Ch.). - Le complexe éthologique du Spondyle sur les bancs perliers du golfe Persique. C. R. Soc. Biol., t. 83, 1920.

46. Plate (L.). - Apogonichthys strombin. sp., ein symbiotisch lebender Fisch von den Bahamas. Zool. Anzeiger, t. 33, 1908 .

4́7. Polmanti. - Studi di fisiologia etologica. Zool. Jahr. bücher (Abth. f. allg. Zool), t. 3o, rgri.

48. Potrs (F.-A.). - The fauna associated with the Crinoids of a tropical coral-reef., etc. Carnegie Instit. of Washington, publ. $\mathrm{n}^{\circ} 212,1915$.

49. Semper (C.). - Lettres à Kílliker. Zeits. $t$. wiss. Zool., t. 13 et 14, I863, 1864.

5o. - Sarnt-Joseph (de). - Sur quelques Invertébrés marins des côtes du Sénégal. Ann. Sc. nat. Zoologie, (sèr. 8), t. 12, 1901. 
51. Sluiter (Ph.). - Die Sipunculiden und Echiuriden der Siboga-Expedition. Siboga Expeditie, livr. 8, I902, p. $19-25$.

52. Sluiter (Ph.). - Ein merkwürdiger Fall von Mutualismus. Zool. Anzeiger, t. 11, 1888 .

Commensalisme (suite)

Espèces myrmécophiles

53. Brurs (Ch. T.). - Two new myrmecophilous genera of aberrant Phorida from 'Cexas. Americ. Naturalist, t. 35,1901 .

54. Büsgen (M.). - Der Honigtaú. Eine biologische Studie an Pflanzen und Pflanzenlaüsen. Jenaische. Zeitsch., t. 25, 1891 .

55. Chonat (R.) et Carrisso (L ). - Une nouvelle théorie de la myrmécophilie. Arch. sci. phrs. nat. Genève, suppl. 1920, t. 3 j.

56. Donisthorpe. - Notes nombreuses sur les animaux myrmécophiles. Entomologist's Record and Journal of Variation, passim.

57. Eschrrich (K.). - Zur Anatomie und Biologie von Paussus turcicus, zugleich ein Beitrag zur Kentniss der Myrmecophilie. Zool. Jahrb. (Atth. f. Syst.), t. 12,1898 .

58. - Ueber myrmecophile Arthropoden, mit besonderer Berücksichtigung der Biologie. Zool. Centralbl., t. 6, 1899 .

59. - Die Termiten oder weissen Ameisen. Leipzig, Igog.

6o. Emery (C.). - Ueber den Ursprung der dulotischen, parasitischen und myrmecophilen Ameisen. Biol. Centralbl., t. 29, I909.

6r. Huber (P.). - Recherches sur les mœurs des fourmis indigènes, 1810 .

62. Ihrring (H. von). - Die Cecropien und ihre Schutzameisen Englers Bot. Jahrb., t. 39, 1902.

63. Janet (C.).- Les fourmis. Bul. Soc. Zool. France,t.21, 1896 . 
6年. - Rapports des animaux inyrmécophiles avec les Fourmis. Limoges, 1897 .

65. Jordan (K. H. C.). - Zur Morphologie und Biologie der myrmecophilen Gattungen Lomechusa, Atemeles und einiger verwandten Formen. Zeitsch. für wiss., Zool., t. Io7, 1913.

66. Le Cerf (F.). - Sur une chenille de Lycænide élevée dans les galles d'Acacia, par les fourmis du genre Cremastogaster. C. R. Acad. Sciences, t. I58, 1914.

67. Mordwilko (A). - Die Ameisen und Blattlaüse in ihren gegenseitigen Beziehungen und das Zusammenleben von Lebewesen itberhaupt. Biolog. Centralbl., t. 27, 1907.

68. Овегтнӥr (Ch.). - Symbiose des papillons et des fourmis. C. R. IX Congr. Internat. Zool. (Monaco), I913.

69. - La symbiose des fourmis et des chenilles de Lycana. G. R. Acad. Sciences, t. I69, I9I9.

70. Pı́́ron (H.). - La genèse des instincts esclavagistes et parasilaires chez les fourmis. Rev gén. Sci.pures et appl., t. 29, 1910.

7r. Tutr (J. W.). - The connection between ants and Lycænid larvæ. Entomol. Record, t. 20, 1908.

72. - * Natural History of the British Butterflies, t. r, p. $30-37$.

73. "Ule. - Ameisenpflanzen. Botan. Jahr., t. 3;, rgo6.

74. Wasmann (E.). - Zur nieheren Kentniss der echten Gastverhæltnisse bei den Ameisen und Termiten. Biol. Centralb., t. 23, 1903 (passim).

75. - Ursprung und Entwicklung der Sklaverei bei der Ameisen. Ibid., t. 25, 1905 (passim).

76. - Ueber das Wesen und den Ursprung der Symphilie. Ibid., t. 3o, r910 (passim).

77. - Die Ameisen und ihre Gæste. Ciongrès internat. d'Entomol., I9I I (p. 209).

78. - Die Myrmecophilen und Termitophilen. G. R. $I I I^{\mathrm{e}}$ Congr. Internat. Zool. Leyde, 1895 .

79. - Beitr. zum sozialen Parasitismus und der Sklaverei bei den Ameisen. Biol. Centralbl., t. 28, 1908. 
So. Wherler (W. M.). - An extraordinary ant-guest. Americ. Naturalist., t. 35, I901.

8I. WheELer (W. M.). - An interpretation of the slavemaking Instincts in Ants. Bull. Amer. Mus. Nat. Hist., t. $2 \mathrm{r}, 1905$ (p. I-16)

82. ${ }^{\star *}$ Wheeler (IV. M.).- Ants; their structure, development, and behavior (Columbia Univ. Biological Series, $I X)$. New-York, 1910).

\section{Symbiose (I. - Animaux)}

83. Altmann (R.). - Die Elementarorganismen und ihre Beziehungen zu den Zelleu. Leipzig, r8go ( $2^{\circ}$ éd., I894).

84. Balbiani. - Mémoire sur la génération des Aphides. Ann. Sc. nat. (Zool.) (sér. 5), t. 11,1869, t. I4 (18jo), t. 15 (ISJ2).

85. Bary (A. de). - Die Erscheinung der Symbiose, 1879 (trad. dans Revue Internat. des Sciences, t. 3, 1879).

86. Beijerinck: - Culturversuche mit Zoochlorellen, Lichengonidien und anderen niederen Algen. Bot. Zeit., t. 48,1890 .

87. Blochmans. - Ueber das regelmässige Vorkommen von bacterienæhnlichen Gebilden in den Geweben und Eiern verschiedener Insekten. Zeits. f. Biol., t. 2f, I887.

88. Bonvier (G.). - Recherches sur la synthèse des Lichens. Ann. Sci. Nat., Bot. (sér. 7), t. 9, 1889.

89. ** Bouvier (E.-L.). - La chlorophylle animale et les phénomènes de symbiose entre les algues vertes unicellulaires et les animaux. Paris, Bul. Soc. Philomathique (sér. 8), t. 5ั, 1892.

9o. "Brandt(K.). - Ueber die morphologische und physiologische Bedeutung des Chlorophylles bei Thieren. Mitth. Zool. Stat. Neapel, t. 4, 1883.

91. "* Buchner (P.).- Studien an intracellularen Symbionten. I. - Arch. f. Protistenk., t. 26, 1912; Il. - Ibid., t. 39, I 9 I 8 . 
92. Crenkowsky. - Ueber Schwärmerbildung bei Radiolarien. Arch. $f$. mikr. Anat, t. $7,18 \mathrm{jI}$.

93. Cohnndy (M.). - Expériences sur la vie sans microbes. Ann. Inst. Pasteur, t. 26, r912.

94. Conte et Fauchron. - Présence de levures dans le corps adipeux de divers Insectes. $C_{0} R$. Acad. Sci., t. 145,1909 .

95. Dangeard (P.-A.). - Etude de l'Ophrydium versatile. Bory, le Botaniste, $2^{\circ}$ série, $189^{n}$.

96. Delage (Y.). - La structure du protoplasma el les théories de l'hérédité et les grands problèmes de la Biologie générale. Paris, 1895 .

97. Drlcourt (A.) et Guyénot (E.). - Génétique et Miiieu. Bull. scient. France-Belgique, t. 45,1911 .

98. Elenkine. - La symbiose équilibre instable entre les organismes associés. Trav. Soc. Imp. Natural. SaintPétersbourg, t. 37, r9o€ (en russe, analysé dans l'Année Biologique, I9o6).

99. Entz (Geza). - Ueber die Natur der Chlorophyllkœrpershen niederer Tiere. Biol. Centralbl., t. I, 1881. roo. Escinerich (K.). - Ueber das regelmässige Vorkommen von Sprosspilzen in dem Darmepithel eines Kæfers. Biolog. Centrablt., t. 20, 19oo.

Ior. Famintzin. - Beiträge zur Symbiose von Algen und Thieren. Mém. Acad. Saint-Pétersbourg, t. 36 et 38 , I889 et 1891 .

102. Frank (B.). - Ueber die auf Wurzelsymbiose beruhende Ernæhrung gewisser Baüme durch Unterirdische Pilze. Ber. deutsch. bot. Gesells, t. 3, 1885.

103. Galippr (V.). - Parasitisme normal et microbiose. Paris, 1917 .

ro4. " Giard (A.). - L'Isaria densa, Champignon parasite du Hanneton commun. Bull. Scient,, France-Bel. gique, t. 2ł, 1892 .

105. Grassi (B.) et Foa (A.). - Intorno ai Protozoi dei Termitidi. R. G: Accad. Lincei (sér. 5), t. 20, 1911.

106. Guilliermond (A.). - Mitochondries et symbiotes. $C$. R. Soc. Biol., t. 8.2, I919.

107. "Guyénot (E.). - Recherches expérimentales sur la 
vie aseptique et le développement d'un organisme en fonction du milieu. Bull. Biol. France-Belgique, t. 51,1917 .

108. * Hadzi (J.). - Ueber die Symbiose von Xanthellen und Halecium ophiodes. Biolog. Centralbl., t. 31, I91I. ro9. Hertwig (O.). - Die Symbiose im Tierreiche, 1883. Ilo. Huxlky (Th.). - On the agamic reproduction and morphology of Aphids. Trans. Linn. Soc. London, t. 22,1863 .

iir. Kerble (F.), and Gamble (F. W.). - On the isolation of the infecting organism (Zoochlorella) of Convoluta roscoffensis. Proc. Roy Soc. (sér. B), t. 77, 1905.

112. - The origin and nature of the green cells of Convoluta roscoffensis. Quart Journ. micr. Science, t. 5r, 1907.

113. Gamble (F. W.). and Kreble (F.). - The bionomics of Convoluta roscoffensis, with especial reference to its green cells. Quart. Journ. micr. Science, t. 47. I904.

II4. Javelly (E.). - Les corps bactéroüdes de la Blatte (Periplaneta orientalis) n'ont pas encore été cultivés. C. R. Soc. Biol., t. 7J, 1914 .

115. Juliv (Ch.). - Les embryons du Pyrosoma sont phosphorescents; les cellules du testa constituent les organes lumineux du cyathozoïde. C.R. Soc. Biol., t. 66,1909 .

116. - Recherches sur le développement embryonnaire de Pyrosoma giganteum. Zool. Jahrb., suppl. XV, 1912.

117. Karawaiew (W.). - Zur Anatomie und Metamorphose des Darmkanals der Larve von Anobium paniceum Biol. Centralbl., t. 19, 1899.

I18. Lagursse (E.), - Mitochondries et Symbiotes. $C$. $R$. Soc. Biol , t. 82, 1919 .

I19. Le Dantec (F.). - Hecherches sur la symbiose des Algues et des Protozoaires. Ann. Inst. Pasteur, t. 6, 1893 .

120. Leydig (F.). - Einige Bemerkungen über die Entwicklung der Blattlaüse. Zeits. f. wiss. Zool., t. 4, 18 š .

121. - Zur Anatomie von Coccus hesperidum. Ibid.. t. 5, 185 I. 
122. Lumière (A.). - Le mythe des Symbiotes. Paris, I919. 123. Mangan (J.). - The entry of zooxanthella into the ovary of Millepora and some particulars concerning the medusa. Quart. Journ. micr. Science, t. 53, I909.

I24. Mrraier (L.). - Recherches sur les Bactéroüdes des Blattes. Arch. f. Protistenk., t. 9, 1907.

125. - Les cellules uriques du Cyclostome et leur bactérie symbiote. Arch. anat. microsc., t. ı́, 1913.

126. Metchnikoff (E.). - Untersuchungen uber die Embryologie der Hemipteren. Zeits. f. wiss. Zool., t. I6, I 866

127. Metchnikoff (Mme Olga). - Note sur l'influence des. microbes sur le développement des têtards. Ann. Inst. Pasteur, t. I5. Igo I.

128. Moniez. - Sur un champignon parasite de Lecanium hesperidum (Lecaniascus polymorphus.) Bull. Soc. Zool. France, t. 12, 1887.

129. Nuttall et Thierfelder. - Thierisches Leben ohne Bakterien im Verdanungskanal. Zeits. $f$. physiol. Chemie, t. 21, 1895.

I3o. Pierantoni (U.). - Les micro-organismes physiologiques et la luminescence des animaux, Scientia, t. 23, 1918 .

13i. - Per una piu esatta conoscenza degli organi fologeni dei Cefalopodi abissali. Archivio Zoologico, t. 9, 1920.

132. - L'origine di alcuni organi d'Icerya purchasi e la simbiosi ereditaria. Bal Soc. Nat. Napoli, t. 23, I9Io.

133. - Ulteriori osservazioni sulla simbiosi ereditaria degli Omotteri. Zool. Anz., t. 36, rgı.

134. - Struttura ed evoluzione dell organo symbiotico di Pseudococcus citri e ciclo biologico del Coccidomyces dactylopii. Arch. $t$. Protistenkunde, t.31, rgi3.

135. - La luce degli Insetti luminosi et la simbiose ereditaria.'R. (i. Acad. Sci. Napoli, I9Ít.

x36. - Gliorgani simbiotici e la luminescenza batterica dei Cefalopodi. Pubbl. Staz. Zool. Napoli, t. 2, 1918. 
137. - Le simbiosi fisiologiche e le attivita dei plasmi celIulari. Rivista di Biologia, t. I, Igr9.

138. Portirn (P.). - Recherches physiologiques sur les champignons entomophytes. Paris (Thèse Fac. Sciences), rgir.

139. Portier (P.). - Les Symbiotes. Paris, I9I8.

:4o. Regaud (A.). - Mitochondries et Symbiotes. C. R. Soc. biol., t. 82. 1919.

I/qr. Roubaud (E.). - Les particularités de la nutrition et la vie symbiotique chez les mouches tsétsés. Ann. Ins. Pasteur, t.33, rgrg.

1́2. Schaudixs (F.) - Untersuchungen über den Generationswechsel von Trichosphaerium sieboldii. Abh. K. Akad. Berlin, t. 1899.

1\{3. Sulc (K.).-Kermincola kermesina und Physokermina, neue mikroendosymbiontiker der Cocciden. Sitzber. bahm. Ges. Wiss. Prag., r9o6.

I 44. - Pseudovitellus und æhnliche Gewebe der Homopteren sind Wohnstætte symbiotischer Saccharomyceten. Ibid, rgro.

145. Whrtney. - Artificial removal of the green bodies of IIydra viridis. Biol. Bull. Wood's Hole, t. 13, 1907.

146. Wollman. - Sur l'élevage des mouches stériles. Ann. Inst. Pasteur, t. 25, I9Ir.

147. Warmixg. - Lehrbuch der œkologischen Pflanzengeographie, rgo2.

148. Zirpolo (G.) - I batteri fotogeni degli organi luminosi di Sepiola intermedia. Næf. Bacillus pierantonii, n. sp. Bull. Soc. Natur. Napoli, t. 3o, r917.

I49. - Micrococcus pierantonii, nuova specie di batterio fotogeno dell' or'gano luminoso di Rondeletia minor Naef. Ibid., t. 31, 1918 .

150. - I batteri fosforescente e le recente richerche sulla biofotogenese. Natura, t. 10, 1919.

\section{Symbiose (II. - Végétaux)}

I5i. Bervahd (Noël). - Etudes sur la tubérisation. Rev. gén. Botan, t. 14, 1902. 
552. Bernard (Noël). - L'évolution dans la symbiose. Les Orchidées et leurs champignons commensaux. Ann. Sc. Nat. (Botanique), (sér. 9), t. 9, 1909.

153. - Remarques sur l'immunité chez les plantes. Bull. Inst. Pasteur, t. 7, x909.

154. Bornet (E.). - Recherches sur les gonidies des Lichens. Ann. Sc. Nat., (Bot.), (sér. 5), t. 17, 1873. ıว5. BürgefF (H.). - Die Wurzelpilze der Orchideen. Iena, I909.

156. Chodat (R.). - Monographies d'algues en culture pure. Matér. pour la flore cryptogamique de la Suisse, t. 6, rgo3.

157. * Costantin (J.). - La vie des Orchidées. Paris, 1917. 158. Elfving. - Untersuchungen über die Flechtengonidien Act. Soc. Scient. tennicce, t. 44, 1913.

I59. ** Gallaud (I.). - Etudes sur les mycorhizes endotrophes. Rev. gén. Botanique, t. $17,1904$.

16o. Letrllikr (A.). - Etude de quelques gonidies de Lichens. Inst. Botan. Univ. Genève (sér. 9), fasc. ? 1917 (Thèse U. Genève).

16r. MorLlkr (A.). - Ueber die Kultur flechtenbildender Ascomyceten ohne Algen. Diss. Münster i W., r887. 162. Moreau (M. et Mme F.). - Recherches sur les Lichens de la famille des Peltigéracées. Ann. S i. Nat.(Botanique, (sér. 10), 6i, 1919.

163. Rews (M.). - Ueber die Entstehung der Flechte Collema glaucescens Hoffm. durch Aussaat der Sporen desselben auf Nostoc lichenoïdes. Monatsb.K.Akad. Wiss. Berlin, $18 j \mathrm{r}$.

164. Reinke. - Abhandlungen über Flechten. Jahrb. $t$. wiss. Bot., t. 26, 189 .

165. StanL. - Beitræge zur Entwicklungsgeschichte der Flechten. Leipzig, 187 .

166. Schwendener (S.). - Ueber die wahre Natur der Flechten. Verh. Schweiz. Natur/. Gesells, t. 5̆1, 1867. 167. - Die Algentypen der Flechtengonidien. Bâle, 1869.

168. Tobler. - Das physikalische Gleichgewicht von Pilz und Alge in den Fleshten. Ber. deutsch. bot. Gesellsch., t. 27, 1909 . 
i69. Treub (M.). - Notes sur l'embryogénie de quelques Orchidées. Amsterdam, 1879.

I69 bis. - Etudes sur les Lycopodiacées. Ann. Jard. bot., Buitenzorg, t. 8, I89o.

\section{Actions réciproques de l'hôte et du parasite}

170. Apathy (S.). - Beschaffenheit und Function der Halsdrüsen von Hirudo medicinalis. Medic. Naturw. Mitth. Koloszuar, 1897.

IjI. Mrsnil et Caullery. - Néoformations papillomateuses chez une Annélide (Potamilla torelli), dues probablement à l'influence de parasites (Haplosporidie et levure) Bull. Scient. France, Belgique, t. 45, 1911.

172. Cú́not (L.). - Etudes physiologiques sur les Orthoptères Arch. Biol., t. I4, 1896 (p. 32 r et suiv.):

173. Dastre et Stassano.- Existence d'une antikinase chez les parasites intestinaux. - Antikinase des macérations d'Ascaris et de Tcenia.C.R.Soc.Biol., t. 55, 1903.

I7千. Giard (A.). - Sur la transformation de Pulicaria dysenterica Gærtn. en une plante dioique. Bull. Scient. France, Belgique, t. 20, 1889.

Ijó. Haycraft (J.-B.). - On the action of a secretion obtained from the medicinal leach on the coagulation of the blood. Proc. R. Soc. London, 1884.

176. Hollande (A. Ch.). - Réactions des tissus du Dytiscus marginalis L. au contact de larves de Distomes enkystées et fixées aux parois du tube digestif de l'Insecte. Arch. Zool. expér., t. 59, 1920.

I77. Jameson (L.). - On the origin of Pearls. Proc. Zool. Soc. London, 1902, t. I.

ig8. Laveran (A.) et Mrswil (F.). - De la sarcocystine, toxine des Sarcosporidies, C. R. Soc. Biol,, t. 51, I899.

179. LaEb (L.) et Surtu (A.-J.). - Ueber eine die Blutgerinnung hemmende Substanz in Anchylostoma caninum, Centrabl.f. Bakt. u. Paras., t. 37, I, Ig13. 
180. MrazeK (A.). - Zur Auffassung der Myxocystiden. Arch. f. Protistenk, t. 18, I910.

I81. Ṕ́rez (J.). - Effets du parasitisme des Stylops sur les Apiaires du genre Andrena. Proc. verb. Soc. Sc. phys. nat. de Bordeaux (sér. 2), t. 3, 1879.

182. - Des effets du parasitisme des Stylops sur les Apiaires du genre Andrena. Arch. Soc. Linn. Bordeaux, t. $40,1886$.

183. Rovbaud (E.). - La méthode trophique dans la lutte contre les Insectes et les affections qu'ils transmettent. Rev. génér. Sci. pures et appliquées, t. 31, 1920 184. - Anopliélisme et Paludisme. La question du danger palustre en France. Rev. génér. Sci. pures et appl., - t. 29,1918 .

185. Seurat (L.-G.). - L'huître perlière; nacre et perles, I vol. Paris, rgor (Encyclopédie Léauté).

186. Shipley (A.-E.), and Fearnsides (E.-G.). - The effects of Metazoan parasites on their hosts. Journ. of Econom. Biol., t. ז, 1906.

187. Sмiтн (G.). - Studies in experimental analysis of sex. Part. 4. Quart. Journ. Micr. Science, t. 54, r910 et Part. 7 Ibid., t. 57, 191 I.

188. Timberlake. - Experimental Parasitism. A Study of the biology of Limnerium validum Cv. U. S. Dept. of Agric., Bureau of Entomology. Techn. sér. ${ }^{\circ} 19$, part. 5, 1912 .

189. WARD (H.-B.). - The influence of Parasitism on the host. Amer. Assoc.f. Ads. of Science, t. 56, 1907.

19o. Weinberc: (M.).- Substances hémotoxiques sécrétées par les larves d'CEstres. C. R. Soc. Biol., t. 65, 1908.

191. - Toxines vermineuses. Bull. Inst. Pasteur, t. Io, 1912.

192. - Die Echinokokken und die Serumdiagnostik der Echinokokkenkrankheit. Handb. der pathog, Mikroorg. (Kolle und Wassermann), 2éd., t. 8, 1913.

193. - Recherches sur la toxine ascaridienne. Hygiène de la viande et du lait, 1913.

194. Weinland.-Ueber ausgepresste Extracte von Ascaris 
lumbricoides und ihre Wirkung. Zeits. f. Biol., t. 43, 1902 .

195. - Ueber Antifermente, I, Il. Ibid., t. 44 et 45, 1903.

195 bis. Wheeler (W. M.). - The polymorphism of Ants, with an account of some singular abnormities due to parasitism. Bull. Amer. Mus. Nat. Hist., t. 23, $190 \%$.

196. - The parasitic origin of macroërgates among Ants. Amer. natural., t. 35, I90 I.

197. - The effects of parasitic and other kinds of castration in Insects Journ. Exp. Zool., t. 21. 1910.

\section{Galles (végétales)}

198. Beiserinck (W.). - Beobachtungen über die ersten Entwicklungsstadien einiger Cynipidengallen. $A b h$. K. Akad. Wetensk. Amsterdam, t. 22, 1882.

199. - De la cécidie produite par le Nematus caprece sur le Salix amygdalina. Arch. Néerl. Sc. exac. et nat., t. 21,1887 .

200. Cotre (J.). - Recherches sur les galles de Provence. Bull. Soc. Philom. (sér. 10), t. 4, 1912.

20I. Hovard (A.). - Les Zoocécidies des Plantes d'Europe et du Bassin de la Méditerranée, 2 vol. Paris, I9o8. I9o9.

202. Küster (E.). - Die Gallen der Pflanzen. Leipzig, 19ri. 203. - Art. Gallen. Handworterb. d. Naturw., t. 4. 204. Magnus (W.). - Die Entstehung der Pflanzengallen. verursacht dureh Hymenopteren. Iéna, I9r'́.

205̌. Molliard (M.). - Action hypertrophiante des produits élaborés par le Rhizobium radicicola Beyer., C. $R$. Acad. Sc., t. 155, 1912.

206. - Recherches physiologiques sur les galles. Rev.gén. Botan., t. 25, 1913.

207. - Production artificielle d'une galle. C. R. Acad. Sc., t. 165,1917 .

208. - Fleurs doubles et parasitisme. C. R. Acad. Sc., t. $132,190 x$. 
209. - Virescence et prolifération florales produites par des parasites agissant à distance. $C$. R. Acad. $S c$, t. 139,1904 .

210. - Sur la prétendue transformation des Pulicaria dysenterica en une plante dioïque. Rev. gén Botan., t. 21,1909 .

211. Sмith (E. F.). - Chemically induced crowngalls. Proc. Nat. Acad. of Sciences. Washington, t. 3, I9I7.

\section{Protozoaires}

212. Archiv. für Protistenkunde (Iena, depuis 1902).

213. " Butschli (O.). - Protozoa, in: Bronn's Klassen und Ordnungen des Tierreichs.

214. " Calkins (G. N.) - The Protozoa. New-York, Igor.

215. "* Doflerin (F.). - Lehrbuch der Protozoenkunde ( $4^{\circ}$ éd.), Iéna, I9I6.

216. ** Minchin (E. A.). - Sporozoa in E. Ray Lankester. A Trealise on Zoology, Protozoa.

2s7. - An introduction to the study of the Protozoa, with special reference to the parasitic forms. Londres, I912, (5iz p.).

218. Gaullery (M.) et Mesnil (F). - Recherches sur les Actinomyxidies. Arch. f. Protistenk., t. 6, 1905.

219. Chatton (Ed.). - Le kyste de Gilruth dans la muqueuse stomacale des Ovidés. Arch. Zool. expér, (sér. 5), t. 5, 1910 (N. ęt R.).

220. - Les Péridiniens parasites. Morphologie, reproduction, éthologie. Arch. Zool. expér., t. 59, 1920.

22I. Cú́not(L.). - Recherches sur l'évolution et la conjugaison des Grégarines. Arch. de Biologie, t. 17, 1900. 222. Duвoscq (O.) - Selysina perforans. Arch. Zool. expér., t. 58,1918 .

223. Grassı (B.). - Die Malaria-Studien eines Zoologen, $2^{\circ}$ éd., Iéna, rgor (25o p.).

224. Hrsse (E.). - Sur Myxocystis mrazeki. C. R. Soc. Biol., t. 57,1905 . 
225. - Contríbution à l'étude des Monocystidées des Oligochètes. Arch. Zool. expér. (sér. 5), t. 3, rgog.

226. Laverax (A.). - Leishmanioses, etc. Paris, I 917 (521 p.) 227. Laveran et Mesnil. - Trypanosomes et Trypanosomiases, $2^{\circ}$ éd. Paris.

228. LÉGER (L.). - Contríbution à la connaissance des Sporozoaires parasites des Echinodermes. Etude sur le Lithocystis schneideri. Bull. Scient. France, Belgique, t. 3o, 1897 .

229. - La reproduction sexuée chez les Stylorhynchus. Arch. f. Protistenk., t. 3, 1904.

23o - Les Schizogrégarines des Trachéates. I. Le genre Ophryocystis, Ibid., t. 8, I907.

23I . Légrr (L.) et DuboscQ (O). - L'évolution schizogonique de l'Aggregata (Eucoccidium) eberthi. Arch.J. Protistenk, t. 12, 1908 .

232. - Recherches sur les Myriapodes de Corse et leurs parasites. Arch. Zool. expér. (sér. 4), t. I, rgo3.

233. - Les Grégarines et l'épithèlium intestinal des Tra. chéates. Arch. Parasitol., t. 6, 1902.

234. - Nouvelles recherches sur les Grégarines et l'épithélium intestinal des Trachéates. Arch. f. Protistenk, t. 4, 190\%.

235. - Sur les premiers états du développement des Grégarines du genre Porospora (Nematopsis). C. R. Soc. Biol.. t. 75 , 1913.

236. - Le cycle évolutif de Porospora portunidarum. C. $R$. Acad. Sci., t. 156, 1913.

237. Mathis (C.) et Mrrgier (L.) - L'amibe de la dysenterie Entamceba dysenterice C. et L. Bull. Inst. Pasteur, t. $14,1916$.

238. Mrssil (F.). - Aperçu sur l'hérédité dans les maladies à Protozoaires. Bull Inst. Pasteur,t. 3, ı9o5̃.

239. - Modes de propagations des Trypanosomiases; les Trypanosomes chez l'hòte invertébré. Ibid., t, 10, I912.

240. - Maladies infectieuses et invertébrés transmetteurs. Ibid., t. I1, 1913 .

241. Mesvil et Roubaud. - Essais d'inoculation du paludisme au Chimpanzé. Ann. Inst. Pasteur, t. 34, 1920. 
242. Pérrz (Ch.). - Sur une Glugea nouvelle, parasite de Balanus amaryllis. C. R. Soc. Biol., t. 57, 1905.

243. Ross (R.). - Researches on malaria. Journ. Army Med. Corps, I905.

244. Schaudinn (F.), - Untersuchungen über den Generationswechsel der Coccidien. Zool. Jahrb., Abth.f. Anat., t. 13, 1904.

245. - Untersuchungen über die Fortpflanzung einiger Rhizopoden. Arb. K. Gesundheitsamt., t. 19, 1903.

246. - Generations- und Wirtswechsel bei Trypanosoma und Spirochaete. Arb. K. Gesundheitsamt., t. 20, I904.

247. - Studien über Krankheiterregende Protozoen I. Cyclospora caryolytica Schaud. Arb. K. Gesundheitsamt, t. I8, 1902 .

248. - Studien über Krankheiterregende Protozoen. II. Plasmodium vivax, der Erreger der Tertianfiebers beim Menschen. Arb. K. Gesundheitsamt, t. I9, 1902 .

249. Simpleck (M.). - Etude cytologique d'Adelea ovata. Ann. Inst. Pasteur Paris, t. 13, 1899.

25̆o. - Cycle évolutif de Caryotropha mesnili. Bull. Acad. Sciences Cracovie, I902; Ibid., I90J.

25r. - Sur la reproduction sexuée de Monocystis ascidia. Bull. Ac. Sciences Cracovie, I\$99.

252. Stempell (W.). - Ueber Nosema anomalum, Arch. $t$. Protistenk., t. 4, 1904.

253. Tuḱlohan (P.). - Recherches sur les Myxosporidies. Bull. scient. France Belgique, t. 26, 1895 .

254. "Walker (E. L.). - The parasitic amobre of the intestinal tract of man and other animals. Journ. med. Research., t. 17, 1908.

\section{Cœlentérés}

255. * Chun (C.). - Cioelenterala, in Bronn's Klassen und Ordnungen des Tierreichs. (P arasitisme des Cunina p. 295 š et suiv.). 
25̃6. Ussow. - Eine neue Form von Süsswasserpolypen. Morphol. Jahrb., t. 12, 1887.

\section{Dicyémides et Orthonectides}

25j. Beneden(Ed. van.). - Rech erches sur les Dicyémides. Bull. Acad. R. Belgique, t. 41-42, 18j6.

258. Caullery (M.). - Le cycle évolutif des Orthonectides. $8^{e}$ Congr. Internat. Zool. Graz., rgro.

25̃9. Caullery (M.) et Lavallér (A.). - La fécondation et le développement de l'œuf des Orthonectides. Arch. Zool. expér. (sér. 4), t. 8, 1908.

260. - Recherches sur le cycle évolutif des Orthonectides. Bull. Scient. France, Belgique, t. 46, 1912.

261. Caullery (M.) et Mesnil (F.). - Recherches sur les Orthonectides. Arch. Anat. Microsc., t. 4, I9or. 262. Grard (A.). - Les Orthonectides, nouvelle classe du phylum des Vermes. Journ. Anat. physiol., t. 15, I879.

263. Hartmann (M.). - Untersuchungen über den Generationswechsel der Dicyemiden. Mém. Acad. Roy. Belgique (Cl. des Sciences) N. S., t. I, 1907.

264. Lamerre (A.). - Contribution à la connaissance des Dicyémides. Bull. Scient. France Belgique, t. 5o, 5ı, 53 (1916-I9!9).

265. Wheelen (.W M.). - The life-history of Dicyema. Zool. Anz., t. 22, 1899.

266. Whitman (C. O.). - Contribution to the embryology, life-history and classification of the Dicyenids. Mitth. Zool. Stat. Neapel., t. 4, 1882.

\section{Plathelminthes}

267. Велнам (W. B.).- The Platyhelmia, etc... in A Treatise on Zoulogy, edited by E.Ray Lankester, vol. 4, rgor.

268. " Braun (M ). - Vermes. in Bronv's Klassen und Ordnungen des Tierreiches (Trématodes et Cestodes). 
269. - Ueber parasitische Schnurwürmer. Centralbl. $f$. Bakt. u. Parasitenk., t. 3, 1888.

270. Cirry (L.-R.). - The life history of Diplodiscus temporatus. St., with especial reference to the development of the parthenogenetic eggs. Zool. Jahrb., Abth. f. Anat., t. 28, I909.

271. Caullery (M.) et Mrsnil (F.). - Recherches sur les Fecampia. Giard, Turbellariés Rhabdocèles parasites internes des Crustacés. Ann. Fac. Sciences Marseille, t. 13, 1903.

272. Dollfus (R.). - Continuité de la lignée germinale chez les Trématodes digéniques. C. R. Acad. Sci., t. 168, 1919.

273. Graff (L. von). - Die Turbellarien als Parasiten und Wirthe.Festschrift Univ. Graz, 1902.

274. - Turbellarien in Brons's Klassen und Ordnungen des Tierreiches.

295. Grassi (B.) e Rovalli (G.). - Ricerche embriologiche. sui Cestodi. Catane, 1892 .

256. Hallez (P.). - Biologie, histologie et embryologie d'un Rhabdocole parasite du Cardium edule, le Provortex cardii n. sp. Arch. Zool. expér. (sér. 4), t. 9, 1909.

277. Нвскегт. - Unters. über die Entwicklungs-und Lebensgeschichte des Distomum macrostomum. Bibliotheca Zoologica, fase. 4, 188y.

278. Hofmaxn (K.). - Beiträge zur Kentniss der Entwicklung von Distomum leptosomum Olsson. Zool. Jahrb. (Abth. f. Syst.), t. 12, 1899.

279. Iturbe y Gonzalez. - El huesped int. del Schistosomum mansoni. Caracas, 1917.

280. * Joyeux (Ch.). - Cycle évolutif de quelques Cestodes (Recherches expérimentales). Bull. Biol. France, Belgique, suppl. 11, r920.

281. Leuckart (R.). - Zur Entwicklungsgeschichte des Leberegels. Arch. $f$. Naturgesch., t. 48, 1882.

282. * Leiper (R. T.). - Report on the results of the Bilharzia-Mission in Egypt., Igró. Journ. R. Army Med. Corps, t. 25, 28 (1915-1918). 
283. Lüне (M.). - Trématodes et Cestodes, in : Die Süsswasserfauna Deutschlands, fasc. Iz et 18, I909-1910.

284. Lutz (A ). - Schistosomum mansoni and Schistosomatosis observed in Brazil. Mem. Instit. Oswaldo Cruz, t. II, I9I9.

285. Mryairi (K.) et Suzuki (M.). - Sur le développement de Schistosoma japonicum (en japonais) Tolyo Med. Journ., 1913; analyse dans Tropical Diseases Bull., 1914 .

286. Nakagawa (K.). - Human pulmonary distomiasis caused by Paragonimus westermanni. Journ. Exp. Med., t. 26, 1917.

287. - The mode of infection in pulmonary distomiasis; certain fresth-water Crabs as intermediate hosts of Paragonimus westermanni. Journ. of infect. Diseases, t. 18,1916 .

288. Reuss (H.). - Die Cercarie und Sporocyste des Distomum duplicatum. Zeits. $f$. wiss. Zool., t. $7_{4}, 1903$.

289. Rosen (F.). - Recherches sur le développement des Cestodes: I. Le cycle évolutif des Bothriocéphales. Bull. Soc. Neuchâtel. des Sci. nat., t. 43, r918. - II Le cycle évolutif de la Ligule, etc. Ibid., t. 45, 1919.

290. Rosen (F.) et Jasickı (C.). - Le cycle évolutif de Dibothriocephalus latus. Ibid., t. $42,191 \%$.

29r. Thоmas (A. P.). - The life history of the liver-fluke, Quart. Journ. Micr. Science, t. 23, 1883.

292. Yosmida (S.). - On the intermediate hosts of the lungdistome Paragonimus westermanni. Journ. of Parasitology', t. 2 , 1926 .

\section{Annélides et Hirudinées}

293. * Caullery (M.). - Labidognathus parasiticus, cas nouvcau d'endo-parasitisme évolutif chez les Euniciens. C. R. Soc. Biol., t. 77,1914 .

294. Eisig (H.). - Ichthyotomus sanguinarius, eine auf Aalen schmarotzende Annelide. Fauna und Flora des Golfes von Neapel., Monogr., 28, 1906. 
295. Kovalevsky (A.). - Etude sur l'anatomie d'Acanthobdella pelledina. Bull. Acad. Sci. Saint-Pétersbourg, t. 5,1896 .

296. Spengel (J. W.). - Oligognathus bonellice.eine schmarotzende Eunicee. Mitth. Zool. Stat. Neapel., t. 3, I88x.

297. Potts (F.-A.). - A new type of parasitism in the Polychaeta. Proc. Cambridge phil. Soc., t. 16, I9ı ,p.409. 298. Saint-Josepu (de). - Les Annélides des còtes de Dinard. Ann. Sci. Nat. (Zoologit), (sér. 7), t. 5, r888, (p. 287).

299. Wheeler (W.M.). - The sexual phases of Myzostoma. Mitth Zool. Station Neapel, t. 12, 1896.

\section{Némathelminthes}

3oo. Camerano (L.). - Monografia dei Gordii. Mém. Acad. Sci. Torino (sér. 2), t. 47, 1897.

3o i Kaiser (J. E.). - Die Acanthocephalen. Biblioth. Zoologica. Heft. 7 , I893.

302. Krilin (D.). - Sur un Nématode nouveau. Aproctonema entomophagum, parasite d'ıne larve de Diptère. C. R. Acad. Sci., ᄂ. 155, 1917.

3o3. Leuckart (R.). - Neue Beitræge zur Kentniss des Baues und der Lebensgeschichte der Nematoden. Abh. K. Sachs. Gesells Wiss. (Math. nat. Kil.), t. 13, I887.

304. Lовв (L.) et Sмiтн (A.-J.). - Ueber eine die Blutgerinnunghemmende Substanz in Anchylostoma caninum Centralbl. f. Bakt. u. Paras., I. Abth., t. 37, 1904.

305. Looss. - Die Wanderung der Ancylostomum - und Strongyloüdes larven von der Haut nach den Darm. C. R. $6^{\text {e }}$ Congr. Internat. Zool. Berne, Igo4.

3o6. - The anatomy and life history of Agchylostoma duodenale. Le Caire. Rec. Egypt. Govt. School.-Med., t. $4, \operatorname{Ig} 11$.

307. Montgomery (T. H.). - The adult organisation of Paragordius varius Leidy. Zool. Jahrb. (Abth. $t$. Morph.), เ. I8, 1903. 
308. Nor (G.). - Sul ciclo evolutivo della Filaria bancrofti. Cob. e della F. immitis. Leidy. Rich. fatte nel Lab. di Anat. norm. Univ. Roma, t. 8.

3og. - Il ciclo evolulivo della Filaria grassii Rendic.Accad. Lincei, t. $7 \mathrm{I} 7,1908$.

3ro. Ransom (H.) et Forster (W. D.). - Life history of Ascaris lumbricoides and related forms. Journ. Agric. Research. Washington, t. II, 1917.

31. - Recent discoveries concerning the life history of Ascaris lumbricoides. Journ. of Parasitology, t. 5, Igo9.

312. Roubaud(E.). - Le Ver de Guinée (Filaria medinensis). Etude sur la faune parasitaire de l'Afrique occidendale française, $\mathrm{I}^{\mathrm{er}}$ fasc., I9I4 (222-244).

313. Seurat (1..-G.). - Contribution à l'étude des formes larvaires des Nématodes parasites hétéroxènes. Bull. Scient. France, Belgique, t. 49, 1916.

3i4. Strwart (F. H.). - On the development of Ascaris lumbricoides. L. and Ascaris suilla Deg.- in the Rat and Mouse, Parasitology, t. 5, 1917.

315. - On the life history of Ascaris lumbricoides, IV. Parasitology, t. 11, I9I9.

3i6. Strubell (A.). - Untersuchungen über den Bau und die Entwicklung des liübennematoden. Heterodera schachtii Cassel, Biblioth. Zoologica, I888.

3ig. Villot (A.). - Monographie des Dragonneaux. Arch. Zool. expér., t. 3, 187'́

3r8. - Nouvelles recherches sur l'organisation et le développement des Gordiens. Ann. Sc. Nat. (Zool.), (sér. 6), t. II, I88I.

3r9. Yoshida (S.). - On the development of Ascaris lum. bricoides. Journ. of Parasitology, t. 5, 1919.

\section{Crustacés}

320. Calman (W. T.). - The life of Crustacea. Londres, rgI I.

32r. "* Giesbrecht (IV.). - Crustacea, in Handbuch. der 
Morphologie der Wirbellosenthiere (A. LANG). Iéna, I9I3.

3\%2. Sars (G. O.). - An account of the Crustacea of Norway. t. II. Isopodes, I899.

323. Stebbing (T. R. R.). - A History of Crustacea (Recent Malacostraca). Londres, 1893 .

324. Bonnier (J.). - Note sur le Pionodesmotes phormosoma, Copépode parasite du Phormosoma uranus. Rés. Camp. Scientif. Princ. Monaco, fasc. 12, 1898.

325. ** Bonnizr (J.). - Contribution à l'étude des Epicarides. Les Bopyrida. Trav. Stat. Zool. Wimereux, t. 8, I900.

326. "Boone (P. L.). - A new chinese Isopod Ichthyoxenus geei. Proc. U. S. Nat. Museum, t. 5j, 1920 (p. 497วั02).

327. Canu (E.). - Les Copépodes du Boulonnais. Trav. Stat. Zool. Wimereux, t. 5, 1892.

328. Caullery (M.). - Sur les phases du développement des Epicarides; vérification expérimentale de la nature des Microniscidae. C. R. Acad. Sc., t. 145, 1907.

329. - Recherches sur les Liriopsida, etc... Mitth. Zool., Stat. Neapel, t. 18, 1908.

33o. Caullery (M.) et Mesnil (F.). - Sur deux Monstrillides parasites d'Annélides. Bull. Scient. France, Belgique, t. 48, 1914.

33r. - Recherches sur Hemioniscus balani.Bull. Scientif. France, Belgique, 1. 34, 1901.

332. - Ancyroniscus bonnieri. Epicaride parasite d'un Sphéromide (Dynamene bidentata). Bull.biol.France, Belgique, t. $5 \%, 1920$.

333. - Xenocoloma brumpti, Copépode parasite de Polycirrus arenivorus C. Bull. biol. France, Belgique, t. 53, I919.

334. Chatton (E.) et Brénent (E.). - Sur un nouveau Copépode Ascidicole incubateur (Ooneides amela), parasite des Leptoclinum. Bull. Soc. Zool. France, t. 40, 1915 .

335. - Les oostégites, les ptérostégites et la cavité incu- 
batrice des Ascidicolidae (Copépodes). Développement, Homologies, Valeur phylogénétique et taxonomique. Ibid.

336. Coutık̇Re (HI.). - Sur un type nouveau de Rhizocéphales. C. R. Acad. Sc., t. 134, 1902 .

337. Drlage (Yves). - Evolution de la Sacculine. Arch. Zool. expérim. (série 2), t. I, I884.

338. Giard (A.). - Sur l'éthologie du genre Thaumaleus Kr. C. R. Acad. Sc., t. 120, 1895 .

339. - Sur le parasitisme des Monstrillider. Ibid., t. 123, з 896 .

339. bis. - Sur le parasitisme placentaire des Monstrillides. Sur la signification générale du parasitisme placen. taire. C. R. Soc. Biol., t. 49, 1897 .

34o. Giard (A.) et Bonnier (J.). - Contribution à l'étude des Bopyriens. Trav. Stat. Zool. Wimereux, t. 5, 188 y.

34 I. Hansen (H. J.). - The Choniostomatidce. A family of Copepoda, parasites on Crustacea Malacostraca. Copenhague, 1897 .

342. - Crustacea Malacostraca. The Danish Ingolf-Expedition, vol. III, $\mathrm{n}^{\circ} 5, \mathrm{I} 9 \mathrm{r} 6$ (p. 22I).

343. Hrsse (E.). - Mémoire sur les Pranizes el les Ancées, etc. etc. Mém. Acad. Sciences. Paris, t. 18, 186ł.

3‡4. Knipovitch (N.). - Beitr z. Kentniss der Gruppe Ascothoracida. Trav. Soc. Nat. S. Pétersbourg, t. $23,1892$.

345. Lacaze-Duthiers (H. de). - Histoire de la Laura gerardice. Mém. Acad. Sciences, t. 42, 1882.

346. Malaquin (A.). - Le parasitisme évolutif des Monstrillides. Arch, zool. expér. (sér. 3), t. 9, rgor.

347. Mayrr (P.). - Ueber den Hermaphroditismus bei einigen Isopoden. Mitth. Zool. Stat. Neapel, t. I, 1879 .

348. Mortensen (Th.) and Strphenson (K.). - On a gallproducing parasitic Copepod infesting an Ophiurid. Vid. Medd. fra Dansk Naturhist. Foren, t. 69, 1918. 349. Pelsenera (P.).- Ethologie de quelques Odostomia et d'un Monstrillide parasite de l'un d'eux. Bull. scient. France, Belgique, t. 48, 1914 . 
35o. Potrs (F. A). - On the Rhizocephalian genus Thompsonia and its relation to the evolution of the group. Carnegie Instit. of Washington, Publ. 202, 1915, (p. I-32).

35r. Scotr (Th. and And.). - The british parasitic Copepoda (parasites ou Fishes), 2 vol. (Ray Society), 1911I913.

352. Sмiтн (Geoffrey). - Rhizocephala, in Fauna und Flora des Golfes von Neapel., monog., 29, Igo6.

353. WrLson (Ch. B.). - North American Copepods (Argulida, Caligina, Ergasilida, Lernœopodida, Lernaida, etc... Proc. S. U. Nat. Museum (passim).

\section{Arachnides}

354. Neumann (G.). - Révision de la famille des Ixodida Mém. Soc. Zool. France (passim).

355. - Notes sur les Ixodida Arch. Parasitol. (passim).

356. Nuttall (G. H. F.), Warburton (C.) etc. - Ticks, A monograph of the Ixodidœ. Cambridge, I9ı.

35j. Nuttall (G. H. F.). - Observations on the biology of Ixodida. Parasitology, t. 6, 1913.

358. Shipley (A. E.). - An attempt to revise the family Linguatutida. Archiv. Parasitol., t. I, 1898.

359. Warburton (C.). - Mites, Ticks, etc... in the Cambridge Natural History, vol. 4, 1909.

360. Shipley (A. E.). - Pentastomida. The Cambridge Natural History, t. 4, 1909.

36r. Bonnet (A.). - Recherches sur l'anatomie comparée des Ixodidés. Ann. Univ. Lyon (N.-S,) fasc. I, 1907.

362. Canestrini (G.). et Kramer (P.).- Demodicidoe and Sarcoptida. Das Tierreich., liv. \%, 1899.

363. Neumann (L.).- Ixodida. Das Tierreich., liv. 26, 19 I. 364. Nalepa (A.). - Eryophyida (Phytoptida). Das Tierreich., liv, 4. 1898 .

365. Sabbatini (I..). - Ferment anticoagulant de l'Ixodes ricinus. Archio. itál. Biol., t. 31, 1899. 


\section{Insectes}

366. Bureau of Entomology (U.S. Department of Agriculture) Publications diverses sur les Insectes nuisibles. 367. Insect Life (U.S. Department of Agriculture, 1888-1895). 368. Henneguy.- Les Insectes(Morphologie, reproduction, embryogénie), Paris, 1904.

369. Sharp (David). - Insects. The Cambridge Natural History. t. 5, 1895 et t. 6, 1899 .

3jo. Bugnion (E.). - Recherches sur le développement postembryonnaire, l'anatomie et les mœurs de l'Encyrtus fuscicollis. Rec. Zool. Suisse, t. 5, I891.

3ji. Giard(A.). - Sur le développement du Litomatix truncatellus Dalman. Bull. Soc. Entom. France, 1898.

372. HowAln and Fiske. - The importation into the United States of the parasites of the Gypsy moth and the Brown-Tail-Moth. - U. S. Dep. of Agriculture, Bureau of Entomology. Bull., n॰ 9I; I9II.

3ך3. Jost (H.). - Beitræge zur Kentniss des Entwicklungsganges der Larve von Hypoderma bovis de Geer Zeits. f. wiss. Zool., t. 86, I907.

374. Knilin (D.). - Recherches sur les larves de Diptères Cyclorhaphes (Cycle évolutif de Pollenia rudis F.etc...) Bull. scient. France Belgique, t. 49, 1915.

3j5. Keilin (D.) et Baume-Pluvinel (G. de la). - Formes larvaires et biologie d'un Cynipide entomophage (Eucoila keilini). Bull. scient. France Belgique, t. $47,1913$.

376. Lichtenstein (J.) et Picard (F.). - Etude morphologique et biologique de Sycosoter lavagnei, Hécabolide parasite de l'Hypoborus ficus. Bull. biol. France Belgique, t. 5̆ $\mathbf{1}, \mathbf{1 9} 8$.

377. Marchal (P.). - Recherches sur la biologie etle développement des Hyménoptères parasites. I. La Polyembryonie spécifique ou germinogonie. Arch. Zool. expér. (sér. 4), t. 2, :904.

378. - Utilisation des Insectes auxiliaires Entomophages dauš la lutte contre les Insectes nuisibles à l'agri- 
culture. Ann. Inst. nat. Agronom. (sér. 2), t. 6, 1907.

3'99. - Recherches sur la biologie et le développement des Hyménoptères parasites: Les Platygaster.Arch.Zool. expér. (sér. 4), t. 4, 1906.

380. - Les Sciences biologiques appliquées à l'agriculture et la lutte contre les ennemis des plantes aux EtatsUnis. Ann. des Epiphyties, t. 3, 1916, etc., à part.

38r. Neiva (A.) et Gomès (F.). - Biologia da Mosca do Berne (Dermatobia hominis) observada em todas as suas phases. Ann. Paulist. med. chirur., t. 8, I917.

382. Patterson (J.). - Observations on the development of Copidosoma gelechiae. Biolog. Bull. Wood's Hole t. 29,1915 .

383. - Studies on the biology of Paracopidosomopsis. Ibid., t. 32 et 33 , 1917; t. 35,1918 .

384. - Polyembryony and Sex. Journ. of Heredity, t. 10, I9I9.

385. Rodhaiv (J.). - Nouvelles observations sur la biologie de Passeromyia heterochcela. Bull. biol. France Belgique, t. 52 , 1919 .

386 Rodiain (J.) et Bequaert (J.). - Observations sur la biologie de Cyclopodia greeffi Karsch. Nyctéribie parasite d'une Chauve-souris congolaise. Bull. Soc. Zool. France, t. 40, 1915.

38:- - Matériaux pour une étude monographique des Diptères parasites de l'Afrique I-III. Bull. scientif. France, Belgique, t. 49, 5o et 52, 1916-1919.

388. Roúbaud (E.). - La Glossina palpalis. Sa biologie, son rôle dans l'étiologie des Trypanosomiases. Mission d'études de la maladie du sommeil au Congo français. Paris, Igog.

389. - Recherches sur les Auchméromyies, Calliphorines à larves suceuses de sang. Bull. scient. France, Belgique, $\mathrm{t} .47$, 1913.

39o. - Les producleurs de myiases et agents similaires chez l'homme et les animaux. Etudes sur la faune parasitaire de l'Afrique occidentale française, fasc.I, I9I4. 
39i. - Auto-inoculation et développement primaire dans les muqueuses buccales de la larve du Gastrophile équin (CEstre du Cheval). C. R. Acad.Sc., t. 164, I917.

392. - Précisions sur Phormia azurea, Muscide à larves hémophages parasite des Oiseaux d'Europe. Bull. Biol. France Belgique, t. 5̌ , 1918.

393. Sergrnt (Ed. et Et.). - La Thim'ni, myiase humaine d'Algérie causée par l'Estrus oris. Ann. Instit. Pasteur, t. 21, 1007 .

394. Silvestri (F.). - Contribuzioni alla conoscenza biologica degli Imenotteri parassiti.I Biologia del Litomastix truncatellus Dalm. Ann. Scuol. sup. Agricolt. Portici, t. 6 rgo6.

395. Sмiти (H. S.). - The Cihalcidoid genus Perilampus, etc. U.S. Dep. of Agric. (Bureau of Entomology). Techn. séries, ${ }^{\circ} 19$, part. IV, I9I I.

3y6. Tномpson (W.-R). - Sur la spécificité des insectes entomophages. C. R. Soc. Biol., t. Jō, 1913.

397. - Contribution à la connaissance de la larve Planidium. Bull. scient. France Belgique, t. 48, 1915.

398. Townsexd (Ch. H. T). - A record of results from rearings and dissections of Tachinida. U.S. Dep. of Agric., Bureau of E'ntom.,Tech. séries, $\mathrm{n}^{\circ}$ 12, p. 6,1908.

\section{Mollusques}

399. Bonnevie (K.). - Enteroxenos oestergreni, ein neuer in Holothurien schmarolzender Gastropode. Zool. Jahrb. (Abth.f. Anat.) t. 15, 1902, p. 23 I-792).

400. - Ueber den Parasistimus der Anodontalarven. Verhandl. Ve Intern. Zool. Congres. Berlin, Igor (p. j61). 40I. - Ueber den Parasitismus der Anodontalarven. in der Fischhaut. Biol. Centralb., t. 15, 1895.

402. - Накмs (IV.).- Die postembryonale Entwicklung der Unioniden. Zoolog. Jahrb. (Abth. f. Anat.), t. 28, 1909 (Communications préliminaires dans Zoolog. Anzeiger, t. 3i, 190z et 32, 1908).

M. Cacllery. - Le Parasitisme 
403. Kozhler (R.) et Vaney (C.). - Entosiphon deimatis; Revue suisse de Zoologie,t. I1, 1903.

404. Lefèvre (G.) et Curtis (W. C.). - Reproduction and Parasitism in the Unionida.Journ. of exper.Zool.,t.9, I9Io.

405. Lefìve (G.) et Curtis (W. C.). - Metamorphosis without parasitism in the Unionida. Science, t. 33, IgII (p. 863).

406. MüLren $\left(J_{\uparrow}\right)$. - Ueber die Erzeugung von Schnecken in Holothurien. Arch. Anat. Physiol., 1852 (p. 10э).

407. *Nierstrasz (H. F.). - Die parasitischen Gastropoden. Ergebnisse und Fortschritteder Zoologie, t. 3, 1913.

408. Reuling (F. H.). - Acquired immunity to an animal parasite. Journ. of infect. diseases, t. 24, I9r9.

409. Schrerholz. - Ueber die Entwicklung der Unioniden. Denksch,Ak. wiss. Wien (Math-Naturw. Kl.), t.55, 1888. 410. Voigt (W.). - Entocolax ludwigii, ein neuer seltsamer Parasit aus einer Holothurie. Zeits. t. wiss. Zool. t. 47, 1888 (p. 658).

411. "VAney (Cl.). - Adaptation des Gastropodes au pa. rasitisme. Bull. scientif. France Belgique, t. 46, 1913.

\section{Divers}

412. Handworterbuch der Naturwissenschaften.léna, 1912-1914 Articles : Parasiten [W. Benecke, végétaux]. - Parasitismus [M. Lühe]; Srmbiose [A. Reghensperger, animaux; W. Nienburg, lichens; H. Burgeff, plantes supérieures et champignons ou bactéries].

413. Caullery (M.) et Mesnil (F.). - Les formes épitoques et l'évolution des Cirratuliens. Ann. Univ. Lyon, fasc. 38,1898 .

4I4. Cuḱnot (L.). - La genèse des espèces animales. Paris, $2^{\circ}$ éd. $19^{21}$.

415. Giard (A.). - OEuvres diverses, 2 vol. Paris, I9II-1913. /116. Goldschmidt (R.) - Experimental intersexuality and the sex-problem. Amer. Naturalist., t. 5o, 1916.

417. Harmer (S. F.). - Preliminary note on embryonic 
fission in Lichenopora. Proc. Roy. Soc. London, t. 57, I895. - On the development of Lichenopora verrucaria F. Quart. Journ. Micr. Sci., t. 39, 1896.

418. Lillie (F. R.). - The free-martin : a study of the action of sex-hormones in the foetal life of cattle.Journ. exper. Zool., t. 23, 1917.

419. * Massart (Jean). - L'intervention des animaux dans l'évolution des végétaux. Bruxelles, Revue universitaire, 1893.

420. SeMPen (C.). - Die natürlichen Existenzledingungen der Thiere, 2 vol., Leipzig, 1880. 


\section{ERRATA}

\begin{tabular}{|c|c|c|c|}
\hline ages & lignes. & au lieu de: & lire: \\
\hline 67 & & départ & début \\
\hline 74 & 6 et 9 & Tuniciens & Eunicien s \\
\hline $9^{5}$ & 1 & $\begin{array}{l}\text { le parasitisme, tant } \\
\text { chez les tubes }\end{array}$ & $\begin{array}{l}\text { te parasitisme ; } \tan t \text {, } \\
\text { chez les tubes }\end{array}$ \\
\hline 97 & I & Eutoconcha & Entoconcha \\
\hline 162 & $\begin{array}{l}4 \text { (du som- } \\
\text { maire) }\end{array}$ & Schistosonum & Schistosomum \\
\hline 183 & 12 & qui vit dans & qui vit sur \\
\hline I 88 & 6 & Tryponosomes & Trypanosomes \\
\hline 217 & dernière & spécifité & spécificité \\
\hline 232 & 3 & préétable & préétablie \\
\hline 255 & dernière & porteur & porteurs \\
\hline $26 \dot{0}$ & 3 & sur de témoins & sur des témoins \\
\hline 267 & 15 & plurinuclées & plurinucléées \\
\hline 269 & $\mathrm{x}$ & Hapalacarcinus & Hapalocarcinus \\
\hline 270 & 21 & intéressants & intéressantes \\
\hline 3 & 8 & Hіррорһе & Hippophae \\
\hline $35 \mathrm{I}$ & av. dern. & LAGUESSF & LAGUESSE \\
\hline 353 & $i d$ & susceptiblse & susceptibles \\
\hline
\end{tabular}




\section{INDEX ALPHABÉTIQUE DES AUTEURS ET DES MATIÈRES}

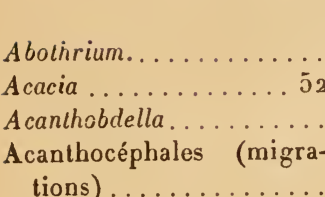

Achrea. .

Acuariidx

Adamsia, 25, 26, 27, 28,

$29,32,33$

Ega . . . . . . . 59

Agamogonie..........

Ageniaspis.

Aggregala

Alcoce.

Alepas

Allantonema....... 192

Allélositisme

Alpheidre.

Alturuxy.

Alydus.

Amphilina

Amphiprion

Amphistomum

Anceus.

Anchistus

Anchorina

Ancylostomum... 71, 235

Ancyroniscus.... I1 3, I I j
Pages

167

53

69

38

38

176

282

102

198

205

220

63

63

I 96

$3 \circ 9$

19

341

37

200

17

172

103

58

214

252

I 7
Pages

Anelasma.........6 $63 \quad \mathbf{1 2 6}$

Anergales........47 52

Anthomyidx.......... $15 \mathrm{r}$

Anticoagulant (ferment).. 7 I Apanteles........ $153 \quad \mathbf{1 5 5}$

Аратну........... 7 I

Aphis.............. 45

Apogonichthys.......... 58

Apothécie........... 308

Archigetes........ 167500

Arele............... $\mathbf{1 9}$

Artari ............. 312

iscaris... 195, 236, $237, \quad 251$

Aspidusiphon......2.20 21

Asterophila........83 83

Astomata.......... 70

Astrochordeuma......... 268

Alemeles....... 38, $40 \quad 47$

Athelges........... 107

Alla............54 55

Atlaphila........... 37

Attractonema .......... 196

Auchmeromyia... 67, 22'i 240

Aulax ............. 278

Aunivillius........... 33

Awerintzeff. . . . . . 285

Ayers........... $\mathbf{1 5 9}$

Azleca. . . . . 54,55 
Pages

Bacterium tumefaciens..... 279

Bactéroïdes........... 298

Balanoglossus.......2 2 I 22

Balbiani........... 39 I

Bary A. de......28 I 3 I 2

Baur ............... $9^{5}$

BÉCHAMP.......... 34 I

Beckia

BeiJerinck , 27jo 285,286

3 г $2 \ldots \ldots \ldots \ldots$

Beneden P. J. van... 164

Bequaert .

Bernard Noël, 3 I 3,32 I et suiv.

Bierry

Bilharz

Bilharzia.. $172,173,175$

Biontergasie.

Bithynis.

Blehparipa

Blochmann....... 298

Boas J. E. V

Boeving.

Bonnier G.

Bonnier J. 24, 106, 109 , 215,255 .

Bopyridx, 106, 107, et suiv. $g^{3} \ldots \ldots \ldots \ldots$.

Borket. . . . . . . 3og

Borratiatle...... 20, 3o

Bothriocephalus..... I67

Bouffard . .

Bouvier........20, 23

Braconidx.

Bradynema.

Bradypus

Brandt K

Braula

Bruge

97
341
37

$3 \mathrm{r} 6$

165

239

337

352

173

I $9^{3}$

32

I 9

238

299

II 9 42

309

268

262

3 I I

3 I

I 68

186

283

150

192

55

289

43

184
Pages

Brumpt . . . . . . . . . $\quad \mathbf{r} 86$

Buchiner........... 294

Bugnion. . . . . ....... 208

Bunodeopsis........ 3o $\mathbf{3 2}_{2}$

Buphagus.......... $35 \quad 36$

Buhgeff...... 326, 327332

Burger..........2 28 $2 \hat{y}$

Cabiropsidx... . 107, I 13 I I4

Cinlandruccio ......... 169

Calliactis............. 24

Cancricepon............ 104

Capulidx..........83 83

Carunx............. 18

Carcelia ............ 228

Carcinus (castr. parasit.). . $\quad 258$

Carteria ............. $\quad 287$

Cary .............. 203

Caryophyllæus ......... 200

Caryotropha.......... 265

Cassis ............. 26

Castration parasitaire 254 et suiv. Caullery (M.) I I 4 , I 15 , เ 3 เ , г 36, г 37, 1 44, 146, $248 \ldots \ldots \ldots \ldots 267$

Cécidie.... 245,270 et suiv. Cécidogène... 66, 270 et suiv. Cecropia......52,53 55

Géphalodie.......... 309

Céphalopodes (org. lumineux)........ 3or et suiv.

Ciercaire.......... 170

Cercocystis .......... $\mathbf{1 6 6}$

Cerruts ............. $\mathbf{x} 46$

Cestolaires.......... 167

Cestodes (migrations) I 63 et suiv.......... 200

Cetonia...........37 38

Chaeromyia.......224 240

Chitoplerus. 
Pages

Chalcidid ${ }^{2 . . . \ldots \ldots \ldots \ldots . . .150}$

Сhutron.........6.6 6o 267

Cheimatobia

I 54

Chevreux 23

Chlamydomonas.

Chlamydophrys

Chlımydopsis

Chlorella

Сhodat.......5 56, 314

Chondromyces

Chrysomyia

Cicadomyces

Cienkovskx. . . . . . 283

Cirolana

Cllaparède

Claviger ..... 41, 42, 46

Cleptobiose

Clypeoniscus

Clytra.

Coccidomyces

Caceloplana.

Conurus

Conevor.

Collix

Comanthus.

Commoptera

Compsilura

Conte

Copidosoma

Coracidie.

Cordia.

Cordylobia .........240

Coronula.

Cothurnia

Coupix ........ 24, 25

Coutière.......... I 9

Cowles.

Grabes (Déguisement) 32

Crambactis.
.85
Pages

Crambessa............. $\quad \mathbf{1 8}$

Cremastogaster......... 44

Crinoniscus.......... 117

Crossocosmia.......... $\quad 238$

Crotophagus.......... 35

Crypsidomus........... 130

Cryptomonas........... 286

Cryptoniscidie I 06, I12, I 3 , I 1 . ........... I 5

Cryptoniscienne (larve)... I 105 Ctenosculum.........83 84

Cucullanus........... I76

Cúńnot. . . . . . . . $248 \quad 298$

Culcita........... I9 58

Cumoechus............ 215

Cumonsicidx.......... 107

Cunina............ 94 200

Cyamus.........6.64 69

C.yclopodia........... 239

Cymothoidæ 69, Iо2, го3. I 6

Cynipidx......... ז 50 $\quad 276$

Cypris (larve) I 20 et suiv. .

Cyproniscido.......... 107

Cysticerques...... I63 et suiv,

Cysloccoccus........... 312

Dactylophorus.......... 2 I4

Dajidæ....... Io6, 1 I 2 I $9^{3}$

Danalia........... I07 I 3

Daxgeard ......... 283

DaYilofF ............ 3

Darwin. . . . . . . $48 \quad 49$

Dastre............ 250

Davainea ............. $\quad \mathbf{I} 66$

Déguisement (des Crabes), $32 \ldots \ldots \ldots \ldots \ldots \ldots$

Delage (Y.), I 2 I, I 23, I 34340 Delcourt. . . . . . . 348 349

Dendrosomides......... 62

Dermatobia........... 24 I 
Pages
Pa....

Dexiidx.......... $151 \quad 238$

Dexodes

Dicyémides.

Dinarda.

Digénétiques (Trémalodes) $169 \quad 203$

Diplodiscus .

Dipplidium........ 165

Discophrya ............

Dislomum, 170, 17r, :72, I $73,203,2$ I $8,246 . \ldots$.

Doflein . . . . . . 32, 63

Dolium

Dollfus

(R.)

Doropygus

Dorylus

Dromie.

Drude.

Duboss (R.)... 247, 34́1

DuboscQ, 180, 181, 21 ,

Duerdex. . . . . . 3. 3. 3 I

Dulosis.

Duplorhis

Echeneis

Echinocordium.

Echinococcus

Echinoslomum.

Echinothrix

Ecitochara.

Ecilomorpha

Ecilomyıa

Eciton

Eisig........ 71,73 et suiv.

Elexkine.

Elfving.

Емену....... 37, 53

Encyrtus, 205, 206, 207,
203

337 310

238

197

37

I 66

62

255 285

203

60

43

33

321

343

265

34

48

I 26

16

2 I

166

I7

20

47

38

43

47

58

212
Pages

Endens ............. 22

Engraulis........... 19

Enterocola............ 60

Enteropsis............ 60

Enteroxenos. . 84, 95, $9^{6} \quad 9^{8}$

Enihylacus............ II 3

Entocolax..... 8 83, $9^{5} \quad 97$

Enloconcha, 84, 94, 95, 96

$97 \quad 9^{8}$

Enloconchidx, 83 84, 94, $99 \quad 19^{2}$

Entomophages (Insectes),

I 50 , et suiv.

Entoniscidx 106, 108, 110 , I $14,193 \ldots \ldots \ldots \ldots 194$

Entovalva.......... 82

$\operatorname{Entz(G.)...........~} 283$

Ephippodonla........ $8 \mathbf{2}$

Epicarides, 69, 102, 103 et suiv. $26 x$

Epiphytes........... 61

Epilelphusa......... 59

Epizoaires............ $6 \mathbf{6}$

Epizoanthus......... $66 \quad 28$

Epœcus............ 52

Enickson. . . . . . . . . . 3 1 I

Eschericir. . . . . 4 4 1, 46, 299

Esclavage (Fourmis) 48 et suiv.

Eucocridium ........... $\mathbf{1} 80$

Eucoila ............ 158

Eulimidx.... 83, 84, 94, 99

Eumedon.............. 20

Eupagurus, 23, 25, 27, 33, 282

Eupeleteria........... 238

Euryloma ........... 56

Eustrongylus ......... 235

FABRE .......... 32 I

Famitzin . 284, 286, $288 \quad 289$

Faccheron . . . . . . 292

Fauré Frémet........ 6 I 
Pages

Pages

Faurot.......... 26, 29

148

Faussek.

234

Fecampia

58

Fierasfer........ 57,

233

Filaria, $176,177, \mathbf{1} 78$, 183

247

Filippi (de).

I 54

Fiske.

I 30

Fleming ............ I 48

Forel.....37, 45, 48 5o

Formica, 38, 39, 40, 42, $49,50,5$ I

Formicoxenus......... 38

Forster..........236

Frank 318

Free-Martin.

50

237

334

Galippe ............ 342

Gallaud ......... 3 i 9

Galleria

320

38

Galles........2 26 z et seq.

GambeE........287

Gavin.

289

158

Garnault .

298

Gasterostomum

Gastrosiphon, 84, 90, 91, $9^{3}, 9^{4}, 96,97$

Gear.

172

Georgevitch

GIARD, 22, 31，32， 106, $109,124,137,138,140$, $141,201,207,215,217$, $246,247,254,255,257$. $258,259,262,263,270$ Glochidium, 82,147 et suiv. $245,264,265$

Glossina

Glyptus

Gnathia. 70, 102, 103, 1 I5 Ginathomysis

Gnomoniscus ............ 114

Goldschmidt (R.)...... 261

Gonospora........2 214 248

GrafF (L. von)....... 287

Grassi (B.)...... $169 \quad 182$

Gravier.......... 22 13o

Grégarines.......... 265

GUÉNÉE............ 44

Guilliermond.......... 351

Gчуе́хот.......... $348 \quad 349$

Gonzalez ........... 17 '

Gordiens ........ I49 179

Gyrocutyle .......... 200

Haizı ........... ${ }_{28} 87$

H.ескеL............. 94

Hæmatocleptes ......... $\mathbf{1 4 6}$

Hæmocera . . . . . . $138 \quad 139$

Hæmogregarina ......... 183

Hxmoproteus....... 18 I 183

Haliotis............ 59

HaMa $\ldots \ldots \ldots \ldots \ldots .286$

Haysev (H.J.).... Io6 2 I5

Hapalocarcinus....... $20 \quad 268$

Ilaplosporidium. ....... $\quad \mathbf{2 6 7}$

Haplosyllis ............ 74

Harmer (S.-F.)........ 211

Harmothö̈............ 24

HakMs......... $148 \quad 149$

Hantmans......... 198

Haygraft......... 71

Неатн............ 63

Hellriegel ......... 3i 6

Hélotisme. .......... 3 I I

270

I 85

48

142

24

Hemioniscidx... 107, I13 I I4

Henneguy. . . . ....... 298

Hepalus............. 28

Herduan . . . . ....... 247

HeRPIN . . . . . . . . . 82 
Hersiliodes............ 22

Hertwig (O.)........ ${ }_{282}$

Hesse (E.).... 102, 2 I5 265

Hetaerius. . . . . 37, 38

Heterocentrotus......... 19

Heterocyathus......... 20

Heterodera.... 256, $270 \quad 273$

Hétérophysaire (complexc) $\quad 246$

Heteropsammia.......20 20

Hétéroxènes(Parasites) \ 63 et suiv.

Hexacanthe (embryon) I 64 et suiv.

Hippobosca.

Hippolytidæ.

Hipponoe.

Histriobdella

Hoffmann.

Homœopraxie.

Homophysaire (complexe).

Hornele . . ..........

Howa Rd

IIUber.

Huxley.

Hyas

Hydnophyilum . .

Hydractinia . . . . 24, 25, Hymenolep is $\mathbf{1} 66, \mathbf{1} 69, \mathbf{1} 88$,

$$
200 .
$$

Hyperina.

Hyperparasiles....... I3

Hypocoma

Hypsagonus. ..........

Icerya. . . . . I 53, 293

Ichneumonidx.

Ichthyocodium

Ichthyonema .

Ichthyotomus. . . 71, 73 et

Ichthyoxenus.
Inering H. von... 54, $55 \quad 56$ Inachus(castr.-parasit.) 260, 26 I

262

Inquilinisme.....57 et suiv. Intermédiaire(IIôte) I 63 et suiv . Intersexualité......... 26 r IRMisch . . . . . . . . 32 I Isaria. . . . . . . . . 346

ITURBE. . . . . . . . 174

JAMESON L. . . . . . . . . . 247

J JNET Ch. . . ....... 46

J AVELLY . . . . . . . . . 2998 350

Johannsen. . . . . . . . . 34 亿́

JoRDAN K. H........ 40

JoYeux . . . . . . . . . 2 2 I9 220

Jungersen . . . . . . . . . 63

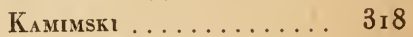

Karawaiew. . ........ 299

Karyolysus.......... 183

KEEBLE , . . 286, 287, 289, 290

KEILIN , I 58, 159, I6 I, $239, \quad 254$

KEPPEN ........... $\mathbf{1 9} 8$

Kermincola .......... 294

Klossia. ............ $\mathbf{1 8 0}$

Косн . . . . . . . . I $46 \quad$ I 86

KoEHLER........ 85, $81 \quad 87$

Künckel a'Hergulajs.... I 157

Küchenmeister $\ldots \ldots \ldots$ I 63

Lavidognathus. . . . . . . . 146

Labrorostratus. . . . . . I46 $\quad 147$

Laenilla.............. 22

Laguesse. . . . . . . . . 35 I

LAMEERE. . . . . . . . . . I 98

Lamellaria ........... 66

LANG (H.). . . . . . . . 36

Lankester (Ray) ....... 283

Lasidium. . . . . . . . . . 149

Lasius. . . . . . . . . . . $38 \quad 42$

Laurent . . ......... 316 
Lavar.LÉE ........... I44

LAVERAN 217,252

Lecanium

Le Davtec

LÉGER (L.), $180, \mathrm{r} 8 \mathrm{r}, \mathrm{I} 86$ I $87,188,214,220,248$ 249.

LEIPER

Leishmania

Lelaps.

Lepas

Leptothorax

Lernæodiscus.

Lestobiose.

LETELLIER.

Leuckart.

Leucochloridium

Leucocytozoon..........

Leydig 147

Lichens .

Lichtensteiv (J.).......

Liebig.

Ligula.

Lillie (F.-R.).... . 26 I

Limncrium.

LINDNER

Liparis (dispar, chrysorrhoea), 152 et suiv. 228 , $229,248,249$.

Linguatulides (migrations)

Liptotena.

Liriopsidx..... 107, 113

Lissocarcinus. ..........

Lithocystis..... 248, 249

Lithomastix. . . . . . . 207

Loeb (J.). . . . . . . 279

Loeb (L.)......... $7^{\text {I }}$

Loimia . . . . . . . . . . . .

Lomechusa, $38,39,40,4$ I
Pages

265

153

284

265

174

I 86

37

59

52

120

.49

315

I9)

17 I

183

292

suiv.

I57

$3 \times 6$

167

262

248

$2 g^{2}$

26 I

I 79

67

255

I 9

347

208

349

252

22
Pages

44. 47 Looss........ э $73,235 \quad 252$ Loxosoma ............ 63

LUMIÈré(A.) . . . . . . . . 354

LuNEL . . . . . . . . . . . 18

Lutz............ $174 \quad 175$

Lycona ........... 44

Lycopodiacées (mycorhizes des).

$321 \quad 336$

Lynchia. . . . ....... $6_{7}$

Lysiosquilla........... 22

Mc Callum. ......... I8 8 I

Macroergates........ 253

Magrus .......... 275 333

Malacobdella........ 59

Malaquin...24, 74, 138 I39

Mâles complémentaires... I 94

Malpighi............ 273

Mangan........... 287

Maxson (P.)........ 177

Marchal, т54, т58, г59; $205,206,207,208 \quad 21 \mathrm{I}$

Marchoux ......... 352

Martin (L:) . . . ...... 352

Megadenus......... $84 \quad 87$

Melia..........30, 31 3 2

Mélophage ........... 67

Mencier.......... $298 \quad 353$

Mermis ........... 253

Mesill (F.), I I 4, I 15, I3 I, 136, 137, 138, 214, 207, 23o, 242, 348, 252, $265 \quad 267$

Messor .......... 49

Métacercaire........ 17 I

Метсниiкоf, 291, 292,

$346 \quad 348$

Metopina.......... 43

Micaria........... 37

Microdon........... 37 
Microniscus......... $\begin{array}{r}\text { Pages } \\ 105\end{array}$

Migrations....... 63 et suiv.

Mineciton........... $38 \quad 4$ I

Minch:ж.......... $\mathbf{1} 88$

Minkiewicz ......... 33

Minous ............ 63

Miracidium ........ 178

Mitochondries.... 3ł 3 et suiv.

Moebies ............ 3o

Moldiard, $256,257,273$,

274,278

323

Moeller. . . . . 30 30, 3og 3i 3

Moniez. . . . . ..... 292

Monocystis (Ciestodes) .... $\quad 166$

Monogénétiques (Trématodes).

Monomorium

I 69

Monstrtlidie. . . 36 et suiv.

Monlacuta.........2 I

Moneau (F ).

Molacilla.

Mucronulia. . . . 84, 88

Müller. (Fritz). . 53, 54

Müller (J.)...... 94

Mutualisme ........

Mya.

Mycétome... 291, 293 et suiv. Mycétocyle......293 et suiv. Mycorhizes......316 et suiv.

Myiases .......... $16 \mathrm{I}$

Myrmecodia......... 52

Myrmecophila ........ 37

Myrmécophiles.... 36 et suiv.

Myrmedonia ......... 38

Myrmécoxènes........ 37

Myrus.......... $73 \quad 74$

Myxobactéries ........ $3 \mathbf{1 6}$

Myxocystis......... . ${ }_{2} 66$

Myzostomes

Nabis .

Pages

NEGELI

Nagana

340

Naucrales

220

Nectonema

16

(hétéroxènes).. 176

Nemalopsis........ I80 I8 8 I

Nephromyces.......281 290

Nereilepas..........24 43

Nereis............. 24

Nicéville (de)....... 44

Nierstrasz........... 100

Nodosités (à bactéroïdes). 3 I 6

Nomeus............. $\quad 18$

Nonagria........ 346 347

Nosema. . . . . . 242, 266347

Nolodelphys.......... 60

Novius............. . $\quad$ 53

Nudiclava .......... 63

Nettall . . . . . . . . . . 348

Nychia. .......... 22

Nyciolherus.......... 65

Овектнӥк........... 44

Odostomia........... 8 2

OEcophylla ......... $\mathbf{3}_{\mathbf{2}}$

OEstridż...71, 151, 211 255

Oligognathis .......... 146

Ollulanus........... $\quad 176$

Oucosphère...... 16'ł et suiv.

Oocinète........... $\mathbf{1 8 \mathbf { 2 }}$

Ooneides............ 60

Oostégites........... 108

Opaline........665 70

Opercularia.......... $6 \mathbf{1}$

Ophiodromus........... 22

Ophioglossées (mycorhizes des).........32 I 336

Ophioseides........... 60

Ophryodendron........ 62 
Ophryoscolecidæ.....6. $65 \quad 282$

Orasema.

158

Orchidées(Mycorhizes des), 322 et suiv.

Ornithomyia

Orthonectides, 143 et suiv.

I 99

Pachycondyla

Pagures

Paxtel

Parabiose.

255

43

Paracopidosomopsis...... 208

Paragonimus........172 17,5

Parasites hématophages... intermittcnts....

Parasitosyllis.. ........

Parexorisla. 229

Parthenoped

Passeromyia

Pasteur.

Patterson.

71

66

7'

238

I 20

240

347

208

Paussus.......... 4

Peclen

42

29

Pelseneer $\begin{array}{ll}82 & 138\end{array}$

Pelseneeria 84,87

Pérez Ch 24, 58

Pérez J

Perigonimus.

Pellogasler, 113, 120, 126, 1 27, 1 28, 205, 255 ...

Perilampus.

Perixguey.

Perles

Pfitzer

Pheidole

88

266

258

63

Phellia

Phormia.

Phronime.

Phytozoaires

26 I

247
Picard (F.).

Pieraxtoxi, 291 et suiv., 30 s et suiv. $342 \ldots \ldots-344$

Prérox ........... $5_{2}$

Pinna............. 58

Pinnothère.......... 59

Pionodesmoles ....... $268 \quad 269$

Piroplasma........... 243

Placentaire (Parasitisme). I 142

Planidium (larve)....... ז 58

Plusmodium.... 221, 230 233

Plate............. I7 58

Plalyarthrus.......... 37

Platyceras......... $83 \quad 84$

Plalygaster.......... $158 \quad 208$

Plérocercoïde larve).... 167

Pleurocrypla......... 216

Phiyxus ........... э07

Phyllomyza.......... 35

Physocephalus......... 176

Physogastrie.......... 47

Pocillopora.......... 19

Podasconidz........ г го I 14

Podocoryne......... $25 \quad 63$

Polia .............. 0 14

Pollenia...... 161, 239 248

Polycercus........... 302

Polydecles........... 30

Polyembryonie......... 205

Polyergus............. $5 \mathrm{I}$

Polygnolus........20- 21 I

Polyonyx............. 33

Polypodium.......... 200

Ponlania............ $27^{5}$

Ponlonia.......... $58 \quad 59$

Poriles ............ 19

Porospora........ I 80 I $8 \mathrm{r}$

Pontiea....... 342 , et suiv.

Porlunion. . 109, 110, 215219 


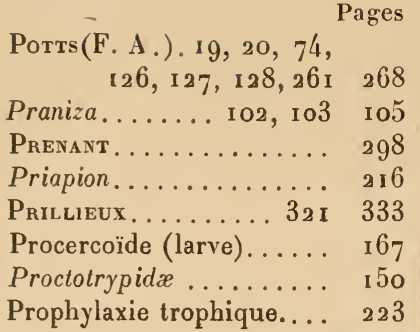
et suiv.

Proteosoma........ I $82 \quad 228$ Protélien (Parasitisme)... I 35 et suiv.

Protocalliphora.....667 340

Protocorme .......... 324

Provisoire (Hôte) ...... 163 et suiv.

Pseudomyrma......... 56

Pseudopallium ......... 87

Pseudovitellus ........ 29I

Psyllomyia.......... 43

Pterocephalus......... 214

Phromalus........ I55 157

Plychodera.......... 2 I

Puccinia............ I 89

Pulicaria........... $\quad 257$

Putnam........... 292

Pycnosoma........... ${ }_{239}$

Pyramidellidx........ 82

Quatrefages de....... $7^{5}$

Quedius.............. 38

Rassom ........ 236, 237

Rathke .................... 262

Rédie........... I 70

Rees............. 3og

Regaud........... 35 I

Reinke ........... 312

Reissex........... 32 I

Remora
Reuling .......... $\quad 264$

Reuss ............ 203

Rhatdonema......... 192

Rhipicephalus......... I 78

Rhizobium.......... 278

Rhizocéphales...... I 8 804

Rhizoctonia...... $3_{2} 6$ et suiv.

Rhizostoma......... I8

Rhopalona.......... 2 I4

Rhopalura 344, 145, 192, Ig $8 \ldots \ldots \ldots \ldots \ldots \ldots$

RiLey ............ I 53

Robillardia.......... 84

Rodhain .......... 239

Rosen (F.)... I67, 168. 220

Rosenia......... 84, 87

Ross (R.)......... 18 2

Roubaud. I 177, 188, 222 , $223,224,225,226,230$, 23 I, $240,241,244,264$. $299, \ldots \ldots \ldots \ldots \ldots 300$

Rovelli (B.)........ 169

Sabbatini ..........

Saccopsis............ 130

Sacculina.... I 3 , I 18 et suiv............ 253

Sagartia 23, 25, 26, 27 , $30,32 \ldots \ldots \ldots \ldots \ldots .33$

SAINT-Joseph (de), $22,146, \quad 147$

Sarcocystine......... ${ }_{252}$

Sarcophagidae......... $\mathbf{1 5}$ r

Sarcotretes........... 63

SArs (G.-O.)...... I05, 2 I 5

Scalpellum .......... 63

Sснаснт,......... 32 I

Schaudina ......... 286

SchewiakofF ......... 284

SсHімке Wiтch ........ 125

Schimpe R.......... 53 
Sehistosomum $172, \quad 173$,
$175,218 \ldots \ldots \ldots \ldots$.

Schizogenèse

Schizogonie

Schizosaccharomyces......

Schizolrypanum.........

Schloesing

Schimarda

Schwendener. . . 28 1, 309

Scioberetia

Scopelus

Scutellista

Selysina

Semper . . 20, 58, 59, 86

Sekera..............

Sergent ........225

Seurat..... I $8,19,20$

SHARP.

Shibata

Siedlecki

Sigronet

Silvestri.

Pages

237

201

I 96

292

I 85

316

75

3 II

82

63

152

267

268

287

226

247

150

333

265

292

Sluiter.

207

Sмiтн (A. J . . ....... 7

Sнiтн (E. F.). . 278,279

Смитн (Geoff.) 1 2/, 125 , $127,128,253 \ldots \ldots$.

Solenopsis ...... 38, 43

Soridie.

Sphzrularia

Spirachtha

Spengel.

Sphæromidæ.

Spirocerca.

Spiroptera

Spongicola

Sporocyste

Stahl.

Staphylocystis.

308
Stasisia

Pages

240

Stassito........... 250

Staurosoma.......... 217

Stempell ........ $266 \quad 267$

Stephexsen ......... 268

Stewart .......... 236

Stoecharthrum........ 192

Stomatome......... 55

Strombus .......... $26 \quad 58$

Strongyloides ......... 236

Stumluavy ........ 299300

Stylactis........... 63

Stylifer.... . 84, 89, 91 $9^{2}$

Stylocometes.......... 62

Stylops ............. 258

Suberites .......... $33 \quad 34$

Sulc ..... 292, 293, $296 \quad 299$

Sunaristes........... 24

Sycosoler............. 157

Symbiose......28 28 et suiv.

Symbiotes......344 et suiv.

Symphiles......... $37 \quad 38$

Synapticola.......... 82

Synechthres........37 38

Syngamus ........... 193

Synolpheus ......... 19

Synœcie ............ 14

Synœques..........36 38

I 97

47

146

I 18

I 76

I 66

59

170

$3 \circ 9$

202

Systropus ............ 157

Tachinaires..... I 5 I, $228 \quad 337$

Trnia...164 et suiv. 196202

Termes............. 48

Termitobia.......... 47

Termilomorpha....... 47

Tetrilus............ 37

Tetramorium......... $55_{2}$

Termitophiles ........ 36

Termitoxènes......... 37

Thalessa.......... 157 


\begin{tabular}{|c|c|c|}
\hline & Pages & Pages \\
\hline Theiler & 243 & Tylois \\
\hline HiERFELDER . . . . . & 348 & Typton..... \\
\hline himni... & 225 & Unionidx...... I'y et suiv. \\
\hline номеsоn (W.-R.).... & 249 & Urceolaria. ............. \\
\hline hompsonia $120,126,127$, & & Urothoë............ \\
\hline I 28 & 204 & VANEY. . . . $85,86,87$ \\
\hline hrixion & 238 & Van Tieghem. \\
\hline Thyca.....83,84, 85, 86 & 99 & VEJDovsKY \\
\hline Thylacie.........245 & 20 & VRIESDE.... \\
\hline Thylacoplethus....... I 20 & 126 & WAHRLICH. . \\
\hline Thyreostenus & 37 & WARMING. \\
\hline IMBERLAKE $\ldots \ldots \ldots \ldots$ & 248 & $W_{\text {Asmann }}, 36,40,4 \mathrm{r}, 46$, \\
\hline iq & 243 & $47,48,49,50 \ldots \ldots$ \\
\hline obLER . . . . . . . & 312 & Weinberg..... $71,25 I^{\cdot} 252$ \\
\hline ND $\ldots \ldots \ldots \ldots$ & 238 & Weingand . . . . . . . . . \\
\hline ox & 25 I & $W_{\text {EIS }}$ \\
\hline chthys....... & 17 & Wesenberg-Lund . . . . . . \\
\hline Trachyuropoda......... & 37 & WHEELER, $41,43,49,52$, \\
\hline LL. . . . . . & 74 & 56, ז \\
\hline rématodes. I 69 et suiv. & 20 & Wheeleriel!a. \\
\hline$\ldots \ldots \ldots \ldots$ & 324 & WHitney \\
\hline horus ...... & 167 & Willfahrt. \\
\hline Tric & 176 & WiREN. \\
\hline$\ldots \ldots \ldots$ & $6 \mathrm{t}$ & Wollman . . . . . \\
\hline Tric & 39 & Wooncoce............ \\
\hline nphides. & 65 & Xenocœeloma, i3o et suiv., \\
\hline Tric & 62 & $140,142,19^{3}, 19^{5}, 217$. \\
\hline iose. . . . . & 45 & Xenodusa....... 38, 40 \\
\hline Trouvelot & $\mathbf{1} 53$ & Yoshida............ 236 \\
\hline $\begin{array}{l}\text { Trypanosoma, I84, 185, } \\
\text { 186, 220, } 221 \ldots \ldots\end{array}$ & & $\begin{array}{l}\text { Zırpolo........ 301, } 302 \text { } 303 \\
\text { Zoochlorelles.... } 282 \text { et suiv. }\end{array}$ \\
\hline Tubicinella. . & 63 & Zooxanthelles.... 282 et suiv. \\
\hline & 306 & \\
\hline
\end{tabular}


Gaston DOIN, Éditeur, 8, place de l'Odéon, Paris=6

\section{ENCYCLOPÉDIE SCIENTIFIQUE}

Publiée sous la direction du D' TOULOUSE

Nous avons entrepris la publication, sous la direc. tion générale de son fondateur, le $\mathrm{D}^{\text {r Toulouse, }}$ Directeur à l'Ecole des Hautes études, d'une ExcyCLOPÉdiE SCIENTIFIQUe de langue française dont on mesurera l'importance à ce fait qu'elle est divisée en 40 sections ou Bibliothèques et qu'elle comprendra environ 1.00o volumes. Elle se propose de rivaliser avec les plus grandes encyclopédies étrangères et même de les dépasser, tout à la fois par le caractère nettement scientifique et la clarté de ses exposés, par l'ordre logique deses divisions et par son unité, enfin par ses vastes dimensions et sa forme pratique.

PLAN GÉNÉRAL DE L'BNGTCLOPÉDIE

Mode de publication. - L'Ẹncyclopédie se composera do monographies scientifiques, classées méthodiquement et formant dans leur enchaînement un exposé de toute la science. Organisée sur un plan systématique, cette Encyclopédie, tout en évitant les inconvénients des Traités, - massifs, d'un prix global élevé, difficiles à consulter, - et les inconvénients des Dictionnaires, où les articles scindés irrationnellement, simples chapitres alphabétiques, sont toujours nécessairement incomplets, - réunira les avantages des uns et des autres.

Du Traité, l'Encyclopédie gardera la supériorité que possède un ensemble complet, bien divisé et fournissant sur chaque science 
tous les enseignements et tous les renseignements qu'on en réclame. Du Dictionnaire, l'Encyclopédie gardera les facilités de recherches par le moyen d'une table générale, l'Index de l'Encyclopédie, qui paraîtra dès la publication d'un certain nombre de volumes et sera réimprimé périodiquement. L'Index renverra le lecteur aux différents volumes et aux pages où se trouvent traités les divers points d'une question.

Les éditions successives de chaque volume permettront de suivre toujours de près les progrès de la science. Et c'est par là que s'affirme la supériorité de ce mode de publication sur tout autre. Alors que, sous sa masse compacte, un traité, un dictionnaire ne peut être réédité et renouvelé que dans sa totalité et qu'à d'assez longs intervalles, inconvénients graves qu'atténuent mal des suppléments et des appendices, l'Encyclopédie scientifique, au contraire, pourra toujours rajeunir les parties qui ne seraient plus au courant des derniers travaux importants. II est évident, par exemple, que si des livres d'algèbre ou d'acoustique physique peuvent garder leur valeur pendant de nombreuses années, les ouvrages exposant les sciences en formation, comme la chimie physique, la psychologie ou les technologies industrielles, doivent nécessairement être remaniés à des intervalles plus courts.

Le lecteur appréciera la souplesse de publication de cette Encyclopédie, toujours vivante, qui s'élargira au fur et à mesure des besoins dans le large cadre tracé dès le début, mais qui constituera toujours, dans son ensemble, un traité complet de la Science, dans chacune de ses sections un traité complet d'une science, et dans chacun de ses livres une monographie complète. ll pourra ainsi n'acheter que telle ou telle section de l'Encyclopédie, sûr de n'avoir pas des parties dépareillées d'un tout.

L'Encyclopédie demandera plusieurs années pour être achevée; car pour avoir des expositions bien faites, elle a pris ses collaborateurs plutôt parmi les savants que parmi les professionnels de la rédaction scientifique que l'on retrouve généralement dans les œuvres similaires. Or les savants écrivent peu et lentement : et il est préférable de laisser temporairement sans attribution cerm tains ouvrages plutôt que de les confier à des auteurs insuffisants. Mais cette lenteur et ces vides ne présenteront pas d'inconvé- 
nients, puisque chaque livre est une œuvre indépendante et que tous les voluines publiés sont à tout moment réunis par l'Index de l'Encyclopédie. On peut donc encore considérer l'Encyclopédie comme une librairie, où les livres soigneusement chóisis, au lieu de représenter le hasard d'une production individuelle, obéiraient à un plan arrêté d'avance, de manière qu'il n'y ait ni lacune dans les parties ingrates, ni double emploi dans les parties trés cultivées.

Caractère scientifique des ouvrages. - Actuellement, les livres de science se divisent en deux classes bien distinctes : les livres destinés aux savants spécialisés, le plus souvent incompréhensibles pour tous les autres, faute de rappeler au début des chapitres les connaissances nécessaires, et surtout faute de définir les nombreux termes techniques incessamment forgés, ces derniers rendant un mémoire d'une science particulière inintelligible à un savant qui en a abandonné l'étude durant quelques années; et ensuite les livres écrits pour le grand public, qui sont sans profit pour des savants et même pour des personnes d'une certaine culture intellectuelle.

L'Encyclopédie scientifique a l'ambition de s'adresser au public le plus large. Le savant șécialisé est assuré de rencontrer dans les volumes de sa partie une mise au point très exacte de l'état actuel des questions; car chaque Bibliothèque, par ses techniques et ses monographies, est d'abord faite avec le plus grand soin pour servir d'instrument d'études et de recherches à ceux qui cultivent la science particulière qu'elle présente, et sa devise pourrait être : Par les savants, pour les savants. Quelques-uns de ces livres seront même, par leur caractère didactique, destinés à servir aux études de l'enseignement secondaire ou supérieur. Mais, d'autre part, le lecteur non spécialisé est certain de trouver, toutes les fois que cela sera nécessaire, au seuil de la section, dans un ou plusieurs volumes de généralités, - et au seuil du volume, - dans un chapitre particulier, - des données qui formeront une véritable introduction le mettant à mème de poursuivre avec profit sa lecture. Un vocabulaire technique, placé, quand il y aura lieu, ̀̀ la fin du volume, lui permettra de connaitre toujours le sens des mots spéciaux. 


\section{II}

\section{ORGANIBATION SGISNTIFIQUE}

Par son organisation scientifique, l'Encyclopédie paraft devoir offrir aux lecteurs les meilleures garanties de compétence. Elle est divisée en Sections ou Bibliothèques, à la tête desquelles sont placés des savants professionnels spécialisés dans chaque ordre de sciences et en pleine force de production, qui, d'accord, avec le Directeur général, établissant les divisions des matières, choisissent les collaborateurs et acceptent les manuscrits. Le même esprit se manifestera partout : éclectisme et respect de toutes les opinions logiques, subordination des théories aux données de l'expérience, soumission à une discipline rationnelle stricte ainsi qu'aux règles d'une exposition méthodique et claire. De la sorte, le lecteur, qui aura été intéressé par les ouvrages d'une section dont il sera l'abonné régulier, sera amené à consulter avec confiance les livres des autres sections dont il aura besoin, puisqu'il sera assuré de trouver partout la même pensée et les mêmes garanties. Actuellement, en effet, il est, hors de sa spécialité, sans moyen pratique de juger de la compétence réelle des auteurs.

Pour mieux apprécier les tendances variées du travail scientifique adapté à des fins spéciales, l'Encyclopédie a sollicité, pour la direction de chaque Bibliothèque, le coucours d'un savant placé dans le centre même des études du ressort. Elle a pu ainsi réunir des représentants des principaux Corps savants, Etablissements d'enseignement et de recherches de langue française :

Institut.

Académie de Médecine.

Collège de France.

Muséum d'Histoire naturelle.

École des Hautes-Études.

Sorbonne et École normale.

Facultés des Sciences.

Faeultés des Lettres.

Facuttés de Médecine.

Instituls Pasteur.

École des Ponts et Chaussées.

École des Mines.

Écols Polylechnique.
Conservatoire des Arts et Metiers.

Ecole d'Anthropologie.

Institut national agromique.

École vétérinaire d'Alfort.

Ecole superieure d'Électricite.

Ecole de chimie industrielle de Lyon.

Ecole des Beaux-Arts.

Ecole des Sciences politiques. Observatoire de Paris. Hôpitaux de Paris. 


\section{III}

BOT DE L'ENCTCLOPÉDIE

Au xvis' siècle, « l'Encyclopédie „ a marqué un magnifique mouvement de la pensée vers la critique rationnelle. A cette époque, une telle manifestation devait avoir un caractère philosopbique. Aujourd'hui, l'heure est venue de renouveler ce grand offort de critique, mais dans une direction strictement scientifque ; c'est là le but de la nouvelle Encyclopédie.

Ainsi la science pourra lutter avec la littérature pour la direction des esprits cultivés, qui, au sortir des écoles, ne demandent guère de conseils qu'aux œuvres d'imagination et à des encyclopédies où la science a une place restreinte, tout à fait hors de proportion avec son importance. Le moment est favorable à cette lentative ; car les nouvelles générations sont plus instruites dans l'ordre scientifique que les précédentes. D'autre part la science est devenue, par sa complexité et par les corrélations de ses parties, une matière qu'il n'est plus possible d'exposer sans la collaboration de tous les spécialistes, unis là comme le sont les producteurs dans tous les départements de l'activité économique contemporaine.

A un autre point de vue, l'Encyclopédie, embrassant toutes les manifestations scientifiques, servira comme tout inventaire mettre au jour les lacunes, les champs encore en friche ou abandonnés, - ce qui expliquera la lenteur avec laquelle certaines sections se développeront, - et suscitera peut-être les travaux nécessaires. Si ce résultat est alteint, elle sera fière d'y avoircontribué.

Elle apporte en outre une classification des sciences et, par ses divisions, une tentative de mesure, une limitation de chaque domaine. Dans son ensemble, elle cherchera à refléter exactement le prodigieux effort scientifique du commencement de ce siècle et un moment de sa pensée, en sorte que dans l'avenir elle restele document principal où l'on puisse retrouver et consulter le témoignage de cette époque intellectuelle.

On peut voir aisément que l'Encyclopédie ainsi conçue, ainsi réalisée, aura sa place dans toutes les bibliothèques publiques, 
universitaires et scolaires, dans les laboratoires, entre les mains des savants, des industriels et de tous les hommes instruits qui reulent se tenir au courant des progrès, dans la parlie quils cultivent eux-mêmes ou dans le domaine scientificjuc. Elle fcra jurisprudence, ce qui lui dicte le devoir d'impartialité qu'elle aura à remplir.

Il n'est plus possible de vivre dans la société moderne en ignorant les diverses formes de cette activité intellectuelle qui rúro!utionne les conditions de la rie; ei l'intcrdépendance de la scicnce ne permet plusaux savants de rester cantonnés, spécialisćs dans un étroit domaine. Il leur faut, - et cela leur est souvent difficile, - se mettre au courant des recherches voisincs. A tous, l'Encyclopédie offre un instrument unique dont la purtie scientifique et ociale ne peut échapper à persoune.

\section{IV}

CLASSIFICATION DES MATIËRES SCIENTIFIQLES

La division de l'Encyclopédie en Bibliothèques a rendu nécessaire l'adoption d'une classification des sciences, où se manifcste nécessairement un certain arbitraire, étant donué que les sciences se distinguent beaucoup moins par les diffirences de leurs oljjutsque par les divergences des aperçus et des habitudes de notre usprit. Il se produit en pratique des interpénétrations réciproques untre leurs domaines, en sorte que, si l'on donnait à cliacun l'élenduc a laquelle il peut se croire en droit de prétendre, il envahirait tous les territoires voisins; une limitation assez stricte est nicessitée par le fait mème de la juxtaposition de plusieurs sciences.

Le plan choisi, sans viser à constituer une synthèse philosophique des sciences, qui ne pourrait être que subjectice, a tendu prurtant à échapper dans la mesure du possible aux habitudes traditionnelles d'esprit, particulièrement à la routine didactique, et à s'inspirer de principes rationnels.

Il y a deux grandes divisions dans le plan général de l'Encyclopédie; d'un côté les sciences pures, et, de l'autre, toutes les lcchnologies qui correspondent à ces sciences dans la shjpire des 
applications. A part et au début, une Bioinoinéque d'introduction générale est consacrée à la philosophie des sciences (bistoire des idées directrices, logique et méthodologie).

Les sciences pures et appliquées présentent en outre une division générale en sciences du monde inorganique et en sciences biologiques. Dans ces deux grandes catégories, l'ordre est celui de particularité croissante, qui marche parallèlement à une rigueur décroissante. Dans les sciences biologiques pures enfin, un groupe de sciences s'est trouvé mis à part, en tant qu'elles s'occupent moins de dégager des lois générales et abstraites que de fournir des monographies d'êtres concrets, depuis la paléontologie jusqu'à l'anthropologie et l'ethnographie.

Etant donnés les principes rationnels qui ont dirigé cetteclassifivation, il n'y a pas lieu de s'étonner de voir apparaitre des groupements relativement nouveaux, une biologie générale, une physiologie et une pathologie végétales, distinctes aussi bien de la botanique que de l'agriculture, - une chimie physique, etc.

En revanche, des groupements hétérogènes se disloquent pour que leurs parties puissent prendre place dans les disciplines auxquelles elles doivent revenir. La géographie, par exemple, retourne à la géologie, et il y a des géographies botanique, zoologique, anthropologique, économique, qui sont étudiées dans la botarique, la zoologie, l'anthropologie, les sciences économiques.

Les sciences médicales, immense juxtaposition de tendances très diverses, unies par une tradition utilitaire, se désagrègent on des sciences ou des techniques précises; la pathologie, science de lois, se distingue de la thérapeutique ou de l'hygiène qui ne sont que les applications des données générales fournies par lessciences pures, et à ce titre mises à leur place rationnelle.

Enfin, il a paru bon de renoncer à l'anthropocentrisme qui exigeait une physiologie humaine, une anatomie humaine, une embryologie humaine, une psychologie humaine. L'homme est intégré dans la série animale dont il est un aboutissant. Et ainsi, son organisation, ses fonclions, son développement s'éclairent de toute l'évolution antẹrieure et préparent l'étude des formes plus romplexes des groupements orpaniques qui sont offertes par l'étude des sociétés.

On peut voir que, malgréla prádominance de la préoccupation pratique dans ce classement des Bibliothèques de l'Encyclopédie 
scicntifique, le souci de situer rationnellement les sciences dano leurs rapports réciproques n’a pas été négligé. Enfin il est à peine besoin d'ajouter que cet ordre n'implique nullement une hiérarchie, ni dans l'importance ni dans les difficultés des diverses sciences. Certaines, qui sont placées dans la technologie, sont d'une complexité extrime, et leurs recherches peuvent figurer parmi les plus ardues.

Mode Le la publication. - Les volumes, illustrés pour la plupart, seront publiés dans le format in-1 8 jésus et cartonnés. De dimensions commodes, ils auront 400 pages environ, ce qui représente une matière suffisante pour une monographie ayant un objet défini et important, établie du reste selon l'économie du projet qui saura éviter l'émiettement des sujets d'exposition. 


\section{TABLE DES BIBLIOTHÈQUES}

Dingcteur: Dr Toulouse, Directeur de Laboratoire à l'Ecole des Hautes Etudes.

Sbcrḱtaire général : H. Piéron.

Directeurs des Bibliothìques :

1. Histoire et Philosophie des Sciences.

A. REy, professeur d'Histoire de la philosophie dans ses rapports avec la Science à la Sorboune.

\section{Scienges pures}

A. Sciences mathématiques :

2. Mathématiques. .

J. Disach, chargé de cours à la Faculté des Sciences de l'Université de Paris.

3. Mécanique. - J. Drach, chargé de cours à la Faculté des Sciences de l'Université de Paris.

B. Sciences inorganiques :

4. Physique. .

A. Leduc, professeur-adjoint de physique à la Sorbonne.

5. Chimie physique.

6. Chimie. . .

J. Perrix, professeur de chimie-physique à la Sorbonne.

A. Pictet, professeur à la Faculté des Sciences de l'Université de Genève.

7. Astronomie et Physique céleste. .

8. Météorologie.. .

9. Minéralogie el Pétrographie. .

10. Géologie... .

I1. Océanographie physique. . .
J. Mascart, professeur à l'Université, directeur de l'Observatoire de Lyon.

J. Mascart, professeur à l'Université, directeur de l'Observatoire de Lyon.

A. Lacroix, secrétaire perpétuel de l'Académie des Sciences, professeur au Muséum d'Histoire naturelle.

M. Boule, professeur au Muséum d'Histoire naturelle, directeur de l'Institut de Paléontologie humaine.

J. Richard, directeur du Musée Océnographique de Monaco. 


\section{Sciences biologiques normatives :}

13. Biologie générale. M. Gavlent, professeur de zoologie à la Sorbonne.

13. Physique biologique.

14. Chimie biologique.

15. Physiologie et $P a$. thologie végétales.

16. Physiologie. .

17. Psychologie. .

18. Sociologie . .

19. Microbiologie et Parasitologie. . 20. Patho- $\begin{aligned} & \text { A.Patho- } \\ & \text { logie. me- } \\ & \text { dicale. } \\ & \text { B. Neu- } \\ & \text { rologie. } \\ & \text { C. Path. } \\ & \text { chirurgi- } \\ & \text { cale. }\end{aligned}$

20. Patho- $\begin{aligned} & \text { A.Patho- } \\ & \text { logie. me- } \\ & \text { dicale. } \\ & \text { B. Neu- } \\ & \text { rologie. } \\ & \text { C. Path. } \\ & \text { chirurgi- } \\ & \text { cale. }\end{aligned}$

20. Patho- $\begin{aligned} & \text { A.Patho- } \\ & \text { logie. me- } \\ & \text { dicale. } \\ & \text { B. Neu- } \\ & \text { rologie. } \\ & \text { C. Path. } \\ & \text { chirurgi- } \\ & \text { cale. }\end{aligned}$

20. Patho- $\begin{aligned} & \text { A.Patho- } \\ & \text { logie. me- } \\ & \text { dicale. } \\ & \text { B. Neu- } \\ & \text { rologie. } \\ & \text { C. Path. } \\ & \text { chirurgi- } \\ & \text { cale. }\end{aligned}$
A. Imaert, professeur à la Faculté de Médecine de l'Université de Montpellier.

G. Bertrand, professeur de chimie biologique à la Sorbonne, professeur à l'Institut Pasteur.

f. Mangin, de l'Institut, directeur du Muséum d'Histoire naturelle.

J.-P. Langlois, professeur agrégé à la Faculté de Médecine de Paris, directeur de la Revue générale des Sciences.

E. Toulouse, directeur de Laboratoire à l'Ecole des Hautes-Etudes, médecin en chef de l'asile de Villejuif.

G. Richard, professeur à la Faculté des Lettres de l'Université de Bordeaux.

A. Calmette, professeur à la Faculté de Médecine de l'Université, directeur de l'Institut Pasteur de Lille, et F. Bezançon, professeur à la Faculté de Médecine de l'Université de Paris, médecin des Hôpitaux.

M. Klippel, médecin des Hôpitaux de Paris.

E. Toulouse, directeur de Laboratoire à l'Ecòle des Hautes-Etudes, médecin en chef de l'asile de Villejuif.

R. Proust, professeur agrégé à la Faculté de Médecine de Paris, chirurgien des Hôpitaux.

D. Sciences biologiques descriptives:

21. Paléontologie. . M. Bovle, professeur au Muséum d'Histoire naturelle, directeur de l'Iustitul de Paiéontologie humaine. 
22. Bota- $\left\{\begin{array}{l}\text { A. Généra- } \\ \text { lités et pha- } \\ \text { néroganas. }\end{array}\right.$ nique.

B. Crypto games

23. Zoologie.

24. Anatomie et Embryologie. . .

25. Anthropologie et Ethnographie.

96. Economie politi- G. Rexard, professeur d'Histoire du que. . . .
H. Leсомте, de l'Institut, professeur au Muséum d'Histoire naturelle.

L. Mavgin, de l'Institut, directeur du Muséum d'Histoire naturelle.

(i. Hoclbent, prolesseur de Loologic à l'Ecole de Médecine de Rennes.

C. Houlbert, professeur dé Źoologie à l'Ecole de Médecine de Rennes.

G. Papillaclt, directeur-adjoint du Laboratoire d'Anthropologie à l'Ecole des Hautes-Etudes, professeur à l'Ecole d'Anthropologie.

\section{Sciences appliquées}

\section{A. Sciences mathématiques :}

27. Mathématiques appliquées.

28. Mécaniques appliquées et génte.
M. D'Ocagne, professeur à l'Ecole polytechnique et à l'Ecole des Ponts et Chaussées.

M. d'Ocagne, professeur à l'Ecole polytechnique et à l'Ecole des Ponts et Chaussées.

\section{B. Sciences inorganiques :}

29. Industries physiques. . .

3o. Photographie. .

31. Industries chimiques.

32. Géologie et minéralogie appliquées.

33. ':onstruction.
H. Chaumat, professeur au Conservatoire des Arts et Mćtiers, sous-directeur de l'Ecole supérieure d'Electricité de Paris.

A. Seyewftz, sous-directeur de l'Ecole de Chimie industrielle de Lyon.

J. Derome, inspecteur général de l'Jnstruction publique, inspecteur des Etablissements classés.

J. Cayeux, professeur au Collège de France et à l'Institut national agronomique.

A. Mesnatier, professeur au Conservatoire des Arts et Métiers et à l'Ecole des Ponts et Chaussées. 


\section{Sciences biologiques :}

34 Industries biologiques.

G. Bertrand, professeur de chimie biologique à la Sorbonne, chef de service à l'Institut Pasteur.

35. Botani- A.Phaneque ap- rogames. pliquée et B. Crytoagricult. (games.

36. Zoologie appliquée.

37. Thérapeutique générale et pharmacologie.

38. Hygiène et médecine publiques.

39. Psychologis appliquée.

H. Lecomte, de l'Institut, professeur au Muséum d'Histoire maturelle.

L. Mangin, de l'Institut, directeur du Muséum d'Histoire naturelle.

J. Pellegrin, assistant au Muséum d'Histoire naturelle.

G. Pouchet, membre de l'Académie de Médecine, professeur à la Faculté de Médecine de l'Université de Paris.

A. Calmette, professeur à la Facultó de Médecine de l'Université, directeur de l'Institut Pasteur de Lille.

E. Toulouse, directeur de Laboratoire à l'Ecole des Hautes-Etudes, médecin en chef de l'asile de Villejuif.

40. Sociologie appliquée. . .

Tн. Ruyssen, professeur à la Faculté des Lettres de l'Université de Bordeaux.

M. Albert Maire, bibliothécaire à la Sorbonne, est chargé de l'Index de l'Encyclopédie scientifique. 


cp

ceot 


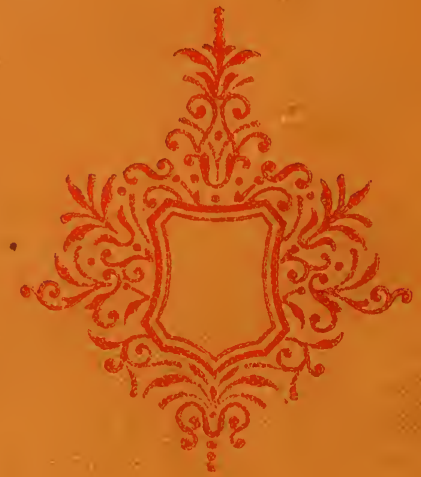

